\title{
MODELING TO SUPPORT GROUNDWATER CONTAMINANT BOUNDARIES FOR THE SHOAL UNDERGROUND NUCLEAR TEST
}

\author{
prepared by \\ Karl Pohlmann, Greg Pohll, Jenny Chapman, Ahmed E. Hassan, \\ Rosemary Carroll, and Craig Shirley \\ submitted to \\ Nevada Site Office \\ National Nuclear Security Administration \\ U.S. Department of Energy
}

MARCH 2004

Publication No. 45184 
Reference herein to any specific commercial product, process, or service by trade name, trademark, manufacturer, or otherwise, does not necessarily constitute or imply its endorsement, recommendation, or favoring by the United States Government or any agency thereof or its contractors or subcontractors. The views and opinions of authors expressed herein do not necessarily state or reflect those of the United States Government or any agency thereof.

This report has been reproduced directly from the best available copy. Available for sale to the public from:

U.S. Department of Commerce

National Technical Information Service

5285 Port Royal Road

Springfield, VA 22161

phone: (800) 553-6847

fax: (703) 605-6000

email: order@ntis.gov

online ordering: http:/www.ntis.gov/ordering.htm

Available electronically at http://www.osti.gov/bridge

Available for a processing fee to the U.S. Department of Energy and its contractors, in paper, from:

U.S. Department of Energy

Office of Scientific and Technical Information

P.O. Box 62

Oak Ridge, TN 37831-0062

phone: (865) 576-8401

fax: (865) 576-5728

email: reports@adonis.osti.gov 


\title{
MODELING TO SUPPORT GROUNDWATER CONTAMINANT BOUNDARIES FOR THE SHOAL UNDERGROUND NUCLEAR TEST
}

\author{
prepared by \\ Karl Pohlmann, Greg Pohll, Jenny Chapman, Ahmed E. Hassan, \\ Rosemary Carroll, and Craig Shirley \\ Division of Hydrologic Sciences \\ Desert Research Institute \\ University and Community College System of Nevada
}

Publication No. 45184

submitted to

Nevada Site Office

National Nuclear Security Administration

U.S. Department of Energy

Las Vegas, Nevada

March 2004

The work upon which this report is based was supported by the U.S. Department of Energy under Contract \# DE-AC08-00NV13609. Approved for public release; further dissemination unlimited. 
THIS PAGE INTENTIONALLY LEFT BLANK 


\section{EXECUTIVE SUMMARY}

Groundwater flow and radionuclide transport at the Shoal underground nuclear test are characterized using three-dimensional numerical models, based on site-specific hydrologic data. The objective of this modeling is to provide the flow and transport models needed to develop a contaminant boundary defining the extent of radionuclide-contaminated groundwater at the site throughout 1,000 years at a prescribed level of confidence. This boundary will then be used to manage the Project Shoal Area (PSA) for the protection of the public and the environment.

The PSA is located in north-central Nevada along the crest of the Sand Springs Range. The Shoal nuclear test was detonated on October 26, 1963. It had a yield of 12 kilotons and was located at a depth of $367 \mathrm{~m}$ below land surface. The Sand Springs Range is comprised of fractured granite and is bounded on the east and west by alluvium-filled valleys. Faulting is present in the range, with a prominent shear zone and other major faults striking southwest to northeast across the site. Groundwater recharge occurs by infiltration of precipitation on the mountain range, with regional discharge occurring in the valleys. A groundwater divide occurs below the upland area of the range, separating flow to the east and west. The nuclear test is located on the eastern side of the divide such that groundwater from the nuclear test area moves toward Fairview Valley.

Geologic and hydrologic data to support the modeling were gathered during three different periods. First, regional hydrogeologic investigations and detailed site geology studies were conducted in support of the nuclear test in the 1960s. Second, the U.S. Department of Energy (DOE) drilled and tested four hydrologic characterization wells in 1996 that provide site-specific hydraulic parameters. After the 1996 data collection, an interim groundwater model was developed by Pohll et al. (1998). It was the basis for a Data Decision Analysis (Pohll et al., 1999b) that evaluated model uncertainties and identified optimum methods of reducing uncertainty. As a result of the recommendations of the DDA, the third data collection period occurred in 1999 to 2000, when DOE drilled and tested another four wells at the site, and conducted a tracer test between two of the wells.

Data from these studies support a fundamental conceptual model for groundwater flow at the PSA of groundwater flow through the fractured granite, toward the adjoining valleys. Recharge is uniformly distributed across the surface of the Sand Springs Range, originating as precipitation. A hydrologic divide coincides with the upland areas of the range, forming a no-flow boundary west of the nuclear test. A region of higher conductivity and higher porosity is located around the cavity and chimney as a result of the nuclear test. A significant refinement to the conceptual model as a result of the 1999 field work is the recognition of a low-conductivity shear zone creating an impermeable no-flow boundary east of the nuclear test, dipping to the west.

Alternate conceptual models for the behavior of the shear zone, flow conditions on the west side of the range, and for other aspects of the boundary conditions and parameters, are evaluated using models designed expressly for this purpose. A model of Fairview Basin is used to establish recharge and discharge relationships and general hydrologic properties, and ensure consistency with properties demanded by the natural basin boundaries. A model of the northern Sand Springs Range is used to evaluate alternate models for hydrologic behavior of the shear zone, based on 
observed hydraulic heads and hydraulic tests in nearby wells. The shear zone was determined to be a very low permeability barrier. Alternate models for hydraulic parameters and boundary conditions are examined with a model of the vicinity of the Shoal site. The results from these tests of alternate models were used to construct the PSA flow and transport model.

The numerical PSA model is oriented southwest to northeast, with a no-flow boundary paralleling the groundwater divide to the west, a no-flow boundary along the shear zone to the east, specified flux through the southwestern face to account for recharge upgradient of the model domain, and specified head where groundwater flow exits the model on the northeastern face. Recharge is also applied evenly over the upper model surface, and specified flux is set at the lower surface to account for groundwater exiting the domain vertically under the force of the downward-directed gradient. The model is roughly rectangular in plan view; 1,588 m wide from northwest to southeast on the upgradient edge, and 1,900 $\mathrm{m}$ long from southwest to northeast. It is $1,300 \mathrm{~m}$ thick, from the water table downward. Cell size in the model is approximately $20 \mathrm{~m}$ on a side.

Uncertainty is incorporated in the important flow parameters. Several independent methods of estimating recharge resulted in a potential range of recharge over the PSA of 0.05 to $0.7 \mathrm{~cm} / \mathrm{yr}$. The recharge rate and the incoming flux from the southwest (from recharge upgradient of the model) are selected using Monte Carlo techniques to sample from this distribution. The flow system is conceptualized as a stochastic continuum with hydraulic conductivity treated as a random variable. The fractured granite is divided into two flow categories: large, oriented fractures and small, random fractures. The large, oriented fractures represent the high-hydraulic conductivity fracture flow system developed by the anisotropic structural grain of the range. The small, random fractures provide flow conduits through otherwise impermeable matrix blocks. The distribution and orientation of the two flow categories is allowed to vary through 1,000 realizations, adhering to spatial statistics derived from fracture observations from boreholes. The hydraulic conductivity $(K)$ of the large-fracture category is randomly selected from a distribution of $1.0 \times 10^{-5}$ to $1.0 \mathrm{~m} / \mathrm{d}$, based on hydrologic testing. The conductivity of the small-fracture category is also variable from the range of field data, but is selected during calibration of each flow realization to observed head values. The $K$ value of the small-fracture category thus depends on the $K$ of the large-fracture category, the recharge value, and the spatial distribution of fractures in the realization. Individual calibration ensures the integrity of each realization relative to known characteristics of the flow system (measured heads). Each realization is weighted based on goodness of fit to the observed head data and these weights are used later to calculate the level of confidence for the contaminant boundary.

Groundwater flow in the PSA model basically moves toward the northeast, paralleling the structural grain of the Sand Springs Range. There is a strong component of vertical flow, driven by the surface recharge. The relative proportion of lateral to vertical flow varies from one realization to the next, driven by the $K$ values assigned to the two flow categories. Embedded within this natural flow field is a region of higher $K$ and higher porosity representing the nuclear cavity, chimney, and surrounding disturbed zone. 
The cavity region is the source of the contaminants in the transport model. The radionuclides resulting from the Shoal test are grouped into transport classes corresponding to their release behavior and transport characteristics. Two release modes are simulated: hydraulic release, where radionuclides are free to migrate in the flow field immediately after the test; and glass dissolution release, whereby nuclides included in the nuclear melt glass are released as the glass dissolves. The glass dissolution rate is treated as a random variable, controlled by a range of reactive surface area of 0.001 to $0.01 \mathrm{~m}^{2} / \mathrm{g}$. At the low end of the range, just over three percent of the glass dissolves in 1,000 years; at the high end, almost 30 percent dissolves. All radionuclides have at least five percent of their mass released immediately after the nuclear test, to account for any small portion not incorporated into the puddle glass.

Once released, contaminant migration is simulated using a random-walk particle-tracking method. The retardation processes of sorption and matrix diffusion are included in the transport analysis. Sorption behavior is based on the results of both laboratory and field experiments. Lithium sorption in the field tracer experiment was considerably stronger than in the laboratory batch sorption experiments, suggesting that applying laboratory values for other cationexchanging radionuclides should be conservative. The lithium breakthrough curve from the twowell tracer test indicated that sorption occurs both in the matrix and on fracture surfaces, though sorption in the matrix is much greater. The tracer test also clearly revealed the importance of matrix diffusion during transport processes in the Sand Springs granite. This was observed in the test by comparing the breakthrough of bromide with that of Pentafluorobenzoate, a large molecule with a smaller free-diffusion rate than bromide. The dual-porosity conceptual transport model is implemented in the random-walk particle-tracking method using a particle transfer approach. A Markov chain model is used to simulate the particle transfer between the mobile and immobile waters. It was calibrated for the Shoal site using the tracer test results. Porosity is another critical transport parameter derived from the tracer test. It is also treated as uncertain in the transport model, with the mean (0.025) and standard deviation (0.023) determined by analysis of the tracer breakthrough behavior. The 90 percent confidence interval for effective porosity ranges between 0.005 and 0.07 .

The nuclear cavity and surrounding damaged zone are represented by three zones, based on the performance of the Shoal test and relationships observed in granite at various distances from the working points of French nuclear tests. Porosity in the nuclear cavity is chosen from a uniform range between 18 and 35 percent (the estimated bulking porosity is 30 percent based on geometric considerations), and assigned a $K$ from a distribution with a mean of $43 \mathrm{~m} / \mathrm{d}$. The damaged zone around the cavity is represented as a spherical zone with a porosity range of 7 to 18 percent and a distribution of $K$ with a mean of $8.6 \mathrm{~m} / \mathrm{d}$. This is surrounded by a transition zone from the damaged area to native fractured granite where the porosity is selected from the porosity range for the natural granite, but the mean $K$ of the distribution is set at the high end of the natural $K$ range, $0.86 \mathrm{~m} / \mathrm{d}$.

The average maximum groundwater velocity is $2.6 \times 10^{-3} \mathrm{~m} / \mathrm{d}$, while the mean value is $2.3 \mathrm{x}$ $10^{-5} \mathrm{~m} / \mathrm{d}$. This is lower than previous estimates due to the higher mean porosity, lower recharge 
rate, and lower $K$. There is a much higher degree of confidence in the distribution of porosity used in the present model because it is based on the site-specific tracer test. Likewise, estimates of the recharge rate have been refined by more detailed modeling of recharge processes, while the range of $K$ reflects the collection and analysis of data from the four wells drilled in 1999, as well as those from 1996, and the analysis of long-term pumping and recovery during the tracer test. The velocity fields from the flow realizations form the foundation for transport calculations using a random-walk particle-tracking method. The starting mass of each radionuclide is represented by thousands of individual particles whose motion through the model domain is tracked.

Particle movement in the transport model reflects the patterns of flow simulated in the flow model. Particles move vertically downward, accompanied by lateral movement in a northeasterly direction. The downward movement is due to the surface recharge, and the northeastern trend is oriented with the major fracture trend, $\mathrm{N} 20^{\circ}$ E. How far the particles travel in different realizations is dependent on the location and hydraulic conductivity of the fractures, the fracture porosity, surface recharge, and value of flux at the southern inflow boundary, all of which are spatially variable and/or uncertain parameters. With the uncertainty of the flow and transport parameters, many flow scenarios are possible, and in combination with the different possible values for the transport parameters, a spectrum of possible transport regimes results. These are statistically analyzed to obtain maps of the contaminant boundaries, using the goodness-of-fit weights obtained during calibration of the flow realizations. Examples of individual contaminant boundary maps are presented for unclassified estimates of ${ }^{3} \mathrm{H},{ }^{90} \mathrm{Sr},{ }^{137} \mathrm{Cs}$, and ${ }^{151} \mathrm{Sm}$. At a 50 percent confidence interval, concentrations above the maximum contaminant levels of the Safe Drinking Water Act barely exist beyond the initial source location through a 1,000-year period. At a 95 percent confidence level for the tritium class, there is a lateral extent of about $180 \mathrm{~m}$ in the $y$ direction downstream of the cavity, and a vertical extent of about $160 \mathrm{~m}$ below the cavity. Based on these results, the ${ }^{3} \mathrm{H}$-contaminated area will be localized in the vicinity of the source. The other nuclides examined have smaller boundaries than tritium, due to their retardation properties.

The numerical model was verified quantitatively and qualitatively using independent data sets. The quantitative verification used the hydrogeologic parameters and stresses of the steadystate model to simulate the system behavior to the pumping and injection stresses applied during the tracer experiment. The quantitative verification required that the steady-state model be converted to a transient model to simulate the dynamic nature of the tracer experiment. This transient modeling was performed in a Monte Carlo framework, using all 1,000 realization from the steady-state analysis. The median prediction for the drawdowns at HC-6 and HC-7 is in excellent agreement with the observed data. The quantitative verification analysis indicates that the modeling errors associated with the verification simulations are less than or equal to the errors produced by the calibrated steady-state model, indicating successful verification. The qualitative verification used chemical and isotopic data from groundwater collected in the Sand Springs Range and Fairview Valley to evaluate consistency with the conceptual model. Differences between the chemical and isotopic character of Shoal site groundwater with that observed in the valley immediately eastward support the shear zone as a barrier to eastward flow. The data indicate little contribution to Fairview Valley groundwater from groundwater beneath the PSA, 
again identifying the shear zone barrier, and also supporting low recharge volumes originating on the range. The high degree of chemical variability for groundwater at the PSA supports the conceptual view of a fracture flow system, with the variability indicating a relatively disconnected fracture system. Both the stable isotopes and radioactive ${ }^{14} \mathrm{C}$ indicate long groundwater residence times (all but one sample in excess of 10,000 years) consistent with the slow groundwater velocities in the model, and the process of matrix diffusion.

The data collection, testing, and analysis during the late 1990s significantly improved the understanding of flow and transport at the Shoal site. These improvements have been incorporated into the flow and transport models presented here. Uncertainties inevitably remain for any depiction of a subsurface system, due to the spatial variability of the system and the inability to sample and test but a small portion of it. The models presented here accept this uncertainty and incorporate it into the numerical process so that the impact of uncertainty is included in the results. Individual calibration of each flow realization ensures the integrity of the model to known characteristics of the flow system, and a weighting procedure carries this information into the transport calculations. The resulting confidence intervals presented for the contaminant boundaries will allow decision makers to determine future actions for the Shoal site, incorporating the model results and related uncertainty into their decisions. 
THIS PAGE INTENTIONALLY LEFT BLANK 


\section{CONTENTS}

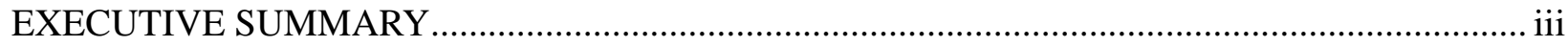

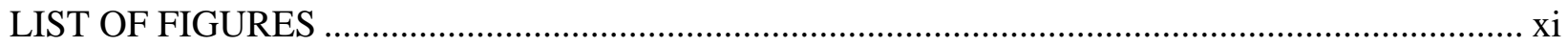

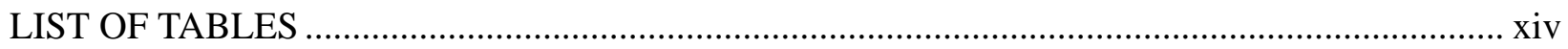

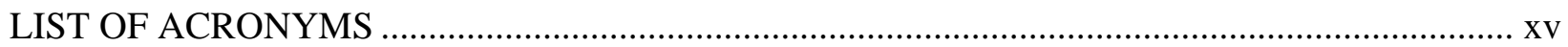

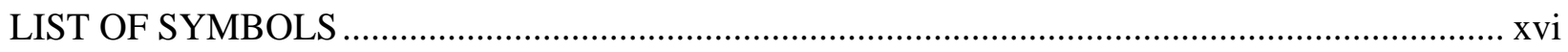

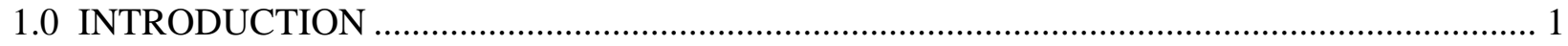

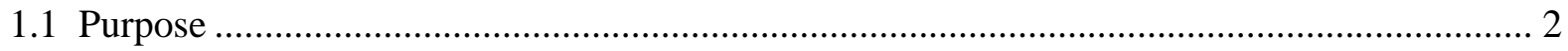

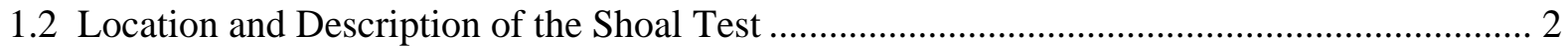

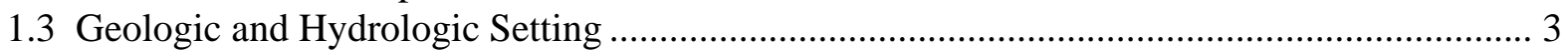

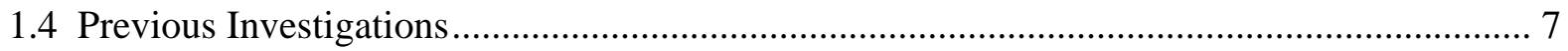

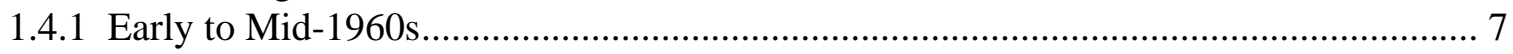

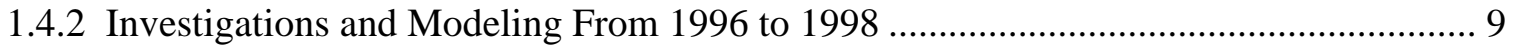

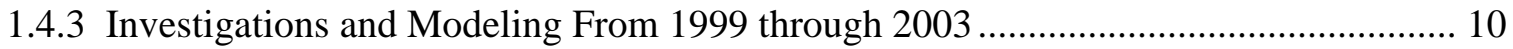

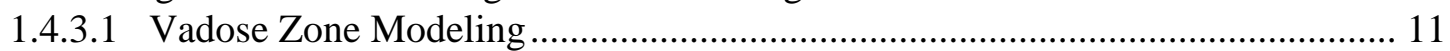

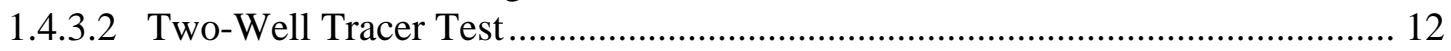

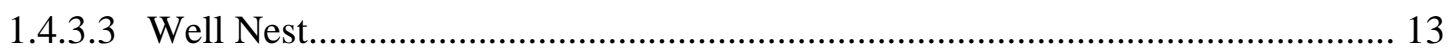

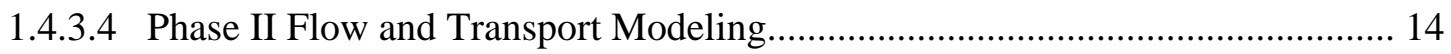

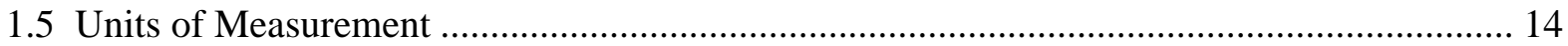

2.0 PSA CONCEPTUAL FLOW MODEL AND EVALUATION OF ALTERNATE MODELS ... 15

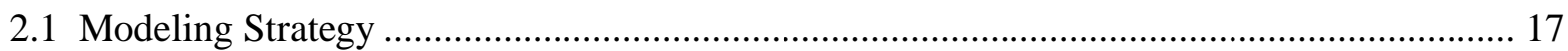

2.2 Evaluation of Regional Context: the Model of Fairview Basin ......................................... 19

2.2.1 Components of the Conceptual Model.............................................................19

2.2.2 Numerical Model.............................................................................................23

2.3 Alternate Conceptual Models for the Shear Zone: Model of Northern Sand Springs Range 27

2.3.1 Components of the Conceptual Model Tested .................................................27

2.3.2 Field Investigation of Shear Zone Hydraulic Properties .........................................29

2.3.3 Numerical Model..........................................................................................29

2.4 Alternate Conceptual Models for Hydraulic Parameters and Boundary Conditions: Model of

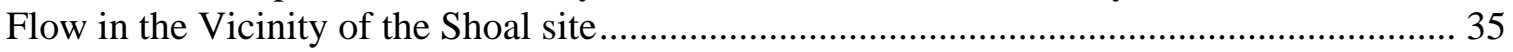

2.4.1 Components of the Conceptual Model Tested ....................................................37

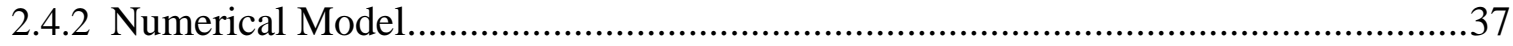

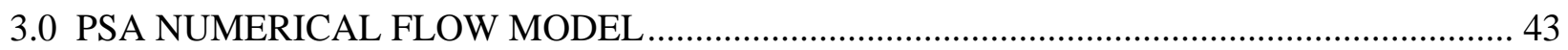

3.1 Additional Conceptual Elements Specific to the PSA Flow Model .................................... 43

3.1.1 Stochastic Continuum Representation of Hydraulic Conductivity .............................. 43

3.1.2 Impacts of the Nuclear Test on the Hydraulic System: The Cavity and Chimney ....... 44

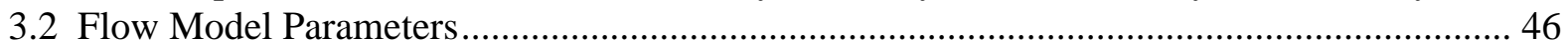

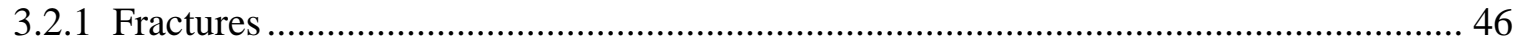

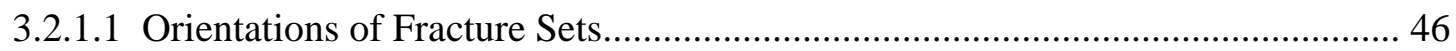

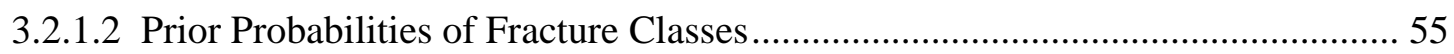

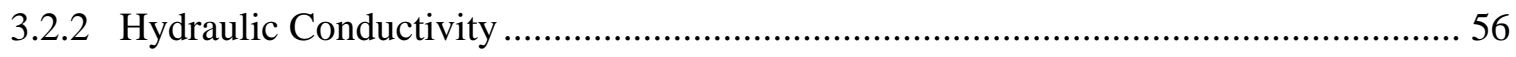

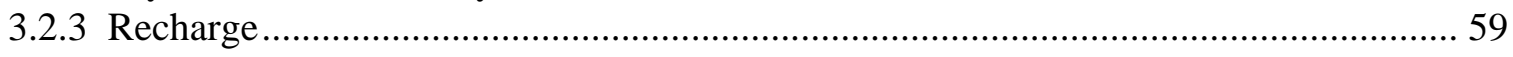

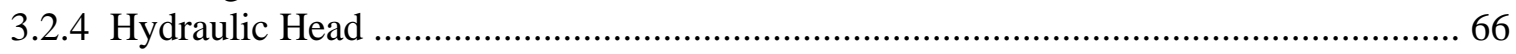

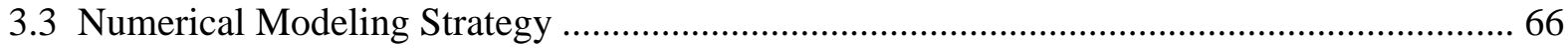

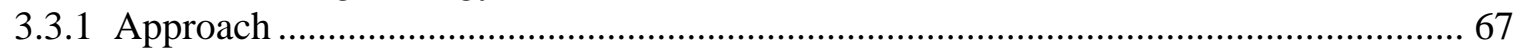

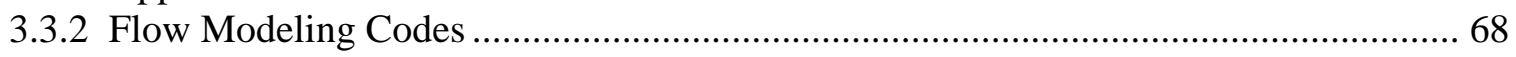

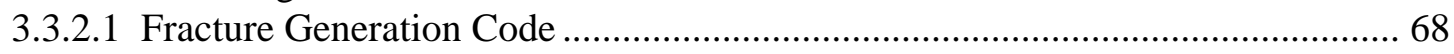

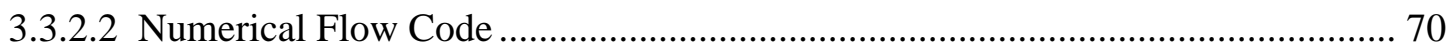




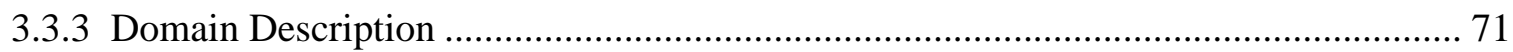

3.3.4 Boundary Conditions............................................................................................... 71

3.3.5 Calibration Process.............................................................................................. 75

3.3.6 Bayesian Weighting Procedure ………………………………………………...... 75

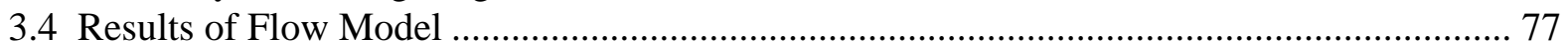

3.4.1 Hydraulic Conductivity Calibration ......................................................................... 77

3.4.2 Distributions of Fracture Zones and Hydraulic Head .................................................. 80

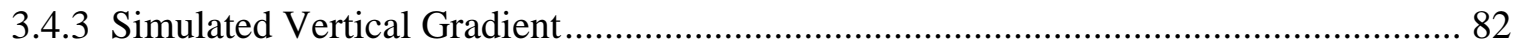

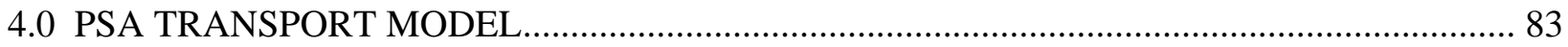

4.1 Components of the Conceptual Transport Model................................................................... 83

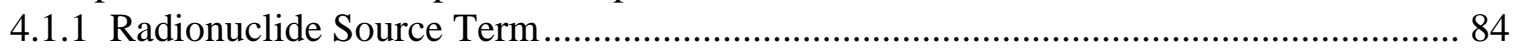

4.1.2 Release Functions.................................................................................................... 86

4.1.2.1 Volume/Surface Mode Designation................................................................. 90

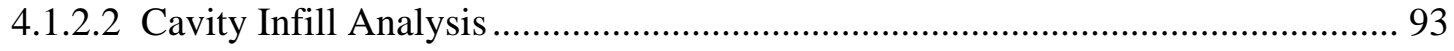

4.1.2.3 Nuclear Melt Glass Dissolution ..................................................................... 94

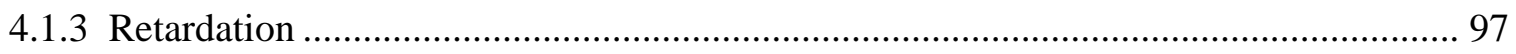

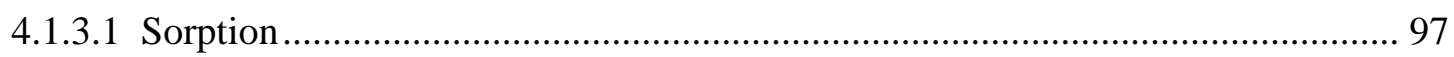

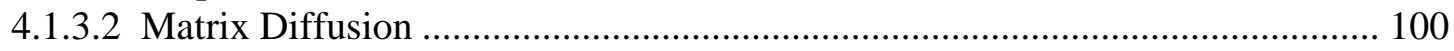

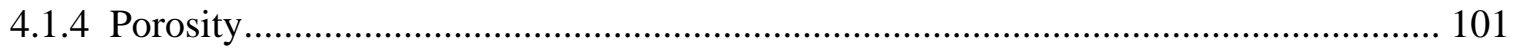

4.1.4.1 Cavity Porosity............................................................................................ 103

4.2 Numerical Modeling Strategy …………………………............................................. 105

4.2.1 Solving the Contaminant Transport Problem............................................................. 105

4.2.2 Contaminant Boundary Maps.................................................................................... 111

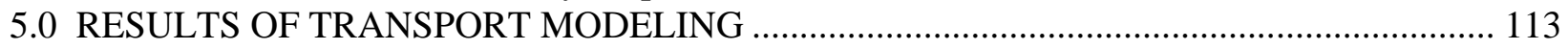

5.1 Groundwater Velocity ................................................................................................. 113

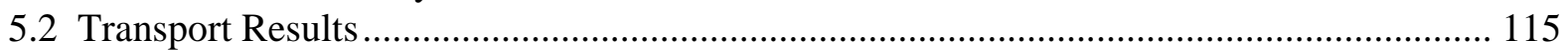

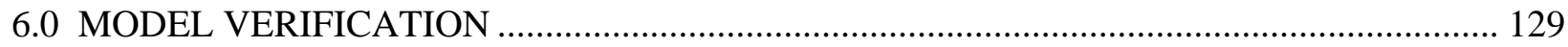

6.1 Numerical Model Verification................................................................................... 129

6.2 Conceptual Model Verification .............................................................................................. 133

6.2.1 Chemical and Isotopic Characteristics of Site Groundwater ....................................... 133

6.2.2 Implications of Chemical and Isotopic Characteristics for Flow Beneath the Range. 139

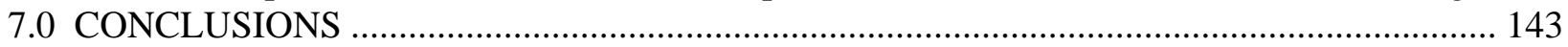

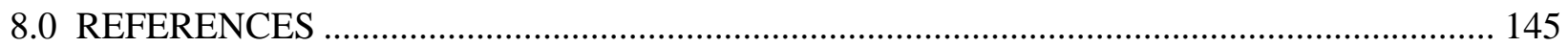

APPENDICIES

A: Summary Information for Wells Used in This Study ................................................. A-1

B: Quality Assurance Statement........................................................................... B-1

C: Glass Dissolution Solution ............................................................................... C-1

D: Methodology for Incorporating Matrix Diffusion in PTRACK ……………………….... D-1 


\section{LIST OF FIGURES}

1.1 Location of the Shoal site in west-central Nevada. .............................................................. 3

1.2 Map showing exploratory boreholes and characterization wells at the PSA, which is located in the northeast corner of the land withdrawal area. ..................................................................... 4

1.3 A diagrammatic representation of the shaft and drift complex and location of ground zero (asterisk). ....................................................................................................................... 5

1.4 Cross section through the Sand Springs Range and valleys on either side..................................... 6

2.1 Relationships between data and supportive modeling activities that contributed to the simulation of groundwater flow in the PSA model................................................................ 16

2.2 Three-dimensional depiction of the PSA conceptual model. ..................................................... 17

2.3 Map showing outline and major features of the Fairview Valley topographic basin, the areas covered by the three regional groundwater flow models, and the locations of measured water levels (the blue circles)

2.4 Location and orientation of the shear zone in the central Sand Springs Range (University of Nevada, 1965)

2.5 Configuration of the finite-element mesh, boundary conditions, and zones of hydraulic properties in the two-dimensional model of Fairview Basin.

2.6 Map showing groundwater heads simulated in the Fairview Basin model.

2.7 East-west profile through the Shoal site showing the large change in hydraulic head observed between HC-7 and HC-5.

2.8 Comparison of water levels between the pumping well HC-5 and the observation wells (a) HC-6, (b) HC-7 and (c) HC-8.

2.9 Comparison of $\mathrm{dh} / \mathrm{dt}$ for observation well HC-6, taken on a one-day timestep, with respect to drawdown in well HC-5.

2.10 Configurations of the finite-element mesh, boundary conditions, and zones of hydraulic properties in the three-dimensional model of the Sand Springs mountain block. ...................... 32

2.11 Sensitivity of simulated head difference across the shear zone (between wells HC-7 and HC-5) to $K$ of shear zone core.

2.12 Effect of shear zone $K$ structure on groundwater flow direction.

2.13 Configuration of the finite-element mesh and boundary conditions of the three-dimensional model of the PSA.

2.14 Three-dimensional perspective of the PSA model domain and the reverse particle tracks (the dotted lines) used to estimate the maximum size of the upland recharge area (outlined with a dashed line).

2.15 Plot showing sections of the PSA vicinity models and the simulated flowpaths from the Shoal source with respect to the PSA model domain.

3.1 Vertical cross section through the model grid identifying the $K$-zones used to describe the nuclear cavity and chimney and associated cavity radii (Rc). .................................................... 46

3.2 Schematic of a representative fracture borehole intersection. ........................................................ 47

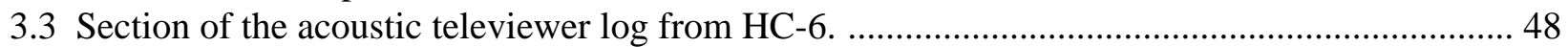

3.4 Rose diagram showing all PSA fracture strikes, using 3 classes.............................................. 50

3.5 Projection of pole of plane onto lower hemisphere. ................................................................... 52

3.6 Schmidt projection of all fracture orientations, lower hemisphere projection, equal area............ 53

3.7 Contour plot of all fracture orientations using a one percent grid radii....................................... 54

3.8 Histogram of hydraulic conductivity measurements in the granite aquifer at the PSA. .............. 57

3.9 Configuration of the finite element model used to analyze pumping and recovery during the

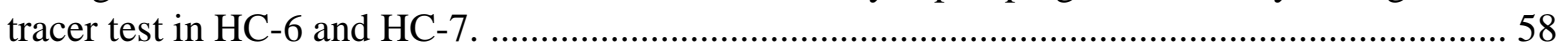

3.10 Comparison of simulated water levels to observed water levels in tracer test well HC-7. ....... 59 
3.11 Probability distribution function for the revised recharge model, the vadose zone modeling of Pohll et al. (1998), and the triangular distribution applied to recharge for the PSA groundwater flow model.

3.12 Map showing the domain of the PSA flow and transport model and its location with respect to selected land surface features and the Shoal land withdrawal boundary.................... 72

3.13 Model domain in (a) plan view and (b) cross-sectional view through line A-A'. ................... 73

3.14 Diagram showing patterns of groundwater flow resulting from recharge in the upland area to the southwest of the PSA model domain.

3.15 Plots of (a) calibrated $K_{1}$ values verses recharge values, and (b) calibrated $K_{1}$ values versus RMSE.

3.16 Composite histogram showing calibrated $K_{1}$ values for the 1,000 realizations, $K_{2}$ values for 10 randomly selected realization, and a composite histogram representing the complete simulated distribution of $K$.

3.17 Fracture network (on the left) and associated head distributions (on the right) for realizations 155, 544 and 933.

4.1 Flow chart of the transport model source and processes considered.

4.2 Relationships between data and supportive modeling activities that contributed to the simulation of radionuclide transport in the PSA model.

4.3 Nuclear melt glass mass dissolved per time, expressed as percent of starting mass.

4.4 Numerically derived distribution of effective porosity and the associated lognormal distribution.

4.5 Geometry of the Shoal cavity and chimney, from data in Hazelton-Nuclear Science (1965).... 105

4.6 Porosity and hydraulic conductivity assignments to model cells to represent the cavity/chimney, the damaged zone, and a transition zone from the damaged area to native fractured granite.

4.7 Distribution of particles representing the radionuclide source.

4.8 Release of particles as a function of glass dissolution rate for a total of 80,000 particles. ....... 110

5.1 Plot of the distribution of log10-transformed maximum velocity vectors for all realizations. .. 113

5.2 Plots of the distributions of average velocities in the three coordinate directions for all

5.3 Snapshots of the three-dimensional particles distribution (projected in plan and vertical views) for class 1 simulations showing the extent and pattern of movement in a single flow realization.

5.4 Projected maps of the maximum concentration distribution for ${ }^{3} \mathrm{H}$ for the flow realization

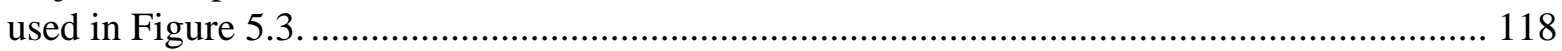

5.5 Same as Figure 5.4, but for a different realization............................................................ 119

5.6 Maximum concentrations at two cells sorted in an ascending order for 12 realizations that produce the lowest Cmax values.

5.7 Individual GLUE weights and the cumulative weights for the 12 realizations that produce the lowest Cmax values at cell 1.

5.8 Cmax versus the cumulative GLUE weights with the arrows showing how the cell is determined to be within or outside of the contaminant boundary at the 90 percent confidence level

5.9 Contaminant boundary maps for ${ }^{3} \mathrm{H}$ delineating the areas exceeding $20,000 \mathrm{pCi} / \mathrm{L}$ at the 50 percent confidence level for the 1,000-year simulation period.

5.10 Contaminant boundary maps for ${ }^{3} \mathrm{H}$ delineating the areas exceeding $20,000 \mathrm{pCi} / \mathrm{L}$ at the 95 percent confidence level for the 1,000-year simulation period.

5.11 Contaminant boundary maps for ${ }^{90} \mathrm{Sr}$ delineating the areas exceeding $8 \mathrm{pCi} / \mathrm{L}$ at the 50 percent confidence level. 
5.12 Contaminant boundary maps for ${ }^{90} \mathrm{Sr}$ delineating the areas exceeding $8 \mathrm{pCi} / \mathrm{L}$ at the 95 percent confidence level.

5.13 Contaminant boundary maps for ${ }^{137} \mathrm{Cs}$ delineating the areas exceeding $200 \mathrm{pCi} / \mathrm{L}$ at the 50 percent confidence level.

5.14 Contaminant boundary maps for ${ }^{137} \mathrm{Cs}$ delineating the areas exceeding $200 \mathrm{pCi} / \mathrm{L}$ at the 95 percent confidence level.

5.15 Contaminant boundary maps for ${ }^{151} \mathrm{Sm}$ delineating the areas exceeding $1,000 \mathrm{pCi} / \mathrm{L}$ at the 50 percent confidence level.

5.16 Contaminant boundary maps for ${ }^{151} \mathrm{Sm}$ delineating the areas exceeding $1,000 \mathrm{pCi} / \mathrm{L}$ at the 95 percent confidence level. 126

6.1 Injection rate for HC-6 during the tracer test experiment. 127

6.2 Pumping rate for HC-7 during the tracer test experiment.

6.3 Simulated and observed drawdown for HC-6.

6.4 Simulated and observed drawdown from HC-7.

6.5 Piper diagram expressing relative percentages of major ions dissolved in Shoal groundwater. 135

6.6 Stiff diagram expressing ion concentrations in Shoal groundwater. 136

6.7 Stable isotopic composition of Shoal groundwater. 137 


\section{LIST OF TABLES}

1.1 Investigations and associated scope for Shoal-related projects.

2.1 Initial estimates and calibration values of parameters used in the two-dimensional model of Fairview Basin

2.2 Comparison of simulated to measured heads at selected well locations in the model of Fairview Basin.

2.3 Representative values of hydraulic parameters used in the model of the Sand Springs Range. . 33

2.4 Comparison of simulated to measured heads in the model of flow in the vicinity of the PSA... 38

3.1 Fracture summary statistics (ND = not defined).

3.2 Global prior probabilities for Flow Categories 1 and 2 as determined from borehole fracture score analysis of video logs.

3.3 Summary of hydraulic test data for wells near the PSA. From Mihevc et al., 2000.................. 60

3.4 Coefficients for each precipitation zone to relate precipitation to groundwater........................ 62

3.5 Coefficients as derived by Nichols (2000) for estimating groundwater recharge...................... 63

3.6 Precipitation volumes as derived from the PRISM map, and estimated (unadjusted) groundwater discharges for 16 hydrologic basins in central Nevada.

3.7 The 95 percent confidence intervals and median values of Project Shoal recharge as estimated by the revised recharge model and the vadose zone modeling of Pohll (1998). ....... 66

3.8 Selected static water level measurements from wells near the PSA. ....................................... 67

3.9 Summary statistics for the results of the PSA flow model. ............................................... 77

3.10 Simulated model values for selected flow realizations shown in Figure 3.17....................... 82

4.1 List of radionuclides important for investigations of transport from underground nuclear tests, as presented by Smith et al. (1995)........................................................................ 87

4.2 Daughter products in the decay chains generated by radionuclides in Table 4.1. ................... 89

4.3 Release functions assigned to Shoal source term nuclides, based on literature references

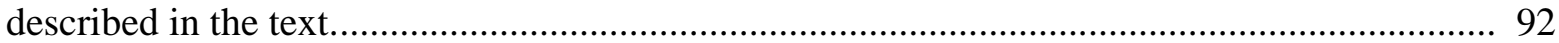

4.4 Comparison between chemical composition of Shoal granite and nuclear melt glass. .............. 95

4.5 Retardation values used in the transport model ............................................................... 101

5.1 Values of parameters specific to individual transport classes. ............................................ 115

5.2 Values of parameters common to all transport classes..................................................... 116

6.1 Chemical analyses of water samples collected from the HC wells at the Shoal site, along with analyses of groundwater from other wells in the area of the Sand Springs Range (from Chapman et al., 1994).

6.2 Apparent groundwater ages based on carbon isotopic data............................................... 139 


\section{LIST OF ACRONYMS}

$\begin{array}{ll}\text { AEC } & \text { Atomic Energy Commission } \\ \text { AMSL } & \text { above mean sea level } \\ \text { ATV } & \text { acoustic televiewer } \\ \text { CADD } & \text { Corrective Action Decision Document } \\ \text { CAIP } & \text { Corrective Action Investigation Plan } \\ \text { CDF } & \text { cumulative distribution function } \\ \text { CFR } & \text { Code of Federal Regulations } \\ \text { FFACO } & \text { Federal Facility Agreement and Consent Order } \\ \text { DDA } & \text { Data Decision Analysis } \\ \text { DOE } & \text { U.S. Department of Energy } \\ \text { DOE/NV } & \text { U.S. Department of Energy, Nevada } \\ \text { DRI } & \text { Desert Research Institute } \\ \text { EPA } & \text { U.S Environmental Protection Agency } \\ \text { GIS } & \text { Geographic Information System } \\ \text { GLUE } & \text { Generalized Likelihood Uncertainty Estimator } \\ \text { GPS } & \text { global positioning system } \\ \text { GZ } & \text { ground zero } \\ \text { IAEA } & \text { International Atomic Energy Agency } \\ \text { IT } & \text { International Technology Corporation } \\ \text { LANL } & \text { Los Alamos National Laboratory } \\ \text { LLNL } & \text { Lawrence Livermore National Laboratory } \\ \text { MPC } & \text { maximum permissible concentration } \\ \text { MSL } & \text { mean sea level } \\ \text { NAD } & \text { North American Datum } \\ \text { NBS } & \text { National Bureau of Standards } \\ \text { NDEP } & \text { Nevada Division of Environmental Protection } \\ \text { NTS } & \text { Nevada Test Site } \\ \text { PDF } & \text { probability distribution function } \\ \text { PEST } & \text { parameter estimation } \\ \text { PMC } & \text { percent modern carbon } \\ \text { PSA } & \text { Project Shoal Area } \\ \text { RMSE } & \text { root mean squared error } \\ \text { RWPT } & \text { Random-Walk Particle Tracking } \\ \text { SGZ } & \text { surface ground zero } \\ \text { SSR } & \text { sum of squared residuals } \\ \text { UGTA } & \text { underground test area } \\ \text { UTM } & \text { Universal Transverse Mercator } \\ \text { WP } & \text { working point } \\ \text { DAR }\end{array}$




\section{LIST OF SYMBOLS}

\begin{tabular}{|c|c|}
\hline$A_{s p}$ & Specific surface area \\
\hline$A_{L}$ & Longitudinal macrodispersivity \\
\hline$A_{T}$ & Transverse macrodispersivity \\
\hline$b$ & Fracture half aperture \\
\hline$C$ & Radionuclide concentration \\
\hline$C_{m}$ & Block-averaged concentration \\
\hline$C_{\max }$ & Maximum concentration \\
\hline$C_{0}$ & Initial concentration \\
\hline$D^{*}$ & Effective diffusion coefficient \\
\hline$D_{m}^{*}$ & Effective diffusion coefficient in the matrix \\
\hline $\mathbf{D}$ & Local hydrodynamic dispersion tensor \\
\hline$F_{f m}$ & Transport rate from fracture to matrix \\
\hline$F_{m f}$ & Transport rate from matrix to fractures \\
\hline$H$ & Hydraulic head \\
\hline IAP & Ion activity product \\
\hline$K$ & Hydraulic conductivity \\
\hline$K_{1}$ & Hydraulic conductivity of fracture category 1 \\
\hline$K_{2}$ & Hydraulic conductivity of fracture category 2 \\
\hline$K_{T}$ & Equilibrium constant \\
\hline$K_{d}$ & Distribution coefficient \\
\hline$K_{e}$ & Effective hydraulic conductivity \\
\hline$k_{g}$ & Glass dissolution rate \\
\hline$L_{R}$ & Spherical resultant length \\
\hline$M_{0}$ & Initial mass of radionuclides \\
\hline$N P$ & Number of particles in the random-walk simulations \\
\hline$N P_{G}^{t}$ & Number of particles released via glass dissolution at time $t$ \\
\hline$P_{f m}$ & Forward transfer probability \\
\hline$P_{m f}$ & Backward transfer probability \\
\hline$Q$ & Total solute mass flux \\
\hline$q$ & Point solute mass flux \\
\hline$R$ & Recharge \\
\hline$R_{c}$ & Cavity radius \\
\hline$R_{m}$ & Retardation factor in the matrix \\
\hline$t$ & Time \\
\hline$T$ & Transmissivity \\
\hline$V_{f}$ & Water volume in fractures \\
\hline
\end{tabular}




$\begin{array}{ll}V_{m} & \text { Water volume in matrix } \\ \mathbf{V} & \text { Velocity vector } \\ \mathbf{V}_{\max } & \text { Maximum velocity vector } \\ \alpha_{L} & \text { Longitudinal local dispersivity } \\ \alpha_{T} & \text { Transverse local dispersivity } \\ \delta_{i j} & \text { Kroneker delta } \\ \Delta t & \text { Time step } \\ \Delta x & \text { Spatial grid size } \\ \kappa & \text { Directional concentration parameter } \\ \lambda & \text { Decay rate } \\ \mu & \text { Undecayed moment } \\ \mu_{d} & \text { Decayed moment } \\ \mu_{0} & \text { Water viscosity } \\ \mu_{S} & \text { Mean sine of directions } \\ \mu_{c} & \text { Mean cosine of directions } \\ \mu_{R} & \text { Mean resultant length } \\ \omega & \text { Radionuclide's half-life } \\ \rho_{0} & \text { Fluid density } \\ \sigma & \text { Standard deviation } \\ \bar{\theta} & \text { Mean direction } \\ \theta & \text { Directional measurement (e.g., azimuth) } \\ \theta_{e f f} & \text { Effective porosity } \\ \theta_{f} & \text { Fracture porosity } \\ \theta_{I} & \text { Spherical polar coordinates } \\ \theta_{m} & \theta, \phi)\end{array}$


THIS PAGE INTENTIONALLY LEFT BLANK 


\section{$1.0 \quad$ INTRODUCTION}

The U.S. Department of Energy (DOE) and State of Nevada are working together through a Federal Facility Agreement and Consent Order (FFACO) to identify sites in Nevada of potential historic contamination and implement proposed corrective actions based on public health and environmental considerations. This includes completing environmental corrective action activities at facilities where nuclear-related operations were conducted. The closure process involves thorough investigations of the potential impacts of facilities on public health and the environment, providing the information needed to choose appropriate remedies. For underground nuclear tests specifically, Appendix VI of the FFACO defines a Corrective Action Strategy to define boundaries around each test area that contain water that may be unsafe for domestic and municipal use. The strategy is to characterize groundwater flow and contaminant transport through modeling utilizing site-specific hydrologic data.

Though the vast majority of underground nuclear tests occurred at the Nevada Test Site (NTS), a limited number of tests were conducted at other locations. The Project Shoal Area (PSA), about $50 \mathrm{~km}$ southeast of Fallon, Nevada, is the location of the Shoal test. Shoal was a 12kiloton-yield nuclear detonation that occurred on October 26, 1963 (U.S. DOE, 2000). The test was part of a program (Vela Uniform) to enhance seismic detection of underground nuclear tests in active earthquake areas.

The original Corrective Action Investigation Plan (CAIP) for the PSA was approved in September 1996 and described a plan to drill and conduct testing of four characterization wells, followed by flow and transport modeling. The resultant drilling is described in a data report (DOE, 1998a) and the data analysis and modeling in an interim modeling report (Pohll et al., 1998). After considering the results of the modeling effort, DOE determined that the degree of uncertainty in transport predictions for Shoal remained unacceptably large. As a result, a second CAIP was developed by DOE and approved by the Nevada Division of Environmental Protection (NDEP) in December 1998 (U.S. DOE, 1998b). This plan prescribed a rigorous analysis of uncertainty in the Shoal model and quantification of methods of reducing uncertainty through data collection. This analysis is termed a Data Decision Analysis (DDA) (Pohll et al., 1999b) and formed the basis for a second major characterization effort at Shoal. The details for this second field effort are presented in an Addendum to the CAIP, which was approved by NDEP in April 1999 (U.S. DOE, 1999). Four additional characterization wells were drilled at Shoal during summer and fall 1999; details of the drilling and well installation are in IT Corporation (2000), with testing reported in Mihevc et al. (2000). A key component of the second field program was a tracer test between two of the new wells (Carroll et al., 2000; Reimus et al., 2003).

This report presents the groundwater flow and transport model for the Shoal underground

nuclear test. This second round of modeling builds upon the first flow and transport model, the data gathered in both of the field programs in the 1990s, as well as data gathered in the 1960s at the time of the nuclear test. 


\subsection{Purpose}

The purpose of this work is to characterize groundwater flow and contaminant transport at the Shoal underground nuclear test through numerical modeling using site-specific hydrologic data. The ultimate objective is the development of a contaminant boundary, a model-predicted perimeter defining the extent of radionuclide-contaminated groundwater from the underground test throughout 1,000 years at a prescribed level of confidence. This boundary will be developed using the numerical models described here, after they are approved for that purpose by DOE and NDEP.

\subsection{Location and Description of the Shoal Test}

For the purposes of conducting the Shoal test, DOE (then, the Atomic Energy Commission [AEC]) withdrew a $10.4 \mathrm{~km}^{2}\left(4 \mathrm{mi}^{2}\right)$ area in the Sand Springs Range, Churchill County, Nevada from U.S. Bureau of Land Management public lands (Public Land Order numbers 2771 and 2834). This area is now referred to as the PSA (Figure 1.1). Ground zero of the Shoal test is located at State Plane Coordinates (Nevada West Zone) 557544 feet East and 1620170 feet North (UTM Zone 11, NAD 27, $380811.9 \mathrm{~m}$ North, $4339691.3 \mathrm{~m}$ East) and at an elevation of 1,227 m. This is near the middle of the square of withdrawn land and at a depth of $367 \mathrm{~m}$ below the land surface elevation of $1,594 \mathrm{~m}$. A map of the portion of the PSA related to the present work is shown in Figure 1.2.

The site is on the crest of the Sand Springs Range on a minor intramountain plateau named Gote Flat. The range trends north-south between Fairview Valley to the east and the salt pans of Fourmile Flat to the west. The total relief between the range and valleys is about $500 \mathrm{~m}$. There are no permanent streams or lakes, though a major intermittent drainage course leads down Ground Zero Canyon to Fairview Valley. Sparse, low vegetation covers the area. Valleys in the region are characterized as semi-arid, and the mountains sub-humid. Annual precipitation for the PSA is estimated between 20 and $30 \mathrm{~cm}$ (Gardner and Nork, 1970; Hardman and Mason, 1949). Maximum temperatures exceed $38^{\circ} \mathrm{C}$ in July and August, with minimums of $-18^{\circ} \mathrm{C}$ in December and January.

The design and implementation of the Shoal nuclear test was relatively simple, compared to many underground tests. Given the objective to detonate a nuclear device in an active seismic area and compare the resultant seismic signals with those from earthquakes of the same energy range (U.S. AEC, 1964), the primary instrumentation involved seismic stations at the land surface. The nuclear device was emplaced at the end of a 305-m-long drift mined east from a vertical shaft (Figure 1.3). Sand was used to stem the shaft and drift. The nuclear explosion vaporized rock in the immediate vicinity, creating a 26-m-radius cavity in the rock (Hazelton-Nuclear Science, 1965). Overlying rock subsequently collapsed into this cavity, creating a chimney with a height of $108.5 \mathrm{~m}$ above the test point. 

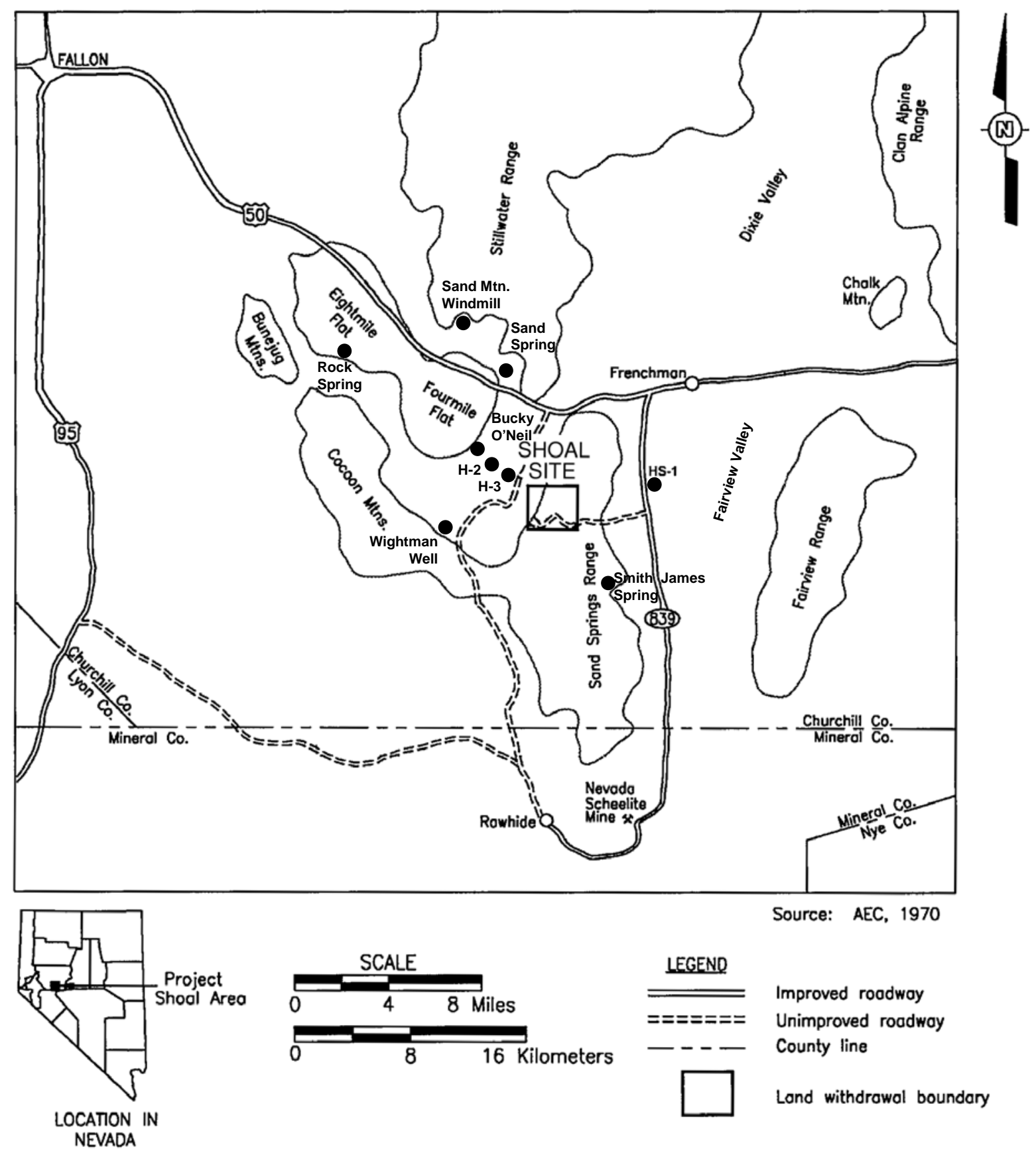

Source: AEC, 1970
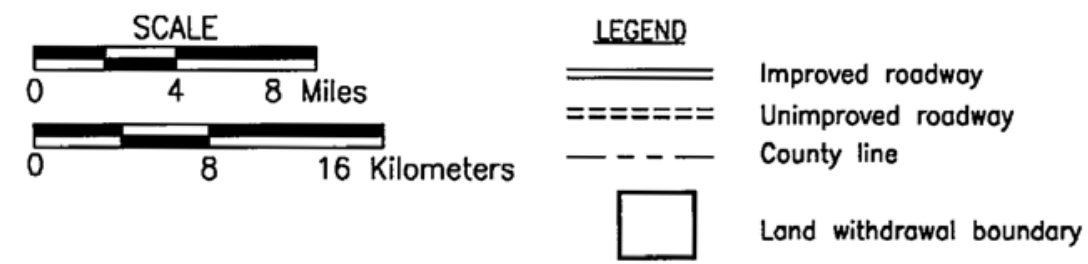

Figure 1.1. Location of the Shoal site in west-central Nevada. Also shown are the locations of wells and springs used for interpretation of the regional groundwater flow system.

\subsection{Geologic and Hydrologic Setting}

Presented below is the general geologic and hydrogeologic setting of Shoal, essentially as presented in Pohll et al. (1998). For additional details, particularly in regard to the hydrochemical environment, the reader is referred directly to Pohll et al. (1998). 


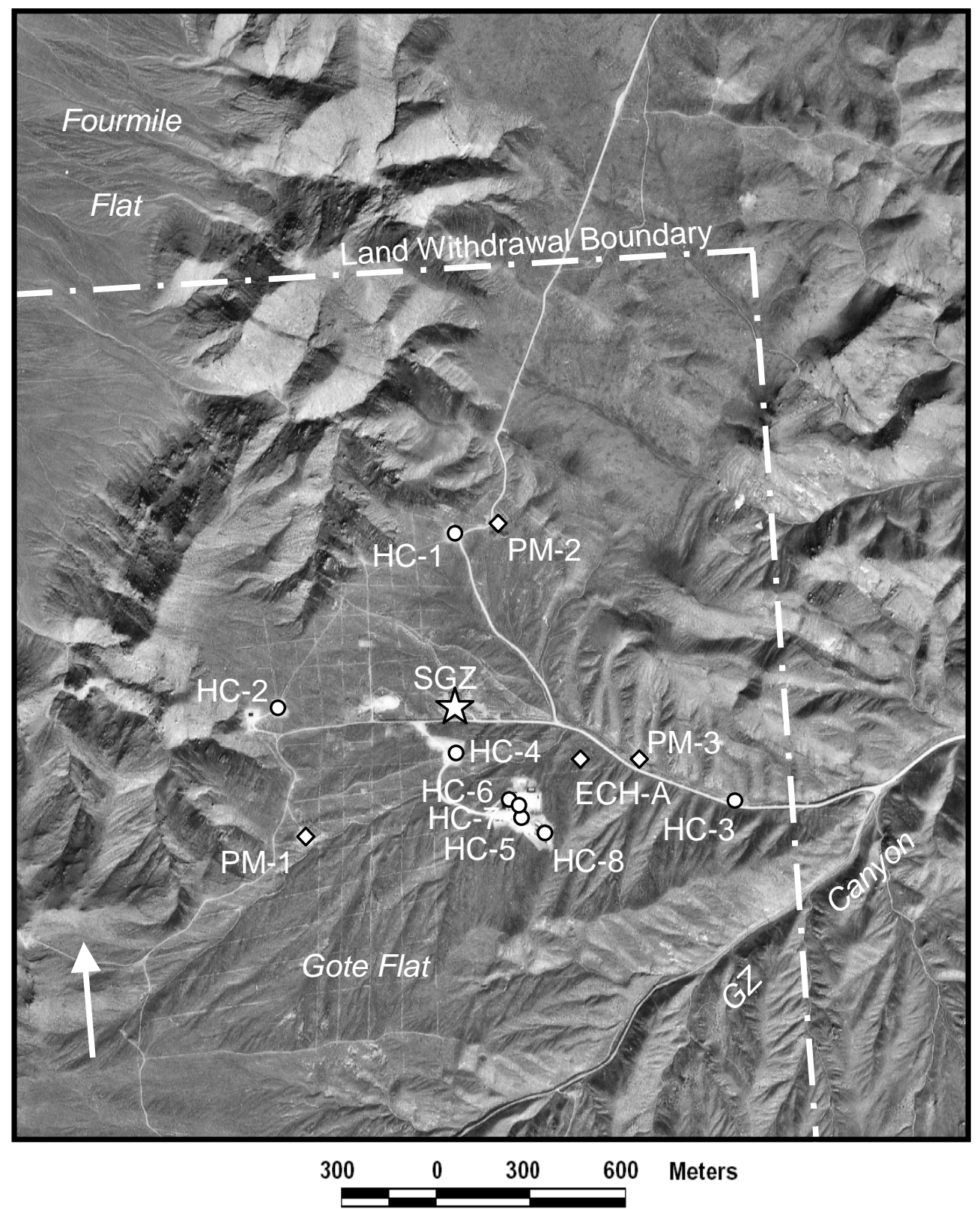

Figure 1.2. Map showing exploratory boreholes and characterization wells at the PSA, which is located in the northeast corner of the land withdrawal area. Plugged wells are shown as diamonds and active wells are shown as circles.

The Sand Springs Range is typical for a range in the Basin and Range physiographic province: a fault block mountain defined by nearly vertical northeast- and northwest-trending faults. The range is predominantly a Cretaceous-age granite, with adjacent metamorphosed Paleozoic and Mesozoic marine sediments. To the east, Fairview Valley contains a thick sequence (up to $1,765 \mathrm{~m}$ ) of Tertiary- and Quaternary-age alluvial and aeolian sediments (Figure 1.4). Fourmile Flat on the west consists of alluvial fans, pediment sands and gravels, and aeolian and 


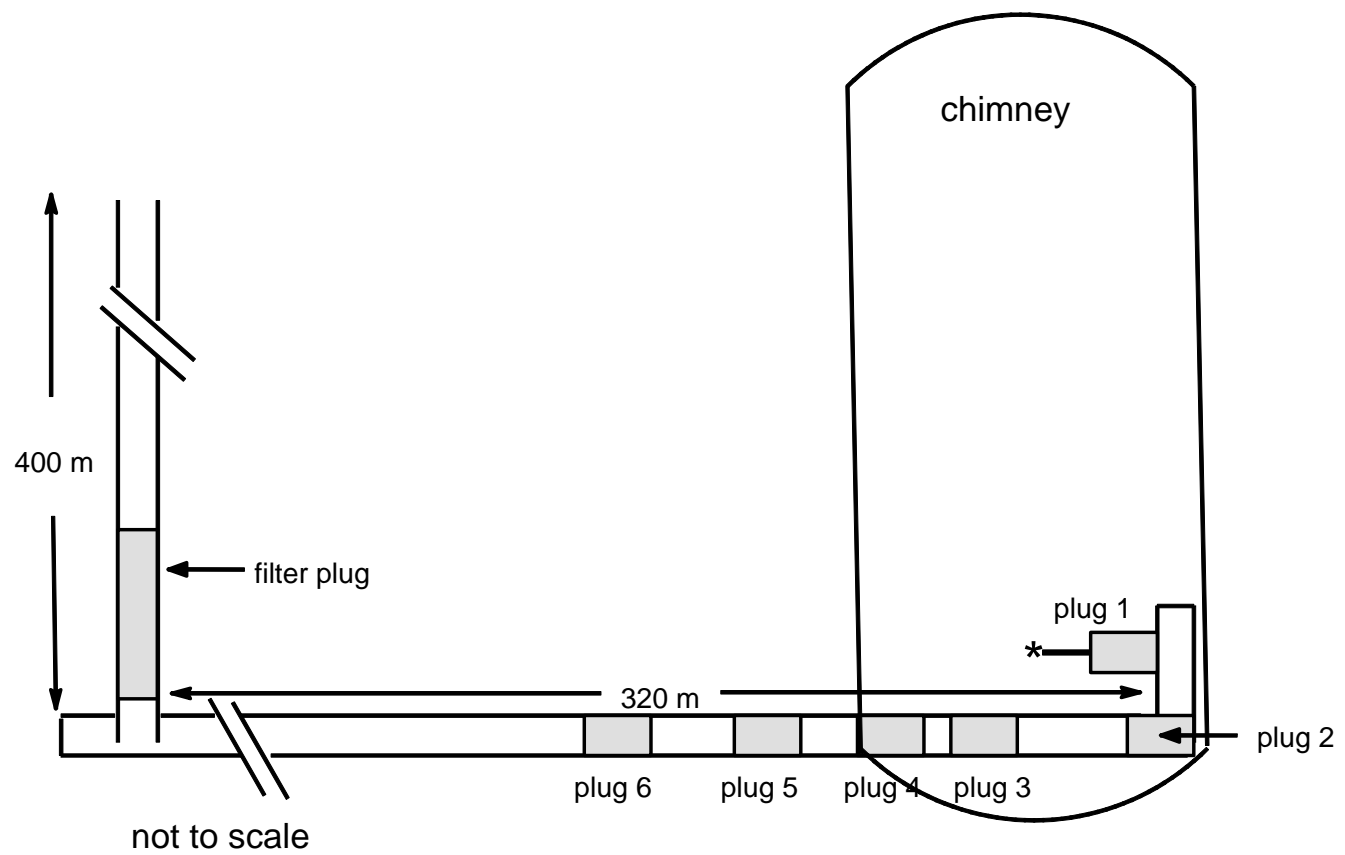

Figure 1.3. A diagrammatic representation of the shaft and drift complex and location of ground zero (asterisk). The original cavity radius is $26 \mathrm{~m}$ and chimney height $108 \mathrm{~m}$.

playa deposits. A relatively shallow west-sloping crystalline basement extends from the Sand Springs Range beneath Fourmile Flat; as a result, sediment thicknesses are limited to a maximum of about $395 \mathrm{~m}$ on the west side of the range. The area is relatively active tectonically and the effects are seen in numerous faults and fractures. Intermittent faulting is present in high- and moderate-angle, northeast- and northwest-trending faults within the center of the Sand Springs Range.

The highland area of the Sand Springs Range is a regional groundwater recharge area, with regional discharge occurring both in the Fourmile and Eightmile flats area to the west of the range, and in the Humboldt Salt Marsh in Dixie Valley to the northeast of the range. Beneath the Sand Springs Range, groundwater occurs within fractured, predominantly fresh granite. Groundwater occurs about $300 \mathrm{~m}$ below ground surface in the general vicinity of the test. Decreasing hydraulic potentials with depth support the interpretation of the range as a recharge area. A few high-altitude springs discharging from perched zones in the granite can be found to the south in the range.

In the adjacent valleys, groundwater occurs in alluvial material eroded from the highland areas. Discharge of water originating on the western side of the Sand Springs Range occurs at springs and by evapotranspiration along the edge of the salt pan in Fourmile Flat. Groundwater potentials beneath Fourmile Flat generally increase with depth, as is common in discharge areas. Groundwater from the eastern part of the Sand Springs Range discharges into Fairview Valley. The alluvium is much thicker in Fairview Valley, as compared to Fourmile Flat. Though three 


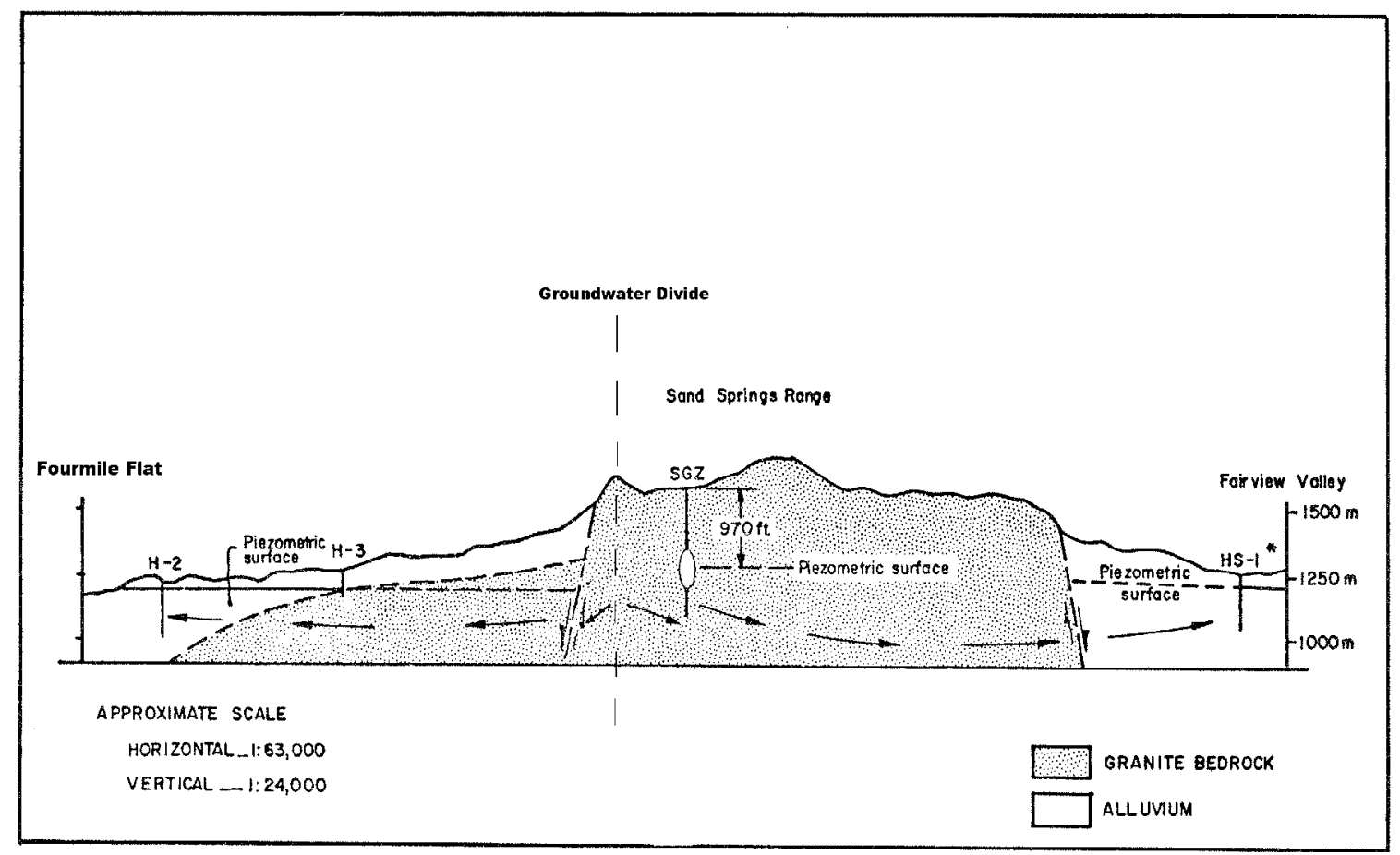

Figure 1.4. Cross section through the Sand Springs Range and valleys on either side.

alluvial aquifers, separated by clay horizons, were identified in site characterization studies, it was concluded that the units act as a single hydraulic system (University of Nevada, 1965). The flow in Fairview Valley is primarily lateral with limited vertical gradients. No discharge to the surface occurs in Fairview Valley; groundwater moves northward to the regional discharge area in Dixie Valley.

Site characterization data from the 1960s indicated that the groundwater divide separating flow to Fourmile Flat from flow toward Fairview Valley occurs west of the nuclear test and that hydraulic heads decrease with increasing depth. These interpretations have been validated by data from the recent wells. The wells installed in 1996 indicated declining hydraulic heads eastward across Gote Flat, steepening sharply in Ground Zero canyon as indicated by heads at well HC-3 (information about wells at the PSA and in the surrounding area is included in Appendix A). The drilling and testing in 1999 revealed that the sharp decrease in hydraulic head down the canyon is caused by a structural shear zone that causes a low permeability flow barrier east of ground zero. This is supported by chemical and isotopic evidence that groundwater flow from the site area is not a major contributor to the alluvial aquifer as sampled by well HS-1, east of the site in Fairview Valley (Pohll et al., 1998). The characteristics of the shear zone are discussed later in this report. The 1999 wells were also completed at varying depths of 378, 771 and $1087 \mathrm{~m}$, allowing confirmation of a strong component of downward directed flow. 


\section{$1.4 \quad$ Previous Investigations}

Major investigations of the subsurface hydrogeology and radionuclide transport from the Shoal underground nuclear test can be divided into three time periods. First, investigations conducted in the early to mid-1960s supported the selection and use of the Shoal site for a nuclear test. Key among these investigations is a 1965 report by the University of Nevada that details all of the original site characterization work. Occasional studies occurred during the intervening decades, including routine groundwater monitoring. The next major period of investigation was from 1996 to 1998, when corrective action work began under the FFACO. The most recent sequence of work began in 1999 and is ongoing. This is a second round of the corrective action effort.

Major reports providing information important to the PSA are listed in Table 1.1, along with their scope. The culmination of the work from the 1996-1998 period is Pohll et al. (1998). That report contains a reanalysis and synthesis of the preceding work and as a result, no effort is made in this report to provide an exhaustive review of the older information. However, it may be of use for some readers to understand the evolution of the conceptual model of groundwater flow and radionuclide transport for the Shoal site, and the data guiding that evolution, leading up to this work. This evolution, for each of the major investigative time periods, is presented below.

\subsubsection{Early to Mid-1960s}

Hydrogeologic investigations in support of the Shoal underground nuclear test (University of Nevada, 1965) were part of the foundation developed by the pioneering hydrogeologist George Maxey for understanding groundwater flow in desert basins (Maxey, 1967). The drilling on the Sand Springs Range and in the adjacent valleys, provided a hydraulic head data set that allowed Maxey to characterize a "local" Great Basin groundwater system dominated by recharge in the mountain range and discharge areas in the lowlands, where drainage areas are small, flowpaths are relatively short, and interbasin flow is uncommon. Maxey (1967) presents his synopsis of the Shoal hydrogeologic environment as follows:

Local systems have been observed in many areas of the Great Basin. One welldocumented example is associated with Sand Springs Range, Four Mile Flat, and Fairview and Dixie Valleys about 35 miles east of Fallon, Nevada. Here deep drilling at the top of the range yielded data which establishes the configuration of the water table with a ground-water divide closely approximating the topographic divide of the range. Further, potential measurements in holes drilled on or near the divide indicate that ground-water potential decreases with depth thus establishing the recharge area. Holes drilled on either side of the range, in one instance in uniform sand for nearly 800 feet, show an increasing potential with depth, thus establishing the discharge area. 
Table 1.1. Investigations and associated scope for Shoal-related projects.

\begin{tabular}{|c|c|}
\hline Investigation & Scope \\
\hline Cohen and Everett, 1963 & $\begin{array}{l}\text { Regional groundwater hydrology and recharge in the Dixie-Fairview } \\
\text { Valley area }\end{array}$ \\
\hline University of Nevada, 1965 & $\begin{array}{l}\text { Aerial photography, topographic maps, geological mapping, } \\
\text { mineralogical studies, age determinations, drilling operations and } \\
\text { associated geophysical analysis, gravity survey, aeromagnetic survey, } \\
\text { refraction survey, physical tests of borehole cores, general surface } \\
\text { and subsurface hydrology, groundwater chemistry }\end{array}$ \\
\hline Hazelton-Nuclear Science, 1965 & Radionuclide transport, source-term analysis, cavity infill time \\
\hline Gardner and Nork, 1970 & $\begin{array}{l}\text { Detonation type and products, climatology, geology, hydrology, } \\
\text { cavity infill time, radionuclide transport, radioactivity distribution }\end{array}$ \\
\hline Glancy and Katzer, 1975 & Regional groundwater hydrology \\
\hline U.S. DOE, 1984 & Off-site environmental monitoring program \\
\hline Chapman et al., 1994 & Regional isotopic and hydrochemical analysis \\
\hline Chapman et al., 1995 & Scoping calculations of tritium transport \\
\hline U.S. DOE, 1998a & $\begin{array}{l}\text { Drilling operations (fall 1996), geology, geophysics, radiologic } \\
\text { monitoring }\end{array}$ \\
\hline Pohll et al., 1998 & $\begin{array}{l}\text { Conceptual and numerical model of groundwater flow and transport } \\
\text { based on a synthesis of } 1996 \text { field effort with previous studies }\end{array}$ \\
\hline Pohll, 1999 & Recharge analysis \\
\hline Pohll et al., 1999a & Concise journal version of the modeling presented in Pohll et al., 1998 \\
\hline Pohll et al., 1999b & $\begin{array}{l}\text { Data Decision Analysis of impact of prospective field studies on } \\
\text { reducing model uncertainty }\end{array}$ \\
\hline IT Corporation, 2000 & $\begin{array}{l}\text { Drilling operations (summer/fall 1999), geology, geophysics, } \\
\text { radiologic monitoring }\end{array}$ \\
\hline Mihevc et al., 2000 & Hydrologic testing and logging results (summer/fall 1999) \\
\hline Carroll et al., 2000 & Tracer test design and results \\
\hline Lane et al., 2001 & Borehole radar logging results \\
\hline Reimus et al., 2003 & Tracer test interpretation \\
\hline
\end{tabular}

The same model, along with detailed descriptions of the supporting data collection activities, is presented by the University of Nevada (1965). Maxey was a major contributor to the University of Nevada (1965) work. The conceptual model has proved robust through time and is the foundation for the subsequent efforts, including the one reported here. All additional data collection has supported the Sand Springs Range as a recharge area, with groundwater flow directed from the range to discharge areas in the adjacent valleys.

Hazelton-Nuclear Science (1965) built upon the conceptual flow model to develop estimates of contaminant transport. They calculated unclassified values for the radionuclide source, considered recovery time after dewatering caused by the nuclear test, and estimated sorption 
properties. They concluded that slow groundwater velocities and radioactive decay precluded the possibility of hazardous aqueous concentrations of radionuclides migrating more than $1,000 \mathrm{~m}$ from the immediate detonation area.

\subsubsection{Investigations and Modeling From 1996 to 1998}

Though substantial and well-documented efforts had been conducted at the time of the Shoal test to define the site's hydrogeology, problems remained in supporting predictions of contaminant migration. These problems did not stem from concerns regarding the validity of the interpretations drawn with the 1960s data, but rather from the need for additional information. The CAIP for the combined surface and subsurface aspects of the Shoal site (U.S. DOE, 1996) described the existing state of knowledge and the data needed to approach site closure.

A field characterization plan was approved through the CAIP and had the following objectives:

- Determine the groundwater gradient in the test area under undisturbed conditions

- Obtain information on the nature of permeability and porosity in the Sand Springs granite

- Obtain information on recharge conditions

- Obtain information on migration of contaminants from the nuclear test.

These objectives were directed at providing additional information about how the conceptual model applied to groundwater flow and transport at the site. For example, the presence of a hydrologic divide was well demonstrated by the 1960s data, but its location relative to the nuclear test was unclear. Thus, the very basic information of the direction of flow from the nuclear test was a high priority objective. To meet the objectives, four Hydrologic Characterization (HC) wells were drilled in 1996. DOE (1998a) presents the drilling history for wells HC-1, -2,-3, and -4. The data obtained from these wells were used to develop numerical models of groundwater flow and radionuclide transport, as presented by Pohll et al. (1998).

The data collected from HC-1, $-2,-3$, and -4 established that the groundwater divide was located west of the nuclear test (which was also the opinion of the 1960s researchers from their limited data). Given the distribution of head information and the conceptual model of groundwater flow from the mountain range to the valleys, this suggested flow from the nuclear test was essentially southeastward, perpendicular to the divide. The nature of permeability and porosity was confirmed to be confined to fractures in the granite. Bulk and discrete measurements of hydraulic conductivity were made, but no quantification of porosity was possible. Recharge was estimated using temperature profiles. The absence of radionuclides in the inferred downgradient well, HC-3, indicated lack of significant radionuclide transport, though low levels of test-derived nuclides were found in well HC-4, close to the nuclear cavity. Equilibrium sorption experiments were conducted using granite from the site and several cations and anions. The results were used to estimate retardation values. 
The information gathered during the data collection activities contributed to the development of a numerical model for the prediction of radionuclide transport (Pohll et al., 1998; Pohll et al., 1999a). This model was oriented northwest to southeast (along the inferred principal flow direction), with an upgradient no-flow boundary at the approximate location of the groundwater flow divide, no-flow boundaries on the lateral sides (parallel to the direction of flow), and a specified head boundary at the downgradient edge. Recharge entered the model through the upper modeled surface. The fractured rock aquifer was treated as an equivalent porous medium. The field data were used to divide the system into three fracture classes (large, medium, and no/small fractures), and hydraulic conductivities were assigned based on the field data. Fracture orientation and persistence were based on downhole logs and surface mapping. The flow model was calibrated to hydraulic heads. Transport of radionuclides assumed sorption only occurred on fracture surfaces and neglected the process of diffusion into matrix blocks from the fractures.

The numerical model could not be reconciled with three pieces of information from the field program. First, the hydraulic head at HC-3, in the downgradient direction of the model, could not be replicated. The measured head was significantly lower than that predicted by the model. Due to completion difficulties in HC-3, it was unclear if the difference was due to a data quality problem or a model issue. Second, chemical and stable isotopic data from the wells on the range were inconsistent with the range being a major supply for groundwater sampled at well HS-1 in Fairview Valley, east of the site. Understanding the significance of this finding was complicated by the unknown hydraulic role of the range bounding fault and the recharge contribution of the Fairview Range (on the east side of the valley) relative to the Sand Springs Range. Finally, groundwater velocities predicted in the model were too high to be consistent with the general groundwater ages and flow conditions inferred from the isotopic data, which suggested residence times on the order of thousands of years for groundwater in the model domain and thus velocities at least an order of magnitude lower than simulated.

As a result of the questions raised by these inconsistencies, and substantial uncertainty remaining in key model parameters such as porosity, DOE decided that the 1998 model was not adequate for characterizing the Shoal subsurface. The DOE determined that further delineation of the subsurface conditions was required to reduce uncertainty in the input parameters.

\subsubsection{Investigations and Modeling From 1999 through 2003}

A new CAIP was developed for the Shoal subsurface alone in 1998 (the surface aspects of the site had been successfully closed prior to this) (U.S. DOE, 1998b). The plan called for performance of a Data Decision Analysis (DDA) to guide the choice of investigation and data collection methods for minimizing uncertainty in groundwater flow and transport model predictions. The CAIP identified the uncertain parameters to be considered (effective porosity, hydraulic head at the downgradient boundary, recharge, hydraulic conductivity, fracture connectivity, fracture orientations, fracture dip, glass dissolution rate, and retardation) and possible field activities that could provide additional information. 
The DDA (Pohll et al., 1999b) assigned prior distributions for the parameters identified in the CAIP, then used the model of Pohll et al. (1998) to calculate the full uncertainty of the model. The reduction in uncertainty, if a value was assumed to be perfectly known, was then calculated for each uncertain parameter. These uncertainty reductions reflect the contribution of each parameter to model uncertainty. It was found that effective porosity and recharge contributed the largest amount of uncertainty to the model results. Posterior distributions for each parameter were also estimated, based on an evaluation of the effectiveness of possible field activities at providing data on the parameter. These posterior distributions were then used in the model to calculate the reduction in model uncertainty that would be gained by performing each field activity. By combining the uncertainty reduction estimates for the field activities with preliminary cost estimates, a cost-benefit analysis was performed. Activities that provided the highest uncertainty reduction for the lowest cost were identified. The relationship between optimal activities and the parameter uncertainty analysis was clear in the results; the large uncertainty presented by effective porosity and recharge led to the greatest gains in uncertainty reduction for field activities that reduced uncertainty in those parameters.

The DOE used the results of the DDA to propose three activities in an addendum to the CAIP (U.S. DOE, 1999). These activities were as follows: vadose zone modeling, a two-well tracer test, and an environmental tracer/deep-well hydraulic characterization nest (well nest). The two-well tracer test and well nest activities required drilling and testing of new wells at the site. These data collection and interpretive activities were then followed by the flow and transport modeling reported here.

\subsubsection{Vadose Zone Modeling}

The vadose zone modeling was directed at reducing uncertainty in recharge. Meteorological data from the region were combined with hydraulic data from the Shoal subsurface in a numerical model for unsaturated zone flow. The fluid flux in the unsaturated zone was simulated with the one-dimensional model HYDRUS (Vogel et al., 1996). The model domain represented the upper $100 \mathrm{~m}$ at the PSA. Precipitation and evapotranspiration data from the Fallon, Nevada, weather station were used to drive the upper boundary condition. Errors associated with changing precipitation and potential evaporation due to elevational differences and range-top conditions are expected to be small as compared to errors associated with hydraulic properties, which can vary by orders of magnitude. It should also be noted that the precipitation and potential evaporation fluxes are not the actual simulated fluxes, as the infiltration and evaporation in the model are controlled by the hydraulic properties and moisture content near the surface.

The model was constructed in a Monte Carlo environment such that the uncertainty in the hydraulic conductivity could be included and the uncertainty in the predicted recharge rate could be determined. The hydraulic data obtained from stressed thermal flow measurements collected in 1996 were used to create lognormal distributions for three fracture classes (small, medium and large). A total of 1,000 realizations were simulated to assess the recharge rate. The numerical vadose model indicates that the recharge rate ranges between 0.0 and $0.159 \mathrm{~cm} / \mathrm{yr}$ for a 95 percent confidence interval. These estimates are lower than earlier estimates (Maxey-Eakin: 0.6 
to $2.1 \mathrm{~cm} / \mathrm{yr}$; temperature profiles: 1.17 to $1.71 \mathrm{~cm} / \mathrm{yr}$ ). Additional analysis of recharge conditions is presented in Section 3.2.3.

\subsubsection{Two-Well Tracer Test}

The general purpose of the two-well forced-gradient tracer test was to determine subsurface hydraulic properties, including effective porosity. The specific objectives were as follows: 1) determine the effective porosity of the Shoal granite aquifer, 2) determine hydraulic properties of the aquifer, 3) quantify the dispersion coefficient at the 30-m scale (equivalent to the model grid block size), 4) quantify field-scale sorption for weakly sorbing solutes, 5) determine the significance of matrix diffusion, and 6) determine hydraulic properties of the fractures.

The tracer test was conducted between wells HC-6 and HC-7, located approximately $30 \mathrm{~m}$ apart to reflect the scale of the numerical model. Plans for the test are presented in detail by Pohll et al. (1999c), documentation of the conduct of the test and presentation of the data can be found in Carroll et al. (2000); and analysis of the test is presented by Reimus et al. (2003), as well as presented in the transport parameter section of this report. The two wells were drilled approximately $350 \mathrm{~m}$ southeast of the Shoal cavity. They are approximately $375 \mathrm{~m}$ deep, with 35-m-long sections of well screen beginning 40 to $75 \mathrm{~m}$ below the static water table (at a depth of $299 \mathrm{~m}$ ). A submersible pump was set near the bottom of the well screen in HC-7. A temporary pump was used in HC-6 for recirculating the tracers during and immediately after injection to prevent density stratification. Prior to injecting tracers, a weak-dipole flow field was established by pumping $\mathrm{HC}-7$ at approximately 11.3 liters per minute (L/min) while recirculating approximately $1.13 \mathrm{~L} / \mathrm{min}$ of the produced water into HC-6 (the long-term pumping rate was about 7.5 to $8.3 \mathrm{~L} / \mathrm{min}$, and even this reduced rate threatened to dewater HC-7 by the end of the test). After establishing a quasi-steady-state flow field, injection occurred. An initial, smaller volume injection of sodium iodide was performed to evaluate the possibility of rapid transit times and identify any need to modify planned data collection during the main test. No tracer breakthrough occurred, so the larger injection occurred as planned. This consisted of a multiple tracer injection of bromide, pentafluorobenzoate, and lithium on November 10, 1999. Additional injections of cesium and microspheres occurred at later time, but neither were detected in the pumping well. Breakthrough of bromide began about one month into the test. The weak dipole was maintained until the last sample was collected from HC-7 on September 24, 2000. The tracer test was conducted for 319 days, or approximately 7,650 hours. Water levels in HC-7 slowly declined throughout the test and have been slowly recovering through 2003.

The multiple tracers allowed evaluation of flow porosity, evaluation of dual-porosity transport involving matrix diffusion, and evaluation of sorption. The results and interpretations of the tracer test indicate that a dual-porosity conceptual transport model should be used to describe dissolved radionuclide transport at the site. The results are consistent with stagnant water in the dual-porosity system being primarily in the matrix where there is plenty of surface area for radionuclide sorption, as opposed to being free water in fractures. It was also found that lithium sorption in the field tracer test was considerably stronger than in batch laboratory sorption experiments, suggesting the use of laboratory sorption data should be conservative for Shoal. 
Estimates were derived for effective fracture aperture, flow porosity, and longitudinal dispersivity. These estimates spanned ranges of an order of magnitude or more, but the uncertainty is less than would have occurred if only one tracer had been used. Additional interpretation and discussion of the tracer test is located in Section 4.0.

\subsubsection{Well Nest}

Plans for the well-nest activity are presented in Pohll et al. (1999c). Data from the drilling activities can be found in IT Corporation (2000), and testing data are in Mihevc et al. (2000). The objectives of the well nest activity were to (1) provide samples from several depths for groundwater velocity determination using environmental tracers (the primary flow direction in the upper saturated section at the site is downward); (2) provide measurement of hydraulic head variation with depth; (3) determine head in the first zone of saturation to address uncertainties raised by the water level history at HC-3; (4) document fracture frequency with depth and other characteristics (strike, dip, aperture) if possible; (5) determine fracture continuity between boreholes of the nest; and (6) measure hydraulic conductivity as a function of depth.

To meet these objectives, a well cluster, or "nest," was planned to access three different depths in the hydrogeologic system. The most shallow well in the nest was to serve double-duty as one of the tracer test wells. The other two wells, HC-5 and HC-8 were completed at depths of 1,086.5 and $771.1 \mathrm{~m}$, respectively. Each well was completed with a 36.6-m well screen at the bottom of the hole. Hydraulic testing was conducted with submersible pumps to measure aquifer characteristics at the different depths, while water levels were monitored in the other wells. Hydraulic head measurements continued after the tests to establish static levels. Groundwater samples were collected at the conclusion of aquifer testing. Fracture information was primarily obtained through logging operations. The following logs were run and data can be found in Mihevc et al. (2000): radar, acoustic televiewer, video, fracture interpretation, caliper, density, neutron, temperature, natural gamma, spectral gamma, deviation, and resistivity. Additional information for the borehole-radar reflection logs can be found in Lane et al. (2001).

The objectives related to determining fracture characteristics and hydraulic parameters at various depths, as well as addressing the uncertainty related to the low hydraulic head at HC-3, were met with the wells. Of particular importance to the modeling was the finding that fracture density and hydraulic conductivity did not decrease with increasing depth, consistent with assumptions made in the 1998 model. However, the objective of determining the groundwater velocity both with environmental tracers and with hydraulic heads was not achieved. The well nest and tracer test wells had been located to provide data downgradient of the nuclear test, per the 1998 model. During the drilling of the first well, HC-5, a large fault zone was penetrated. The zone was also penetrated by the intermediate depth well, HC-8. The fault zone is related to a shear zone expressed on the land surface. Due to its steep dip to the northwest, though the surface locations of HC-5 and HC-8 are located west of the shear zone, the wells penetrate the fault so that the screened intervals at the bottom are on the east side of the zone. As a result of the findings in HC-5, the tracer test wells, HC-6 and -7, were moved westward from their original planned 
locations so that the tracer test could take place on the same side of the shear zone as the Shoal nuclear test.

The significance of the shear zone is addressed in the modeling presented in this report. By way of introduction, the water levels in HC-7 and HC-5, separated by only $50 \mathrm{~m}$ in a horizontal direction, differ by over $100 \mathrm{~m}$. Thus, the well nest activity identified a major hydraulic barrier at the site and explained the lower hydraulic head observed at HC-3. However, with the fault between the completions of the tracer test wells and HC-5 and -8, there is no vertical flowpath sampled through these wells to use for the velocity determination on the west side (nuclear-test side) of the shear zone.

\subsubsection{Phase II Flow and Transport Modeling}

This report details the flow and transport modeling conducted after the 1999 to 2000 data collection activities. The conceptual model remains unchanged through the three major investigation periods, though it has gained in complexity and realism with each phase. The two most significant changes as a result of the recent data collection are the new understanding that groundwater flows northeastward rather than the more simplistic assumption of flow southeastward (perpendicular to the flow divide), and the recognition of matrix diffusion as an important transport process, rather than the simpler model of only advective transport.

The current understanding of the groundwater system at Shoal, developed from the cumulative information gathered from the 1960s to today, can be summarized as follows. Groundwater flow occurs through fractures in the Sand Springs granite. The orientation and hydraulic properties of those fractures are now much better known than they were in the past. Recharge to the groundwater system occurs by infiltration of precipitation on the mountain range. The amount of recharge is considered to be very small as a result of the low amount of precipitation (given the relatively low elevation of the range) and the effectiveness of the plant cover at using available moisture. A groundwater divide separates flow to the eastward and westward valleys. That divide coincides closely with the topographic divide such that the nuclear test is located on the eastern side. Though groundwater flow from the test moves toward Fairview Valley, a very low permeability shear zone prevents movement directly to the valley, so that groundwater moves northeastward in the vicinity of the Shoal test. Radionuclides from the nuclear test flow not only through the fractures, but are able to diffuse into matrix blocks adjoining the fractures. Comparing this understanding with that of previous studies reveals the contributions of the earlier workers and their data, and the refinements made possible by the recent field activities.

\subsection{Units of Measurement}

Physical quantities are reported in Systeme International (SI) units. Geographical coordinates are reported on the Universal Transverse Mercator (UTM) grid, Zone 11 using the NAD27 datum. 


\subsection{PSA CONCEPTUAL FLOW MODEL AND EVALUATION OF ALTERNATE MODELS}

The PSA flow model simulates three-dimensional, steady-state groundwater flow in the immediate vicinity of the Shoal nuclear test site, and provides the basis for modeling radionuclide transport away from the Shoal nuclear cavity. The development of the PSA flow model required the input and analysis of a variety of information (Figure 2.1).

The conceptual flow model for the site considers groundwater flow through the fractured granite aquifer comprising the Sand Springs Range. Its fundamental components can be seen in the cross sectional view presented in Figure 1.4 and in a three-dimensional depiction of the model domain in Figure 2.2. Water enters the system by the infiltration of precipitation directly on the surface of the mountain range. Because the model does not extend in an upgradient direction to a natural boundary, there is lateral flux into the southern face that originates as recharge through the ground surface upgradient of the model area. Groundwater leaves the granite aquifer by flowing into alluvial deposits in the adjacent basins of Fourmile Flat and Fairview Valley. A groundwater divide runs along the western portion of the Sand Springs Range, west of the underground nuclear test, preventing flow from the test to Fourmile Flat. This divide forms a no-flow boundary on the western side of the model. A very low conductivity shear zone roughly parallels the divide, east of the nuclear test, and creates another no-flow boundary on the eastern edge. The presence of these lateral boundaries causes groundwater from the site to flow in a northeastward direction on its way to Fairview Valley.

Essential components of the Shoal conceptual flow model can be summarized as follows:

- Steady-state conditions

- Isothermal conditions

- Recharge distributed uniformly across the surface of the Sand Springs Range

- A hydrologic divide located along the western portion of the range, forming a no-flow boundary on the west side of the domain

- A low-conductivity, thick shear zone creating an impermeable no-flow boundary along the east side of the domain, dipping to the west at depth (causing the model to pinch in lateral extent with depth)

- The southern model boundary is assigned specified flux corresponding to flow into the domain from the region between the model boundary and the hydrologic divide in that direction; this flux is estimated from the regional models and the surface recharge rate

- Flow exits the model through the northern boundary, directed across the site by the shear zone; this flow is assumed to eventually move to basin fill in Fairview Valley, outside of this model domain

- Flow is simulated using a stochastic continuum approximation comprised of large, oriented fracture zones and intervening zones of granite with random, small fractures; these zones are referred to herein as Flow Category 2 and Flow Category 1, respectively 
- A region of higher hydraulic conductivity and higher porosity is located around the cavity and chimney to represent the impact of the Shoal test on the flow field

- Uncertainty is included for fracture geometry, hydraulic conductivity, surface recharge, and flux through the southern boundary

Considerable additional detail about the conceptual model is developed in subsequent sections.

As compared to environments with complex hydrostratigraphy, the single aquifer of the Shoal fractured granite, situated on the crest of a mountain range, simplifies some model decisions. For example, the site presents no alternate model to that of flow through a fractured granite fed by infiltration of precipitation through the surface of the range and directed toward the adjacent valleys. However, alternate conceptual models are available for some aspects of the PSA flow model. These pertain principally to the hydraulic behavior of the shear zone and the flow conditions on the west side of the range. Additionally, alternatives are possible regarding recharge, discharge, and hydraulic parameters. These features are tested using appropriate models designed for that purpose and the results are provided in the following sections.

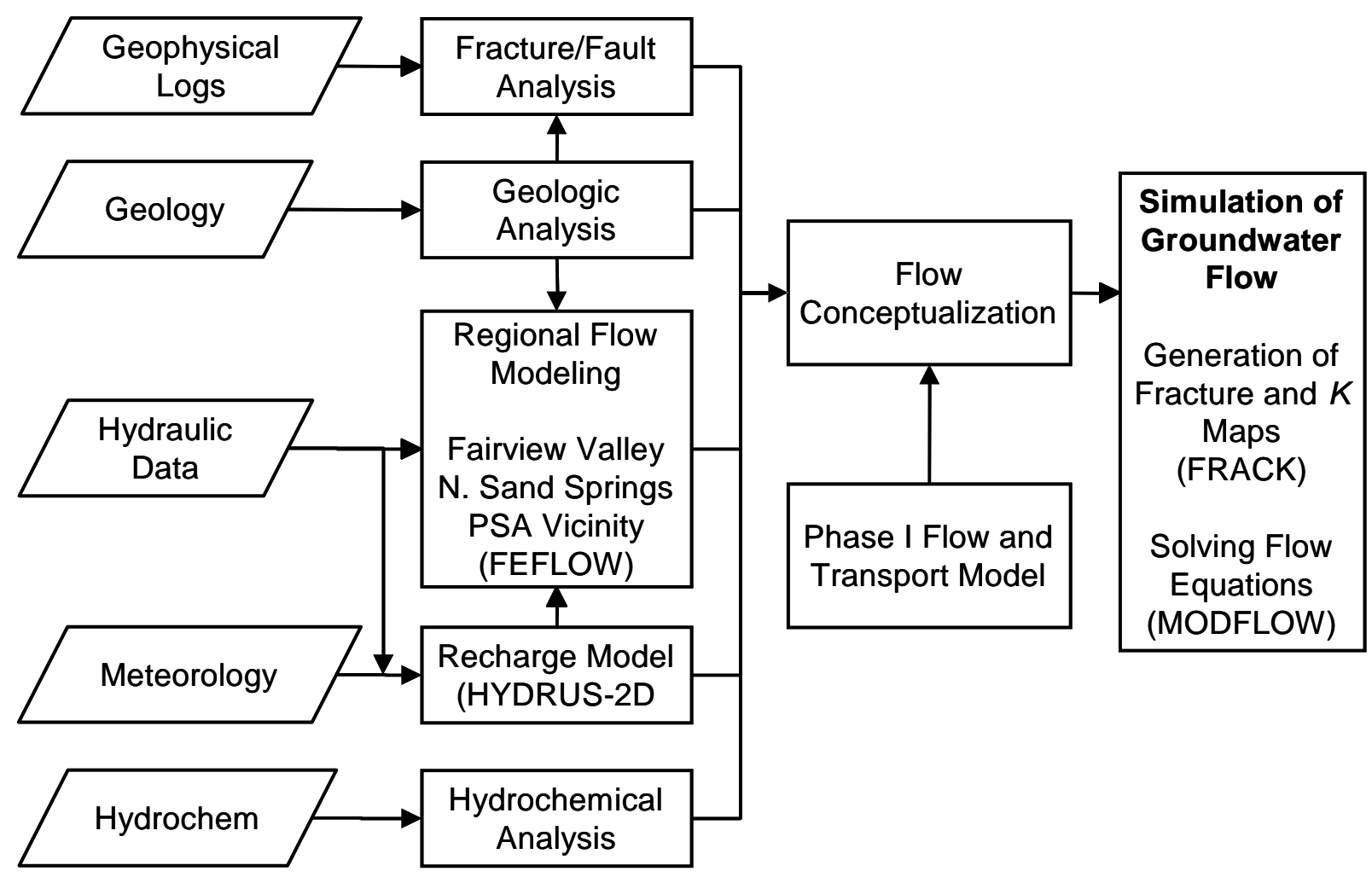

Figure 2.1. Relationships between data and supportive modeling activities that contributed to the simulation of groundwater flow in the PSA model. 


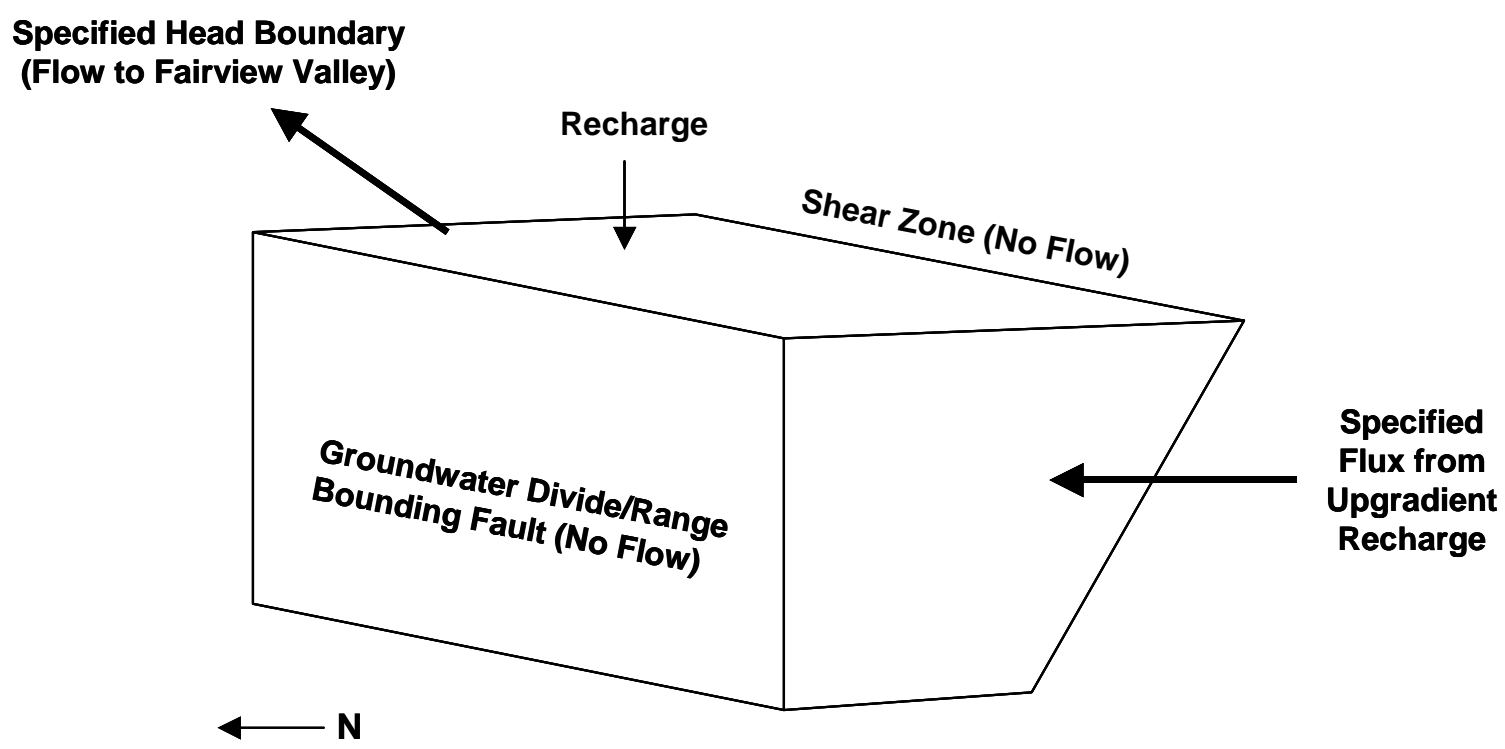

Figure 2.2. Three-dimensional depiction of the PSA conceptual model.

\subsection{Modeling Strategy}

Understanding groundwater flow patterns in the region surrounding the Sand Springs Range is necessary for investigating relationships between recharge, discharge, and transmissivity at the basin scale, and for ensuring consistency between the PSA model and the regional system. A series of deterministic groundwater flow models was developed to investigate alternate models for various aspects of groundwater flow in the Sand Springs Range and Fairview Valley in preparation for the stochastic simulations of groundwater flow and radionuclide transport. All the models represent groundwater flow in the hydrographic basin surrounding and including Fairview Valley (Figure 2.3), which is designated Nevada Hydrographic Area 124 (Rush, 1968).

Deterministic groundwater flow models were used to test various scenarios of recharge, discharge, hydraulic conductivity, and various structural features. Three of these models are described here. The first model, herein referred to as the model of Fairview Basin, is of relatively large scale and is used to assess overall system behavior and to refine the conceptual model at the scale of the hydrographic basin that includes Fairview Valley and the Sand Springs Range. Following development and testing, this conceptual and numerical model is used as the foundation for two three-dimensional models of flow near the Shoal site: a model of the northern Sand Springs Range and a model of the PSA vicinity. These models incorporate the level of detail required to simulate groundwater flow near the test site and are used to test physical aspects of the near-field hydrogeologic system, study sensitivities to parameter values, and assist determination of the configuration and boundary conditions for the stochastic models.

The deterministic flow models were developed using the FEFLOW code (Diersch, 1998), a finite-element simulation package for two and three dimensions that is available from the WASY Institute for Water Resources Planning and Systems Research, Ltd. FEFLOW uses a Galerkin- 


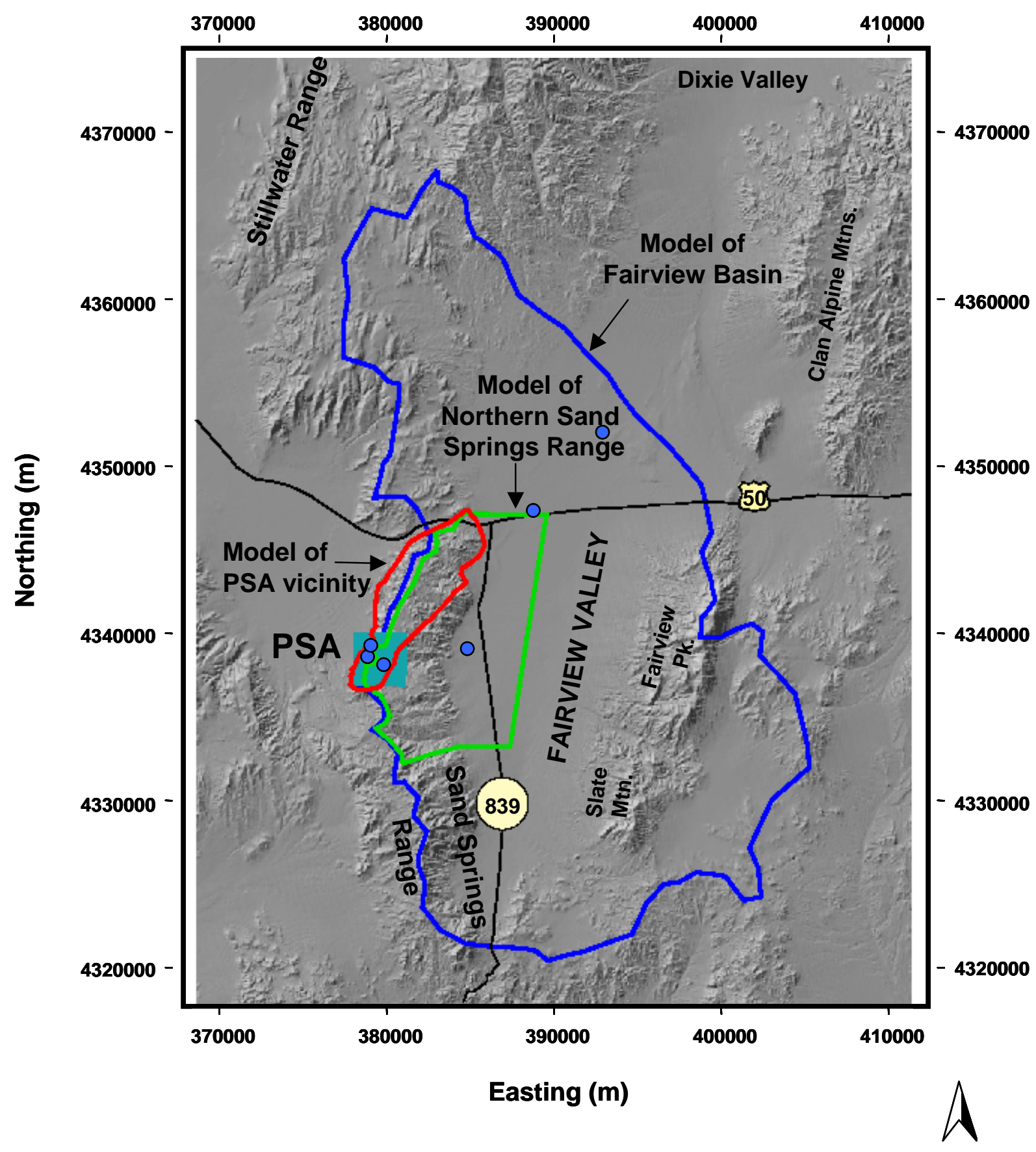

Figure 2.3. Map showing outline and major features of the Fairview Valley topographic basin, the areas covered by the three regional groundwater flow models, and the locations of measured water levels (the blue circles). 
based, finite-element method for solving the advection-dispersion balance equations on unstructured meshes. Though FEFLOW is designed for flow and transport problems involving density-dependent flow, mass, and heat transport processes, the models described here do not include these effects. However, the high-level graphical interface, the Geographic Information System (GIS) capabilities, and the capacity for detailed mesh generation built into FEFLOW are important features that have allowed the rapid development and testing of the models described in this report. Furthermore, the code can account for free surfaces using moving meshes to model three-dimensional, regional unconfined aquifers, an important capability for modeling the unconfined system of the Sand Springs Range. A full description of the code and the results of benchmarking studies are reported by Diersch (1998). Quality assurance processes followed during the modeling are described in Appendix B. Use of the FEFLOW code also allows the straightforward addition of mass and heat transport processes at a later time if desired.

\subsection{Evaluation of Regional Context: the Model of Fairview Basin}

The purpose of the Fairview Basin model was to ensure consistency between the conditions of the PSA model and the known hydrogeologic conditions constraining the regional system. Fluxes into and out of the PSA model, and general hydrologic properties, must be consistent with those for the surrounding hydrographic basin to ensure the quality and correctness of the PSA model.

\subsubsection{Components of the Conceptual Model}

Groundwater in Fairview Basin is conceptualized as originating from precipitation in the mountain ranges that surround the valley, which include the southern Stillwater Range on the northwest, the Sand Springs Range on the west, and Fairview Peak and Slate Mountain on the east (Cohen and Everett, 1963; Harrill and Hines, 1995) (Figure 2.3). Groundwater moves laterally toward the valley through secondary permeability features (primarily fractures) in the crystalline rocks of the mountain ranges, which consist of Tertiary basalts in the southern Stillwater Range, Tertiary rhyolite flows and tuffs in Fairview Peak, and Cretaceous granite in the Sand Springs Range and portions of Slate Mountain (Wilden and Speed, 1974). In addition, Mesozoic(?) metamorphic rocks crop out in the Sand Springs Range. The only wells that extend appreciable depths within the crystalline rocks are those constructed at Shoal by the AEC for Project Shoal and by DOE during subsequent corrective action investigations. The deepest of these wells (HC-5) penetrates granite to its total depth of $1,086.56 \mathrm{~m}$, encountering numerous fracture and fault zones, as well as fluid inflow to the borehole, over this distance. Although hydraulic testing of many of the Shoal wells provides information on the hydraulic properties of the fractured and faulted granite, hydraulic data are not available for the other crystalline rocks in Fairview Basin.

Fairview Valley is a structural bedrock valley partly filled with alluvial sediments. Although not completely penetrated by drilling, alluvium thicknesses have been estimated using gravity surveys (University of Nevada, 1965). The maximum alluvium thickness of approximately 1,770 m appears to occur on the western margin of the basin, directly adjacent to the Sand Springs Range. The basin appears to thin slightly toward the eastern margin, where alluvium thickness is estimated to be approximately 1,220 m. High-angle normal faults form the eastern and western boundaries of 
the valley. Wells near the western margin of the valley (AEC test wells HS-1 and H-4) and in the center of the valley (domestic wells at Frenchmans Station) provide lithologic descriptions of the basin-fill material and hydraulic properties determined from pumping tests (University of Nevada, 1965). Hydraulic heads are available from these wells and the U.S. Navy well at the EW Range Site.

Groundwater flow in the granite intrusion forming the core of the Sand Springs Range is controlled by and restricted to numerous high-angle faults and associated fractures (Figure 2.4) (a complete description of the geology of the Sand Springs Range is given in University of Nevada, 1965). One major fault system is oriented about $\mathrm{N} 50^{\circ} \mathrm{W}$ and includes numerous parallel joints. The second major fault system includes parallel, closely spaced fracture cleavage and has an orientation of about $\mathrm{N} 30^{\circ} \mathrm{E}$ cutting across the northwest-trending system. Both systems are pervasive throughout the range and some faults within each system are grouped together to form fault/fracture zones. Though the rock within the major fault zones is commonly highly altered, "rock a few inches from the structure usually is fresh, solid, and dense" (University of Nevada, 1965).

The most prominent fault zone in the Sand Springs Range belongs to the northeast-trending system and passes through the PSA. Early PSA surface mapping and borehole data suggest that this fault zone dips $55^{\circ}$ to $80^{\circ} \mathrm{NW}$ and may be as much as $60 \mathrm{~m}$ wide (University of Nevada, 1965). Additional data collected in 1999 from boreholes HC-5, HC-7 and HC-8 (Mihevc et al., 2000) indicate that this fault zone trends $\mathrm{N} 20^{\circ} \mathrm{E}$ and dips $72^{\circ} \mathrm{NW}$. Research on the hydrologic significance of shear zones shows that fine-grained fault gouge located within the core may be two to three orders of magnitude less conductive than the adjacent unfaulted rock (Morrow et al., 1984; Evans et al., 1997) and, depending on the orientation of the fault, could provide an important barrier to groundwater flow.

The outer boundary of Fairview Basin is assumed to coincide with the topographic divides defined by the ridge tops of the mountain ranges surrounding Fairview Valley, consistent with previous investigations in the region (Cohen and Everett, 1963; Harrill and Hines, 1995). The boundary in the Sand Springs Range requires additional discussion here, however, owing to its important implications for flow at the PSA. As discussed in Section 1.3, the highland area of the Sand Springs Range is a regional recharge area with the resultant groundwater flow directed toward the adjacent basins to the west and east. The position of the groundwater divide that separates eastward from westward flow is an important aspect of the flow system in terms of its location relative to Shoal ground zero. The crest of the range, represented by the central and western portions of Gote Flat (the area west of HC-5 on Figure 1.2), comprises a compartment of relatively uniform heads that range from 1,289.5 to 1,296.7 m AMSL. Only the head of 1,356.3 $\mathrm{m}$ reported for PM-2 is inconsistent with this pattern, but this value is considered unreliable due to unfavorable borehole conditions at the time of the measurement. Despite their limited range, these heads clearly indicate a declining trend toward the east, suggesting that the groundwater divide is located to the west of Gote Flat. As will be discussed in more detail in subsequent sections of this report, heads on the east side of Gote Flat (eastward from HC-5) are approximately 100 m lower than heads on the range crest. This large drop in head coincides with the position of the northeast- 


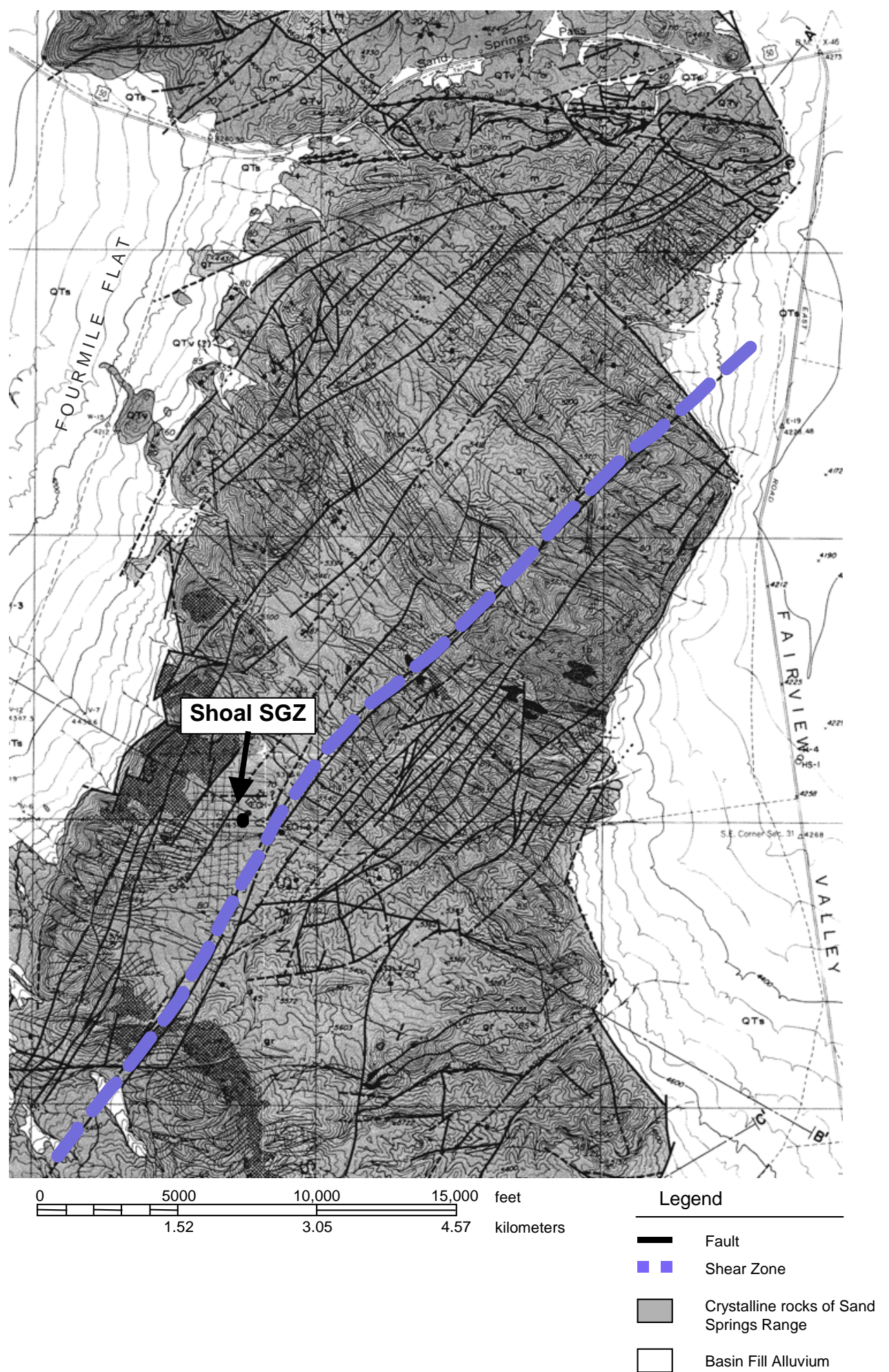

Figure 2.4. Location and orientation of the shear zone in the central Sand Springs Range (University of Nevada, 1965). 
trending major shear zone that crosses Gote Flat and suggests that the shear zone represents a barrier to the expected eastward flow of groundwater off the range.

Heads immediately west of the range in Fourmile Flat are approximately $100 \mathrm{~m}$ lower than those on the range crest and comprise another compartment of relatively uniform heads. Heads at AEC wells H-2 and H-3 (see Figure 1.1) are 1,190.6 and 1,189.9 m, respectively, and springs along the eastern margin of Fourmile Flat playa discharge at elevations between 1,190 and 1,200 $\mathrm{m}$. The low horizontal hydraulic gradient in Fourmile Flat likely results from a combination of highly transmissive basin-fill sediments (University of Nevada [1965] estimated an effective hydraulic conductivity of $4.8 \mathrm{~m} / \mathrm{d}$ from a pumping test in $\mathrm{H}-2$ ) relative to the crystalline rocks in the surrounding ranges and vertically upward directed flow related to regional groundwater discharge in Fourmile Flat playa. The western margin of the Sand Springs Range that separates these two compartments of uniform, but very different, heads thus represents a region of high hydraulic gradients, possibly resulting from a zone of low transmissivity created by the highangle, range- bounding fault mapped here (University of Nevada, 1965) and sketched on Figure 1.4. It is assumed here that the presence of a geologic feature such as this creates a physical boundary in the groundwater system, forcing redirection of most groundwater flow around it and contributing to the formation of a groundwater divide immediately east near the crest of the Sand Springs Range. Though the possibility exists that the fault may act as a conduit for westward flow off the range, this scenario appears inconsistent with the existence of the cell of uniformly high heads on the range crest.

Recharge in Fairview Basin was first addressed by Cohen and Everett (1963) by dividing the Dixie Valley area into several elevation zones and estimating for each zone the annual precipitation rate and percent of precipitation that becomes groundwater recharge. These recharge estimates were revised by Harrill and Hines (1995) using new data and an updated precipitationaltitude relationship. Elevations below 1,524 m (which are restricted to the valley floor) are assumed to contribute no recharge, elevations between $1,524 \mathrm{~m}$ and $1,829 \mathrm{~m}$ are estimated to contribute $0.76 \mathrm{~cm} / \mathrm{yr}$, and elevations above $1,829 \mathrm{~m}$ are estimated to contribute $2.4 \mathrm{~cm} / \mathrm{yr}$. Pohll et al. (1998) estimated a recharge rate of $1.5 \mathrm{~cm} / \mathrm{yr}$ at an approximate land surface elevation of $1,620 \mathrm{~m}$ using thermal profiles in Shoal wells, while a model of the vadose zone at the Shoal site suggests recharge rates range from near zero to $0.16 \mathrm{~cm} / \mathrm{yr}$ (Pohll, 1999).

Natural discharge from the basin is hypothesized as lateral underflow within basin-fill deposits toward Dixie Valley to the northeast; evapotranspiration is considered to be negligible (Harrill and Hines, 1995). Cohen and Everett (1963) estimate the total discharge from Fairview Valley to Dixie Valley to be $1,690 \mathrm{~m}^{3} / \mathrm{d}$ (500 acre-feet per year) by assuming that all subsurface discharge originates as recharge from precipitation in the basin. Harrill and Hines (1995) calculated the groundwater budget of the entire Dixie Valley area, including a detailed reevaluation of groundwater discharge by evapotranspiration in Dixie Valley. Using the same closed system assumption, Harrill and Hines (1995) calculated a higher recharge rate of 7,774 m² (2,300 acrefeet per year) to balance higher estimates of evapotranspiration in the Dixie Valley flow system. Harrill and Hines (1995) moved the lowest altitude of recharge down from 1,829 m (6,000 ft) to 
$1,524 \mathrm{~m}(5,000 \mathrm{ft})$ and thereby greatly increasing the area of the basin assumed to be contributing to groundwater recharge.

Groundwater flow in Fairview Basin is assumed to occur under steady-state conditions. The large size of the hydrologic system and the small quantities of groundwater withdrawn on an annual basis suggest that significant temporal variations in regional water levels are not expected under current climatic conditions.

\subsubsection{Numerical Model}

The numerical model is a two-dimensional representation of flow in Fairview Basin consisting of a horizontal projection of 2,272 triangular elements (Figure 2.5). Flow is assumed to be under steady-state and confined conditions. A specified-head boundary (Dirichlet condition) on the northeast edge of the domain simulates groundwater discharge from Fairview Valley toward Dixie Valley. Heads on this boundary are assigned a value of 1,180 m AMSL based on the water level measured in a nearby well at the U.S. Navy Range Site and the water table map of Cohen and Everett (1963). The remainder of the outer boundaries are no-flow (impermeable) boundaries that coincide with the topographic divides in the surrounding ranges.

The model is divided into three zones for the purpose of assigning hydrologic properties (Figure 2.5 and Table 2.1), with Zone I comprising the basin-fill aquifer and Zones II and III comprising the crystalline rock aquifers. Values of transmissivity $T$ and recharge rate $R$ of each zone are adjusted during calibration to obtain an acceptable match to measured water levels. The initial estimate of $T$ for Zone I is based on the values of hydraulic conductivity, $K$, reported for HS-1, H-4 and the Frenchman's Station wells (University of Nevada, 1965) and an average effective basin thickness of 1,400 m. The crystalline rock aquifers of Zones II and III are assigned a $T$ based on the geometric mean of 10 pumping tests conducted in the HC wells at Shoal (Mihevc et al., 2000). This value is assigned to all crystalline aquifers in the model due to the absence of hydraulic data that might suggest otherwise. It is reasonable to assume that the other aquifers composed of fractured igneous and metamorphic rock have similar hydraulic characteristics owing to similar modes of flow in secondary permeability features.

Though the fractured granite produces a highly heterogeneous flow system, the Fairview Basin flow model represents the granite and the other crystalline rock aquifers of Zones II and III as an equivalent porous medium. This approximation is considered appropriate at the scale of the Fairview Basin model given the high density of fractures and the low density of hydraulic data over the modeled area.

In addition to representing the basin-fill aquifer, Zone I represents the region of the model having land surface elevations below the zero recharge threshold at elevation 1,524 m. Elevations below 1,524 m are assumed to receive no recharge in Fairview Valley (Harrill and Hines, 1995), and thus Zone I is assigned an $R$ of zero. Zone II corresponds to land surface elevations between $1,524 \mathrm{~m}$ and 1,829 $\mathrm{m}$ and Zone III corresponds to land surface elevations above 1,829 $\mathrm{m}$. 


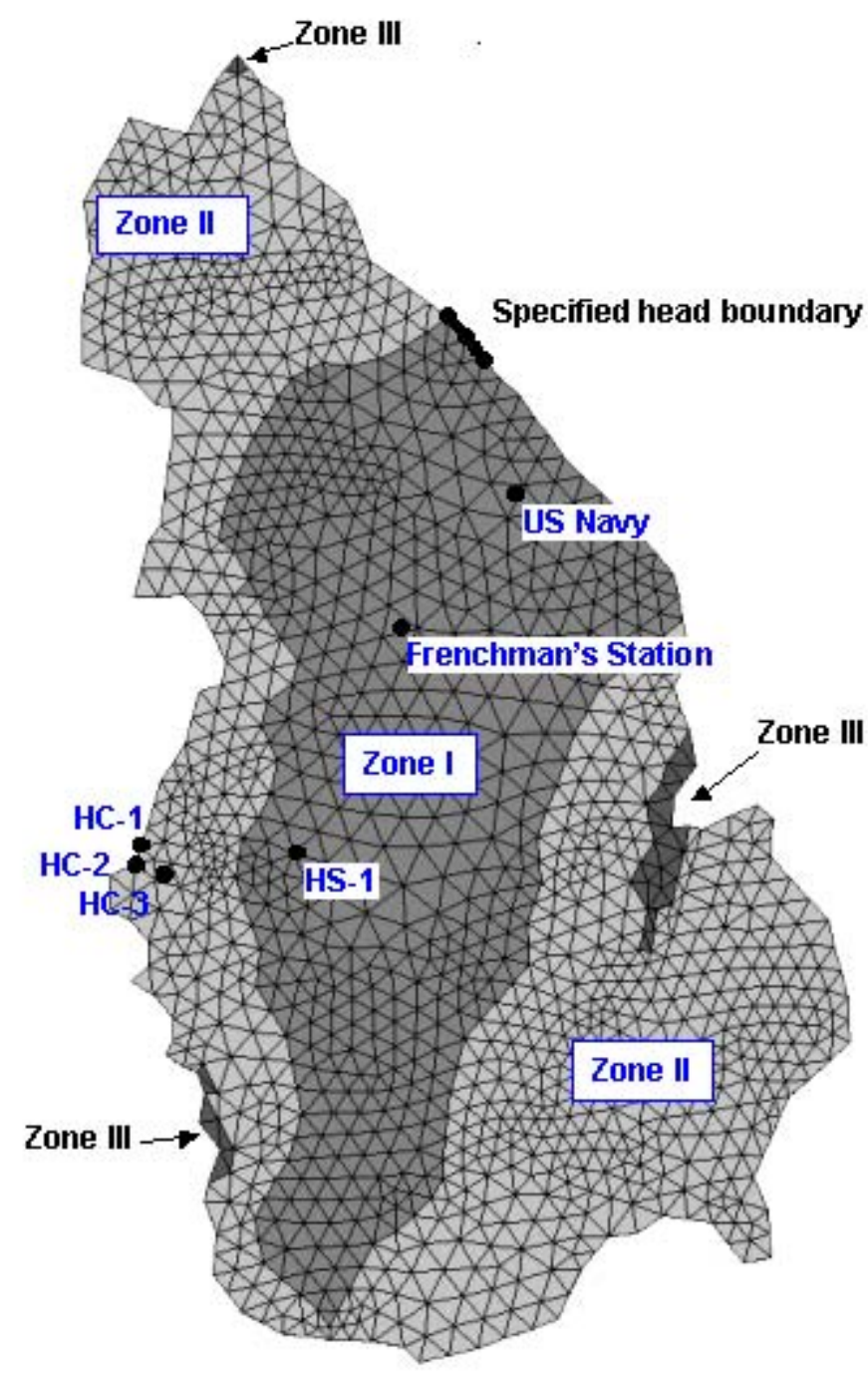

Figure 2.5. Configuration of the finite-element mesh, boundary conditions, and zones of hydraulic properties in the two-dimensional model of Fairview Basin. The locations of measured water levels are also shown.

Model calibration is conducted to ensure that the model adequately simulates the observed behavior of the modeled system, and is often achieved through refinement of the hydrogeologic framework, boundary conditions, and/or hydraulic parameters (ASTM, 1995). Further refinement of the hydrogeologic framework of the Fairview Basin model is limited by the lack of relevant data in the basin, though additional detail is incorporated in the smaller-scale, more complex models developed for the Shoal site. The specified-head boundary is chosen based on an observed value of hydraulic head and previous mapping of the valley and is not considered as part of the calibration; however, the length of this boundary is addressed in the sensitivity analysis (described 
Table 2.1. Initial estimates and calibration values of parameters used in the two-dimensional model of Fairview Basin.

\begin{tabular}{lcc}
\hline \hline & Initial Estimates & Calibration Value \\
\hline Zone I & & \\
Transmissivity, $T\left(\mathrm{~m}^{2} / \mathrm{d}\right)$ & 5,200 & 860 \\
Recharge Rate, $R(\mathrm{~cm} / \mathrm{yr})$ & 0.0 & 0.0 \\
Zone II & & \\
Transmissivity, $T\left(\mathrm{~m}^{2} / \mathrm{d}\right)$ & 12 & 1.5 \\
Recharge Rate, $R(\mathrm{~cm} / \mathrm{yr})$ & 0.76 & 0.62 \\
Zone III & & \\
Transmissivity, $T\left(\mathrm{~m}^{2} / \mathrm{d}\right)$ & 12 & 1.5 \\
Recharge Rate, $R(\mathrm{~cm} / \mathrm{yr})$ & 2.4 & 1.9 \\
\hline \hline
\end{tabular}

below). Thus, the calibration parameters in the Fairview Basin model are restricted to the hydrologic parameters transmissivity and recharge rate.

As shown in Table 2.1, the calibrated value of $T$ in the basin-fill aquifer is within one order of magnitude of the initial estimate. The lower value may be a result of the single-layer configuration of the model, which assumes a single $T$ for the entire thickness of the aquifer that is estimated from pumping tests conducted only in the top few hundred meters. If there is a reduction in hydraulic conductivity with increasing depth in the alluvium, as is often observed in basin-fill deposits, then the $T$ estimated from the pumping tests overestimates the conductivity of the deeper alluvium. If this is the situation, then the calibrated value is more representative of the depthaveraged conductivity of the deposits, which, assuming an average basin thickness of 1,400 m, is about $0.6 \mathrm{~m} / \mathrm{d}$ in this case. Another factor possibly contributing to the lower calibration value is the assumption that the alluvial basin has a constant thickness, even at the southern end where it is very likely that the basin thins as the distance between the Sand Springs Range and Slate Mountain is reduced. It should also be noted that the calibrated value of $T$ in the fractured granite is lower than the initial estimate by almost one order of magnitude. This reduction was necessary to maintain hydraulic heads in the Sand Springs Range at levels as high as those observed at Shoal, particularly given the low simulated recharge rates. Subsequent and more detailed threedimensional modeling at the Shoal site has shown that structural features not included in this simplified two-dimensional model are important factors in the observed head relationships, not $T$ alone. Calibrated recharge rates are slightly lower than the initial values estimated from regional hydrologic budgets, and closer to the values estimated at the Shoal site.

The calibrated flow model provides a reasonable simulation of the hypothesized flow system in Fairview Basin, with recharge occurring in the mountain ranges and subsurface discharge occurring in the direction of Dixie Valley to the northeast (Figure 2.6). The model simulates a discharge rate of $7,960 \mathrm{~m}^{3} / \mathrm{d}$, which is only slightly higher than the $7,774 \mathrm{~m}^{3} / \mathrm{d}$ estimated by Harrill and Hines (1995). The difference in flux can be attributed to differences in the calculations 


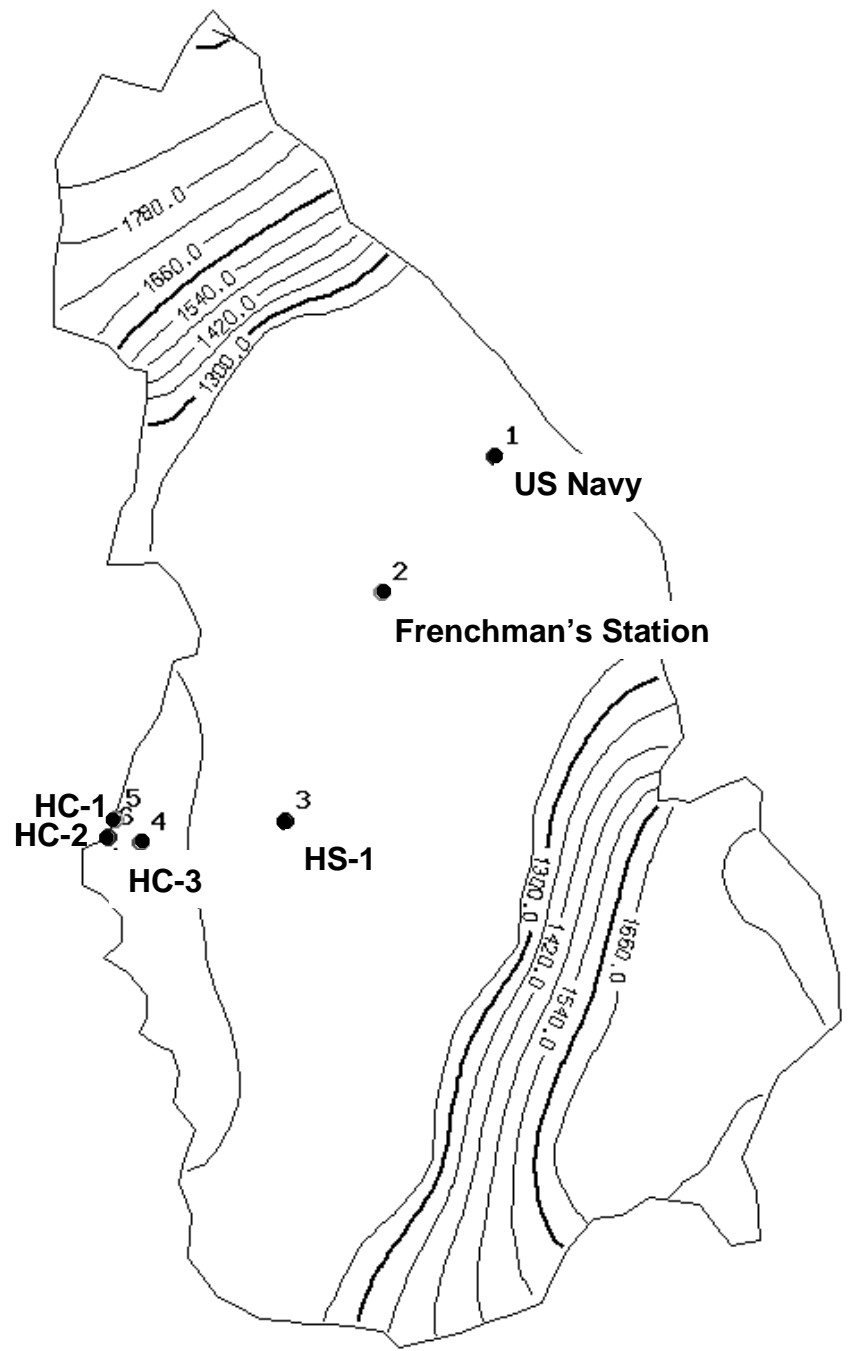

Figure 2.6. Map showing groundwater heads simulated in the Fairview Basin model. Also shown are the locations of measured water levels.

of land surface area due to the way the basin boundaries and elevation zones have been delineated, as well as the choices of hydraulic parameters.

Comparison of heads simulated by the model to heads measured in the field also supports the model simulation of the Fairview Basin flow system (Table 2.2). Heads in the basin-fill aquifer (Navy, Frenchmans Station, HS-1) are simulated within $12 \mathrm{~m}$ of measured values, and with one exception, heads near the summit of the Sand Springs Range (HC-1, HC-2) are simulated to within $6 \mathrm{~m}$ of measured values. The large overprediction of head at HC-3 is a result of not incorporating in this model important structural features of the Sand Springs Range, features that are included in more detailed models as discussed below. Furthermore, the high heads simulated in the northwestern and eastern portions of the model (Stillwater Range and Slate Mountain/Bell Flat, respectively) could not be validated with field data owing to the lack of water 
Table 2.2. Comparison of simulated to measured heads at selected well locations in the model of Fairview Basin.

\begin{tabular}{cccc}
\hline \hline Well Name & Measured $h(\mathrm{~m}$ AMSL) & Simulated $h(\mathrm{~m}$ AMSL) & $\Delta h(\mathrm{~m})$ \\
\hline Navy & 1,190 & 1,189 & 1 \\
Frenchman & 1,197 & 1,191 & 6 \\
HS-1 & 1,208 & 1,196 & 12 \\
HC-3 & 1,192 & 1,285 & -93 \\
HC-1 & 1,294 & 1,291 & 3 \\
HC-2 & 1,293 & 1,299 & -6 \\
\hline \hline
\end{tabular}

levels measured in those areas. The model calibration would be improved with additional water level and hydraulic property data in these areas.

The length of the specified-head boundary is varied to investigate the sensitivity of the model results to this feature. The discharge rate is relatively insensitive to boundary length. For example, reducing the length from 5,000 $\mathrm{m}$ to 2,200 $\mathrm{m}$ reduces the total discharge by less than 0.01 percent. Hydraulic heads showed a greater impact, however, with heads in the basin-fill aquifer increasing by approximately $0.8 \mathrm{~m}$ for the same reduction in boundary length, though the magnitude of the hydraulic gradients (and therefore the groundwater fluxes) remains generally unaffected throughout the model.

\subsection{Alternate Conceptual Models for the Shear Zone: Model of Northern Sand Springs Range}

Though capable of simulating general flow patterns, the regional-scale model as constructed was unable to adequately simulate the head distribution in the vicinity of Shoal revealed by drilling and testing since 1987 (Figure 2.7). Heads near the range crest and on the eastern margin bounding Fairview Valley are relatively uniform, but between HC-6 and HC-5 an abrupt drop in heads in excess of $100 \mathrm{~m}$ is observed over an approximately 100 -m horizontal distance. It is at this location that the University of Nevada (1965) maps a major shear zone trending $\mathrm{N} 30^{\circ} \mathrm{E}$ and dipping steeply to the northwest (Figure 2.4), describing it as several hundred feet wide and "one of the most prominent features of the Range.” Observations of numerous clay-rich intervals, interpreted as zones of fault gouge, were encountered during drilling and geophysical logging of well HC-5 (IT Corporation, 2000), suggesting that this well penetrated portions of the shear zone. The three-dimensional models described below address many of the limitations inherent to the simpler two-dimensional model, allowing for more detailed investigations of the hydrogeologic features controlling groundwater flow with the primary focus on the hydraulic nature of the shear zone.

\subsubsection{Components of the Conceptual Model Tested}

The conceptual model of flow in the Sand Springs Range is consistent with the model developed for Fairview Basin, with only a few modifications. As represented in the regional Fairview Basin model, the flow system in the northern Sand Springs Range is conceptualized as 


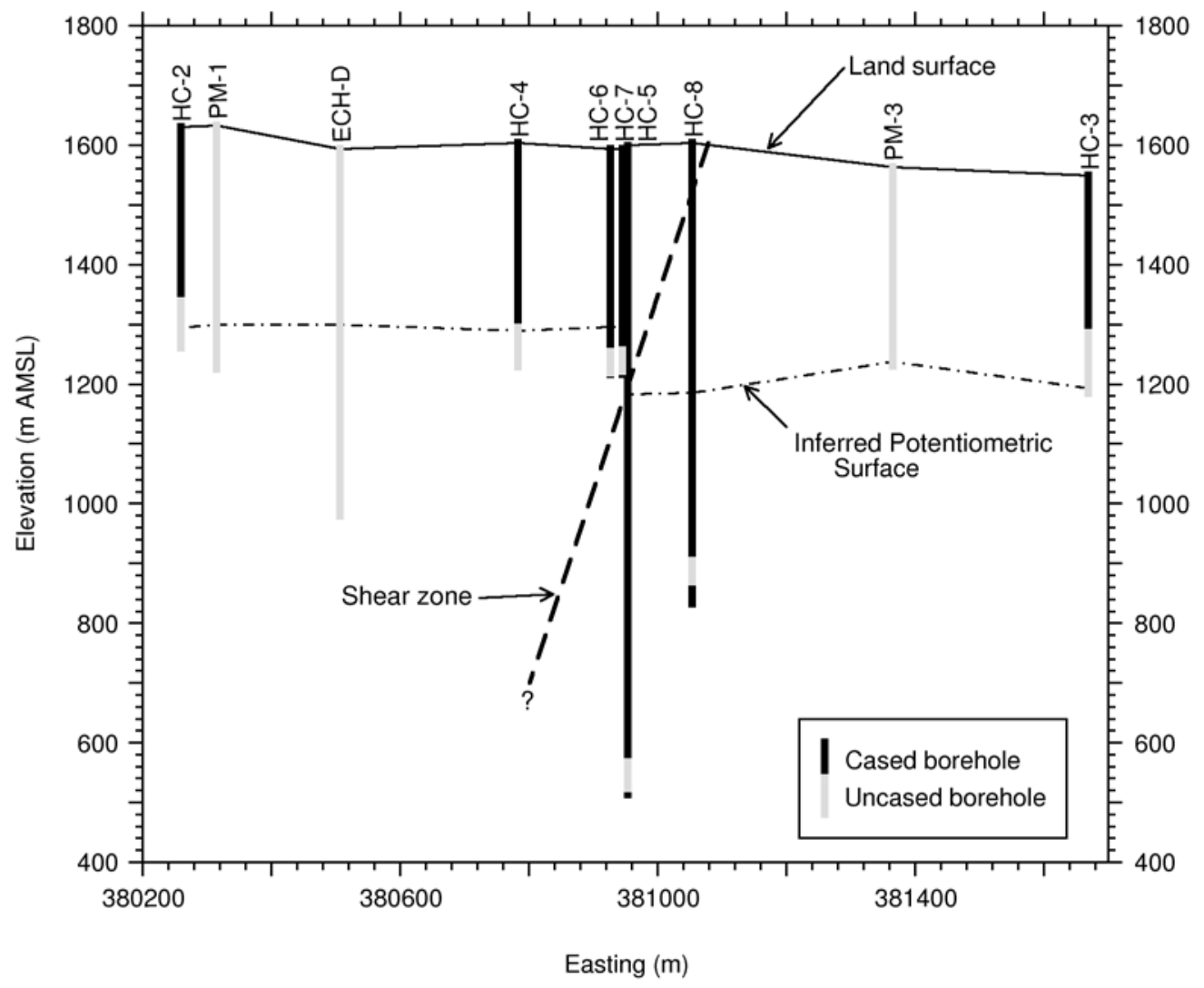

Figure 2.7. East-west profile through the Shoal site showing the large change in hydraulic head observed between HC-7 and HC-5. The wells are projected to the profile from their actual locations, which are shown in Figure 1.2.

being bounded on the west by a hydrologic divide near the crest of the range. Similarly, groundwater is recharged throughout the range and moves laterally eastward toward Fairview Valley through fractured granite; however, the three-dimensional conceptualization also includes a vertical component of flow. Flow in the basin-fill aquifer is primarily directed toward the north as suggested by the Fairview Basin model.

The most important feature added to this conceptual model is the northeast-trending shear zone that passes through the PSA. Fault zones similar to this one can act as barriers, conduits, or some combination of both depending on the hydraulic properties of the components comprising the fault zone (Evans et al., 1997). Caine et al. (1996) summarize the two principal components as a damaged zone (a region of enhanced fracturing, faulting, and veining) and the fault core (finegrained fault gouge or cataclasite). The permeability structure depends primarily on the nature of 
these two zones; relative to the surrounding host rock, an intensely fractured damaged zone may enhance permeability, while clay-rich gouge in the fault core may greatly reduce permeability (Evans et al., 1997). It should be noted, however, that neither the surface mapping nor the subsurface (borehole) data provide strong evidence for a significant damaged zone in the shear zone at the PSA.

\subsubsection{Field Investigation of Shear Zone Hydraulic Properties}

Existing data as well as data collected during the installation and testing of the characterization wells and the tracer test experiment were used to assess the hydrologic significance of the shear zone. These data have been described elsewhere (Carroll et al., 2000; Mihevc et al., 2000). An additional aquifer test was conducted specifically to investigate the shear zone hydraulic properties (Carroll et al., 2001). The primary objective was to determine whether there is a hydraulic response to pumping across the shear zone using existing wells.

Pumping began in well HC-5 on February 2, 2001, at 14:40 and continued until February 12, 2001, 12:49 at an average pumping rate of $23.1 \mathrm{~L} / \mathrm{min}$. The primary observation wells were HC-6 and HC-7, which were instrumented with transducers and dataloggers. Periodic water level measurements were collected in all wells (HC-1, HC-2, HC-3, HC-4, HC-5, HC-6, HC-7 and HC-8). It should be noted that the tracer test conducted from October 1999 until September 2000 induced significant drawdowns in HC-6 and HC-7 from which the wells were still recovering at the time of the HC-5 pumping test.

Figure 2.8 provides a comparison of water level elevations between the pumping well HC-5 and each of the critical monitoring wells HC-6, HC-7 and HC-8. Well HC-8 appears to show a slight response to the pumping of well HC-5. Drawdown in HC-8 occurs two days after pumping begins and then water levels begin to rise two days after the pump in HC-5 is turned off. While a response in well HC-8 was anticipated given that it lies on the same side of the shear zone as HC-5, this response may be somewhat artificial, given the scatter in data points collected both before and after the pump test.

No response is seen between wells HC-5 and HC-7, suggesting that the shear zone acts as a hydrologic barrier to flow. On the other hand, a slight response may be detected in well HC-6. It could be argued that the slope of recovery lessens in HC-6 a day or two after pumping begins and resumes a day or two after the pump is turned off. However, this change in slope is quite small, and somewhat erratic. The change in head over one-day timesteps (Figure 2.9) has no definitive pattern or relationship with the pumping in well HC-5. Given that no response is seen in wells HC-6 and HC-7, it is believed that no hydrologic connection exists across the shear zone.

\subsubsection{Numerical Model}

To investigate the impacts of the shear zone on groundwater flow in the northern portion of the Sand Springs Range, a three-dimensional model was constructed that consists of a horizontal projection of 32,480 triangular prismatic elements in 20 layers. The configuration of the top layer 

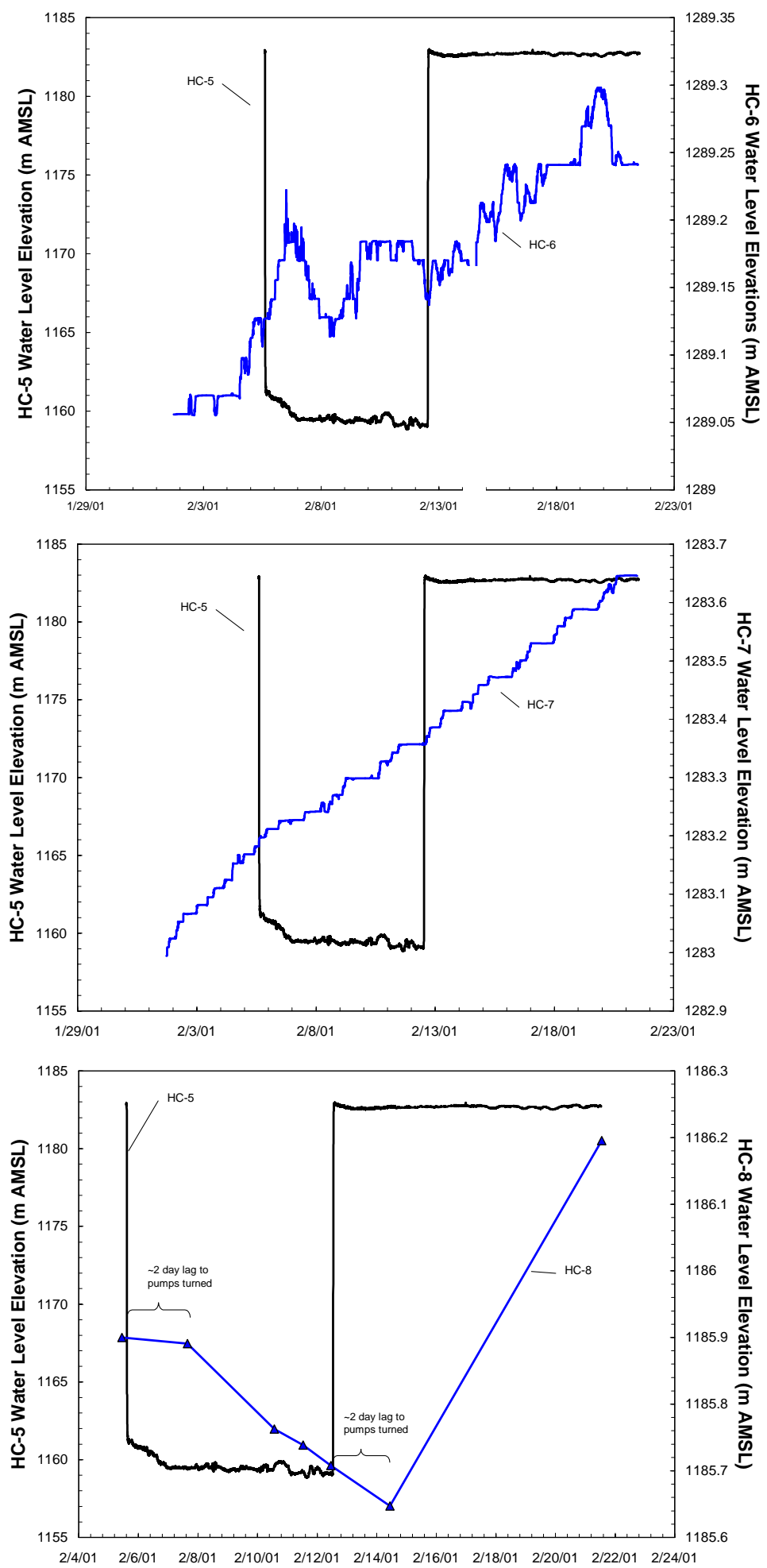

Figure 2.8. Comparison of water levels between the pumping well HC-5 and the observation wells (a) HC-6, (b) HC-7 and (c) HC-8. 


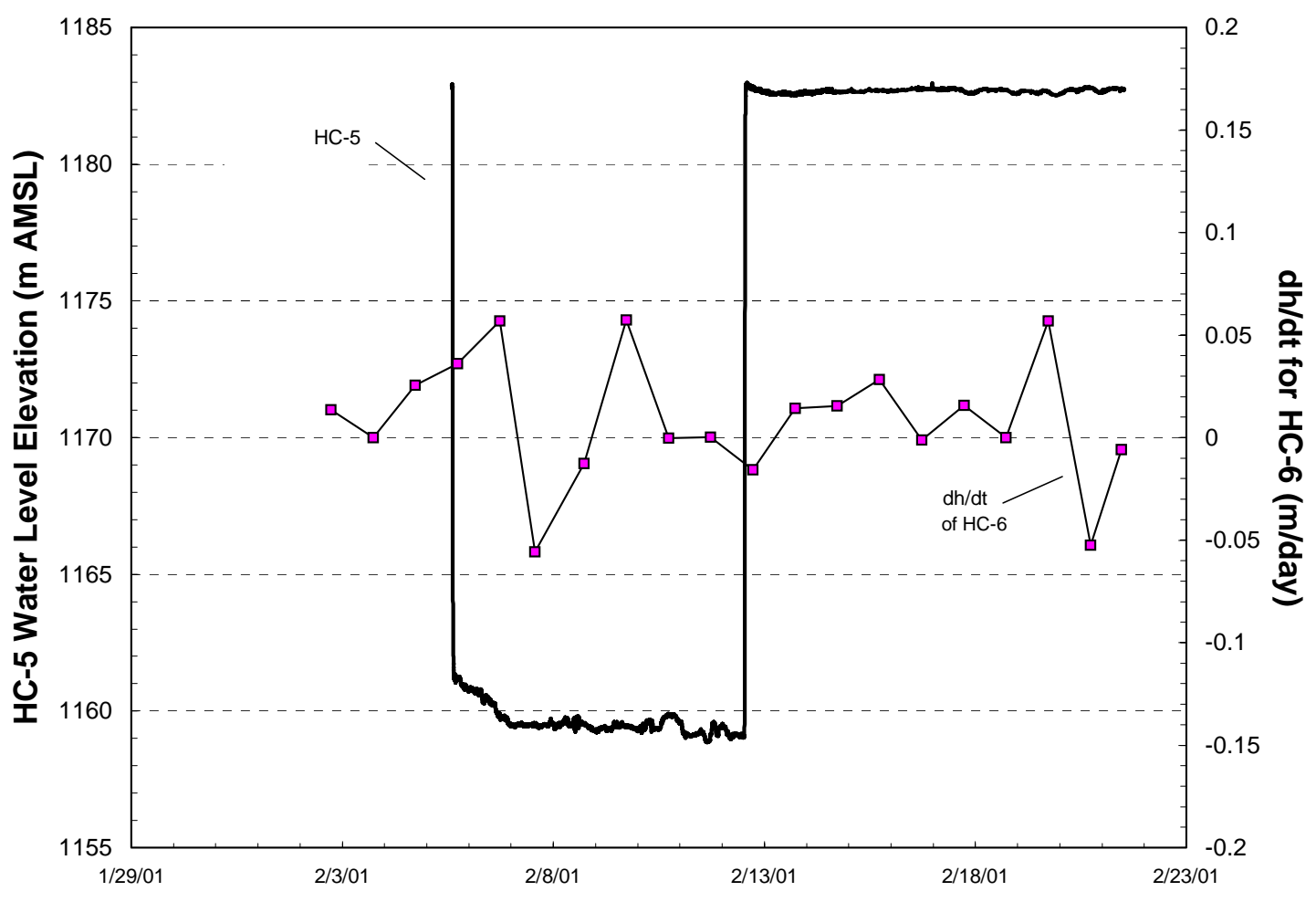

Figure 2.9. Comparison of $\mathrm{dh} / \mathrm{dt}$ for observation well HC-6, taken on a one-day timestep, with respect to drawdown in well HC-5.

is shown in Figure 2.10. The top layer is $150 \mathrm{~m}$ thick to allow for adjustment of the mesh in response to the position of the water table, and the remaining 19 layers are $100 \mathrm{~m}$ thick, but of otherwise identical configuration. The base of the model is at sea level. Flow is assumed to be under steady-state conditions.

Unlike the model of Fairview Basin, this model assumes that the granite aquifer is unconfined and uses FEFLOW's moving mesh option to simulate the location of the water table in the top layer. A specified-head boundary (Dirichlet condition) comprises the entire northern face of the domain and simulates northward groundwater movement through the basin-fill aquifer in Fairview Valley. Heads on this boundary are assigned a value of 1,197 m AMSL based on water levels measured in the Frenchman's Station wells (which the boundary intersects) and the water table map of Cohen and Everett (1963). A second specified-head boundary comprises the eastern half of the southern face of the model and simulates flow into the model through the basin-fill aquifer. Heads on this boundary are assigned a value of 1,203 $\mathrm{m}$ AMSL based on the results of the Fairview Basin model. The remainder of the outer boundaries are no-flow (impermeable) boundaries. The boundary on the west coincides with the surface hydrologic divide at the crest of the Sand Springs Range. The boundary on the east represents a hypothetical flow line extending north-south through the central portion of Fairview Valley. The southwest boundary corresponds 


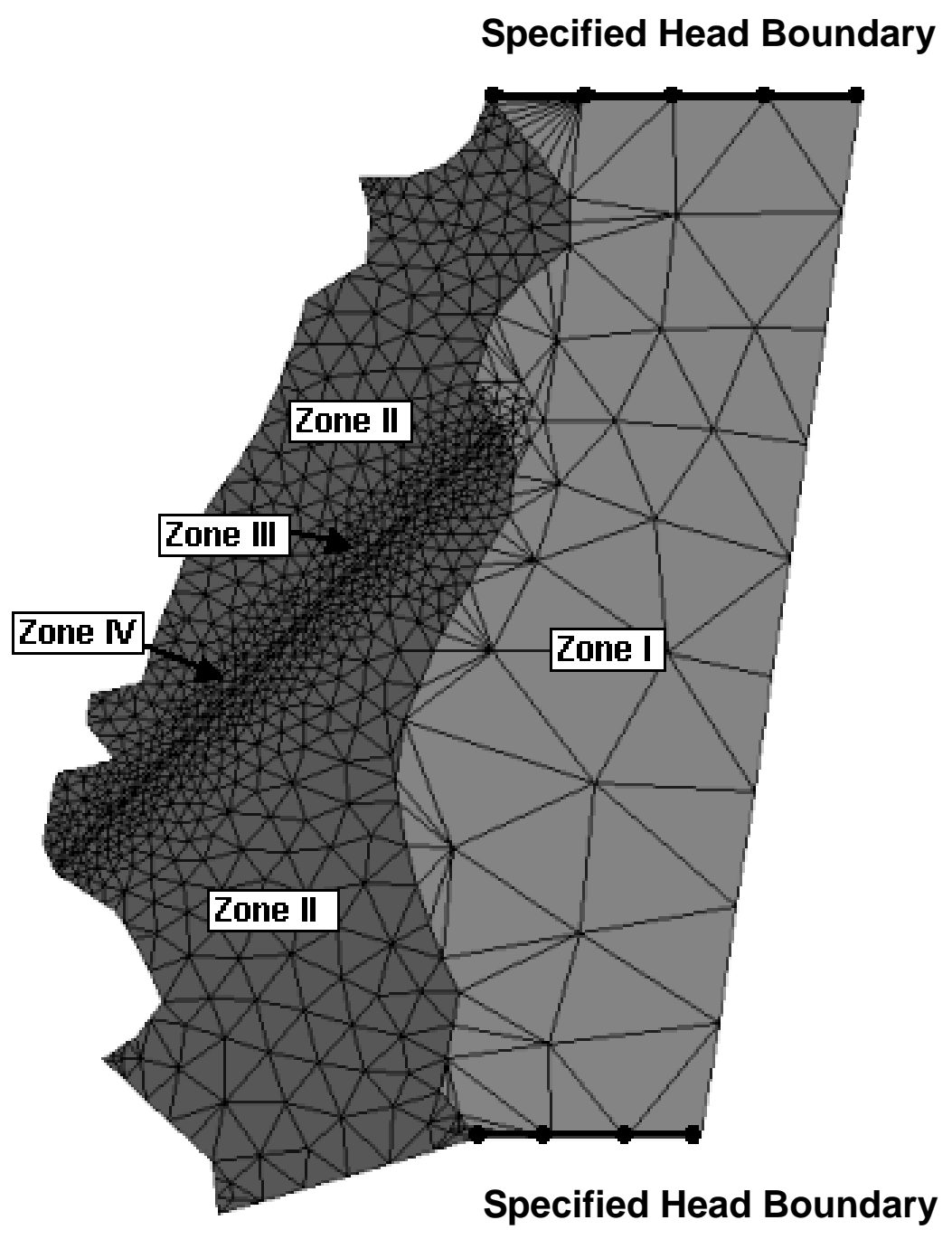

Figure 2.10. Configurations of the finite-element mesh, boundary conditions, and zones of hydraulic properties in the three-dimensional model of the Sand Springs mountain block. Zone III is the core of the shear zone and Zone IV is the hypothesized rubble zone of the shear zone.

to a hypothetical flow line in the granite aquifer extending perpendicular to the axis of the Sand Springs Range. The base of the model lies at sea level and is also treated as a no-flow boundary.

The model is divided into four zones of hydrologic properties (also shown in Figure 2.10). Zones I and II represent the basin-fill aquifer and the granite aquifer, respectively; Zone III represents the core of the shear zone; and Zone IV is used to investigate the impacts of a fractured rubble zone that may form the outer margins of shear zones in similar geologic terrains. 
For Zones I and II, the values of $K$ and $R$ were based on field data and calibration values from previous modeling and were adjusted only slightly during these simulations. The value of $K$ used for Zone I falls within the range of 2.4 to $3.7 \mathrm{~m} / \mathrm{d}$ estimated from pumping tests in HS-1, H-4 and the Frenchman's Station wells (University of Nevada, 1965), but is higher than the effective $K$ used in the Fairview Basin model. The impact of higher $K$ in the alluvium is increased flux only through this portion of the model; heads and fluxes in the mountain block are not significantly impacted. The granite aquifer comprising Zone II was assigned a value of $K$ that is about three times lower than the geometric mean of the seven pumping tests conducted in the HC wells at Shoal (Mihevc et al., 2000) and about three times higher than the effective $K$ used in the Fairview Basin model. The values for recharge on the mountain block and on the valley floor were the same as those used in the two-dimensional Fairview Basin model. These values are listed in Table 2.3.

The finite-element mesh is highly refined near the shear zone to allow for independent adjustment of hydraulic parameters within the damaged zone, core, and surrounding host granite. Each component of the shear zone is modeled as approximately $50 \mathrm{~m}$ in width to conform with the scale of the overall model domain, though field evidence suggests that each of these features may be no more than about $25 \mathrm{~m}$ in width. Furthermore, the shear zone was modeled as a vertical feature to simplify model configuration and modification. It should be noted that because the scale and orientation of the simulated shear zone is not entirely consistent with field conditions, the values of $K$ used in the modeling can be considered only approximate. However, these simplifications are considered appropriate for the purpose of investigating the general hydraulic nature of the shear zone.

The hydraulic configuration of the shear zone is simulated in two modeling scenarios. Scenario A is comprised of a core (Zone III) having a value of $K$ that is orders-of-magnitude lower than the host granite, but no rubble zone (Zone IV). Scenario B includes the same

Table 2.3. Representative values of hydraulic parameters used in the model of the Sand Springs Range.

\begin{tabular}{lc}
\hline \hline \multicolumn{1}{c}{ Zone } & Parameter \\
\hline I (Basin Fill) & 3.1 \\
$\quad$ Hydraulic Conductivity $K(\mathrm{~m} / \mathrm{d})$ & 0.0 \\
$\quad$ Recharge Rate $R(\mathrm{~cm} / \mathrm{yr})$ & $2.6 \times 10^{-3}$ \\
II (Host Granite) & 0.62 \\
$\quad$ Hydraulic Conductivity $K(\mathrm{~m} / \mathrm{d})$ & \\
$\quad$ Recharge Rate $R(\mathrm{~cm} / \mathrm{yr})$ & $2.6 \times 10^{-9}$ to $2.6 \times 10^{-3}$ \\
III (Shear Zone Core) & 0.62 \\
$\quad$ Hydraulic Conductivity $K(\mathrm{~m} / \mathrm{d})$ & \\
$\quad$ Recharge Rate $R(\mathrm{~cm} / \mathrm{yr})$ & $2.6 \times 10^{-3}$ to $2.3 \times 10^{-1}$ \\
IV (Rubble Zone) & 0.62 \\
$\quad$ Hydraulic Conductivity $K(\mathrm{~m} / \mathrm{d})$ & \\
$\quad$ Recharge Rate $R(\mathrm{~cm} / \mathrm{yr})$ & \\
\hline \hline
\end{tabular}


geometric and hydraulic properties of the core, but also includes a rubble zone having a value of $K$ much larger than the adjacent host granite. Though no hydraulic data exist for the core or rubble zones of the Sand Springs Range shear zone, the model is used to test estimates obtained from results of hydraulic testing and modeling in similar systems. The values of $K$ in Zones III and IV were adjusted through large ranges to simulate various hydraulic configurations of the shear zone and to match hydraulic heads measured in adjacent wells. It should be noted that $K$ within individual elements is assumed to be isotropic throughout the model, including within the shear zone. The variation of $K$ in the shear zone produces an anisotropic hydraulic feature within the isotropic $K$ field of the granite aquifer.

The model of the Sand Springs mountain block is used to investigate physical aspects of the hydrogeologic system important to groundwater flow at Shoal. In a general sense, the model provides a reasonable representation of the hypothesized flow system near Shoal, with recharge occurring over the mountain range and groundwater moving downward and laterally toward Fairview Valley. More specifically, the model is useful for investigating the large change in hydraulic heads observed at the shear zone. The sensitivity of Scenario A to $K$ of the shear zone core (Zone III) is shown in Figure 2.11. A $K_{I I} / K_{I I I}$ ratio of 1.0 indicates that the shear zone has the

same hydraulic properties as the surrounding host granite. Reduction in $K$ of the shear zone is accompanied by an increased head difference across the shear zone. The shear zone essentially acts as a near complete barrier to groundwater flow when the $K$ of Zone III is approximately four

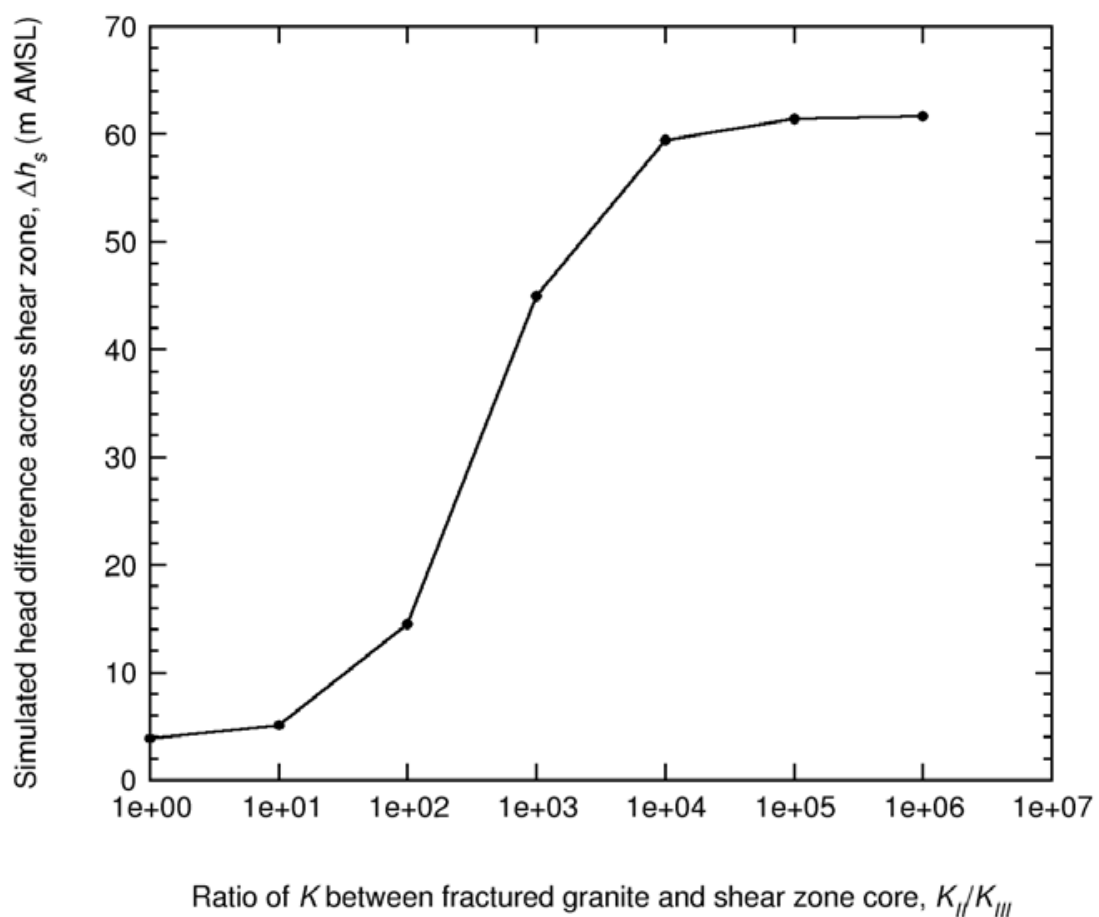

Figure 2.11. Sensitivity of simulated head difference across the shear zone (between wells HC-7 and HC-5) to $K$ of shear zone core. 
orders of magnitude lower than the host granite. Note that this model does not simulate the full extent of the head change observed in the field due to averaging of hydraulic properties at the scale of the model elements. Values of shear zone $K$ within the range between the host granite and about two orders of magnitude lower result in refraction of flow lines within the shear zone and corresponding deflection of pathlines toward it. As the shear zone $K$ is reduced further, a barrier is formed causing the horizontal component of flow on the west side of the shear zone to be increasingly directed toward the northeast (Figure 2.12a) and accompanied by increased gradients, velocities, and path lengths in that direction. There is very little change in the vertical component of flow (Figure 2.12b). Flow on the east side remains directed toward the east and northeast.

The results of Scenario B show that damaged zones simulated between the host granite and both sides of the shear zone core have minimal impact on transport from the Shoal working point (WP) (Figures 2.12a and 2.12b). To simulate a barrier that produced a large head difference across the shear zone, the core (Zone III) was assigned a value of $K$ four orders of magnitude lower than the $K$ of the host granite (Zone II). The rubble zones (Zone IV) were assigned values of $K$ that ranged from two times to several orders of magnitude higher than the host granite. It was found that increasing the conductivity of the damaged zone resulted in heads simulated at levels much lower than those measured at the PSA unless recharge over the range was also increased. As recharge increased, head residuals west of the shear zone were reduced, but head residuals east of the range increased. This situation could only be alleviated by increasing $K$ of the rubble zone and/or host granite on the east side of the shear zone, a situation that is not supported by field data. In addition, the recharge rates utilized to compensate for the high $K$ of the rubble zone exceeded the range of rates reported for the Sand Springs Range by Pohll et al. (1998) and Pohll (1999). Reasonable head distributions could only be simulated when $K$ of the rubble zone was less than about five times higher than $K$ of the host granite. This $K$ structure results in transport pathlines that extend slightly deeper, but about the same horizontal distance, when compared to the scenario without the rubble zone. These modeling results suggest that flow to Fairview Valley is not sensitive to the rubble zone simulated in these models.

The shear zone has the effect of separating flow into two compartments, one to the west with high heads and flow directed to Fairview Valley in a northeast direction along the shear zone, and the other to the east with much lower heads and flow directed more due east. Comparison of heads simulated by the model to heads measured in the field also shows that the model produces a reasonable simulation of the flow system. Most important, however, is the fact that the shear zone has been identified in the field as a critical factor in the flow field within the Sand Springs Range and that this numerical model of groundwater flow is capable of simulating this feature. As a result, the three-dimensional model has been an invaluable tool for establishing the model configuration for the stochastic simulations of groundwater flow and contaminant transport and for investigating possible alternative conceptual models of flow in the area. 


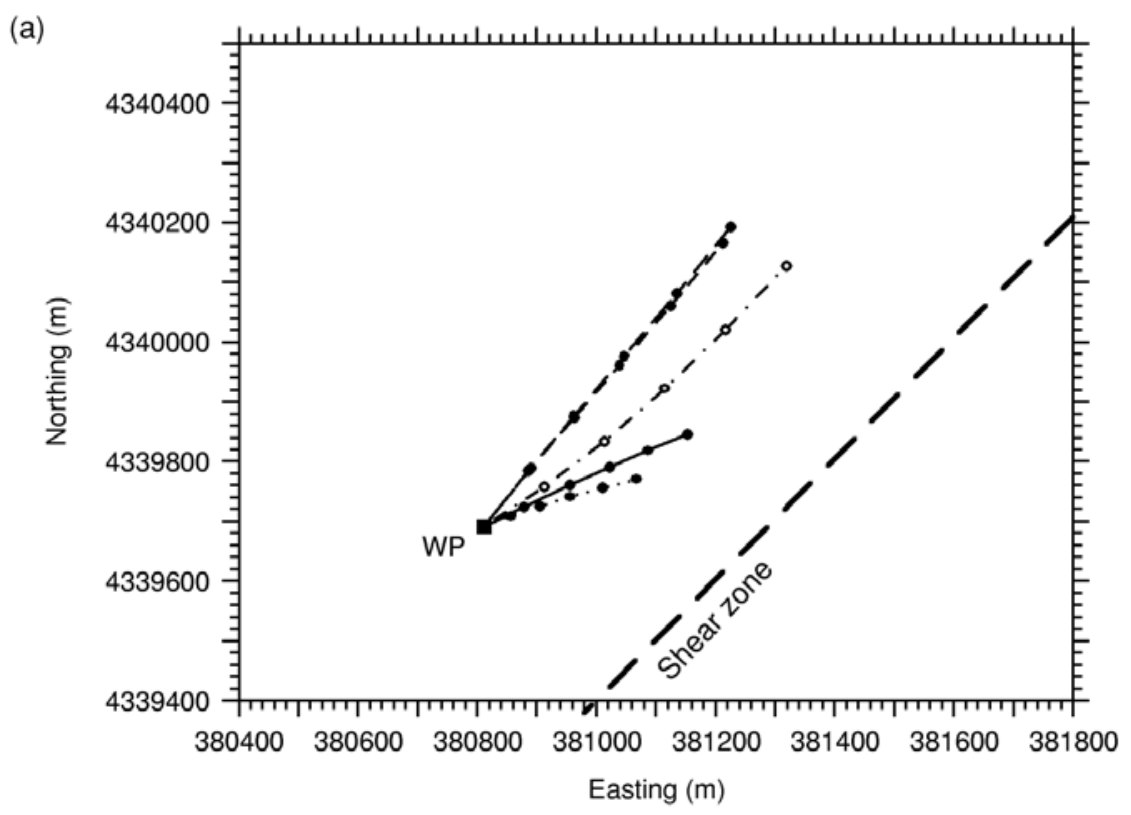

(b)

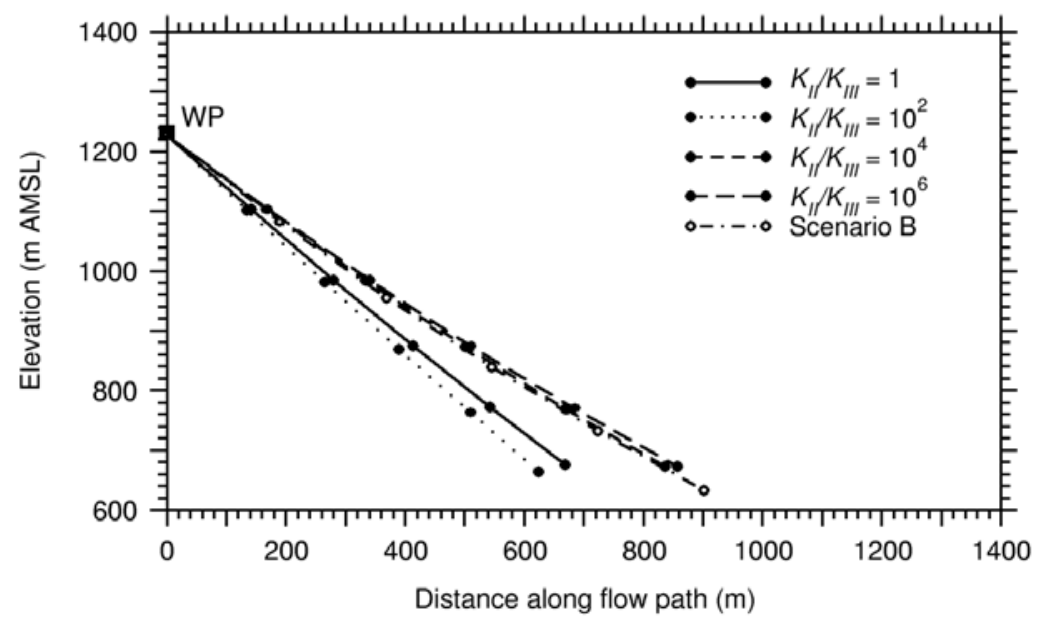

Figure 2.12. Effect of shear zone $K$ structure on groundwater flow direction. In Scenario A, $K$ of the core (Zone III) is varied and $K$ of the rubble zone (Zone IV) is equal to $K$ of the host granite (Zone II). In Scenario B, $K$ of the core is four orders of magnitude lower than the host granite and $K$ of the rubble zone is five times higher than the host granite. A single pathline from the Shoal WP is generated for each simulation (porosity $=0.01, t=1,000$ years).

\subsection{Alternate Conceptual Models for Hydraulic Parameters and Boundary Conditions: Model of Flow in the Vicinity of the Shoal site}

The third deterministic numerical model was constructed to directly address the issues of hydraulic parameters and boundary conditions for the PSA flow model. This model essentially comprises the compartment of flow that occupies the west side of the shear zone in the northern Sand Springs Range (Figure 2.3). 


\subsubsection{Components of the Conceptual Model Tested}

The conceptual model of flow in the vicinity of the PSA is based directly on the results of the northern Sand Springs Range model. The eastern boundary is comprised of the dipping shear zone, which is assumed to be impermeable. Recharge is assumed to be uniform over the area with discharge from the mountain block occurring at the margin of Fairview Valley. The flow system is assumed to be bounded on the west by the range-bounding fault mapped by University of Nevada (1965) that is located near the base of the steep western front of the range. This assumption that the fault represents a vertical hydraulic barrier was tested through separate modeling that included Fourmile Flat. The results suggest that maintaining compartments of uniform, but widely different, hydraulic heads at Gote Flat and Fourmile Flat is reasonably possible only through inclusion of a zone of low $K$ on the western margin of the Sand Springs Range. Northeasttrending, high-angle faults provide a likely explanation for this barrier, as suggested by the results of the shear zone modeling in the northern Sand Springs Range model. The Shoal-vicinity model described here evaluated aspects of the upgradient (southern), downgradient (northern), and bottom boundaries of the PSA model.

\subsubsection{Numerical Model}

The domain of this three-dimensional model consists of 29 layers (Figure 2.13). Unlike the model of the northern Sand Springs Range, this model incorporates the dip and changes in strike along the axis of the shear zone; therefore, lower layers of the model cover smaller areas and are comprised of fewer elements. The domain extends vertically from sea level to 1,350 m AMSL. The top 17 layers (500 to 1,350 m elevation) are $50 \mathrm{~m}$ thick and the remaining layers are $100 \mathrm{~m}$ thick. The top boundary is free and movable to allow for adjustment of the mesh in response to the position of the simulated water table, while the remaining interfaces between layers automatically adapt to the configuration of the top. A specified-head boundary (Dirichlet condition) comprises a portion of the northeast edge of the model to simulate groundwater discharge to the Fairview Valley basin-fill aquifer. The remainder of the boundaries, including the shear zone and the base, are no-flow (impermeable) boundaries. The configuration of the domain as bounded by the shear zone on the east and the structural boundary on the west represents the flow system as being aligned with the dominant northeast-trending structural grain of the range, an assumption that is maintained in the PSA flow and transport model.

Values of $R$ and $K$ are based on field data and calibration values from previous modeling and were adjusted only slightly during these simulations. The recharge value of $0.27 \mathrm{~cm} / \mathrm{yr}$ is based on the range of recharge values calculated for the PSA flow model (described in Section 3.2.3) and the median value of that range of $0.24 \mathrm{~cm} / \mathrm{yr}$. The granite was treated as an equivalent porous medium with a calibrated $K$ value of $1.68 \times 10^{-3} \mathrm{~m} / \mathrm{d}$. Although this value is lower, it is of the same order as the geometric mean $\left(9.4 \times 10^{-3} \mathrm{~m} / \mathrm{d}\right)$ of the seven pumping tests carried out in the new boreholes and is similar to the value used in the northern Sand Springs Range model. The lower value is a result of the modified configuration of the flow domain and, more importantly, the lower value of recharge. Comparison of simulated heads to measured heads are shown in Table 2.4. The overall root mean square error (RMSE) for the simulation is $3.72 \mathrm{~m}$. 
In addition to further testing of the values of $K$ and $R$, this model was used to address four boundary conditions of the PSA flow model: (1) the area of the upland surface area assumed to contribute groundwater flux originating as recharge to the southwestern boundary of the PSA model, (2) the proportion of lateral flux exiting the PSA model domain through the base, (3) the vertical distribution of flux at the southwestern boundary, and (4) the hydraulic heads needed to establish the specified heads on the northeastern boundary.

The area of the upland surface was estimated using FEFLOW's reverse particle tracking routine. The starting points for the reverse particle tracks were the two points having coordinates

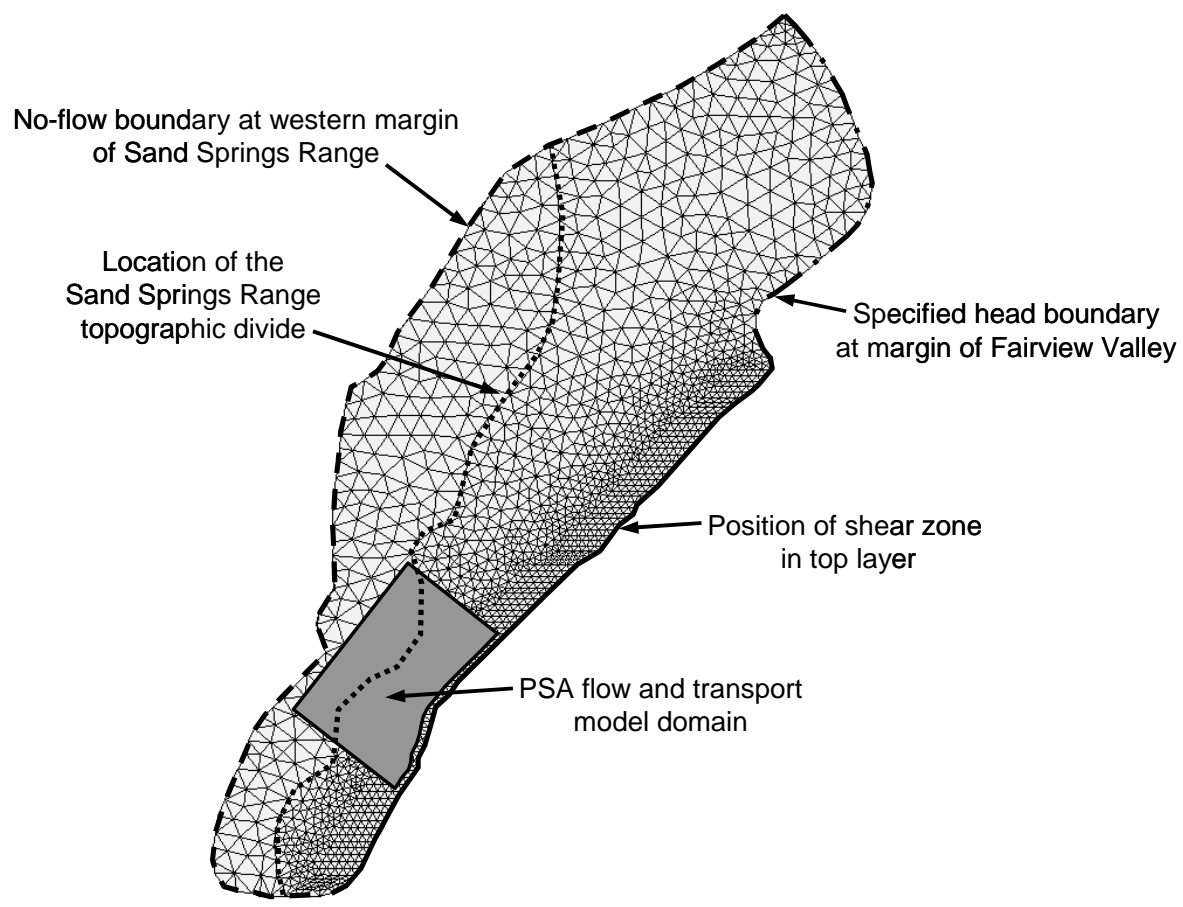

Figure 2.13. Configuration of the finite-element mesh and boundary conditions of the three-dimensional model of the PSA. All external boundaries are no-flow, with the exception of the specifiedhead boundary on the northeast side. Only the top layer is shown; all other layers are of the same configuration.

Table 2.4. Comparison of simulated to measured heads in the model of flow in the vicinity of the PSA.

\begin{tabular}{|c|c|c|c|}
\hline "Well Name & 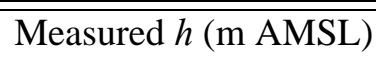 & 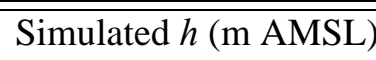 & 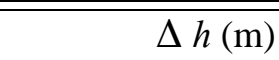 \\
\hline HC-1 & $1,296.68$ & 1290.30 & 6.38 \\
\hline HC-2 & $1,294.02$ & 1295.47 & -1.45 \\
\hline HC-4 & $1,289.51$ & 1295.45 & -5.94 \\
\hline HC-6 & $1,295.49$ & 1295.64 & -0.15 \\
\hline HC-7 & $1,295.78$ & 1295.74 & 0.04 \\
\hline PM-1 & $1,299.46$ & 1297.24 & 2.22 \\
\hline
\end{tabular}


corresponding to the upgradient (southern) corners of the base of the PSA model (Figure 2.14). These two paths were extended upgradient until they intersected the land surface, thereby defining an area between these two points and the line forming the southern boundary of the PSA model. This area on the land surface is assumed to be the source of groundwater recharge that moves through the granite aquifer, first vertically downward and then increasingly horizontally, eventually entering the PSA model as groundwater flux through the southern face. Recharge entering the aquifer outside this area is assumed to pass by the PSA model domain. The area is estimated by this method to be approximately $1,761,000 \mathrm{~m}^{2}$ in size.

To estimate the vertical distribution of horizontal flux to be used on the southwestern boundary of the PSA model, the horizontal flux simulated through a vertical area of each layer was obtained from the model. This area corresponds to the location of the southern face of the PSA model, which is located inside the domain of the deterministic model. Of interest was the proportion, rather than the actual value, of flux in each layer since the total flux entering this boundary of the PSA model is an uncertain parameter and was determined independently for each realization. Therefore, the vertical distribution of the proportion of flux in each layer was determined and then interpolated to the smaller mesh size $(20 \mathrm{~m})$ of the PSA model.

Because the lateral flow has an important vertical component, a proportion of the flux entering the southwest face of the PSA model ultimately exits through the base. This value was calculated by analyzing the locations where the reverse flowpaths originating from the four corners of the base intersect the southwestern boundary, and using FEFLOW's internal flux calculator to estimate the flux through the areas defined by these points. This process is described in more detail in Section 3.3.4.

Values of hydraulic head in the vertical area corresponding to the location of the northern (downgradient) face of the PSA model were calculated by interpolation of heads simulated within the finite-element mesh. These heads were used directly in the PSA model as the specified-head boundary.

The impact on flow patterns caused by the elevation of the no-flow bottom boundary was investigated by increasing model thickness to a depth of -700 m AMSL. As expected, vertical hydraulic gradients increased in response to the lower position of the no-flow boundary, but to maintain calibration, $K$ also had to be reduced. To investigate the combined effect on transport, three-dimensional pathlines from the Shoal WP were simulated for advective transport in both boundary cases using a porosity of 0.025 (the mean of the statistical porosity distribution used in the PSA transport model). As compared to the base-case model, the center of mass in the thicker model migrated approximately 5, 9 and 23 percent deeper in 1,000, 2,500 and 5,000 years, respectively. In conjunction with the increased vertical migration, horizontal migration in the deeper model was reduced. However, because the horizontal component of the contaminant boundary maps is directly comparable to the PSA land withdrawal boundaries, a conservative approach was taken to tolerate some enhancement of horizontal flow caused by the position of the bottom no-flow boundary. 


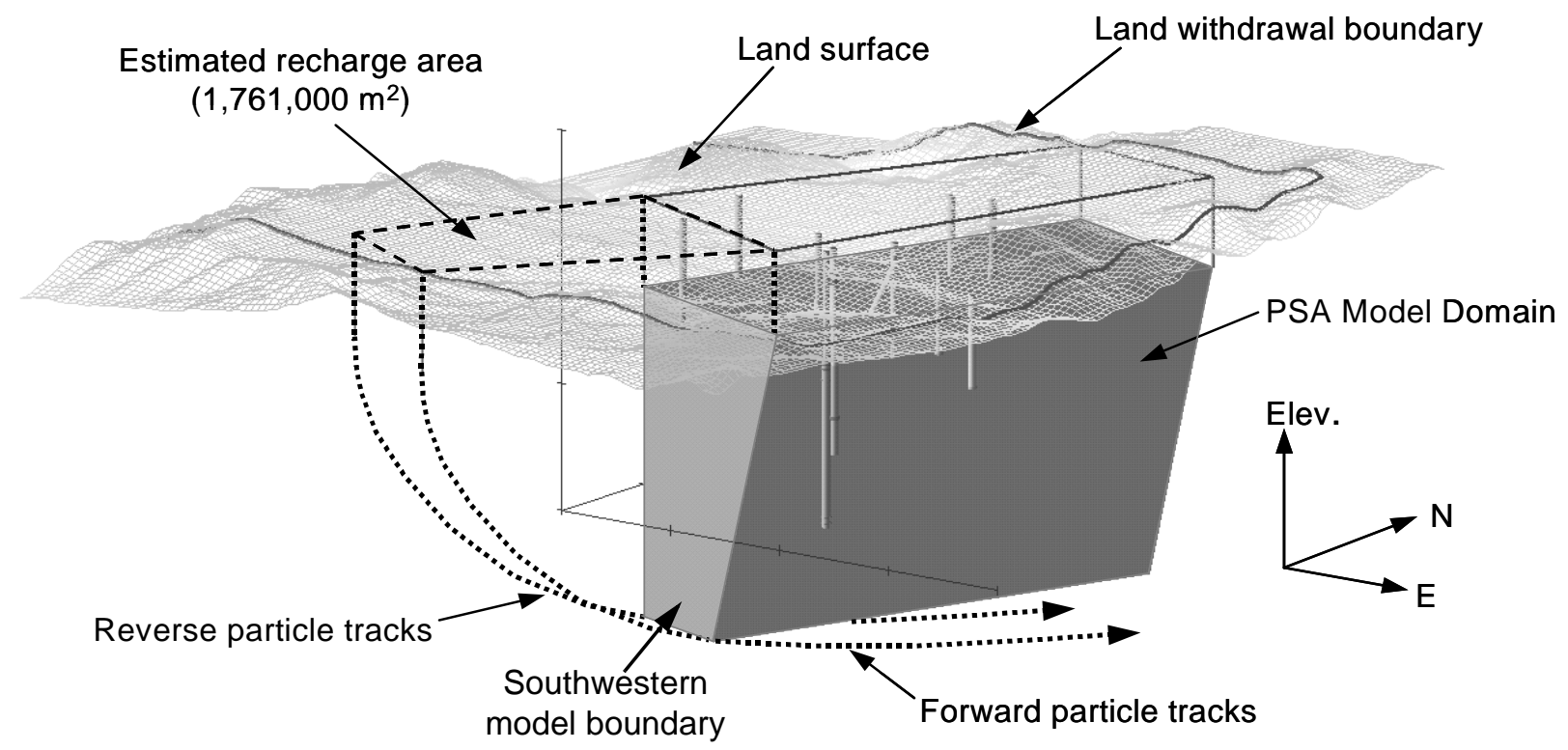

Figure 2.14. Three-dimensional perspective of the PSA model domain and the reverse particle tracks (the dotted lines) used to estimate the maximum size of the upland recharge area (outlined with a dashed line). Recharge entering this area is assumed to enter the PSA model as groundwater flux through the southwestern face, with a portion of the flux exiting through the base (above the forward particle tracks).

Although data collected during the field campaigns of the late 1990s indicate that the groundwater divide near the PSA lies to the west (perhaps coincident with the topographic divide), uncertainty remains as to its location. In fact, the water table below Gote Flat may have very low relief as a result of barriers to flow formed by the shear zone on the east and the rangefront fault on the west, as suggested by early investigators (University of Nevada, 1965). Thus the divide may not be a prominent, easily detectable feature. In any case, the location of the divide has implications for the choice of boundary conditions for the PSA flow and transport model, so the PSA vicinity model was used to further investigate this issue. As discussed previously, the domain of the base-case model is bounded on the west by a no-flow boundary that simulates the range-bounding fault near the margin of Fourmile Flat. This domain was modified by constructing a sensitivity case with a western no-flow boundary positioned at the Sand Springs Range topographic divide (the dotted line on Figure 2.13). Thus, the domain of the sensitivity case consists of all the mesh elements to the east (right side) of the topographic divide. To provide the best comparison to the base case, all other geometric aspects of the sensitivity case are identical and only $K$ was adjusted during calibration. The value of recharge was not adjusted, to maintain consistency with the PSA flow model and the base-case PSA vicinity model.

The modeling showed that the paths of groundwater flow from the Shoal source are not sensitive to the width of the deterministic model in the upland region of the Sand Springs Range (Figure 2.15). Flow is generally controlled by the configuration of the shear zone and is therefore 
directed northeast in both cases. However, reducing the width of the domain near the PSA, as compared to its overall length, required a reduction in $K$ to provide an overall RMSE comparable to the value obtained in the base-case model. This is because the reduced area of recharge in the range highlands is not sufficient to provide the flux required to maintain heads at their observed levels. Heads in the sensitivity case ranged from 20.1 to 31.4 m below observed values compared to the $6.38 \mathrm{~m}$ below to $5.94 \mathrm{~m}$ above observed values in the base class. Reducing $K$ to a value of $1.2 \times 10^{-3} \mathrm{~m} / \mathrm{d}$ resulted in an RMSE of $3.82 \mathrm{~m}$, compared to the RMSE value of $3.72 \mathrm{~m}$ in the base case. Because the flowpaths did not differ significantly between the two cases, it was decided that the base-case model would be used for further investigation of boundary conditions and other aspects of the PSA flow model. This option represents the conservative choice, because the sensitivity case required lower $K$ values, which would ultimately lead to shorter transport paths. Furthermore, the wider domain allows the PSA flow model to include a larger variety of heterogeneous flow directions and prevents clipping of fracture zones and their related flowpaths at the western boundary (it is uncertain whether the topographic boundary represents the location of the groundwater divide), thereby incorporating uncertainty in these aspects of the model.
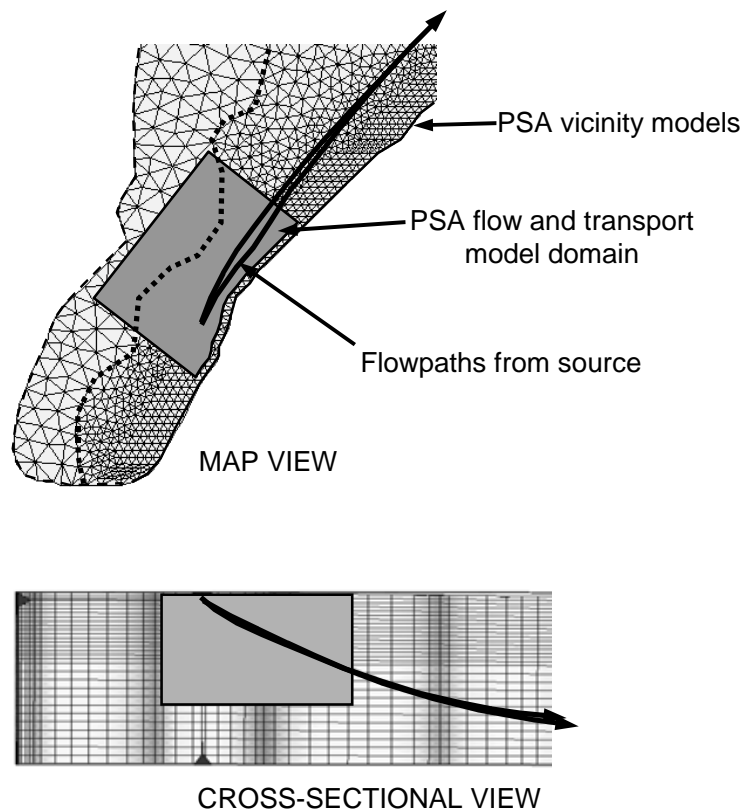

Figure 2.15. Plot showing sections of the PSA vicinity models and the simulated flowpaths from the Shoal source with respect to the PSA model domain. The domain of the sensitivity case is bounded on the west by the topographic divide (shown on the map view as a dotted line). Both cases simulate very similar flowpaths. 
THIS PAGE INTENTIONALLY LEFT BLANK 


\subsection{PSA NUMERICAL FLOW MODEL}

Most of the features of the PSA conceptual model are discussed in detail in the previous section. However, three aspects relate more specifically to the implementation of the conceptual model in the numerical framework. These are the stochastic continuum approach, the flow field near the nuclear test, and the treatment of uncertainty. The stochastic continuum representation of hydraulic conductivity and the impacts of the nuclear test on the flow field are introduced below. The flow model parameters are elaborated in Section 3.2. The approach for including uncertainty, as well as specifics on the implementation of all the components (numerical approach, parameter values, etc.), is provided in Section 3.3. The results of the flow modeling are then presented in Section 3.4.

\subsection{Additional Conceptual Elements Specific to the PSA Flow Model}

\subsubsection{Stochastic Continuum Representation of Hydraulic Conductivity}

One of the largest fundamental refinements for the PSA flow model, as compared to the models previously described to evaluate conceptual alternatives, is in the treatment of hydraulic conductivity for the granite. The previously described deterministic regional models considered the granite as an equivalent homogeneous porous medium, assigning a single value of $K$ to the entire aquifer. While this approach is suitable for evaluating regional groundwater flow and testing boundary conditions, calculating contaminant transport requires a more sophisticated approach so that migration behavior through the fracture system can be approximated. A discrete fracture network model is at the other end of the spectrum and demands knowledge of fracture characteristics in the subsurface beyond what is achievable at the Shoal site.

An approach between these two endmembers is applied here: the aquifer is represented as a stochastic continuum with $K$ treated as a random variable and the granite divided between two hydraulic categories. Flow Category 1 represents the large blocks of the system that are assumed to contain random small fractures that result in a basically isotropic, low- $K$ flow environment. Flow Category 2 represents the strongly oriented, large fractures that dominate fracture flow. This category comprises the high- $K$ flow environment and is spatially distributed to coincide with the structural grain of the range.

It should be emphasized that Flow Category 1 does not represent the matrix blocks used in discrete fracture models. A key conceptual aspect of the model is that flow within these blocks is still assumed to occur only through fractures, albeit small, random fractures as compared to the large, oriented ones controlling most of the flow through Flow Category 2. No advective flow is assumed to occur within the competent granite blocks themselves, which would have $K$ values many orders of magnitude lower than those assigned to Category 1. Despite the lack of advective flow, the competent granite has an important role in transport through matrix diffusion of solutes. With the conceptualization used here of fracture flow for both Category 1 and 2, matrix diffusion is a process within both categories. 
Just as the data are unavailable to determine precise fracture geometries for a discrete network model, there is uncertainty in the exact distribution of the two conductivity categories in the model domain. This uncertainty is directly incorporated into the model by treating the category locations stochastically. Equiprobable geometries of the fracture and matrix classes are simulated, adhering to the spatial statistics derived from the field data. Additionally, the value of $K$ for every location in the model is uncertain. Thus, $K$ is also treated stochastically, with the value for each cell fitting a distribution of $K$ determined from the field data and refined by calibration. Consistent with the conceptual model, the mean value of the $K$ distribution is higher for Category 2 , though there is overlap between the maximum end of the Category 1 range and minimum end of the Category 2 range. The parameter values and stochastic approaches are described in subsequent sections.

\subsubsection{Impacts of the Nuclear Test on the Hydraulic System: The Cavity and Chimney}

The region immediately around the nuclear test is an important subset of the overall hydraulic system. The flow properties in this area may have been significantly altered by the nuclear test and these differences can be included in the model depiction of the physical system. The specific flow parameter impacted is the hydraulic conductivity and the nuclear test is assumed to increase its value over that in the surrounding, unaffected aquifer. The porosity is also affected and will be addressed in Section 4.1.4 with the transport parameters. Though no specific information on the variation of hydraulic parameters is available for the Shoal cavity, observations and modelling results from other nuclear tests provide guidance for parameterization of the flow characteristics of the cavity and vicinity in this model.

An increase in $K$ is expected in the cavity and chimney as a result of the increase in void space caused by vaporization of rock. The cavity and chimney are assumed to be disrupted to the extent that they no longer behave as a fractured rock, but rather as a high-conductivity porous medium. This is implemented in the model by assigning to the cavity and chimney grid cells values of $K$ that are higher than the mean of the $K$ distribution of the surrounding domain. Values of $K$ for the cavity and chimney are chosen from a random distribution and are assigned randomly to the cells corresponding to the cavity and chimney - no spatial correlation within this region of the model is assumed. The mean of this distribution is taken to be $43.0 \mathrm{~m} / \mathrm{d}$, which is two and one half orders of magnitude higher than the mean of the $K$ distribution of the undisturbed granite. A $\log _{10}$-normal distribution having a mean and standard deviation of 1.6 and $0.18\left(\log _{10}[\mathrm{~m} / \mathrm{d}]\right)$, respectively, is used for the simulations.

Fracturing caused by ground motion generated by the nuclear test is hypothesized to also increase $K$ outside the cavity. Fracture intensity from an underground nuclear test varies with distance from the working point. General relationships described by Borg et al. (1976) are as follows. Immediately adjacent to the cavity, and in the chimney, a zone of highly crushed rock is found, extending to a distance of about 1.3 cavity radii, $R_{\mathrm{c}}$, at the level of the test. A pervasively fractured zone then extends between 2.5 to $4 R_{\mathrm{c}}$. Beyond this is a region of widely spaced fractures with less frequent interconnection. Generally, at distances between 3.5 and $5.2 R_{\mathrm{c}}$, the compressive strength of the shock wave is too small to fracture rock (the limit of shear failure). 
For many tests, the limit of shear failure corresponds to the height of the chimney (which is $108.5 \mathrm{~m}$ at Shoal). Though tensile fracturing may take place beyond the shear failure limit, the fractures are typically widely spaced and are considered to contribute little to an increase in overall permeability. Experience in granite at a French nuclear testing site resulted in smaller predicted distances of fracturing, with a fracture zone radius of 26 times the third root of the device yield in kilotons (Derlich, 1970).

The predicted radial cracking distance for Shoal was $159 \mathrm{~m}$ (Beers, 1964). Post-test drilling encountered unbroken granite at a depth of $408 \mathrm{~m}$, implying a fracture radius of $41 \mathrm{~m}$ below the working point (Gardner and Nork, 1970). This distance is believed to encompass the zone of intense fracturing and is reasonably close to the fracturing predicted based on the French experience (60 $\mathrm{m}$ for Shoal using the relationship described above). Shock-induced fractures between the depths of 198 and $350 \mathrm{~m}$ in hole USBM-1 indicate that the lateral extent of subsurface fractures is a minimum of $135.6 \mathrm{~m}$ from the working point (Atkinson, 1964), but these were not of a frequency and intensity likely to increase the overall $K$. Surface fractures due to spalling are not considered here because they are only predicted to occur to a depth of $122 \mathrm{~m}$ below land surface.

The International Atomic Energy Agency (IAEA, 1998) used a treatment of hydraulic properties varying radially from an underground nuclear test in their analysis of tests in the South Pacific. By comparing computed water level recoveries simulated under different conductivity regimes with observations, they concluded that the overall increase in $K$ in the flow field outside the cavity was less than about two orders of magnitude. Lacking such calibration data for Shoal, and given the observations of fracturing, fracture zones are included in the Shoal model to a radius of $100 \mathrm{~m}$ (approximately $4 R_{\mathrm{c}}$ ). These zones do not include discrete fractures; rather, they represent zones around the working point where $K$ of the host granite is likely to be increased as a result of the nuclear test.

Three spherical zones are identified around the Shoal working point and are approximated in the model according to the rectangular grid (Figure 3.1). The values of $K$ chosen for each zone are based on $K$ relationships observed in granite at various distances from the working points of French nuclear tests (Derlich, 1970). The first zone represents the cavity and chimney and the values of $K$ are chosen randomly from a distribution having a mean value of $43.0 \mathrm{~m} / \mathrm{d}$, as described above (this zone is also given a higher porosity as discussed in 4.1.4). The second zone extends from approximately 1 to $2 R_{\mathrm{c}}$ from the working point and is also assigned $K$ values that are substantially higher than that of the undisturbed granite. $K$ values in Zone 2 are chosen from a distribution having a mean of $8.6 \mathrm{~m} / \mathrm{d}$ (a $\log _{10}$-normal distribution having a mean and standard deviation of 0.94 and $0.26\left(\log _{10}[\mathrm{~m} / \mathrm{d}]\right)$, respectively, is used for the simulations). Zone 3 begins the transition from the highly disturbed, near-cavity region, to the unaffected rock. This zone extends from 2 to $4 R_{\mathrm{c}}$ from the test and is assigned $K$ values at the upper end of the distribution from which the $K$ values of the undisturbed granite are selected. The distribution of $K$ values assigned to this zone has a mean value of $0.86 \mathrm{~m} / \mathrm{d}$ (a $\log _{10}$-normal distribution having a mean and standard deviation of -0.063 and $0.26\left(\log _{10}[\mathrm{~m} / \mathrm{d}]\right)$, respectively, is used for the simulations), 


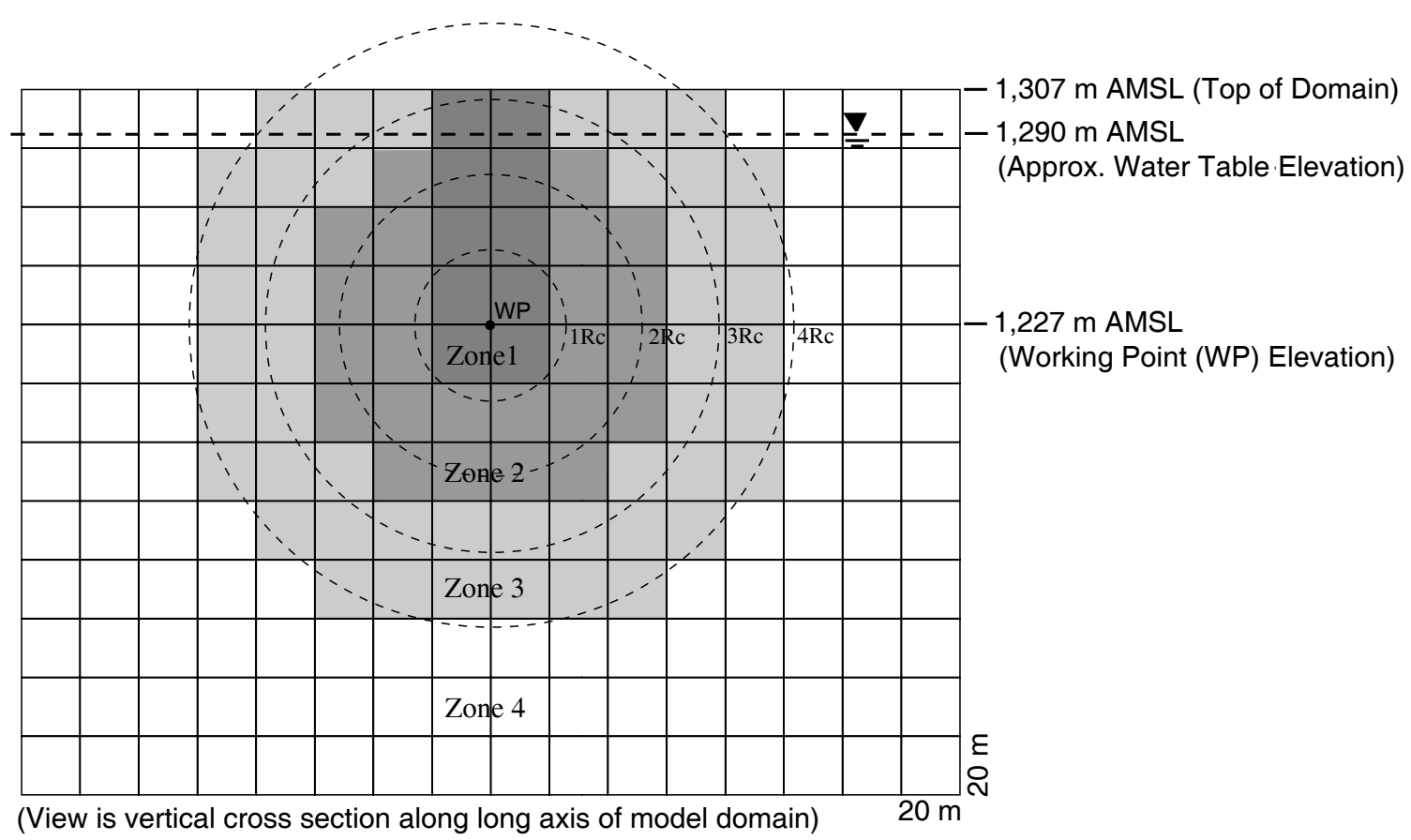

Figure 3.1. Vertical cross section through the model grid identifying the $K$-zones used to describe the nuclear cavity and chimney and associated cavity radii (Rc).

ensuring that this region is treated as having fractures that significantly enhance $K$. The region outside Zone 3 comprises the undisturbed granite aquifer where $K$ is selected from the range of $8.6 \times 10^{-3} \mathrm{~m} / \mathrm{d}$ to $0.86 \mathrm{~m} / \mathrm{d}$ during calibration of the flow model, as described in Section 3.2.2.

\subsection{Flow Model Parameters}

\subsubsection{Fractures}

To incorporate the conceptualization of the PSA fractured granite into the fully threedimensional PSA stochastic continuum flow model requires a description of the fracture and fault geometry that defines the spatial distribution of the two flow categories.

\subsubsection{Orientations of Fracture Sets}

Fractures and faults are characterized using video logs, acoustic televiewer (ATV) logs, and radar logs of boreholes, as well as data from surface mapping of visually observable features. The location, orientation and to a lesser degree the spatial extent of fractures can be estimated using these observations. Orientation data consist of azimuth and dip (inclination of the plane of the fracture from the horizontal). Spatial extent is comprised of the lengths of axis of the fracture plane and the thickness of the plane. Typically, these axes are referred to as length along strike, length along dip, and fracture aperture. The distribution of fracture orientations and the spatial continuity of the nature of fracturing was estimated from the available observations. 
The definitions for joint, fracture, and fault used in this analysis are based on the Dictionary of Geologic Terms (National Academy of Sciences, 1962). A joint is a fracture in rock, generally more or less vertical or transverse to bedding, along which no appreciable movement has occurred. Fractures are breaks in rocks that often arise from folding or faulting. Faults are fractures or fracture zones along which there has been displacement of the sides relative to one another parallel to the fracture.

A common simplifying assumption, and one used throughout this analysis is that fractures can be considered flat planar phenomena. Although it is known that fractures do exhibit curvilinear behavior, such deviation from planarity is considered negligible at the scale of measurements available for this analysis. Those portions of the PSA boreholes used for the fracture analysis lie within an intrusive granitic body. While variations in rock appearance and resistance to drilling were noted, the scale of this variation was large relative to the fractures used in this analysis.

The intersection of an inclined plane with a vertical cylinder such as a borehole has the shape of a sine wave (Figure 3.2). The expected sinusoidal trace can be seen in Figure 3.3, a section of the ATV log from borehole HC-6. A total of 790 azimuths and dips were obtained from ATV and radar logging conducted in boreholes HC-4, HC-5, HC-6, HC-7, and HC-8 (Lane et al., 2001). Acoustic televiewer logging was attempted in all HC boreholes, but unfortunately some of these holes (HC-1 through 3) were elliptical in cross section to such an extent that the resulting logs could not be interpreted for fractures. While the ATV worked well in portions of some boreholes, caution must be used in applying the resulting measurements. The televiewer suffers from limitations that cause the resulting orientations to have a systematic bias. In general, fractures with dips in the middle of the range $\left(0^{\circ}-90^{\circ}\right)$ are most readily detectable on the logs.

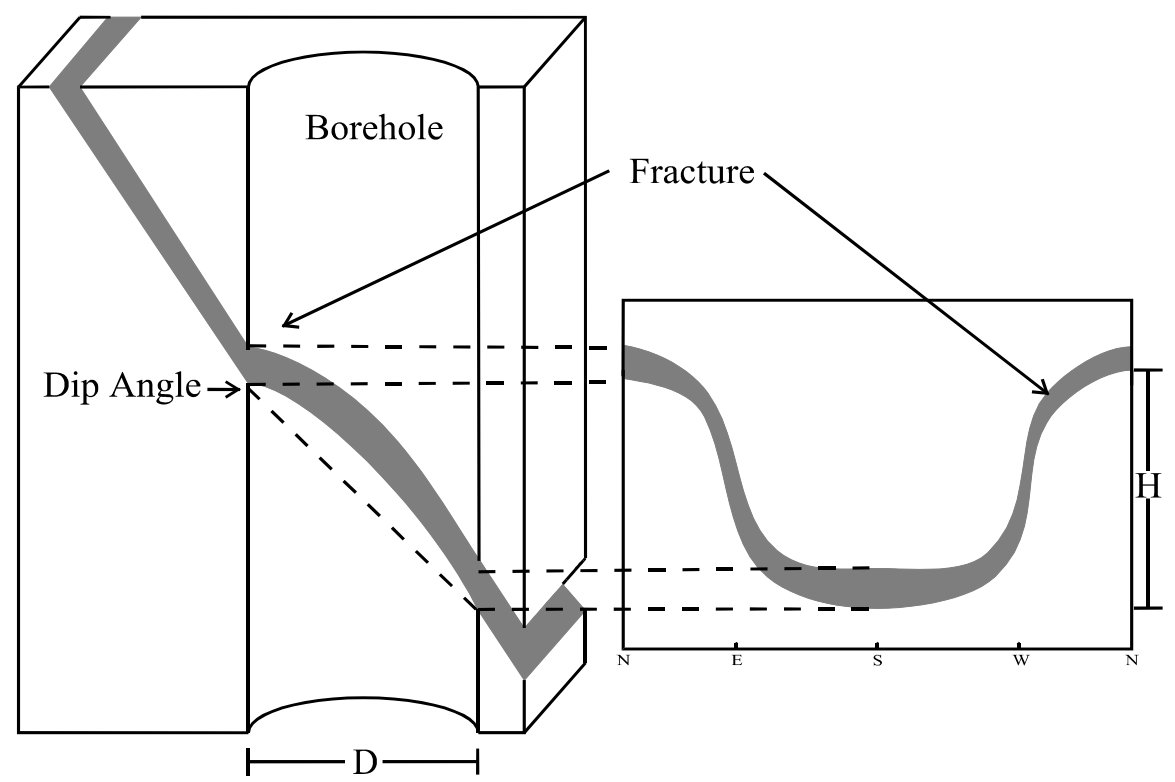

Figure 3.2. Schematic of a representative fracture borehole intersection. 


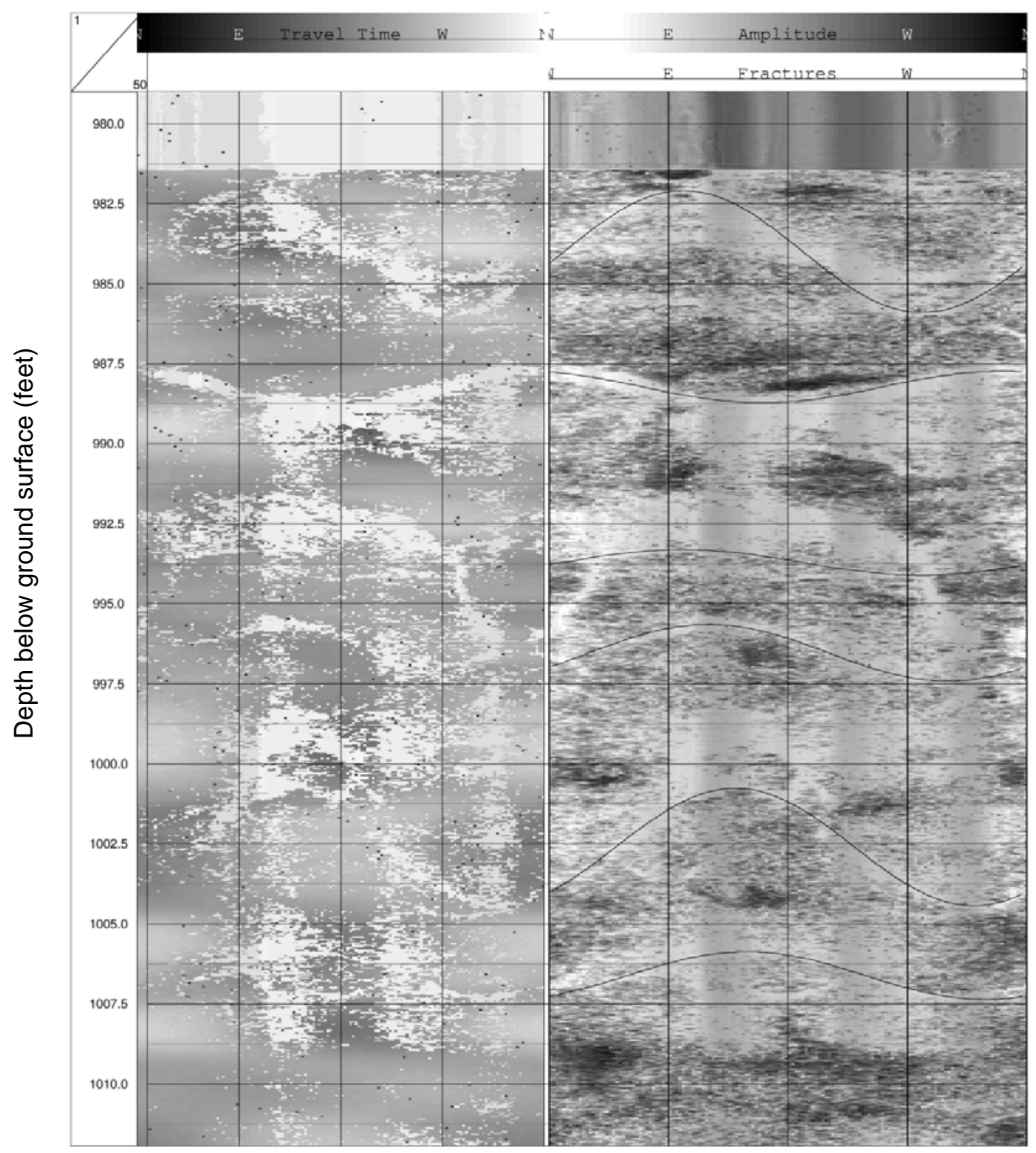

Figure 3.3. Section of the acoustic televiewer log from HC-6. Feet can be converted to meters by multiplying by 0.3048 . 
High-angle or nearly vertically dipping fractures are difficult or impossible to differentiate from borehole eccentricity. Additionally, the higher the fracture angle, the fewer fractures intersected per length of vertical borehole. If all fractures are vertical, i.e., dip at $90^{\circ}$, then a vertical borehole will intersect only those fractures that coincide with the borehole at ground surface. Low-angle or nearly horizontal fractures cannot be distinguished from tool marks or scoring of the borehole wall. Thus, a distribution of dips based on televiewer data will systematically underweight the extremes. The degree of this bias is unquantifiable because it varies with rock hardness and competence, drilling conditions, and other factors that lead to out-of-round and scored holes. Fortunately, the distribution of fracture dips in this study does not indicate an abrupt truncation at high angles or increase at low angles.

Under ideal circumstances, fracture apertures can be roughly estimated with an ATV. Referring to Figure 3.2, it can be seen that for any given dip, a larger aperture fracture would show a larger trace, i.e., a thicker line, than would a smaller aperture fracture. The ability to discriminate large from small aperture fracture is strongly controlled by the resolution of the tool, the borehole conditions, and the logging speed. In this study, efforts were made to distinguish aperture size, but because of borehole conditions the results were concentrated in a few small intervals of borehole. No significant relationship was found between observed fracture aperture and orientation. This may be the result of bias in the observation method. In intervals where both video and ATV logs were available, it was noted that visually detectable large fractures corresponded to intervals where the televiewer was not useable. It may be that orientation data for larger fractures are being selectively lost.

The following discussion of directional statistics is a summary of material found in Davis (1986) and Mardia and Jupp (2000). Circular data such as fracture azimuths cannot be summarized with conventional statistics (Mardia and Jupp, 2000). The mean direction $\bar{\theta}$ of a set of directional measurements, such as azimuths $\theta_{1} . . \theta_{\mathrm{n}}$, is given by

$$
\bar{\theta}=\left\{\begin{array}{l}
\operatorname{atan}\left(\mu_{s} / \mu_{c}\right) \text { if } \mu_{c} \geq 0 \\
\operatorname{atan}\left(\mu_{s} / \mu_{c}\right)+\pi \text { if } \mu_{c}<0
\end{array}\right.
$$

where

$$
\mu_{s}=\frac{1}{n} \sum_{i=1}^{n} \sin \theta_{i}
$$

and

$$
\mu_{c}=\frac{1}{n} \sum_{i=1}^{n} \cos \theta_{i}
$$

The mean direction is the arctangent of the mean sine of all directional measurements divided by the mean cosine of all directional measurements. 
The mean resultant length, $\mu_{\mathrm{R}}$, is the normalized resultant of the unit vectors $\mathbf{x}_{1}, \ldots \mathbf{x}_{\mathrm{n}}$ corresponding to the angles $\theta_{1}, \ldots \theta_{\mathrm{n}} . \mu_{\mathrm{R}}$ given by

$$
\mu_{R}=\mu_{c}^{2}+\mu_{s}^{2}
$$

When $\mu_{\mathrm{R}}=0, \bar{\theta}$ is undefined, which can result when directional measurements differ by $180^{\circ}$.

A rose diagram (Figure 3.4) displays the circular distribution of PSA fracture strikes, with a primary orientation of NNE-SSW being apparent. This orientation is consistent with the fault/ fracture system oriented N $30^{\circ} \mathrm{E}$ as mapped over the entire Sands Springs Range by University of Nevada (1965).

When dealing with spherical data, such as the conjoint azimuth and dip of a planar fracture, this approach is extended so that $\mathbf{x}$ is a unit vector defined by the spherical polar coordinates $(\theta, \phi)$

$$
x=\cos \theta, \sin \theta \cos \phi, \sin \theta \sin \phi
$$

where $\theta$ is the angle measured clockwise from north to the azimuth of the fracture, and $\phi$ is the angle measured down from the horizon to the plane of the fracture.

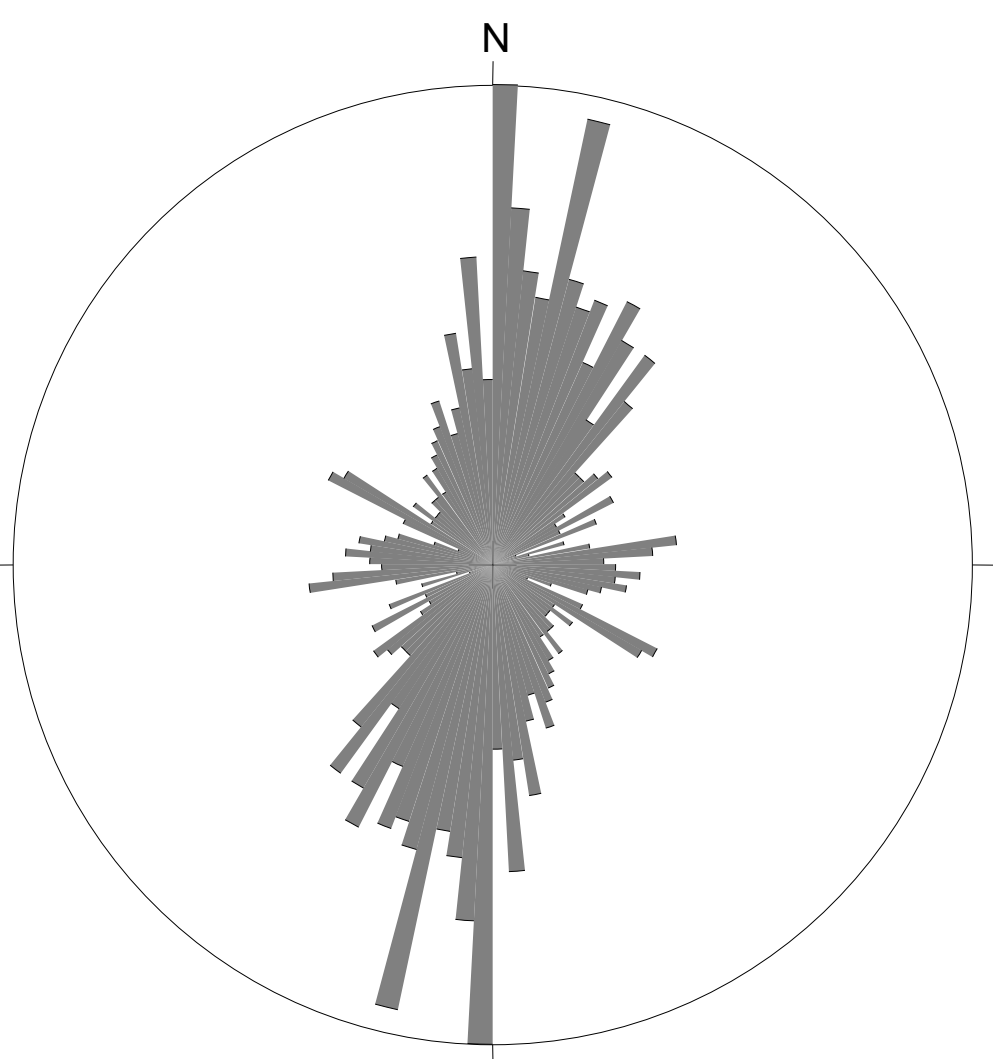

Figure 3.4. Rose diagram showing all PSA fracture strikes, using $3^{\circ}$ classes. 
Following the right-hand rule (facing in the strike direction, dip is measured down from the horizontal on the right-hand side), the Cartesian coordinates of unit vector $\mathbf{x}$ for geologic azimuth and dip measurements are

$$
\begin{gathered}
X=-\sin (\theta) \cos (\phi) \\
Y=\cos (\theta) \cos (\phi) \\
Z=\sin (\phi)
\end{gathered}
$$

where $\theta$ is azimuth and $\phi$ is dip.

The spherical resultant length, $L_{\mathrm{R}}$, is

$$
L_{R}=\sqrt{\left(\sum_{i=1}^{n} x_{i}\right)^{2}+\left(\sum_{i=1}^{n} y_{i}\right)^{2}+\left(\sum_{i=1}^{n} z_{i}\right)^{2}}
$$

The normalized resultant length, $\mu_{\mathrm{R}}$, is

$$
\mu_{R}=\frac{L_{R}}{n}
$$

The coordinates of the mean vector are defined as

$$
\begin{aligned}
& \bar{X}=\sum_{i=1}^{n} x_{i} / L_{R} \\
& \bar{Y}=\sum_{i=1}^{n} y_{i} / L_{R} \\
& \bar{Z}=\sum_{i=1}^{n} z_{i} / L_{R}
\end{aligned}
$$

The mean dip is

$$
\bar{\phi}=\operatorname{asin} \bar{Z}
$$

and the mean azimuth is

$$
\bar{\theta}=\operatorname{atan}(-\bar{X} / \bar{Y})
$$

Observations of planar features such as azimuth and dip are commonly displayed on a Lambert's equal-area projection, or a Schmidt projection as it is known in geological literature 
(Mardia and Jupp, 2000). The process of plotting the projected pole of a plane to a Schmidt projection is illustrated in Figure 3.5.

The observed dips and azimuths used in this analysis are plotted on a Schmidt projection in Figure 3.6. The concentration parameter $\kappa$ describes the clustering about the mean direction, the greater the value of $\kappa$, the more tightly observations are clustered around the mean direction. In application, $\kappa$ can be estimated from the number of observations, $n$, and the resultant vector length $L_{R}$,

$$
\kappa \cong(n-2) /\left(n-L_{R}\right)
$$

when $\kappa$ is greater than 10 (Davis, 1986).

Contour plots are used to visually display the distribution of directional observations. These plots are made by subdividing the hemisphere with a grid and counting the number of points (projected poles) falling within a circle of a specified radius centered on each grid node. The number of points within a circle divided by the total number of points is the relative frequency. This is then contoured to yield a graphic display of the density of observations (Davis, 1986). Figure 3.7 shows a contour plot of the fracture data, where the radii used to count points are sized so the resulting circle equals one percent of the total area of the hemisphere.
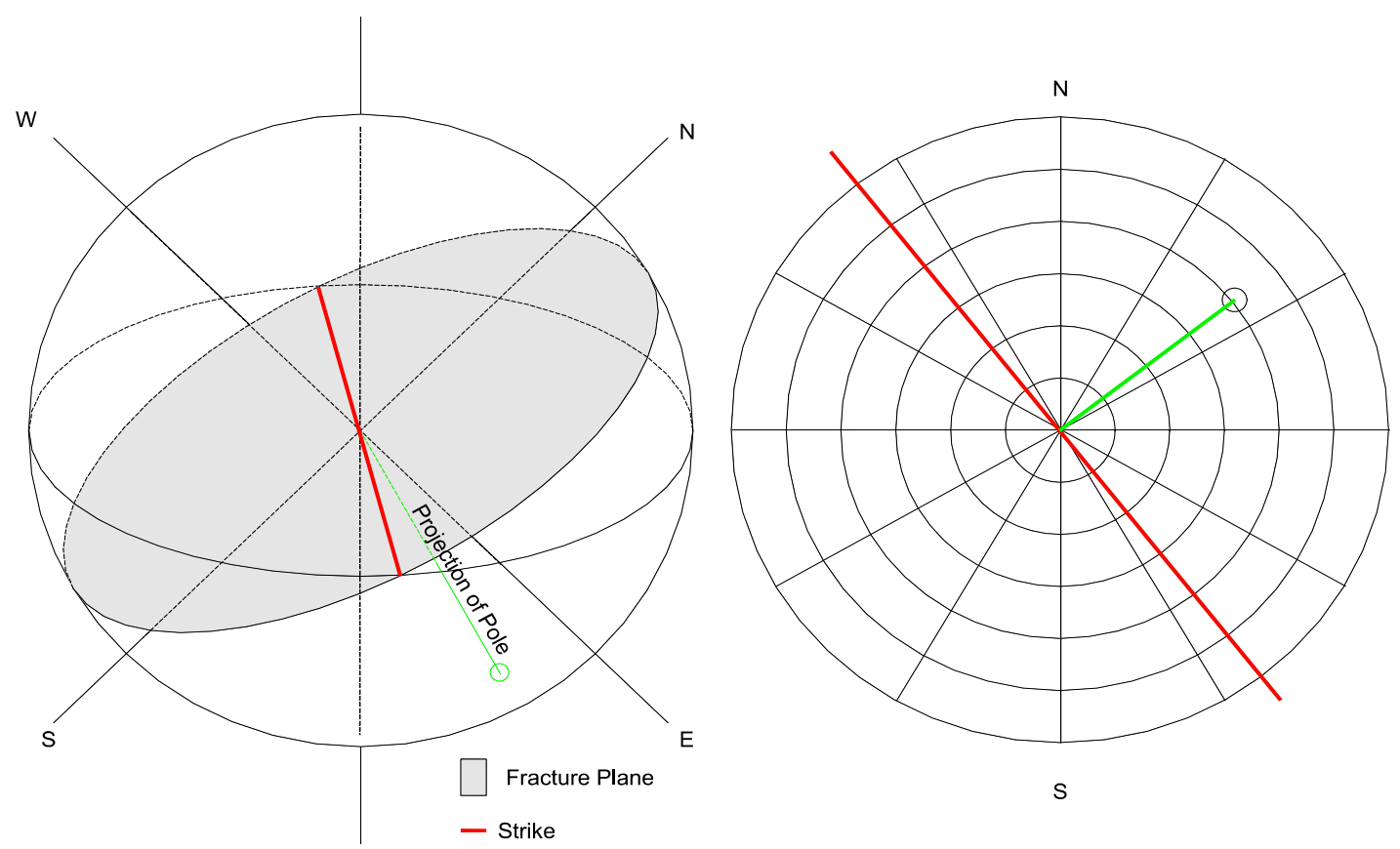

Figure 3.5. Projection of pole of plane onto lower hemisphere. 


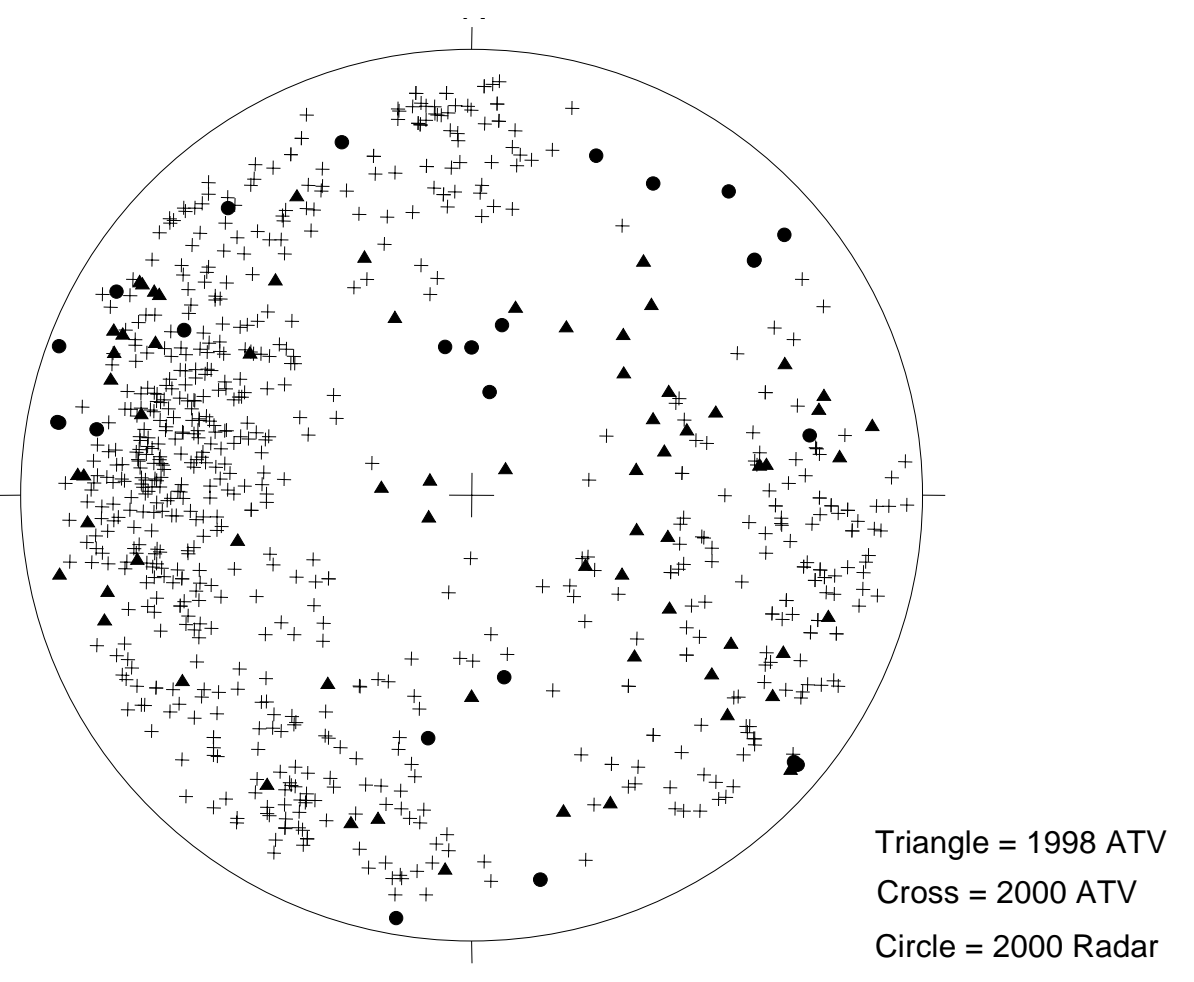

Figure 3.6. Schmidt projection of all fracture orientations, lower hemisphere projection, equal area.

Figure 3.7 clearly illustrates that the orientation of fractures at this site has a multimodal distribution. The four fracture sets labeled 1 through 4 correspond to the most likely directions of fracturing (87.2 percent of all fractures), i.e, the four principal modes. The mean dip and strike of these fracture sets and the prior probability of all fracture sets are summarized in Table 3.1. Fracture sets 5 and 6 combined comprise only 12.8 percent of all observed fractures, yet are spread across 28.6 percent of the area of the projection hemisphere. Because of the relatively low directional concentration displayed by these two fracture sets (calculated $\kappa$ values of 16 and 10.6, respectively), they are not used to describe orientations of fractures. The concentration $\kappa$ is undefined for distributions lacking a mean direction. It should also be noted that if vertical fractures exist, they are underrepresented in this analysis due to the great difficulty in their detection in vertical boreholes.

Fracture sets 1 through 4 were chosen to represent the distribution of orientations for Flow Category 2, which represents zones of strongly oriented, large fractures. These fracture sets have the most well-defined orientations, as indicated by their high degree of clustering around their mean directions, and they contain the highest proportion of the total fractures. Flow Category 1 is assumed to have no preferred spatial orientation.

While it is possible to develop a simpler description of fracture distribution consistent with the observed data, such a distribution would be much smoother than the multi-modal distribution shown in Figure 3.7. Given the strong impact on flow and transport believed to result from the 


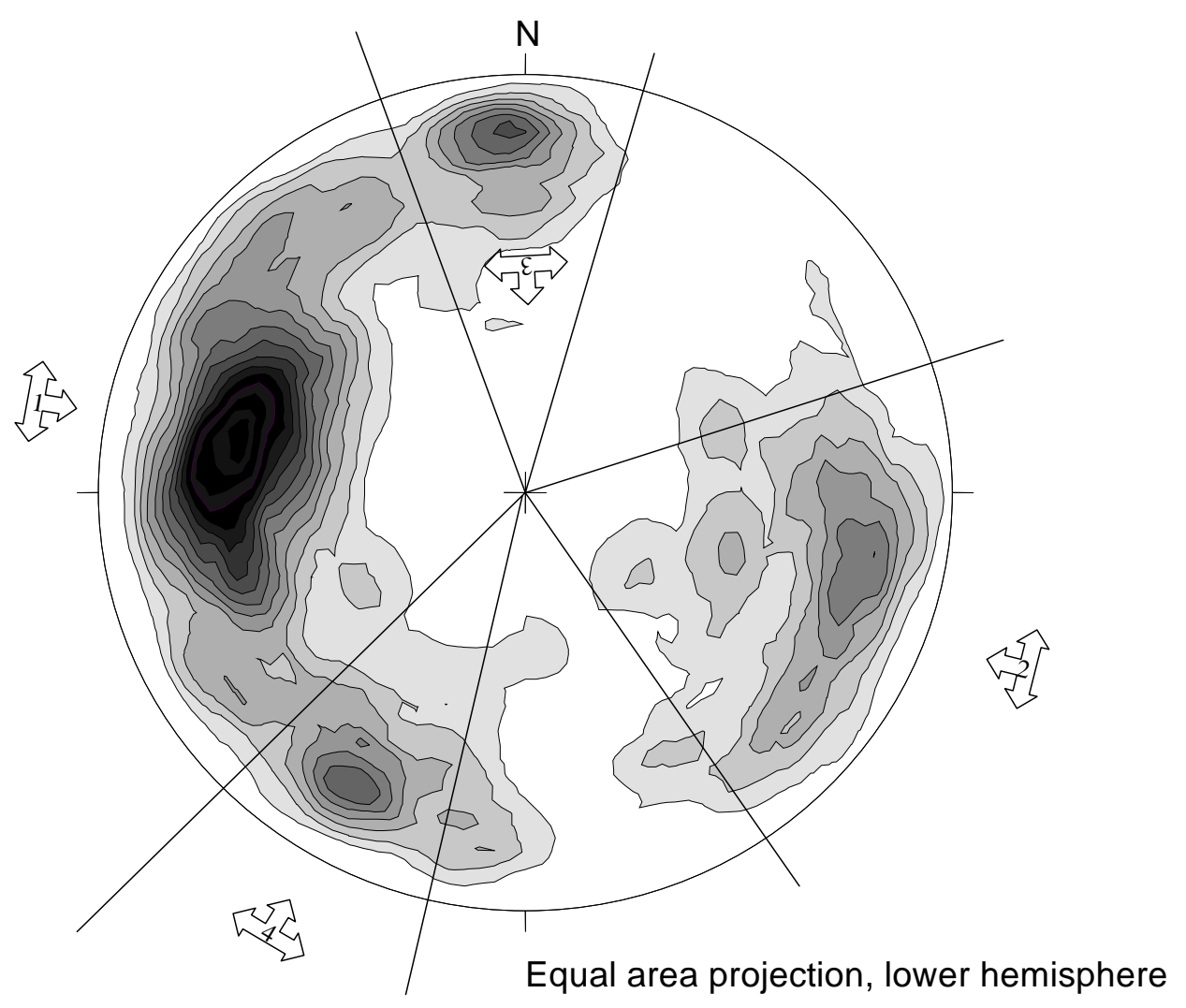

Figure 3.7. Contour plot of all fracture orientations using a one percent grid radii.

Table 3.1. $\quad$ Fracture summary statistics (ND = not defined).

\begin{tabular}{cccccc}
\hline \hline Fracture Set & Count of Fractures & Prior Probability & Mean Strike & Mean Dip & $\kappa$ \\
\hline 1 & 397 & $50.2 \%$ & $8.8^{\circ}$ & $62.2^{\circ}$ & 22.4 \\
2 & 156 & $19.7 \%$ & $193.8^{\circ}$ & $61.8^{\circ}$ & 20.9 \\
3 & 68 & $8.6 \%$ & $86.8^{\circ}$ & $65.7^{\circ}$ & 31.7 \\
4 & 68 & $8.6 \%$ & $301.7^{\circ}$ & $63.8^{\circ}$ & 45.4 \\
5 & 66 & $8.3 \%$ & $351.6^{\circ}$ & $60.9^{\circ}$ & 16.0 \\
6 & 35 & $4.4 \%$ & $214.6^{\circ}$ & $60.8^{\circ}$ & 10.6 \\
All & 790 & $100.0 \%$ & ND & ND & ND \\
\hline \hline
\end{tabular}

actual heterogeneous, discrete, but uncertain, fracture network, it was felt that use of an empirical distribution would properly describe the detailed orientation distribution.

The spatial persistence of fracture features was quantified using a digitized map (Pohll et al., 1998) of fractures observed at land surface (University of Nevada, 1965, Plate 3). Although the fractures are not truly linear features, they were treated as linear so that an average strike could be 
calculated for each fracture. A bimodal distribution of strike orientations resulted and the data were grouped as follows:

\section{Group 1: Strike of 0 to $70^{\circ}$ and 130 to $180^{\circ}$ East of North \\ Group 2: Strike of 70 to $130^{\circ}$ East of North}

Fracture lengths in Group 1 are described using a log-normal distribution with mean length of $572 \mathrm{~m}$ and a natural $\log$ standard deviation of 0.86 . Group 2 contained very few fractures, so a uniform distribution having a range of 100 to $750 \mathrm{~m}$ was used.

The lengths of fractures along the dip direction could not be quantified in the field. Therefore, the distribution of fracture lengths along the dip direction was assumed to be identical to the distribution of lengths along the strike direction. The fracture zone width (the length normal to the fracture plane) was assumed to be $30 \mathrm{~m}$.

\subsubsection{Prior Probabilities of Fracture Classes}

The proportion of model cells assigned to each flow category was determined using the video logs of the HC wells. Several analyses of geophysical logs conducted in PSA boreholes have provided a qualitative classification system that describes fracture size. The earliest work was based primarily on caliper logs, density logs, core samples and, where available, frac-finder logs (University of Nevada, 1965). Three fracture scores were established; intervals having small or no fractures were assigned a score of 1 , intervals having medium-size fractures were assigned a score of 2, and intervals having large fractures were assigned a score of 3 . Following the construction of HC-1, HC-2, HC-3 and HC-4 in 1996, the video and caliper logs of these boreholes were used to classify the fracture intervals using the same classification system (Pohll et al., 1998). Although the system is subjective, Pohll et al. (1998) found that clear distinctions between the classes were evident in these wells (video logs were not conducted in the earlier wells and they were sealed shortly after the Shoal nuclear test). The video logs of the most recent characterization wells (HC-5, HC-6, HC-7 and HC-8) have also been analyzed in the same manner and with results that are very similar to the 1998 analysis. The fracture scores for the HC wells are typically reported at a vertical resolution of $0.3 \mathrm{~m}$, so they have been aggregated over 20-m vertical intervals to be consistent with the scale of the PSA model. Only the fracture score results from the HC wells are used in the PSA flow model because they are calculated using the same types of logs, thus avoiding any discrepancies that might have occurred if the earlier results obtained using different logs had been incorporated.

The classification of the boreholes based on fracture score shows that 64 percent of the combined borehole intervals have small or no fractures (Table 3.2). Approximately 33 percent of the intervals have medium or large fractures and about three percent of the intervals have insufficient data to assign a fracture score. Because Fracture Scores 2 and 3 both indicate the presence of more than minimal fracturing, they were considered to be part of Flow Category 2. Intervals without fracture scores were also included in Flow Category 2 because the loss of data in these intervals may likely be related to intense fracturing and washout of the borehole walls that prevented identification of individual fractures. As a result, the prior probability of Flow Category 2 
Table 3.2. Global prior probabilities for Flow Categories 1 and 2 as determined from borehole fracture score analysis of video logs.

\begin{tabular}{ccccc}
\hline \hline Fracture Score & 1 & 2 & 3 & $0^{*}$ \\
\hline Prior Probability & 0.64 & 0.28 & 0.05 & 0.03 \\
& & & 2 & \\
Flow Category & 1 & & 0.36 \\
Prior Probability & 0.64 & & 28 \\
\hline \hline
\end{tabular}

*indicates no data.

is the sum of the percentages of the borehole intervals having Fracture Series 0, 2 and 3. The prior probability of Flow Category 1 is the percentage of borehole intervals assigned to Fracture Score 1.

\subsubsection{Hydraulic Conductivity}

As discussed above, the principal mechanism for groundwater movement at the PSA is flow through faults and fractures in the granite aquifer, which by virtue of the wide ranges in their size and orientation produce significant aquifer heterogeneity. Variation in hydraulic parameters is also typically observed in fractured rock settings, and consequently in this study $K$ is treated as a random parameter in the stochastic analysis. Hydraulic data and interpretations are available from pumping tests and stressed thermal flowmeter (TFM) tests in seven and two of the HC wells, respectively (Mihevc et al., 2000). The pumping tests were all single-hole tests, with the notable exception of the cross-hole test conducted prior to the tracer test in wells HC-6 and HC-7. Analysis of recovery data was conducted for three of these wells, though these data were not used in the present analysis because they essentially duplicated the drawdown data in their respective wells. In addition, slug test results are available from four of the wells installed during initial site characterization (University of Nevada, 1965). These tests were not used because they were conducted over the entire lengths of the saturated sections of the boreholes, which ranged from 58 to $320 \mathrm{~m}$, and because great difficulties were experienced during testing and analysis (University of Nevada, 1965). The mean of the tested interval lengths of the pumping and TFM tests is $25 \mathrm{~m}$, which is consistent with the scale of the numerical flow model (mesh size of $20 \mathrm{~m}$ ). No correlation was found between the length of the tested interval and the magnitude of $K$. The 16 available $K$ values range from $8.3 \times 10^{-4}$ to $1.7 \times 10^{-1} \mathrm{~m} / \mathrm{d}$ (Table 3.3 ) and a histogram of the $\log _{10^{-}}$ transformed $K$ data values illustrates this range (Figure 3.8).

The single-well hydraulic tests and to some degree the short-term, two-well pumping test at HC-6 and HC-7 provide information about the magnitude and variability in $K$ at the near-20-m scale of the PSA flow model mesh. However, the tracer test conducted in HC-6 and HC-7 represents a long-term hydraulic stress on the system and encompasses a volume of aquifer more consistent with the larger scale of flow and transport at PSA, thereby making it an ideal dataset with which to evaluate hydraulic properties for the flow model. Transient numerical simulations of the tracer test were performed in an inverse mode, using the time-drawdown and time-recovery data as the calibration data set to provide an independent estimate of $K$. 
For simplicity, this three-dimensional model treats the granite aquifer as an equivalent porous medium. The finite element FEFLOW model simulates the injection and withdrawal wells as continuous vertical finite elements so that the pumping rates are distributed evenly over the vertical extents of their screened intervals. The time-pumping rates for both wells are taken directly from the field measurements. Figure 3.9 shows in perspective view the configuration of the 16 layer model and the refinement of the mesh around the tracer test wells in the top layer; lower layers duplicate this mesh design. Layer thicknesses vary from $10 \mathrm{~m}$ in the top 10 layers to $100 \mathrm{~m}$ in the bottom layer and the total thickness of the model is $400 \mathrm{~m}$. A recharge rate of $0.24 \mathrm{~cm} / \mathrm{yr}$ (see discussion of this value in Section 3.2.3) is uniformly applied to the top surface for the full 1,500-day duration of the simulations, though it was found that the results are not sensitive to recharge rate over this period. The free surface is simulated in the top layer as a free and moveable boundary to account for changes in the elevation of the water table during the course of the test. Lower layers are free to move to adapt to the changing configuration of the top layer as the configuration of the free surface changes during and after the test. Values of the storage coefficient were varied slightly during model testing, but were set to 0.019 (the geometric mean of the distribution of fracture porosity described in Section 4.1.4) in the final runs to account for dewatering of the fractured granite near the pumping well. In addition, the model does not include the shear zone as a barrier feature, though it is located within the domain. However, the impact of this feature was tested and no impacts from pumping were observed at the distance of the shear zone from the pumping well.

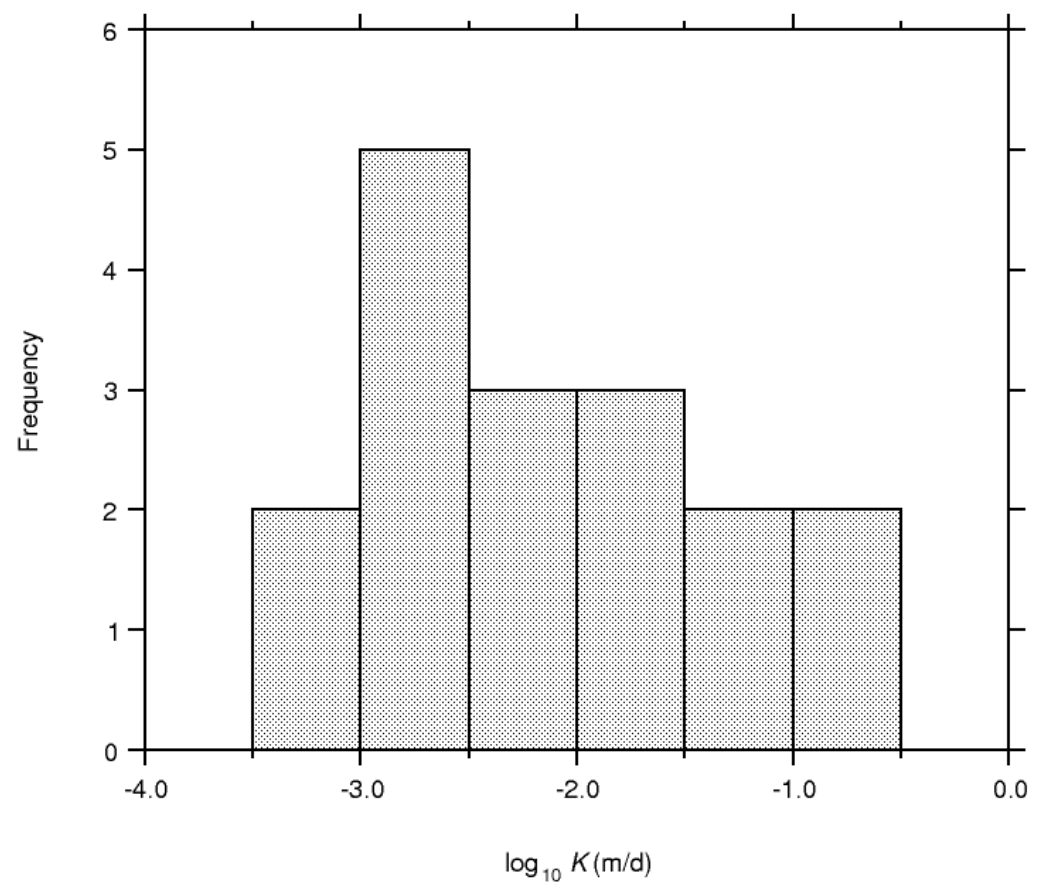

Figure 3.8. Histogram of hydraulic conductivity measurements in the granite aquifer at the PSA. Data from Mihevc et al., 2000. 


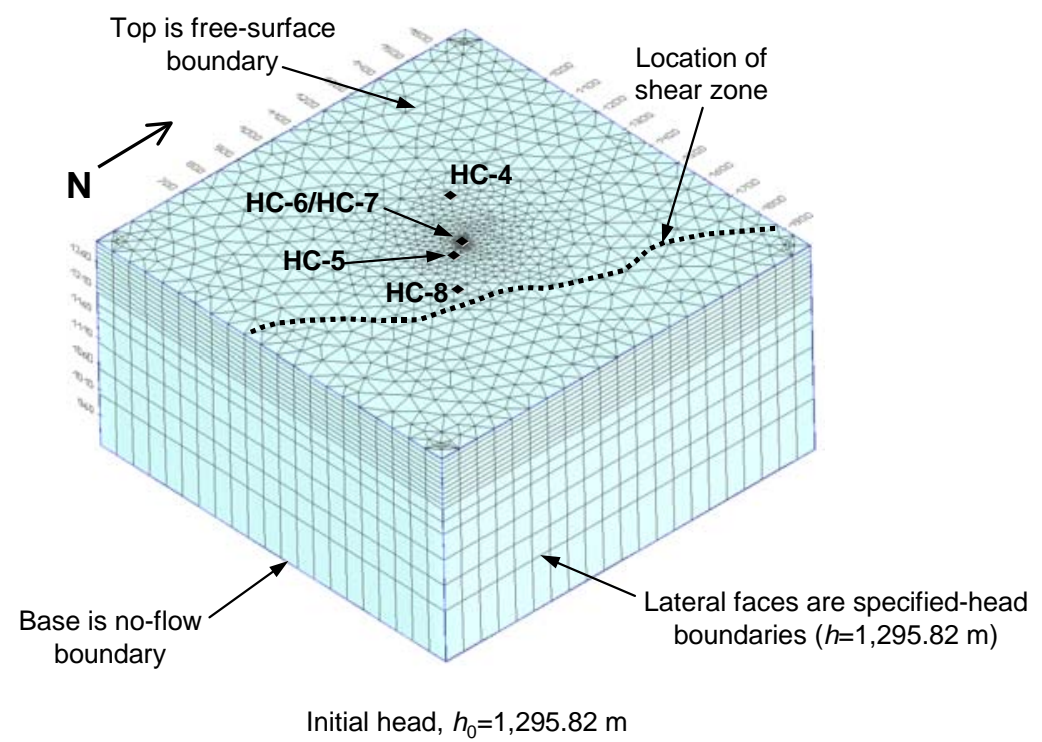

Figure 3.9. Configuration of the finite element model used to analyze pumping and recovery during the tracer test in HC-6 and HC-7. Model elements are approximately 3 to $4 \mathrm{~m}$ wide near HC-6 and HC-7. Model dimensions are $1,300 \mathrm{~m}$ by $1,300 \mathrm{~m}$ by $400 \mathrm{~m}$ thick (note that the vertical dimension is exaggerated here).

The simulated and observed water levels in HC-7 show very good agreement (Figure 3.10) using a $K$ of $2.5 \times 10^{-3} \mathrm{~m} / \mathrm{d}$, especially considering that this model does not include heterogeneity in $K$ nor the impacts of friction losses in the well. Drawdowns were not simulated at any of the other nearby wells, consistent with field observations. The calibrated value of $K$ simulated by this model is consistent with the range of $K$ values obtained from the single-well tests, as it falls near the median of the distribution. It can therefore be concluded that the model of the tracer test provides confirmation of the range of $K$ obtained from the individual single-well tests and is representative of the effective $K$ of the fractured granite at the scale of flow and transport at the PSA.

Flow Category 2 is designed to simulate the distribution of $K$ values, which is assumed to represent the more conductive portions of the granite, and is represented in the model by a $\log _{10^{-}}$ transformed triangular distribution with the minimum at $-5.0\left(1.0 \times 10^{-5} \mathrm{~m} / \mathrm{d}\right)$, the maximum at 0.0 $(1.0 \mathrm{~m} / \mathrm{d})$, and the mean at $-2.5\left(3.2 \times 10^{-3} \mathrm{~m} / \mathrm{d}\right)$. The mean of this distribution is consistent with the calibrated $K$ values obtained from the transient numerical analysis of cross-hole pumping during the 320-day tracer test conducted at HC-6 and HC-7 $\left(3.4 \times 10^{-3} \mathrm{~m} / \mathrm{d}\right)$ and the regional flow model for the PSA $\left(6.9 \times 10^{-3} \mathrm{~m} / \mathrm{d}\right)$. In addition, the range of the $K$ distribution for Flow Category 2 


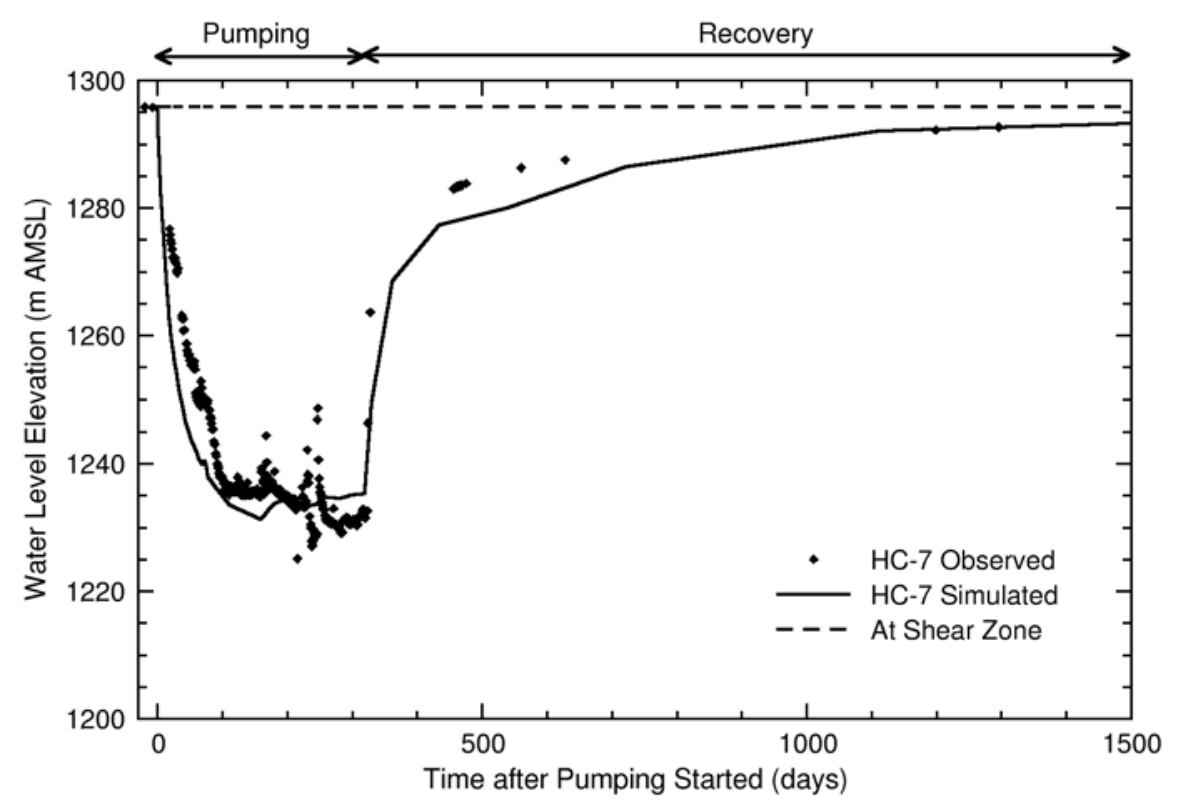

Figure 3.10. Comparison of simulated water levels to observed water levels in tracer test well HC-7. Large fluctuations in water levels during pumping reflect variations in pumping rate (see Figure 6.2 for a plot of pumping rates during the tracer test).

captures the full range of the field data. The $K$ values for Flow Category 1 were obtained during model calibration using the methodology described in Section 3.3.5.

Hydraulic conductivity is treated as statistically homogeneous (stationary) throughout the PSA model domain. Though most of the hydraulic tests were conducted within the upper $100 \mathrm{~m}$ of the saturated zone, the $K$ values obtained from the two deepest tests (HC-5 and HC-8) represent the upper and lower extremes, respectively, of the $K$ range, suggesting that the $K$ variability observed near the top of the saturated section also exists at much greater depths. Furthermore, no trends in fracture density were observed with increasing depth on the fracture score logs. It should also be noted that $K$ is not spatially correlated within either flow category. Every cell within a given individual fracture zone simulated in Flow Category 2 is assigned the same value of $K$ that is chosen from the distribution described above (Section 3.3.2.1). Likewise, every cell in Flow Category 1 of a given realization is assigned the same value of $K$ as determined during model calibration (described in Section 3.3.5).

\subsubsection{Recharge}

Recharge to the groundwater system by infiltration of precipitation through the land surface is a critical parameter controlling the velocity and direction of groundwater flow. In turn, recharge is constrained by the observed hydraulic properties of hydraulic conductivity and head. For example, a recharge rate too high relative to $K$ results in modeled water levels far higher than those observed in the field. The DDA (Pohll et al., 1999b) identified uncertainty in recharge as a significant contributor to overall model uncertainty. As a result, recharge is one of the parameters 
Table 3.3. Summary of hydraulic test data for wells near the PSA. From Mihevc et al., 2000.

\begin{tabular}{|c|c|c|c|c|c|c|c|}
\hline \multirow[b]{2}{*}{ Well ID } & \multirow[b]{2}{*}{ Test } & \multirow[b]{2}{*}{ Date } & \multicolumn{3}{|c|}{ Tested Interval } & \multirow[b]{2}{*}{$\begin{array}{c}K \\
(\mathrm{~m} / \mathrm{d})\end{array}$} & \multirow[b]{2}{*}{$\begin{array}{c}\log _{10} K \\
\left(\log _{10} \mathrm{~m} / \mathrm{d}\right)\end{array}$} \\
\hline & & & $\begin{array}{c}\text { Top } \\
\text { (m AMSL) }\end{array}$ & $\begin{array}{c}\text { Base } \\
\text { (m AMSL) }\end{array}$ & $\begin{array}{c}\text { Length } \\
\text { (m) }\end{array}$ & & \\
\hline HC-1 & Pumping1 & 2/20/1997 & $1,293.70$ & $1,212.70$ & 81.0 & $1.8 \mathrm{E}-02$ & -1.8 \\
\hline HC-2 & Pumping & 2/24/1997 & $1,292.70$ & $1,260.08$ & 32.6 & 2.3E-03 & -2.6 \\
\hline HC-4 & Pumping & 2/23/1997 & $1,285.50$ & $1,225.09$ & 60.4 & 3.5E-03 & -2.5 \\
\hline HC-5 & Pumping1 & 10/11/1999 & 568.58 & 532.00 & 36.6 & 1.7E-01 & -0.8 \\
\hline HC-6 & Pumping & 10/25/1999 & $1,292.26$ & $1,255.68$ & 36.6 & $1.4 \mathrm{E}-02$ & -1.9 \\
\hline HC-7 & Pumping & 10/28/1999 & $1,292.26$ & $1,221.00$ & 36.6 & 2.3E-02 & -1.6 \\
\hline HC-8 & Pumping & 11/11/1999 & 903.84 & 868.33 & 36.6 & 8.3E-04 & -3.1 \\
\hline HC-7/HC-6 & Pumping 2 & 10/28/1999 & $1,292.26$ & $1,255.68$ & 36.6 & $1.5 \mathrm{E}-01$ & -0.8 \\
\hline HC-1 & TFM & 7/9/1997 & $1,242.26$ & $1,232.62$ & 9.6 & 4.6E-02 & -1.3 \\
\hline HC-1 & TFM & 7/9/1997 & $1,232.62$ & $1,225.86$ & 6.8 & 6.1E-02 & -1.2 \\
\hline HC-4 & TFM & 8/7/1997 & $1,292.04$ & $1,286.04$ & 6.0 & 8.6E-03 & -2.1 \\
\hline HC-4 & TFM & 8/7/1997 & $1,286.04$ & $1,274.04$ & 12.0 & 2.9E-03 & -2.5 \\
\hline HC-4 & TFM & 8/7/1997 & $1,274.04$ & $1,267.04$ & 7.0 & 2.0E-03 & -2.7 \\
\hline HC-4 & TFM & 8/7/1997 & $1,267.04$ & $1,255.04$ & 12.0 & 1.3E-03 & -2.9 \\
\hline HC-4 & TFM & 8/7/1997 & $1,255.04$ & $1,246.04$ & 9.0 & 3.1E-03 & -2.5 \\
\hline HC-4 & TFM & 8/7/1997 & $1,246.04$ & $1,236.04$ & 10.0 & 8.6E-04 & -3.1 \\
\hline HC-4 & TFM & 8/7/1997 & $1,236.04$ & $1,228.04$ & 8.0 & $3.8 \mathrm{E}-03$ & -2.4 \\
\hline Mean & & & & & 25 & 3.0E-02 & -2.1 \\
\hline Variance & & & & & 490 & 2.6E-03 & 0.55 \\
\hline
\end{tabular}

${ }^{1}$ Mean value of two tests

2Pumping in HC-7, observations in HC-6

treated stochastically in the flow model. Recharge is applied evenly over the top of the model domain (consistent with the subdued topography and lack of well-integrated drainage of Gote Flat), with the value for each simulation selected from a single-sided triangular distribution ranging between 0.05 and $0.70 \mathrm{~cm} / \mathrm{yr}$. The selection of this range is discussed below.

The Shoal site is in a sub-humid to semi-arid region of the Great Basin. No permanent water bodies or streams exist. Sparse, low vegetation covers the area. Annual precipitation varies from about $13 \mathrm{~cm}$ in the valleys to about $30 \mathrm{~cm}$ in the high mountain ranges (Gardner and Nork, 1970). The gauge at Eastgate, $40 \mathrm{~km}$ east and $75 \mathrm{~m}$ lower in elevation than Shoal, receives the majority 
of its precipitation as snow. The annual precipitation estimate for the Shoal site varies between 20 cm (Gardner and Nork, 1970) and 30 cm (Hardman and Mason, 1949).

The downward vertical hydraulic gradients observed in well ECH-D (University of Nevada, 1965) and in the new wells HC-8 and HC-5, indicate that some portion of this precipitation infiltrates through the $300 \mathrm{~m}$ of unsaturated rock to become recharge to the granite aquifer. The magnitude of this recharge flux is the source of uncertainty. Traditional methods of estimating recharge, such as water balance, are ineffective in arid regions because the size of the quantity being estimated is smaller than the associated errors.

After the DDA identified recharge as a critical parameter in regard to model uncertainty, an analysis of recharge based on meteorological and hydraulic characteristics was performed (Pohll, 1999). A numerical vadose zone model was constructed using HYDRUS (Vogel et al., 1996) to simulate fluid movement in the upper $100 \mathrm{~m}$ at the PSA. Meteorological data from the Fallon, Nevada, weather station were used to drive the upper boundary condition, which represents precipitation and potential evaporation. The model was constructed in a Monte Carlo environment such that the uncertainty in the hydraulic conductivity could be included and the uncertainty in the predicted recharge rate could be determined. A total of 1,000 realizations were simulated to assess the uncertainty in the recharge rate with the 95 percent confidence interval ranging between 0.0 and $0.16 \mathrm{~cm} / \mathrm{yr}$.

Pohll et al. (1998) provided an independent estimate of surface recharge using borehole temperature profiles. Their analysis yielded a range of recharge between 1.17 and $1.71 \mathrm{~cm} / \mathrm{yr}$, with a mean value of $1.45 \mathrm{~cm} / \mathrm{yr}$. It is important to note that recharge estimates based on thermal profiles contain uncertainty due to measurement errors and assumptions in the analysis methodology.

Using the relationship between precipitation and recharge described by Maxey and Eakin (1949), which is generally referred to as the Maxey-Eakin recharge model, an estimated three percent of the annual precipitation will infiltrate and become groundwater recharge $(0.9 \mathrm{~cm} / \mathrm{yr})$ as based on the Hardman (1936) estimate for precipitation (30 cm/yr).

Watson et al. (1976) evaluated the uncertainty associated with the Maxey-Eakin recharge estimates. Watson et al. (1976) applied a multiple regression model to examine the statistical validity of the Maxey-Eakin methodology. Although Maxey and Eakin (1949) did not strictly apply a regression model, their approach is very similar as they used a trial-and-error approach to determine the coefficients such that their model yielded a minimum difference between simulated and observed recharge. The precipitation coefficients are compared in Table 3.4. Although the multiple regression model leads to erroneous results for the 30 to $38 \mathrm{~cm}$ (12 to 15 inch) precipitation zone, in general, the coefficients are similar to those presented by Maxey and Eakin (1949). The multiple regression model provides a method to estimate the 95 percent confidence levels in the coefficients and can be used to assess the uncertainty associated with the MaxeyEakin recharge model. The Watson et al. (1976) model yields a 95 percent confidence interval for recharge between 0.6 and $1.8 \mathrm{~cm} / \mathrm{yr}$ at the PSA. 
The problem with the multiple regression analysis is that the recharge model could not be constrained as was done by Maxey and Eakin (1949). Their model was constructed such that each larger precipitation zone yielded a larger coefficient, as one would expect. Also, the coefficients should not be less than zero, as these values would have no physical meaning. Although the multiple regression model provides a confidence interval, they are based on the assumption that the model errors are normally distributed with a zero mean. This assumption has been violated as can be seen by confidence intervals that also yield coefficients less than zero.

Nichols (2000) developed a recharge model similar to the Maxey-Eakin model, but it used more recent hydrologic data and possibly more reliable estimates of groundwater recharge. Nichols (2000) developed groundwater discharge estimates for 16 hydrologic basins in northeastern Nevada using a combination of spring discharges, estimates of interbasin flow and satellite-derived estimates for evapotranspiration. The discharge estimates were used as an estimate for groundwater recharge, which is a valid approach since groundwater pumping is not a significant component of the water budget within these basins. Precipitation estimates for their model were derived from the Precipitation-elevation Regression on Independent Slopes Model, otherwise known by the acronym PRISM (Daly et al., 1994). It is important to note that the Maxey-Eakin recharge model is based on the Hardman (1936) precipitation map for Nevada. Following Maxey and Eakin (1949), Nichols (2000) created six precipitation zones for which coefficients are derived to represent the percentage of rainfall that becomes groundwater recharge from each zone. Nichols (2000) used a multiple regression model to aid in the calculation of the precipitation coefficients, but they adjusted the measured recharge estimates until the multiple regression model yielded an $\mathrm{R}^{2}$ value of 1.0. The adjustments were required as they imposed two constraints similar to Maxey and Eakin (1949):

1. No coefficient was assumed to be less than zero because a negative percentage has no physical meaning, and

2. The coefficients, or percentage of recharge, should increase from the smallest precipitation zone to the largest.

They also applied a coefficient of zero to the smallest precipitation zone $(<20 \mathrm{~cm}$, or 8 in) citing Maxey and Eakin (1949) as their basis. The Nichols (2000) precipitation coefficients are

Table 3.4. Coefficients for each precipitation zone to relate precipitation to groundwater.

\begin{tabular}{cccccc}
\hline \hline \multirow{2}{*}{$\begin{array}{c}\text { Precipitation } \\
\text { Zone }\end{array}$} & \multicolumn{2}{c}{ Maxey-Eakin } & & \multicolumn{2}{c}{ Watson et al. } \\
\cline { 3 - 5 } \cline { 5 - 5 } (in) & $(\mathrm{cm})$ & Coefficient & & $\begin{array}{c}\text { Coefficient } \\
(\%)\end{array}$ & $\begin{array}{c}\text { 95\% Confidence } \\
\text { Intervals }\end{array}$ \\
\hline$>20$ & $>51$ & $(\%)$ & & $(\%)$ \\
$15-20$ & $38-51$ & 15 & 19 & $+/-15$ \\
$12-15$ & $31-38$ & 7 & -1 & $+/-16$ \\
$8-12$ & $20-31$ & 3 & 4 & $+/-6$ \\
$<8$ & $<20$ & 0 & 0 & $+/-2$ \\
\hline \hline
\end{tabular}


given in Table 3.5. A direct comparison cannot be made with the Maxey-Eakin recharge model as the configurations of the precipitation zones are not the same and a different precipitation map was used in each case. The statistics of the regression model are valid because the regression model was calibrated by adjusting the recharge estimates until the model had an $\mathrm{R}^{2}$ of 1.0. One cannot develop a confidence interval for the coefficients for the same reason.

According to the PRISM map of precipitation, the average annual rainfall for the Sands Springs range is $18 \mathrm{~cm}$ (7 in), which is in general agreement with the (Gardner and Nork, 1970) estimate (20 cm). Therefore, using the Nichols (2000) recharge model, one would estimate that no recharge occurs. However, considering the fact that water levels have not declined in the previous 40 years, it is unlikely that recharge is zero within the Sand Springs Range.

In an effort to reconcile all of the recharge estimates, the data used to derive the Nichols' (2000) recharge model (see Table 3.6) were used to develop a revised recharge model to provide more accurate estimates and confidence intervals for recharge at the PSA. The data used in the Nichols' model are the best currently available so they were used to develop the revised model. As noted above, a multiple regression model cannot be used when constraints are put on the coefficients, so an inversion scheme was used instead. In this case, PEST (Doherty, 2000) software was used to drive the inversion (or calibration) technique. The coefficients for each of the six precipitation zones used in the Nichols' recharge model were adjusted until a minimum error between the simulated and observed recharge was achieved. The two constraints listed above were invoked to ensure that the coefficients were not negative and that they increased with increasing precipitation zones. A minimum value of 0.5 percent increase was required between each precipitation zone.

Because a standard multiple regression scheme was not used, a numerical technique had to be applied to assess the recharge model's uncertainty. A statistical procedure known as the bootstrap method was used to determine the model uncertainty. The bootstrap method is a commonly used technique to ascertain uncertainty and perform hypothesis tests with numerous textbooks and over one thousand technical papers published on the subject in the statistical literature (Efron, 1979; Efron and Tibshirani, 1993). The method is very simple to implement,

Table 3.5. Coefficients as derived by Nichols (2000) for estimating groundwater recharge.

\begin{tabular}{ccc}
\hline \hline Precipitation & & $\begin{array}{c}\text { Nichols (2000) } \\
\text { Coefficient } \\
(\%)\end{array}$ \\
(in) & $>86$ & 62.6 \\
$20-34$ & $51-86$ & 15.8 \\
$16-20$ & $41-51$ & 14.4 \\
$12-16$ & $31-41$ & 13 \\
$8-12$ & $20-31$ & 0.8 \\
$<8$ & $<20$ & 0 \\
\hline \hline
\end{tabular}


Table 3.6. Precipitation volumes as derived from the PRISM map, and estimated (unadjusted) groundwater discharges for 16 hydrologic basins in central Nevada.

\begin{tabular}{|c|c|c|c|c|c|c|c|}
\hline \multirow[t]{2}{*}{ Basin } & \multicolumn{6}{|c|}{ Precipitation Volume (af/yr) - PRISM (Daly et al., 1994) } & \multirow{2}{*}{$\begin{array}{c}\text { Estimated } \\
\text { Groundwater } \\
\text { Discharge } \\
\text { Nichols (2000) } \\
\text { (af/yr) }\end{array}$} \\
\hline & $\begin{aligned} &<8 \text { in } \\
&<20 \mathrm{~cm}\end{aligned}$ & $\begin{array}{c}8-12 \text { in } \\
20-31 \mathrm{~cm}\end{array}$ & $\begin{array}{l}12-16 \text { in } \\
31-41 \mathrm{~cm}\end{array}$ & $\begin{array}{l}16-20 \mathrm{in} \\
41-51 \mathrm{~cm}\end{array}$ & $\begin{array}{c}20-34 \mathrm{in} \\
51-86 \mathrm{~cm}\end{array}$ & $\begin{array}{l}>34 \mathrm{in} \\
>86 \mathrm{~cm}\end{array}$ & \\
\hline Antelope Valley & 0 & 126,356 & 107,720 & 11,611 & 867 & 0 & 17,000 \\
\hline Butte Valley & 0 & 208,886 & 331,732 & 80,872 & 79,414 & 0 & 69,000 \\
\hline Clover Valley & 0 & 0 & 242,963 & 34,601 & 67,210 & 18,555 & 59,000 \\
\hline Goshute Valley & 0 & 304,656 & 226,058 & 52,487 & 9,675 & 0 & 41,000 \\
\hline Hot Creek Valley & 161,019 & 234,328 & 19,175 & 8,595 & 950 & 0 & 5,800 \\
\hline Independence Valley & 0 & 20,016 & 302,256 & 56,173 & 15,970 & 0 & 50,000 \\
\hline Jakes Valley & 0 & 182,857 & 66,887 & 38,721 & 1,011 & 0 & 38,500 \\
\hline Little Fish Lake Valley & 0 & 174,385 & 50,084 & 11,961 & 0 & 0 & 9,700 \\
\hline Little Smoky Valley & 145,134 & 303,574 & 41,217 & 27,756 & 5,678 & 0 & 13,000 \\
\hline Long Valley & 0 & 101,196 & 269,979 & 71,142 & 10,050 & 0 & 48,000 \\
\hline Newark Valley & 4,323 & 162,209 & 231,357 & 61,371 & 56,210 & 0 & 49,000 \\
\hline Railroad Valley (northern part) & 279,951 & 394,891 & 214,587 & 110,252 & 89,567 & 0 & 61,000 \\
\hline Ruby Valley & 0 & 283 & 440,282 & 181,798 & 194,585 & 50,275 & 146,000 \\
\hline Spring Valley & 0 & 432,094 & 339,613 & 175,490 & 194,247 & 0 & 104,000 \\
\hline Steptoe Valley & 0 & 433,648 & 459,139 & 214,966 & 236,436 & 0 & 132,000 \\
\hline Tippett Valley & 0 & 126,738 & 65,075 & 18,497 & 1,596 & 0 & 12,500 \\
\hline
\end{tabular}

statistically sound, and does not require the common assumptions that the underlying data (i.e., model errors) be normally distributed.

The bootstrap process is similar to Monte Carlo simulation in that thousands of realizations are tested to ascertain model uncertainty. For each realization, the complete data set is sampled with replacement such that some of the data may be replicated and some eliminated. Because both the precipitation and groundwater discharge (used as a proxy for recharge) is also uncertain, a random error term was applied to each measured value. The error term was assumed to be normally distributed with a mean of zero and the standard deviation taken as 10 percent of the mean. This is equivalent to the assumption that the measurements are accurate to plus or minus 10 percent. It should be noted that the precipitation and groundwater recharge measurements may have errors larger than 10 percent, which would thereby increase the uncertainty in the revised recharge model predictions.

Once random samples of the precipitation and recharge values are chosen, the inversion technique described above is used to estimate the precipitation coefficients. This process is repeated over 10,000 times to develop a probability distribution function (PDF) for each 
coefficient. The PRISM map predicts average annual precipitation at Project Shoal (and almost the entire Sand Springs Range) to be seven inches $(18 \mathrm{~cm})$, so the results are shown as the precipitation coefficient (from the lowermost zone) multiplied by seven inches and then converted to $\mathrm{cm} / \mathrm{yr}$.

Figure 3.11 compares the probability distribution for groundwater recharge at the PSA using the revised recharge model to the vadose zone modeling of Pohll (1999). The median and 95 percent confidence intervals are also presented in Table 3.7. The model is in general agreement with the vadose zone model; that is, they both predict that the highest probabilities for recharge rates lie between 0.0 and $0.2 \mathrm{~cm} / \mathrm{yr}$. However, the revised recharge model predicts higher probabilities between 0.0 and $0.05 \mathrm{~cm} / \mathrm{yr}$, with probabilities declining slowly out to recharge values of $1.0 \mathrm{~cm} / \mathrm{yr}$.

The results of these various estimates yield a recharge range of 0.0 to $1.8 \mathrm{~cm} / \mathrm{yr}$. The revised recharge model uses the most recent and accurate recharge data in combination with a robust statistical model and it is in general agreement with the vadose zone model of Pohll (1999), which suggests that these two methods are more favorable as compared to the Maxey-Eakin recharge model and the thermal profile methods. Given the uncertainties in all models, a parsimonious model seems appropriate. Therefore, a triangular distribution is chosen to represent the potential

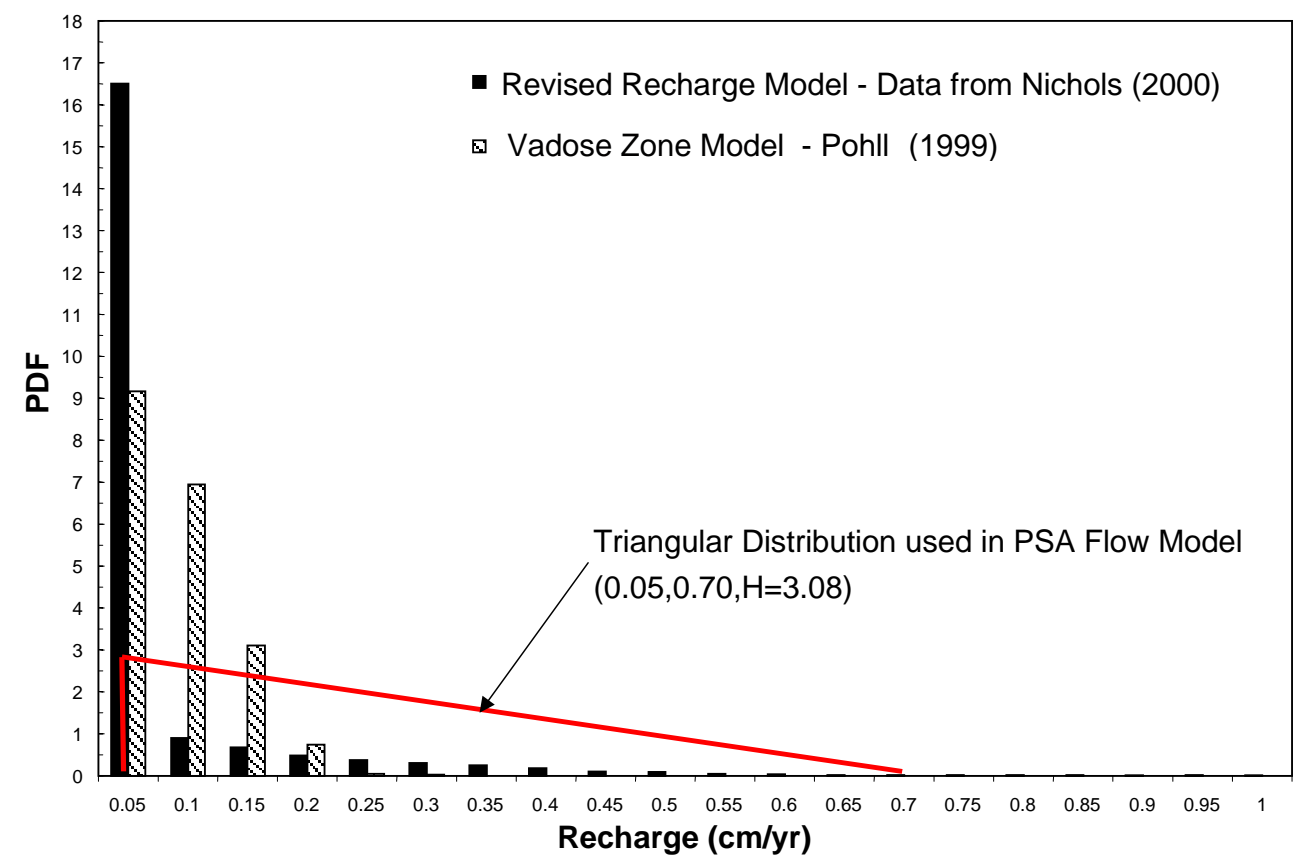

Figure 3.11. Probability distribution function for the revised recharge model, the vadose zone modeling of Pohll (1999), and the triangular distribution applied to recharge for the PSA groundwater flow model. 
Table 3.7. The 95 percent confidence intervals and median values of Project Shoal recharge as estimated by the revised recharge model and the vadose zone modeling of Pohll (1999).

\begin{tabular}{cccc}
\hline \hline Distribution & $\begin{array}{c}\text { Lower 95\% } \\
(\mathrm{cm} / \mathrm{yr})\end{array}$ & $\begin{array}{c}\text { Median } \\
(\mathrm{cm} / \mathrm{yr})\end{array}$ & $\begin{array}{c}\text { Upper 95\% } \\
\text { (cm/yr) }\end{array}$ \\
\hline Revised Recharge Model & 0.00 & 0.00 & 0.36 \\
Pohll (1999) Vadose Zone Modeling & 0.00 & 0.06 & 0.16 \\
Triangular Distribution & 0.06 & 0.24 & 0.60 \\
\hline \hline
\end{tabular}

range of recharge over the PSA as 0.05 to $0.70 \mathrm{~cm} / \mathrm{yr}$ (see Figure 3.11). The triangular distribution provides a compromise by:

1. Excluding recharge rates of zero, which is supported by the lack of long-term declining water levels in the area over the past few decades;

2. Approximating the revised recharge model and the vadose zone model of Pohll (1999), which are deemed favorable;

3. Allowing the possibility of higher recharge rates above the confidence intervals suggested by the revised recharge and vadose zone models, yet with an associated low probability; and

4. Assuming a simple form for the recharge distribution.

\subsubsection{Hydraulic Head}

Water level measurements made during drilling and in the subsequently constructed wells are reported in University of Nevada (1965), Pohll et al. (1998), and Mihevc et al. (2000) and selected data are included in Appendix A and repeated here for the convenience of the reader (Table 3.8). Head measurements were used for developing the conceptual model of flow and for calibrating the flow model. For the present study, water level data obtained in the early PSA wells (ECH-A, ECH-D, PM-1, PM-2, PM-3) were generally less useful than the data collected from the HC wells installed in the 1990s. Many difficulties were experienced in measuring several of the early wells due to the lack of equilibrium head conditions following drilling and well construction (University of Nevada, 1965). In contrast, head measurements in the HC wells were collected over intervals ranging from 33 to $81 \mathrm{~m}$ and great care was used during drilling and testing to minimize perturbations to the aquifer. Periodic measurements have been conducted in several of the HC wells from the date of their construction through the year 2003.

\subsection{Numerical Modeling Strategy}

Previous modeling at the PSA (Pohll et al., 1998, 1999a; Pohll, 1999) indicates that a deterministic approach is insufficient for modeling large-scale flow and transport processes at this site. With limited data to support the choices for individual parameters, the deterministic approach is inadequate for describing the uncertainty of the processes involved. Therefore, a 
Table 3.8. Selected static water level measurements from wells near the PSA. Summarized from Mihevc et al., 2000.

\begin{tabular}{cccc}
\hline \hline \multirow{2}{*}{ Well ID } & \multicolumn{2}{c}{ Open Interval } & Water Level \\
\cline { 2 - 3 } & $\begin{array}{c}\text { Top } \\
\text { (m AMSL) }\end{array}$ & $\begin{array}{c}\text { Base } \\
(\mathrm{m} \text { AMSL) }\end{array}$ & $\begin{array}{c}\text { (m AMSL) } \\
\text { HC-1 }\end{array}$ 1,293.7 $^{\text {HC-2 }}$ \\
HC-3 & $1,292.7$ & $1,212.7$ & $1,296.7$ \\
HC-4 & $1,285.5$ & $1,260.1$ & $1,294.0$ \\
HC-5 & $1,285.5$ & $1,184.6$ & $1,193.6$ \\
HC-6 & 568.6 & $1,228.3$ & $1,289.5$ \\
HC-7 & $1,292.3$ & 532.0 & $1,183.0$ \\
HC-8 & $1,292.3$ & $1,255.7$ & $1,295.5$ \\
PM-1 & 903.8 & $1,221.0$ & $1,295.8$ \\
PM-2 & $1,299.5$ & 868.3 & $1,185.9$ \\
PM-3 & $1,356.3$ & $1,225.0$ & $1,299.5$ \\
ECH-D & $1,287.5$ & $1,226.1$ & $1,356.3$ \\
\hline \hline
\end{tabular}

multi-parameter stochastic approach is used here, through which the uncertainty in the model conceptualization and parameterization can be included in the model results. The approach used acknowledges the uncertainty in the parameters and includes it in the analysis. This allows the simulated maps of contaminant boundaries to contain this uncertainty, expressed as a confidence level in simulated concentrations falling below given threshold concentrations.

\subsubsection{Approach}

The numerical model of groundwater flow at the PSA requires quantitative descriptions of several aspects of the conceptual model including shear zone geometry and hydraulic properties, fracture geometry and hydraulic properties, and groundwater recharge. All of these components of the model contribute to the transport predictions as they determine the pattern and magnitude of groundwater velocities and, as a consequence, influence the travel times of radionuclides from the cavity. Large-scale flow and transport models have shown that the results of radionuclide transport calculations are most profoundly impacted by parameters that affect travel time (Pohll et al., 1999b; Pohlmann et al., 1999; Hassan et al., 2002).

The uncertain components of the PSA groundwater flow model are:

- The orientation and spatial continuity of large fractures.

- The hydraulic conductivity of zones of large, oriented fractures.

- The hydraulic conductivity of intervening zones of small, random fractures. 
- The recharge from precipitation entering the top surface of the model.

- The flux originating from upland recharge that enters the upgradient vertical face of the model.

As discussed in previous sections, the shear zone and hydraulic divide are considered to be no-flow boundaries with known geometry and are treated as deterministic aspects of the model.

Monte Carlo simulation of the three-dimensional distribution of fracture categories is performed on a uniform grid and is based on the fracture orientations obtained from the analysis of PSA borehole logs and land surface fracture maps. Flow Category 1 represents large blocks of the system that are assumed to contain small, randomly oriented fractures, while Flow Category 2 represents strongly oriented, large fractures that dominate fracture flow. Within each fracture map, there are numerous zones of Flow Category 2 that represent large fracture planes (>100 $\mathrm{m}$ in length and width), each of which is assigned a unique, but random hydraulic conductivity value, $K_{2}$, obtained from the distribution described above. The flow modeling is then conducted using MODFLOW-2000 (Harbaugh et al., 2000) to solve the groundwater flow equations and the PEST software package (Doherty, 2000) to automatically calibrate each realization. MODFLOW-2000 is a finite difference flow solver, which uses the hydraulic conductivity distributions and boundary conditions to calculate the three-dimensional hydraulic head field. PEST is a non-linear, model-independent parameter estimation software package. For each Monte Carlo realization, a value of recharge, $R$, is chosen from the distribution suggested by PSA field data and site-specific modeling. PEST and MODFLOW-2000 are used to determine the value of hydraulic conductivity, $K_{1}$, for zones of small random fractures (Flow Category 1) and to ensure that the flow model provides a reasonable agreement to observed hydraulic heads. Thus, this process provides for the internal calibration of each flow realization. The error between simulated and observed heads for each realization is then saved for post-processing so that each transport realization can be weighted according to its goodness of fit to the field data.

\subsubsection{Flow Modeling Codes}

\subsubsection{Fracture Generation Code}

The simulation program FRACK was developed to generate three-dimensional distributions of fracture zones mapped to a finite difference grid. The method used to generate the fracture zones is an extension of the method used by Long et al. (1982), but extended to three-dimensional space as is available in the FRACMAN code (Dershowitz et al., 1993). The spatial distribution and geometry of the simulated fracture zones honor the statistics of the observed fracture orientation and length. The FRACK code also conditions the fracture zones according to fractures observed in PSA boreholes.

The generation of the fracture zones is analogous to methods of Long et al. (1982) and Dershowitz et al. (1982). Although these methods use the fracture simulators to generate fracture networks for discrete fracture models, FRACK generates a fracture network that is then mapped to a finite difference grid for flow simulation using a continuum approach. The general approach 
is to generate planes that represent fracture zones within three-dimensional space. FRACK allows one to simulate fracture sets, with each set having unique statistical properties as is done in FRACMAN. Rather than using a theoretical distribution to represent the fracture statistics (i.e., orientation and length), FRACK utilizes an empirical distribution for fracture statistics as derived from field observations. The use of an empirical distribution allows one to simulate sets of fractures with unique statistical properties without requiring the sets to be defined a priori. It is important to note that FRACK does not incorporate spatial relationships between fractures as is done in more complex programs by Long and Billaux (1987) and Billaux et al. (1989). The FRACK simulator creates a more or less uniform pattern of fractures, which was felt to adequately represent the fracture network within the Sands Springs Range.

The primary input parameters for the algorithm include distributions of fracture orientations (strike and dip), distributions of fracture lengths, general geometry of the grid domain, prior probabilities for each fracture category, and conditioning data describing the locations and geometry of measured fractures within the domain. The distribution of fracture orientations could not be fit satisfactorily by known statistical distributions, so an empirical distribution is used. A total of 722 measured fractures are available at the PSA and these fractures are assumed to adequately describe the parent distribution of fracture orientations. A simple transformation method is used to sample from this distribution by first sampling from a uniform $(0,1)$ distribution, then using this uniform deviate to randomly select one of the 722 fractures. The orientation of the selected fracture is used to generate a random fracture with lengths in both directions determined by randomly sampling the length distribution assigned to that orientation (described in Section 3.2.1.1). In this way, any correlation between strike, dip and length is preserved in the simulated fracture network.

The fracture zones are generated using the following algorithm:

1. The grid domain is constructed and rotated if necessary.

2. The known fractures (conditioning data) are read and saved in a lookup table.

3. The starting locations of the conditioning fractures are mapped to grid cells.

4. If duplicate fractures are found within a single grid cell then a sub-sampling is performed by first grouping the fractures according to the two major orientation thresholds described in Section 3.2.1. This allows for two fractures with unique orientations to begin in a single grid cell. The orientation is then randomly sampled according to a uniform distribution within each grouping.

5. A random fracture length is sampled depending on the fracture orientation.

6. Conditioning fractures are mapped to the grid based on their starting location, orientation and length.

7. After all of the conditioning fracture zones are mapped to the grid, the purely random fracture zones are generated. The first step is to randomly select a fracture origin and then determine the position of the fracture plane based on the orientation and length distributions. 
This process continues until the proportion of cells in Category 2 reaches the assigned prior probability. The program then outputs a three-dimensional array of fracture codes. The code is a simple integer that relates the fracture category to a specific grid cell. If the cell has not been assigned to Category 2, then it is denoted as Category 1.

The fracture map is then converted to a map of hydraulic conductivity for use in the flow model. Cells in Flow Category 2 are assigned a $K_{2}$ value by randomly sampling from the uniform distribution of hydraulic conductivity described in Section 3.2.2. A unique value of $K_{2}$ is assigned to each continuous fracture zone. Cells not containing a continuous fracture (Flow Category 1 ) are assigned an initial $K_{1}$ of $0.01 \mathrm{~m} / \mathrm{d}$.

\subsubsection{Numerical Flow Code}

By representing the PSA fractured flow system as a stochastic continuum, virtually any finite element or finite difference flow code can be used to solve the groundwater flow problem. MODFLOW-2000 (Harbaugh et al., 2000) was chosen for its public domain source, straightforward compilation on a variety of computational platforms, the ability to scale the code to the complexity of the modeling problem through the code's modular design, and its widespread acceptance in the hydrogeologic community. MODFLOW-2000 is the latest version of the code that was originally documented by McDonald and Harbaugh (1984) and received significant updates in 1988 (McDonald and Harbaugh, 1988) and in 1996 (Harbaugh and McDonald, 1996a, b).

MODFLOW-2000 (hereafter referred to as MODFLOW) uses finite difference approximation techniques to solve the general form of the groundwater flow equation in three dimensions (McDonald and Harbaugh, 1988),

$$
\frac{\partial}{\partial x}\left(K_{x x} \frac{\partial h}{\partial x}\right)+\frac{\partial}{\partial y}\left(K_{y y} \frac{\partial h}{\partial y}\right)+\frac{\partial}{\partial z}\left(K_{z z} \frac{\partial h}{\partial z}\right)+W=S_{s} \frac{\partial h}{\partial t}
$$

where

$K_{x x}, K_{y y}$ and $K_{z z}$ are values of hydraulic conductivity along the $x, y$ and $z$ axes, (L/T)

$h$ is the potentiometric head (L)

$W$ is a volumetric flux per unit volume representing sources and/or sinks of water with

positive values for flow into the groundwater system and negative values for flow out $\left(\mathrm{L}^{-1}\right)$

$S_{s}$ is specific storage of the porous material $\left(\mathrm{L}^{-1}\right)$

$t$ is time

The model domain is discretized into a grid of rectangular blocks and Equation (3.17) is solved for hydraulic head at the center of each block. When Equation (3.17) is used in conjunction with initial and boundary conditions, it describes a fully three-dimensional, transient flow system within a heterogeneous and anisotropic medium. For this study, heterogeneous conditions are modeled through the use of three-dimensional $K$ maps, but isotropic conditions are assumed (i.e., $K=K_{x x}=K_{y y}=K_{z z}$ ) within each cell. That is, the anistropy of the fractured granite is developed from the spatial orientation of the fractures and directly incorporated in the $K$ maps so that the 
spatial distribution of $K$ represents the fracture and fault geometry. As such, a conductivity ellipsoid is not required. The main PSA flow model is steady-state (i.e., $\partial h / \partial t=0$ ), though transient versions have been developed for simulation of nuclear cavity infilling (Section 4.1.2.2) and for verification of the PSA flow model (Section 6.1).

\subsubsection{Domain Description}

The domain of the PSA flow and transport model is oriented parallel to the dominant northeast-trending structural grain of the Sand Springs Range and to the shear zone that is located near Shoal surface ground zero (SGZ) and extends northeast to the land withdrawal boundary (Figure 3.12). The model domain is comprised of a randomly distributed network of high- $K$ zones representing medium and large fractures (Flow Category 2) imbedded within a low- $K$ field representing either no fractures or small fractures (Flow Category 1). Around the nuclear cavity and chimney, cells are assigned to a cavity and chimney zone, a damaged zone surrounding the cavity, and an outer zone representing the transition to the host granite aquifer (fully described in Section 3.1.2). Cells designated as the cavity and its associated damaged zones, are constant from realization to realization, though the $K$ values in these zones vary both spatially and between realizations.

The model domain size and discretization were chosen to best represent the fracture network and cavity and to provide detailed information on transport calculations, while maintaining an acceptable number of nodes for computational speed (Figure 3.13). All model cells are $19.856 \mathrm{~m}$ in the $x$ direction and $20.0 \mathrm{~m}$ in the $y$ and $z$ directions. A total of 650,325 cells is incorporated in the domain though only 414,139 cells are active in the model. The remaining 236,186 cells are located east of the shear zone and thus are not included in the flow and transport calculations. The southwest lower left corner of the grid (Figure 3.13a) is situated at 4,339,945.3 m N and 379,521.1 m E (UTM zone 11, NAD 27). The entire grid is rotated 38 degrees east from the azimuth to best accommodate the inferred direction of groundwater flow and the configurations of the shear zone and the western margin of the Sand Spring Range. The top of the grid corresponds to 1,307 m AMSL to represent the uppermost portion of the potentiometric surface, while the bottom corresponds to $7 \mathrm{~m} \mathrm{AMSL}$ (approximately 1,200 m below the potentiometric surfaces in the adjacent valleys). The total depth of $1,300 \mathrm{~m}$ is based on the results of the regional modeling and is considered deep enough to adequately simulate the vertical component of flow in the Sand Springs Range.

\subsubsection{Boundary Conditions}

Surface recharge is applied evenly across the top layer of the model using a value chosen randomly from the recharge distribution (described in Section 3.2.3) for each flow realization.

The southeastern and northwestern faces are modeled as no-flow boundaries. The southeastern boundary is aligned with the surface expression of the western edge of the shear zone, with the subsurface orientation defined by adjusting the dip to 72.5 degrees to be consistent with depths of fault gouge observed in wells HC-8, HC-7 and HC-5, as reported by IT Corporation (2000). The observed head difference of over $100 \mathrm{~m}$ between HC-7 and HC-5 suggests that the shear zone acts as a significant barrier to groundwater flow. This hypothesis is consistent with the 


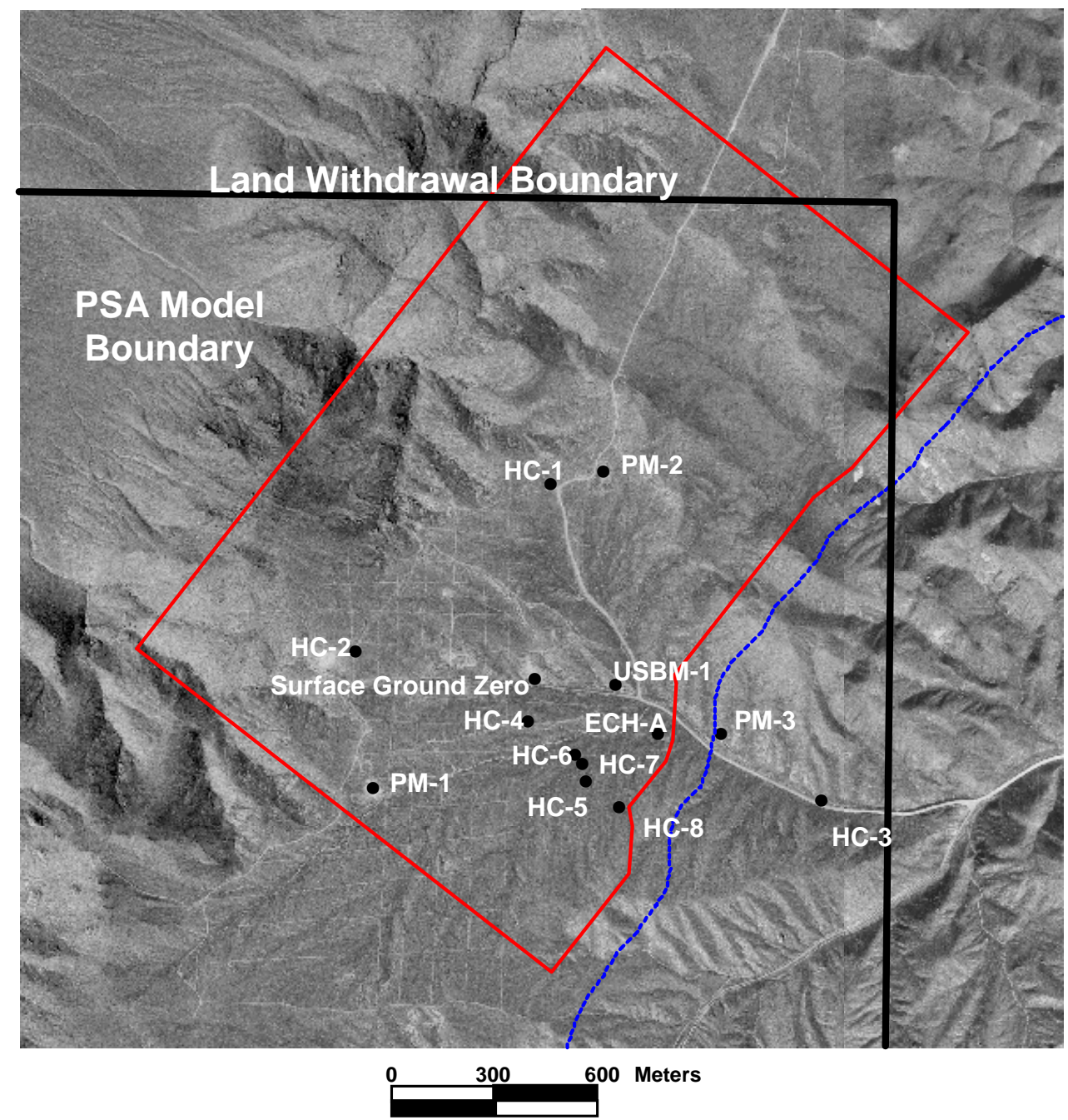

Figure 3.12. Map showing the domain of the PSA flow and transport model and its location with respect to selected land surface features and the Shoal land withdrawal boundary.

results of the regional flow modeling described in Sections 2.3 and 2.4 and the results of numerical simulations of pumping test drawdowns (Carroll et al., 2001). All cells associated with the core of the shear zone as well as all cells to the east of the shear zone are inactive (only active cells are shown in Figures 3.13a and 3.13b). The northwestern edge of the domain is roughly aligned along the western margin of the Sand Springs Range, which is assumed to coincide with the groundwater flow divide and/or flow barrier there. Hydraulic head relationships between Gote Flat and Fourmile Flat suggest the presence of a barrier to flow, perhaps contributing to this divide. The assumption is consistent with geochemical evidence that indicates flow from the Sand Springs Range is a relatively minor contribution to discharge in Fourmile Flat.

A constant head boundary condition is assigned to the northeastern (downgradient) face of the model. The heads on this boundary were extracted from the deterministic PSA-vicinity model 
and thus maintain the simulated vertical head gradient of $-3.6 \times 10^{-3}$. The heads on this boundary are not varied in the Monte Carlo analysis. The location of the northeastern boundary was chosen
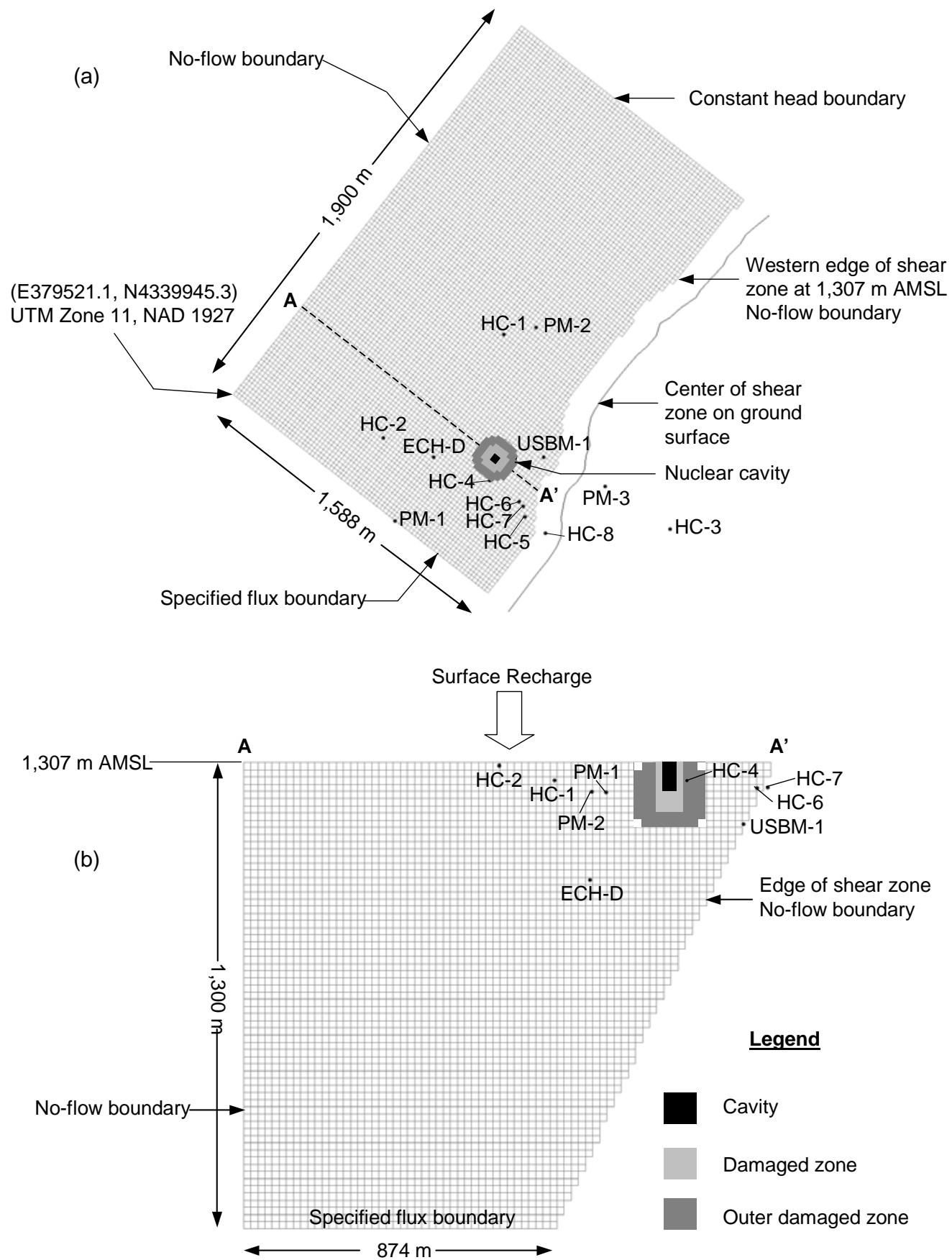

Figure 3.13. Model domain in (a) plan view and (b) cross-sectional view through line A-A'. Observation wells, boundary conditions and regions associated with the nuclear cavity are indicated. Wells are projected onto section. 
to encompass the land withdrawal boundary in that direction, incorporate wells HC-1 and PM-2, and contain simulated contaminant migration over a 1,000-year period.

The southwestern edge of the model is a specified flux boundary that simulates flux into the domain from hydraulically upgradient. The boundary condition is implemented within MODFLOW using the well package by assigning a positive volumetric flux to each active cell along the boundary face. The total volumetric flux across the boundary is treated as uncertain and is computed for each realization using the area of the upland surface contributing water to the model domain in the regional PSA model (as was described in Section 2.4.2) multiplied by the value of recharge chosen for that realization. The size of this recharge area is determined to be approximately $1,761,100 \mathrm{~m}^{2}$, which is smaller than the upland area outlined by the topographic divide because the strong vertical hydraulic gradient forces a portion of the recharge water within the topographic basin to pass below the model domain. The relative vertical distribution of flux on this boundary is obtained from the regional PSA model, and is held constant for all realizations.

Maxey (1967) hypothesized, and the current conceptual model agrees, that the horizontal component of the groundwater flow direction below the highlands of the Sand Springs Range gradually increases with depth below the water table. To preserve this pattern of flow, a portion of the groundwater that enters the flow model domain from the southwest (particularly near the bottom) must ultimately exit the model domain through the base. Therefore, the base is treated as a specified flux boundary that allows groundwater to vertically exit the model domain (Figure 3.14). The total volumetric flux assigned to this boundary is a constant 49 percent of the total volumetric flux calculated to enter the southwestern boundary, with the percentage estimated from the PSA vicinity model. As with the southwestern boundary, the specified flux boundary condition is implemented by assigning (in this case a negative) flux to each active cell on the boundary; likewise, the total base flux is uncertain because its value is directly linked to the random value of recharge chosen for each realization.

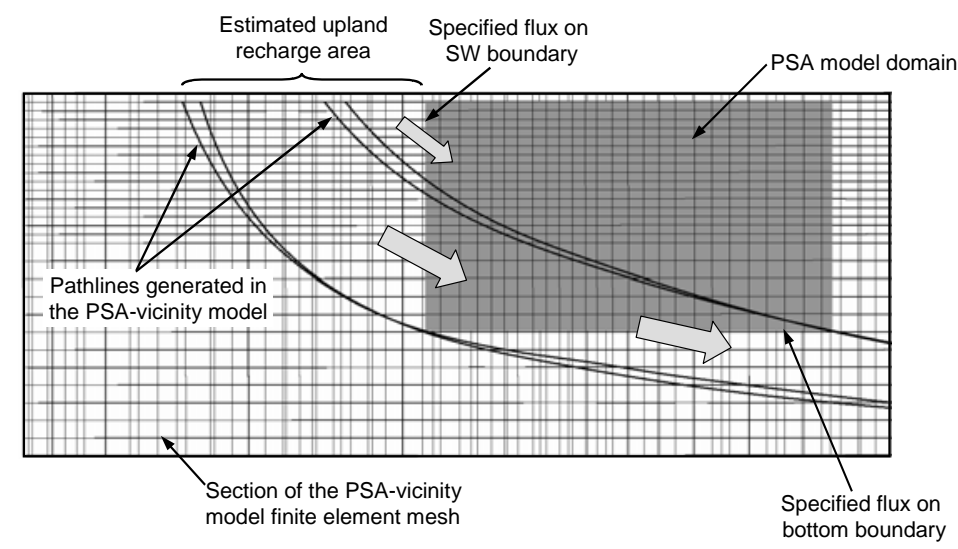

Figure 3.14. Diagram showing patterns of groundwater flow resulting from recharge in the upland area to the southwest of the PSA model domain. Pathlines and internal flux values in the PSA vicinity model were used to determine the proportion of flux entering the PSA domain through the vertical southwest boundary and leaving the domain through the base. 


\subsubsection{Calibration Process}

The Monte Carlo simulations are performed by a PERL script that executes FRACK, MODFLOW and the associated supporting codes, in addition to managing all the input and output files. For each realization, the script generates the following information:

1. A fracture map using observed conditioning data and the FRACK program.

2. Boundary conditions via the MODFLOW recharge, well and constant head packages. Note that the flux boundaries are determined from a randomly selected recharge and the head boundaries are constant for each realization.

3. A hydraulic conductivity field based on the fracture map and random samples for each cell in Flow Category 2. An initial guess for the hydraulic conductivity for Flow Category 1 is also provided to PEST. The hydraulic conductivity values for the cavity region and the related surrounding zones are selected from the appropriate distributions and assigned at this stage.

4. MODFLOW and PEST are executed and the hydraulic conductivity value for Flow Category 1 is automatically calibrated.

5. Upon successful calibration, the simulated hydraulic head, conductivity, fracture code, and recharge data are saved for use in the transport calculations. Summary statistics such as the root-mean-squared error between simulated and observed hydraulic head, and effective conductivities along the three axes, are saved.

The inverse method performed by PEST is CPU-intensive, but greatly increases the accuracy of each realization, as the hydraulic conductivity for Flow Category 1 is determined such that heads are in agreement with measured values. In this study, measured water levels at wells PM-1, PM-2, ECH-D, HC-1, HC-2, HC-4, HC-6 and HC-7 are used as observation values. It is important to note that data obtained from PM-1, PM-2 and ECH-D are considered questionable and therefore are weighted arbitrarily one-hundredth less in sensitivity and error calculations. PEST utilizes a nonlinear regression algorithm to minimize the weighted sum-ofsquared-error between simulated and observed hydraulic heads to determine the optimum value for the hydraulic conductivity of Flow Category 1.

The inversion algorithm used in PEST is essentially the same as UCODE (Poeter and Hill, 1998), and MODFLOW, but numerical testing showed that PEST tended to be a more efficient and stable algorithm for groundwater flow model inversion. Likewise, other inverse codes provide a similar approach and similar calibration estimates, but with a larger computational demand, so little would be gained by choosing a different algorithm.

\subsubsection{Bayesian Weighting Procedure}

In an effort to honor site-specific data throughout the modeling process, the Generalized Likelihood Uncertainty Estimator (GLUE) algorithm is applied (Beven and Binley, 1992) such that flow realizations that are in good agreement with field data receive a larger relative weight 
than those that were in poor agreement. The GLUE procedure is an extension of Monte Carlo random sampling to incorporate the goodness-of-fit of each simulation. A likelihood measure is an evaluation of the quantitative goodness-of-fit. For example, in this study, the likelihood is defined as:

$$
L(\vec{Y} \mid \vec{\Theta})=\left[\sum(\varepsilon)^{2}\right]^{-N}
$$

where

$$
\varepsilon=h_{i}^{s i m}-h_{i}^{o b s}
$$

and, $L(\vec{Y} \mid \vec{\Theta})$ is the likelihood of the vector of outputs, $\vec{Y}$, knowing $\vec{\Theta}$, the vector of random inputs; $h_{i}^{\text {sim }}$ is the simulated head at the point $i$; $h_{i}^{o b s}$ is the observed head at that point; and $N$ is a likelihood shape factor. Although the choice of the $N$ factor is subjective, its value defines its relative function. As $N$ approaches zero, the likelihood approaches unity, and each simulation then has equal weight, as is the case with traditional Monte Carlo analysis. As $N$ approaches infinity, the simulations with the lowest sum of squares error (the simulations that best fit the field data) receive essentially all of the weight, which is analogous to an inverse solution. In this study, the value of $N$ is assumed to be unity, which is a typical value used in this type of analysis (Beven and Binley, 1992; Freer et al., 1996; Franks and Beven, 1997; Morse et al., 2003).

Each realization is weighted based on an application of Bayes equation in the form:

$$
P(\vec{\Theta} \mid \vec{Y})=\frac{L(\vec{Y} \mid \vec{\Theta}) P(\vec{\Theta})}{C}
$$

where $P(\vec{\Theta})$ is the prior probability of the input parameters as determined by the Monte Carlo process, $L(\vec{Y} \mid \vec{\Theta})$ is the likelihood measure from Equation (3.18), C is a normalization constant, and $P(\vec{\Theta} \mid \vec{Y})$ is the posterior density. The posterior density is the probability of the input parameters occurring after taking into account the likelihood measure and is used to calculate the contaminant boundary as described in Section 4.2.2. The weights for individual realizations are determined by Equation (3.20), which is simply a normalization of the likelihood such that the sum of the weights for all realizations is unity. 


\subsection{Results of Flow Model}

\subsubsection{Hydraulic Conductivity Calibration}

One thousand Monte Carlo realizations of the flow field were produced as described in Section 3.3.5. Table 3.9 presents summary statistics of recharge rates, calibrated $K_{1}$ values, RMSE values at monitoring well locations, simulated vertical gradient between model layers 24 and 40, and the percent discrepancy in mass-balance calculations.

Mass-balance errors ranged from near zero to 2.97 percent, though only four of the 1,000 realizations showed errors exceeding one percent. When weighted by the Bayesian likelihoods, these four realizations together account for 0.1 percent of the total, thus the 99.9 percent confidence bounds represent mass-balance errors of less than one percent.

The simulated hydraulic conductivity distribution for Flow Category 1 ranges from $5.8 \times 10^{-9} \mathrm{~m} / \mathrm{d}$ to $1.0 \mathrm{~m} / \mathrm{d}\left(\log _{10} K_{1}\right.$ range of -8.24 to 0.0 ) (Figure 3.15). For comparison, Category 2 is assigned $K_{2}$ values in the range from $1 \times 10^{-5}$ to $1.0 \mathrm{~m} / \mathrm{d}$, and as a result, the majority of the fluid flux is within $K_{2}$ cells and is controlled by oriented fractures. In approximately two thirds of the realizations, the calibrated $K_{1}$ value exceeds the lower limit of the range of assigned $K_{2}$ values. In these realizations, hydraulic conductivity is high in both flow categories and consequently flow is less constrained to $K_{2}$ cells, although it remains that in most realizations the majority of the fracture zones have Table 3.9. Summary statistics for the results of the PSA flow model.

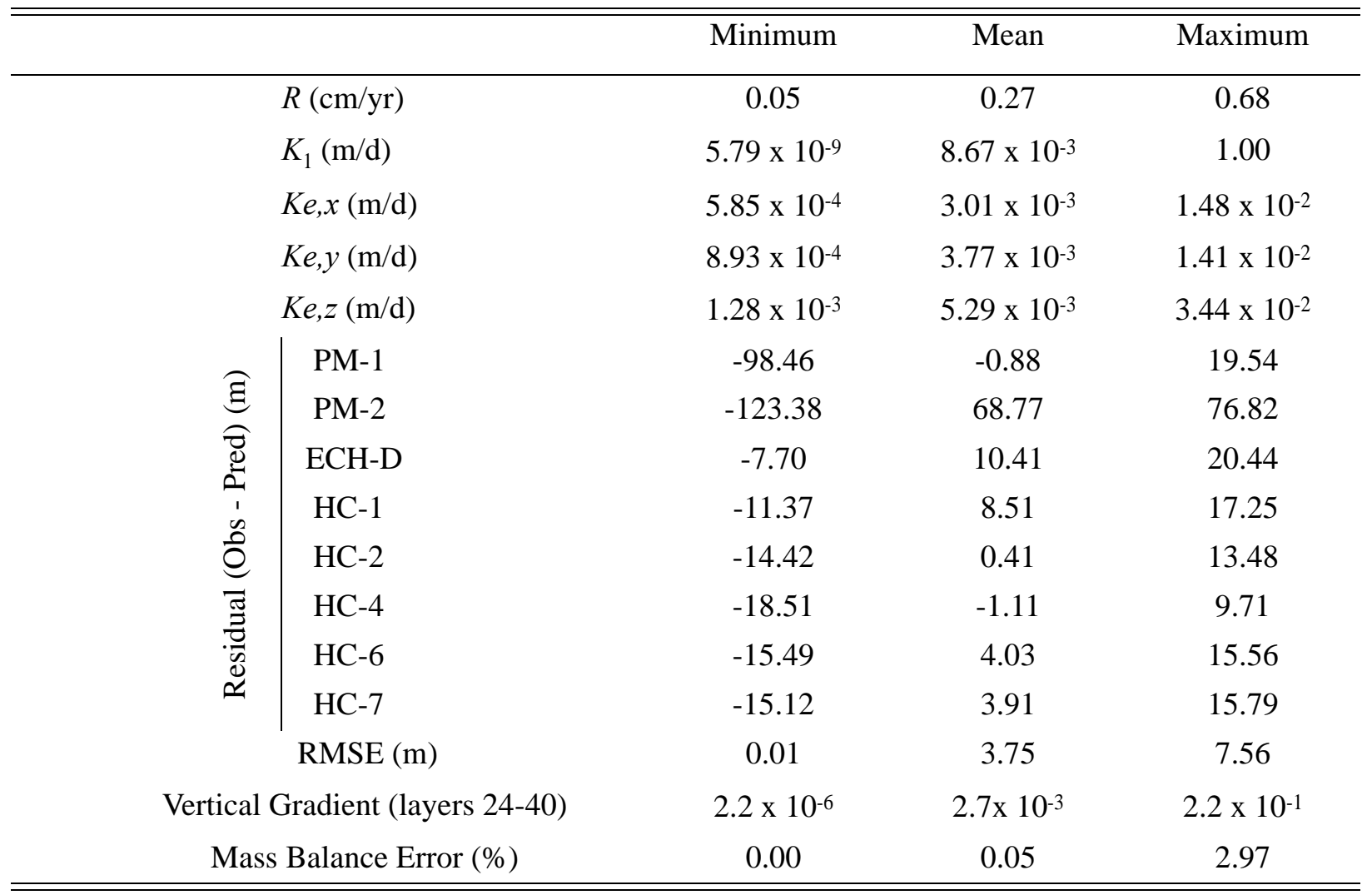


hydraulic conductivity values that exceed the $K_{1}$ for that realization. It is important to note that the same value of effective porosity is used for both categories, which is why the hydraulic conductivity distribution controls the behavior of the flow field.

The ability of the model to equilibrate to the assigned recharge is indicated by the positive correlation between recharge and $K_{1}$ (Figure 3.15a) at a correlation coefficient of 0.76. Because assigned $K_{2}$ values are independent of the choice of recharge, the model calibrates to higher $K_{1}$ values to maintain mass balance at higher assigned recharge values. The scatter observed in the $K_{1} / R$ relationship is attributed to variations between realizations of fracture position, fracture orientation and fracture hydraulic conductivity.

(a)

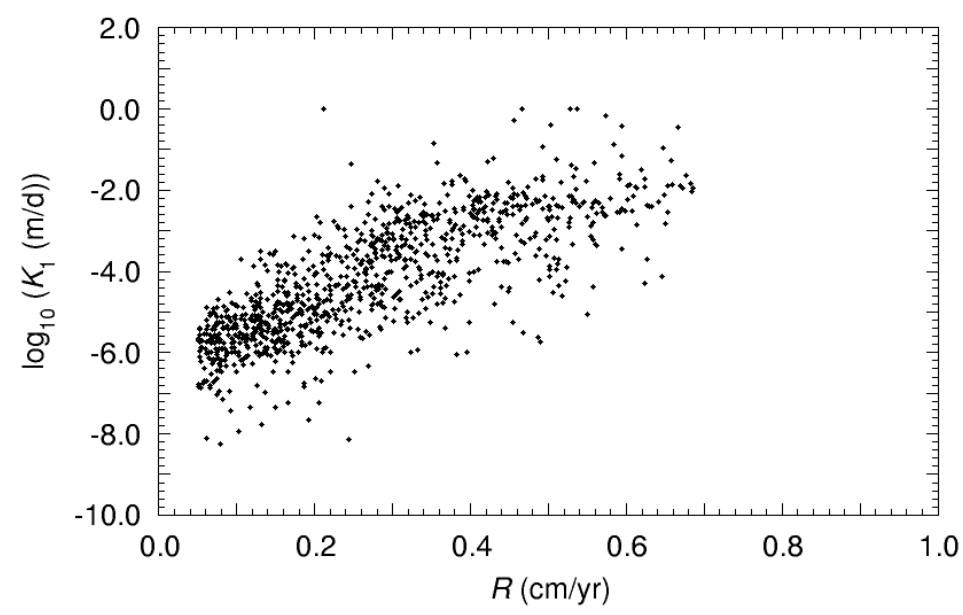

(b)

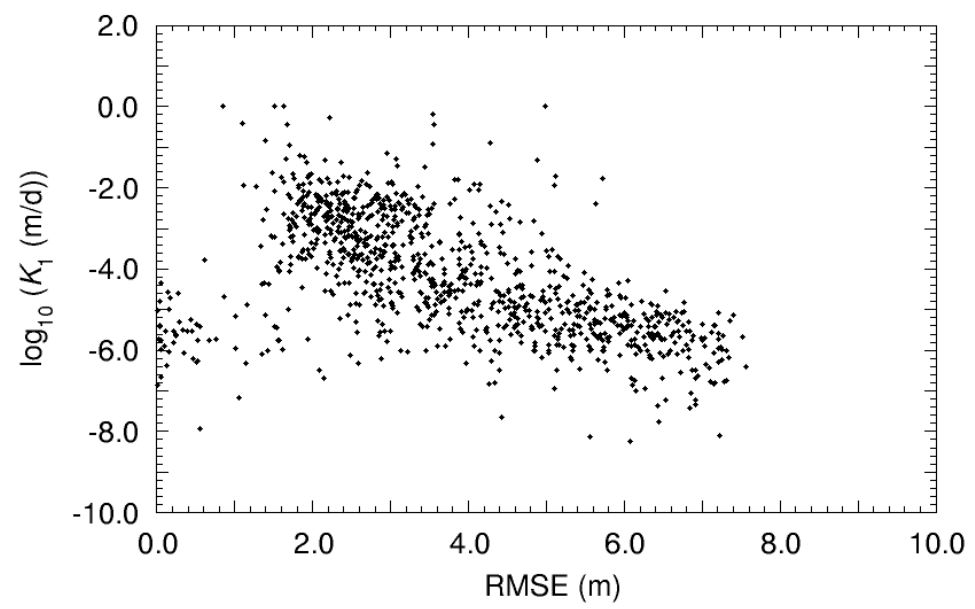

Figure 3.15. Plots of (a) calibrated $K_{1}$ values verses recharge values, and (b) calibrated $K_{1}$ values versus RMSE. 
Figure 3.15b shows the relationship between RMSE and $\log _{10} K_{1}$ and indicates that no strong correlation between $K_{1}$ and RMSE is evident. Again, the scatter observed in this relationship is caused by variability in the flow fields. It should be noted that realizations are weighted in concordance with the inverse of their RMSE, so those having high RMSE receive less weight in the boundary map calculations. It is also important to note that 95 percent of the RMSE values fall between 0.3 and $7.2 \mathrm{~m}$.

The relationship of calibrated $K_{1}$ values to values of $K_{2}$ chosen from the input distribution is shown on Figure 3.16. On this histogram, the $K_{1}$ bars represent the distribution of $K_{1}$ for all 1,000 realizations and the $K_{2}$ bars represent the distribution of $K_{2}$ values from 10 randomly selected realizations. Though each PDF corresponds only to its own flow category, the overall shape of the histogram approximates the simulated distribution of hydraulic conductivity for the entire set of 1,000 realizations. The simulated distribution of $K$ compares well with the field measurements shown on Figure 3.8. The median of both distributions is centered around $\log _{10} K$ values of -2.5 to -3.0, though the model incorporates $K$ values that are both higher and lower than those observed in the field. At the upper end, the extended tail of the simulated distribution represents very conductive fracture zones that may not have been observed or tested in the field, but are reasonable to expect in a fractured granite. Including these high $K$ values is considered a conservative assumption with respect to estimating groundwater flow velocities. The absence of field measurements of very low $K$ values is expected as a result of limitations in borehole testing methods and time; however, the model includes values in the lower portion of the distribution by assigning them to Flow Category 1, within which very few or no fractures occur.

An additional check of the simulated $K$ distribution was conducted by calculating the effective $K$ in each of the three model coordinate directions. Three independent flow models were constructed, each of which utilize boundary conditions that produce groundwater flow in one of the three coordinate directions through the domain. For example, one model incorporates no-flow boundaries on all four lateral faces of the domain, while the top and bottom faces are treated as specified head boundaries with the heads assigned such that a unit gradient is produced from the top of the model to the base. Recharge from precipitation was not included in these models, nor were any other sources or sinks. All 1,000 $\mathrm{K}$ maps simulated by the PSA model were used as input to MODFLOW, which was run in PEST calibration mode to determine the optimum value of $K$ in each coordinate direction. The resulting values of effective $K$ (shown in Table 3.9) are consistent with and supported by the homogeneous $K$ value of $3.4 \times 10^{-3} \mathrm{~m} / \mathrm{d}$ obtained from modeling the tracer test pumping. Note that the tracer test model, though smaller in size and cell spacing as compared to the PSA flow model, also represents flow at a scale approximating the scale of radionuclide transport at Shoal. The fact that these two independent models that apply different approaches to solving the flow problem arrive at very similar results represents another confirmation of the validity of the data interpretation and modeling approach.

The effective $K$ results also suggest near isotropicity in the horizontal directions and a possible low degree of anisotropy between the horizontal and vertical directions $\left(K_{x y} / K_{z}=0.64\right.$, indicating that vertical conductivity is slightly higher than horizontal). Although this vertical 
anisotropy may promote some vertical flow within the model, the wide range of variability of $K$ in all directions probably masks this effect.

\subsubsection{Distributions of Fracture Zones and Hydraulic Head}

Figure 3.17 shows the distribution of fracture zones, $K$, and hydraulic head for three flow realizations. As defined by the fracture conditioning data and orientation statistics, the fracture zones dip both toward the northwest and southeast with a predominantly northeast strike. Although the conditioning data are concentrated near the upper portion of the domain, the fracture zones are evenly distributed throughout the domain such that transport pathways are present throughout the model.

The realizations shown on Figure 3.17 illustrate simulated head distributions for selected combinations of input parameters. Realizations 544 and 155 represent minimum and maximum $R$ values, respectively, of the 1,000 flow realizations. Realization 933 represents a realization with moderate $R$ and a value of $K_{1}$ that exceeds the minimum of the $K_{2}$ distribution. Statistics of the simulation results for these realizations are listed in Table 3.9.

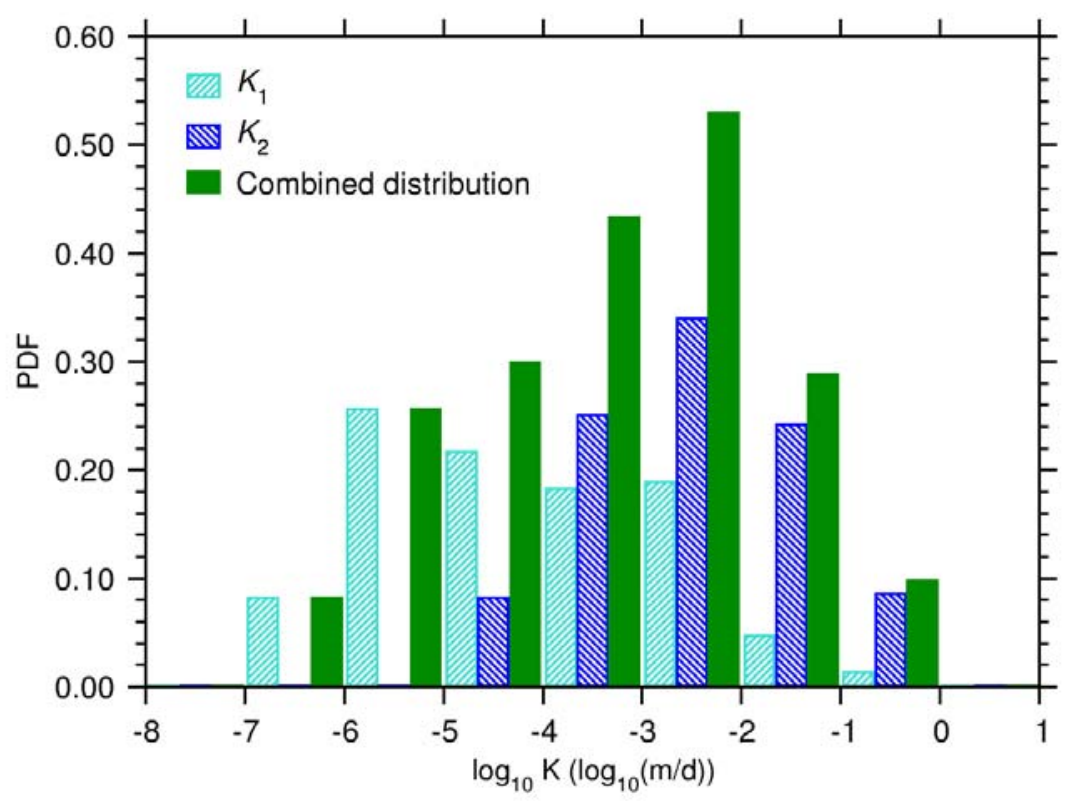

Figure 3.16. Composite histogram showing calibrated $K_{1}$ values for the 1,000 realizations, $K_{2}$ values for 10 randomly selected realization, and a composite histogram representing the complete simulated distribution of $K$. 

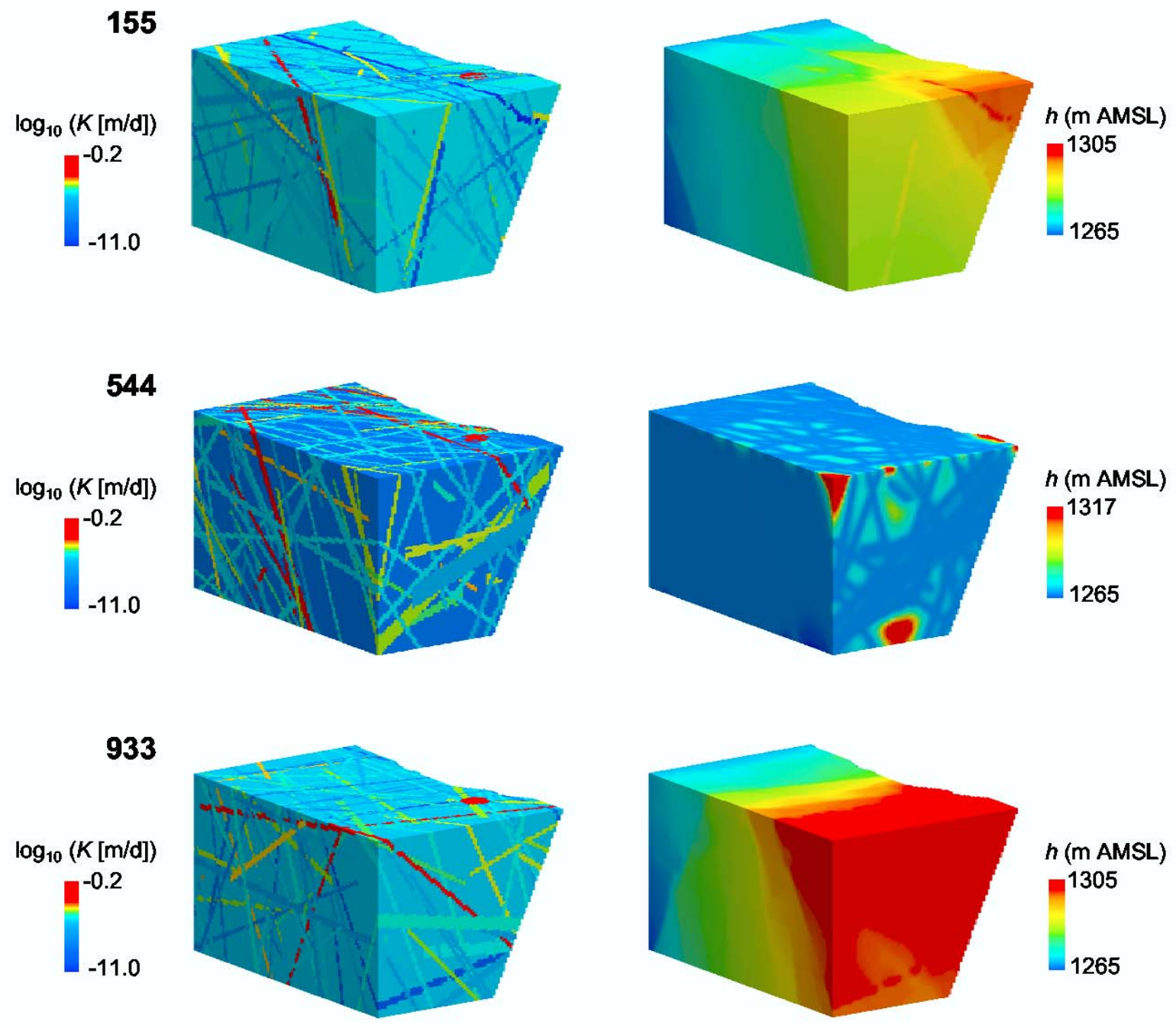

Figure 3.17. Fracture network (on the left) and associated head distributions (on the right) for realizations 155, 544 and 933.

For realizations having very low calibrated $K_{1}$ values, flow is concentrated in the fracture zones. These realizations show some mounding at the water table and high vertical gradients in regions with no fractures, as indicated for realization 544 by the higher simulated head values contoured in Figure 3.17. This mounding results from the inability of large zones of unfractured granite to readily accept all of the applied recharge and is a relatively local effect. The flow model calibration process rejects cases where combinations of $R, K_{1}$ and $K_{2}$ cannot provide an adequately calibrated flow realization.

In those cases where $K_{1}$ is high and $R$ is moderate to high (realizations 933 and 155, respectively), flow is less restricted to fractured zones and becomes more homogeneous. Though 
Table 3.9. S Simulated model values for selected flow realizations shown in Figure 3.17.

\begin{tabular}{cccc}
\hline \hline Realization \# & 544 & 155 & 933 \\
& Low $K_{1}$ & High $K_{1}$ & High $K_{1}$ \\
& Low $R$ & High $R$ & Average $R$ \\
\hline$R(\mathrm{~cm} / \mathrm{yr})$ & 0.05 & 0.68 & 0.37 \\
$K_{1}(\mathrm{~m} / \mathrm{d})$ & $7.93 \times 10^{-7}$ & $1.09 \times 10^{-2}$ & $3.06 \times 10^{-3}$ \\
RMSE $(\mathrm{m})$ & 1.35 & 3.35 & 2.46 \\
\hline \hline
\end{tabular}

the fracture network dominates the modeled hydrology of the PSA, the complex interdependency between the fracture network (location, orientation, $K_{1}$ values) and recharge makes it difficult to broadly generalize on flow results. The stochastic approach used in the model accounts for the uncertainty in these aspects of the system and incorporates this uncertainty in the variability of the flow results.

\subsubsection{Simulated Vertical Gradient}

Little information exists for the deeper sections of the model, creating uncertainty in estimates of vertical gradients. Open borehole measurements taken during the drilling of ECH-D (Hazelton-Nuclear Science, 1965) suggest a vertical gradient approaching 0.5. More recent data collected at wells HC-8 and HC-5 indicate a vertical gradient of approximately 0.01. However, these wells extend through the shear zone and their intakes are outside the domain of the PSA flow and transport model. Here, we compare modeled results with the measured gradient at HC-8 and HC-5, assuming that similar vertical gradients exist on either side of the shear zone. The elevation at the base of the HC-8 screen is $868.4 \mathrm{~m}$ AMSL, while the elevation at the top of the HC-5 screen is $567.7 \mathrm{~m}$ AMSL. The vertical gradient between the corresponding model layers was computed midway between SGZ and the southern boundary face to avoid possible influence by both the cavity cells and the southern boundary condition. The mean simulated vertical gradient is lower than the observed value ( $2.7 \times 10^{-3}$ compared to 0.01 ), however, the field measurement falls well within the range of simulated values (see Table 3.9). Note that vertical gradients are particularly variable near the top of the model where recharging groundwater intersects a wide range of $K$ values, both spatially and between realizations. 


\subsection{PSA TRANSPORT MODEL}

\subsection{Components of the Conceptual Transport Model}

The migration of contaminants from the Shoal underground nuclear test involves a complex system of physical and chemical processes. Some of these processes are the subject of ongoing research conducted by the U.S. Department of Energy. Results from these research programs are used here to refine and improve assumptions used in the previous Shoal transport analysis. A diagrammatic representation of the transport model source and processes considered is shown in Figure 4.1. The relationships between data and supportive modeling activities that contributed to the PSA transport model are shown in Figure 4.2.

The contaminants are the radionuclides produced by the Shoal test and the daughters that are created by radioactive decay. The test design was relatively simple, with sand stemming, such that non-radioactive species are not a concern (Pohll et al., 1998). Most of the radionuclide mass is assumed to be located within the cavity, however, a small portion is distributed throughout a wider fractured region around the cavity. Nuclides are not placed into the unsaturated zone in the model, though it is possible that some were forced upward by the explosion. Neglecting possible contaminant movement in the unsaturated zone is consistent with the eventual return of most volatile nuclides back to the water table by downward movement of recharge water, and as such, conservatively overpredicts starting nuclide masses.

Radionuclides are apportioned according to their volatility among surface deposits and volume deposits in nuclear melt glass. Volatile and surface-deposited nuclides are assumed to migrate once hydraulic equilibrium conditions are reached (see below). Nuclides within the glass

are released according to glass dissolution rates calculated based on glass dissolution behavior and radionuclide melt glass characteristics.

It is assumed that no migration of radionuclides occurs until the cavity has infilled with groundwater, following the dewatering caused by the thermal and compressional forces of the nuclear test. This assumption neglects any molecular diffusion that occurs during the infill period, presuming that the flow of low-contaminant-concentration groundwater toward the hydraulic sink is much larger than the movement of contaminants away from the sink driven by concentration gradients.

Once released, the radionuclides are subjected to retardation processes. Diffusion of contaminants from fractures into surrounding matrix blocks is considered. Parameters for simulating retardation and diffusion processes are estimated from laboratory and field-scale experimental results. Nuclides are grouped according to assumed general sorptive behavior and assigned the same retardation factor because radionuclide-specific data are not available for many of the contaminants in the Shoal environment.

The transport calculations are performed using a particle tracking method. An initial mass is released and its movement tracked through the model domain. All of the contaminant masses used in the transport modeling are assigned a value of one. The results can then be scaled by the 


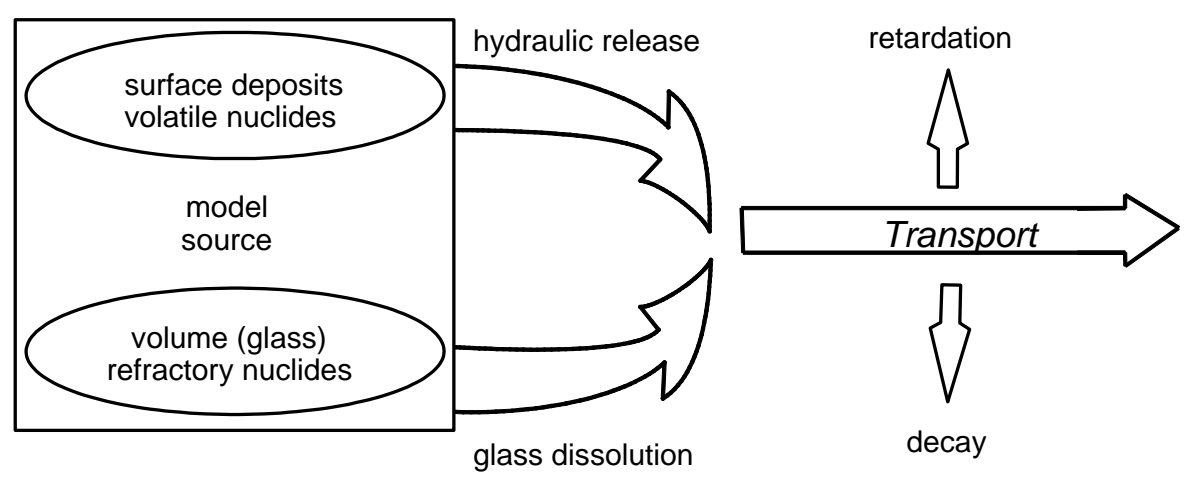

Figure 4.1. Flow chart of the transport model source and processes considered.

classified masses available in Goishi et al. (1995). Unclassified estimates of the tritium $\left({ }^{3} \mathrm{H}\right),{ }^{90} \mathrm{Sr}$, ${ }^{137} \mathrm{Cs}$, and ${ }^{151} \mathrm{Sm}$ produced by Shoal are available in Hazelton-Nuclear Science (1965). These unclassified values are used to scale the results for presentation in this report and to present examples of the types of contaminant boundary maps that will be produced with the classified data.

The various aspects of the transport model are described below, along with the data supporting parameter selection. First, the source term is described in more detail. This is followed by a discussion of release functions, including the apportioning of radionuclides among surface and volume (nuclear melt glass) deposits, calculation of a hydraulic release rate, and development of the nuclear melt glass dissolution function. Attention is then turned to the role of the geologic medium in transport. This begins with a discussion of the transport characteristics of the site interpreted from the tracer test and the implications for the transport model. Information from the tracer test, augmented by laboratory experiments, is then used to describe parameter selection for porosity and for the retardation processes of sorption and matrix diffusion.

\subsubsection{Radionuclide Source Term}

Contaminants resulting from underground nuclear testing can be divided into two broad categories: radionuclides and nonradionuclides. Primary radionuclides can be attributed to three possible origins: 1 ) residual nuclear material that has not undergone a fission or thermonuclear reaction, 2) direct products of the nuclear reactions (fission products and tritium), and 3) activation products induced by neutron capture in the immediate vicinity of the explosion (Borg et al., 1976). In addition, radionuclide daughter products are produced by decay of many of the primary radionuclides. Nonradionuclide hazardous materials have been identified for some tests at the NTS (Bryant and Fabryka-Martin, 1991), though the relative simplicity of the Shoal test indicates they are not an issue at this site (Pohll et al., 1998).

The Shoal radionuclide source term is included in an inventory prepared by Los Alamos and Lawrence Livermore national laboratories for nuclear tests conducted at non-NTS locations 


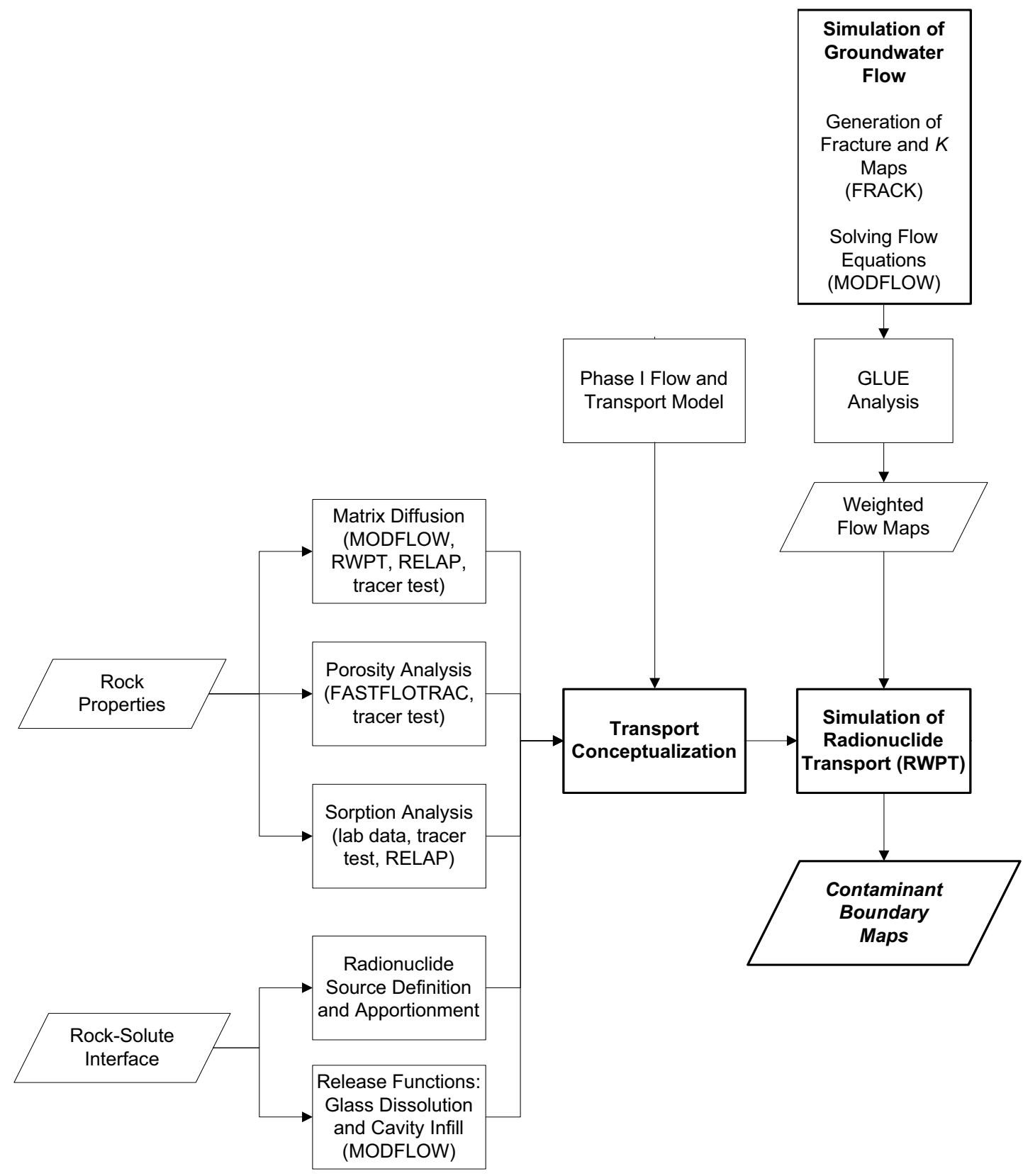

Figure 4.2. Relationships between data and supportive modeling activities that contributed to the simulation of radionuclide transport in the PSA model. Refer to Figure 2.1 for other aspects relating to the flow modeling.

(Goishi et al., 1995). The inventory presented in Goishi et al. (1995) represents the total radiologic source term, given one constraint: radionuclides were excluded from the inventory if they were produced in such low amounts or decayed so rapidly that if the total amount produced during the test was dissolved into a volume of water equal to the volume of the cavity and allowed to decay for 100 years, the resulting aqueous concentration would be less than one-tenth of the maximum permissible concentration (MPC) (Smith et al., 1995). This effectively eliminates 
radionuclides with half-lives less than about 10 years from the inventory. The Goishi et al. (1995) reference is a classified document; however, Smith et al. (1995) discuss uncertainties associated with the source term for the NTS in an unclassified publication that relied on a classified radionuclide inventory for the NTS (Goishi et al., 1994). The radionuclides reported by Smith et al. (1995) do not necessarily have a one-to-one correspondence to those presented by Goishi et al. (1995), but they are presented here to provide consideration of the gamut of release functions and retardation behavior expected for the Shoal source (Table 4.1). Daughter products of these radionuclides are presented in Table 4.2.

A shorter list of radionuclides of significance for remedial investigations at the NTS has also been compiled considering the 56 radionuclides presented by Goishi et al. (1994) for the NTS, and eight additional radionuclides with half-lives less than 10 years that have been encountered in samples of cavity fluids (Smith, 1997). This shorter list is based on the production of a radionuclide in a nuclear test, the relative mobility of the radionuclide determined from historical observations, and the health effects of the radionuclide relative to a total body or organ dose. The radionuclides listed in Table 4.1 that are considered significant by Smith (1997) are indicated on the table.

The mass data for the radionuclides produced by the Shoal test remain classified and cannot be presented in a public document. Calculations are performed here using a unit value for starting mass. The unit-mass-based transport analyses can be converted to true mass in a classified companion document. A result of this approach is that the precise inventory considered for transport needs not be determined in this unclassified work; rather, it is only necessary to include a class of release and retardation to coincide with every radionuclide used later. These unique "classes" are then subjected to the flow and transport calculations and the results retained for scaling with the classified data.

Unclassified calculations of radionuclide production from Shoal are presented by HazeltonNuclear Science (1965). These unclassified estimates are used in this report for demonstrating the scaling process and contaminant boundary calculation. The Hazelton-Nuclear Science estimate for production of tritium is $3.0 \times 10^{4} \mathrm{Ci}$, for ${ }^{90} \mathrm{Sr}$ is $1.9 \times 10^{3} \mathrm{Ci}$, for ${ }^{137} \mathrm{Cs}$ is $2.2 \times 10^{3} \mathrm{Ci}$, and for ${ }^{151} \mathrm{Sm}$ is $4.2 \times 10^{2} \mathrm{Ci}$.

\subsection{2 $\underline{\text { Release Functions }}$}

Radionuclides produced by an underground nuclear test are present in three basic forms: gases, surface deposits, and volume deposits (Smith et al., 1995), the proportions of which can change with time after the detonation. Immediately after the detonation, essentially all of the radionuclides are part of a superheated, expanding gas (Borg et al., 1976). When the temperature and pressure start to drop, many of the gases condense. The condensation occurs based on the boiling point of the nuclide, with the higher boiling points (first to condense) referred to as refractory nuclides, and the lower boiling point species referred to as volatile. A high percentage the refractory species are trapped in the solidifying melt, much of which collects at the base of 
Table 4.1. List of radionuclides important for investigations of transport from underground nuclear tests, as presented by Smith et al. (1995).

\begin{tabular}{|c|c|c|}
\hline Nuclide & On List of Significant Nuclides* & Half-life (y) \\
\hline${ }^{3} \mathrm{H}$ & $\mathrm{X}$ & 12.3 \\
\hline${ }^{10} \mathrm{Be}$ & & $1.6 \times 10^{6}$ \\
\hline${ }^{14} \mathrm{C}$ & $\mathrm{X}$ & 5,730 \\
\hline${ }^{22} \mathrm{Na}$ & & 2.605 \\
\hline${ }^{26} \mathrm{Al}$ & & $7.3 \times 10^{5}$ \\
\hline${ }^{36} \mathrm{Cl}$ & $\mathrm{X}$ & $3.01 \times 10^{5}$ \\
\hline${ }^{39} \mathrm{Ar}$ & & 269 \\
\hline${ }^{41} \mathrm{Ca}$ & & $1.03 \times 10^{5}$ \\
\hline${ }^{53} \mathrm{Mn}$ & & $3.7 \times 10^{6}$ \\
\hline${ }^{59} \mathrm{Ni}$ & & $7.6 \times 10^{4}$ \\
\hline${ }^{60} \mathrm{Co}$ & $\mathrm{X}$ & 5.271 \\
\hline${ }^{63} \mathrm{Ni}$ & & 100 \\
\hline $65 \mathrm{Zn}$ & & 0.66 \\
\hline${ }^{79} \mathrm{Se}$ & & $1.13 \times 10^{6}$ \\
\hline${ }^{81} \mathrm{Kr}$ & & $2.1 \times 10^{5}$ \\
\hline $85 \mathrm{Kr}$ & $\mathrm{X}$ & 10.7 \\
\hline${ }^{90} \mathrm{Sr}$ & $\mathrm{X}$ & 29.1 \\
\hline $93 \mathrm{Zr}$ & & $1.5 \times 10^{6}$ \\
\hline $92 \mathrm{gNb}$ & & $3.6 \times 10^{7}$ \\
\hline $93 \mathrm{~m} N$ & & 16.1 \\
\hline${ }^{94} \mathrm{Nb}$ & & $2.0 \times 10^{4}$ \\
\hline${ }^{93} \mathrm{Mo}$ & & 4,000 \\
\hline${ }^{98} \mathrm{Tc}$ & & $4.2 \times 10^{6}$ \\
\hline 99gTc & $\mathrm{X}$ & $2.13 \times 10^{5}$ \\
\hline${ }^{106} \mathrm{Ru}$ & $\mathrm{X}$ & 1.020 \\
\hline${ }^{107} \mathrm{Pd}$ & & $6.5 \times 10^{6}$ \\
\hline${ }^{113 \mathrm{~m} C d}$ & & 14.1 \\
\hline 121mSn & & 55 \\
\hline${ }^{125} \mathrm{Sb}$ & $\mathrm{X}$ & 2.758 \\
\hline${ }^{126} \mathrm{Sn}$ & & $\sim 1.0 \times 10^{5}$ \\
\hline${ }^{129} I$ & $\mathrm{X}$ & $1.57 \times 10^{7}$ \\
\hline${ }^{134} \mathrm{Cs}$ & $\mathrm{X}$ & 2.065 \\
\hline
\end{tabular}


Table 4.1 List of radionuclides important for investigations of transport from underground nuclear tests, as presented by Smith et al. (1995). (Continued)

\begin{tabular}{|c|c|c|}
\hline Nuclide & On List of Significant Nuclides & Half-life (y) \\
\hline${ }^{135} \mathrm{Cs}$ & & $2.3 \times 10^{6}$ \\
\hline${ }^{137} \mathrm{Cs}$ & $\mathrm{X}$ & 30.17 \\
\hline${ }^{146} \mathrm{Sm}$ & & $1.03 \times 10^{8}$ \\
\hline${ }^{151} \mathrm{Sm}$ & $\mathrm{X}$ & 90 \\
\hline${ }^{150} \mathrm{Eu}$ & & 36 \\
\hline${ }^{152} \mathrm{Eu}$ & $\mathrm{X}$ & 13.48 \\
\hline${ }^{154} \mathrm{Eu}$ & $\mathrm{X}$ & 8.59 \\
\hline 166m Ho & & $1.2 \times 10^{3}$ \\
\hline 178mHf & & 31 \\
\hline $186 \mathrm{~m} R e$ & & $2.0 \times 10^{5}$ \\
\hline 192m Ir & & $2.4 \times 10^{2}$ \\
\hline${ }^{193} \mathrm{Pt}$ & & 50 \\
\hline${ }^{205} \mathrm{~Pb}$ & & $1.5 \times 10^{7}$ \\
\hline${ }^{210} \mathrm{~Pb}$ & & 22.3 \\
\hline${ }^{231} \mathrm{~Pa}$ & & $3.28 \times 10^{4}$ \\
\hline${ }^{232} \mathrm{Th}$ & & $1.40 \times 10^{10}$ \\
\hline${ }^{232} \mathrm{U}$ & & 70 \\
\hline $233 \mathrm{U}$ & & $1.592 \times 10^{5}$ \\
\hline${ }^{234} \mathrm{U}$ & $\mathrm{X}$ & $2.46 \times 10^{5}$ \\
\hline $235 \mathrm{U}$ & & $7.04 \times 10^{8}$ \\
\hline${ }^{236} \mathrm{U}$ & & $2.342 \times 10^{7}$ \\
\hline${ }^{238} \mathrm{U}$ & $\mathrm{X}$ & $4.47 \times 10^{9}$ \\
\hline${ }^{237} \mathrm{~Np}$ & $\mathrm{X}$ & $2.14 \times 10^{6}$ \\
\hline${ }^{238} \mathrm{Pu}$ & & 87.7 \\
\hline${ }^{239} \mathrm{Pu}$ & $\mathrm{X}$ & $2.410 \times 10^{4}$ \\
\hline${ }^{240} \mathrm{Pu}$ & $\mathrm{X}$ & $6.56 \times 10^{3}$ \\
\hline${ }^{241} \mathrm{Pu}$ & & 14.4 \\
\hline${ }^{242} \mathrm{Pu}$ & & $3.75 \times 10^{5}$ \\
\hline${ }^{241} \mathrm{Am}$ & $\mathrm{X}$ & 432.7 \\
\hline${ }^{243} \mathrm{Am}$ & & $7.37 \times 10^{3}$ \\
\hline${ }^{244} \mathrm{Cm}$ & & 18.1 \\
\hline
\end{tabular}

${ }^{*}$ On the list of radionuclides recommended by the UGTA Source and Transport Subcommittee of significance for remedial investigations at the Nevada Test Site (Smith, 1997) 
Table 4.2. Daughter products in the decay chains generated by radionuclides in Table 4.1. This list includes neither daughters produced by parents with a half-life of 10,000 years or greater, nor gaseous daughters.

\begin{tabular}{cc}
\hline \hline Nuclide & Half-life (y) \\
\hline${ }^{39} \mathrm{~K}$ & stable \\
${ }^{63} \mathrm{Cu}$ & stable \\
${ }^{85} \mathrm{Rb}$ & stable \\
${ }^{90} \mathrm{Y}$ & $7.3 \times 10^{-3}$ \\
${ }^{90} \mathrm{Zr}$ & stable \\
${ }^{113} \mathrm{In}$ & stable \\
${ }^{121} \mathrm{Sb}$ & stable \\
${ }^{134} \mathrm{Ba}$ & stable \\
${ }^{137} \mathrm{Ba}$ & stable \\
${ }^{151} \mathrm{Eu}$ & stable \\
${ }^{150} \mathrm{Sm}$ & stable \\
${ }^{152} \mathrm{Gd}$ & $1 \times 10^{14}$ \\
${ }^{154} \mathrm{Gd}$ & stable \\
${ }^{166} \mathrm{Er}$ & stable \\
${ }^{228} \mathrm{Th}$ & 1.9 \\
${ }^{208} \mathrm{~Pb}$ & stable \\
${ }^{239} \mathrm{~Np}$ & $6.45 \times 10^{-3}$ \\
\hline \hline
\end{tabular}

the cavity as "puddle glass." These are the volume deposits, whose release is controlled by dissolution of this glass.

Nuclides with somewhat lower boiling points remain volatile longer and are able to migrate upward through void spaces in the rubble chimney (e.g., Cl, I). Some portion of these is included within the solidifying puddle glass, but a portion is also deposited as coatings on chimney rubble surfaces. Nuclides included in these surface deposits can be released by relatively rapid processes such as ion exchange, as well as by dissolution, and thus the surface deposits are more susceptible to leaching than the radionuclides that are volume deposited. Ion exchange and dissolution of these surface coatings are dependent upon the mineralogy of the precipitates and their controlling thermodynamics. The specific form that these surface deposits take at Shoal is unknown, and even if it were, comprehensive thermodynamic parameters and supporting data on the transient temperature and pressure conditions are not available. For these reasons, no attempt was made to formulate a geochemical release function for the surface-deposited radionuclides. Rather, it was assumed that the surface deposits were immediately dissolved upon contact with groundwater and available for migration through the groundwater system. This assumption results in an overestimation of the availability of the surface-deposited radionuclides for transport, as the dissolution and exchange processes described above may be considerably smaller in magnitude 
and slower in occurrence than modeled. With no geochemical component to the release, the migration from the cavity of the surface-deposited nuclides is governed by the "hydraulic release.” The hydraulic release defines the process of re-equilibration of the hydraulic head within the cavity (recovery to static water level from the depressed condition caused by the test), as well as flushing of contaminants from the cavity by the flow-through of groundwater.

Some of the radionuclides produced remain in gaseous form (e.g., $\mathrm{Kr}$ and $\mathrm{Xe}$ ) and may be incorporated in solidifying phases, dissolved in groundwater, or escape the saturated zone to migrate through the unsaturated section. That portion dissolved in groundwater will migrate as controlled by the hydraulic release described above. Other nuclides are gaseous, but then decay to a nongaseous nuclide. In these cases, the preceding decay chain behavior is an important control on the distribution and release of daughter nuclides. For example, both ${ }^{137} \mathrm{Cs}$ and ${ }^{90} \mathrm{Sr}$ can be found in surface deposits throughout the chimney, as well as in the puddle glass, because of gaseous precursors. Prompt injection is another release process that may transport gaseous species under early cavity conditions. Gaseous tritium and strontium and cesium precursors may be forced several cavity radii away from the detonation point through explosion-induced fractures arranged radially away from ground zero (Smith, 1995). It is uncertain whether refractory species are transported by prompt injection.

Several of the processes described above require elaboration to understand how they were implemented in the transport analysis. Following are additional discussions of the apportioning of radionuclides between volume and surface deposits, the hydraulic release function, and nuclear melt glass dissolution.

\subsubsection{Volume/Surface Mode Designation}

The proportioning of radionuclides into the melt glass used here is the same as that used in the previous modeling. The explanation for that proportioning presented in Pohll et al. (1998) is repeated below.

Refractory and volatile behavior designations for the Shoal radionuclides were culled from literature references (Borg, 1975; Borg et al., 1976; Smith, 1995; Kersting, 1996) whenever possible. For those nuclides with no specific literature reference, volatilities of oxides (Bedford and Jackson, 1965; Kirkorian, 1981) and melting point temperatures were used to assign a behavior consistent with the volatilities and melting points of known refractory and volatile nuclides. The assignments made here are generally consistent with designations made in other studies of transport from underground nuclear tests (IAEA, 1998; Tompson et al., 1999).

A small proportion of nuclear melt glass is not incorporated in the bottom puddle, but is distributed through the collapsing chimney as a result of splashes caused by blocks of granite falling into the puddle, or as fine droplets entrained with escaping cavity gases (Smith, 1995). The exact amount distributed in this way at Shoal is not known. Based on broad experience at Lawrence Livermore National Laboratory examining glass samples from underground testing, Borg (1975) estimates that at most, only two to three percent of refractories are lost from good puddle glass. Rabb (1970) found that isotopes other than ${ }^{137} \mathrm{Cs},{ }^{125} \mathrm{Sb},{ }^{95} \mathrm{Zr} /{ }^{95} \mathrm{Nb},{ }^{147} \mathrm{Pm}$, and ${ }^{185 \mathrm{~W}}$ 
were 95 percent or more in the glass with the remainder elsewhere for the Pile Driver test. Based on this information, it is assumed here that five percent of the total mass of even the refractory species is lost from the puddle glass. Thus, the designated refractory radionuclides have 5 percent of their mass considered surface deposited, with the remaining 95 percent volume deposited (Table 4.3).

Two nuclear experiments have been conducted in granite where the apportioning of ${ }^{90} \mathrm{Sr}$ and ${ }^{137}$ Cs was investigated (Borg et al., 1976). The Pile Driver test, conducted in granodiorite at the NTS, investigated the vertical distribution of the isotopes in nuclear melt glass (an early bulk estimate of the ${ }^{137} \mathrm{Cs}$ distribution estimated 12 percent in the melt, no data on ${ }^{90} \mathrm{Sr}$ were given; Rabb, 1970). At the lowest sampling depth, the amount of ${ }^{137} \mathrm{Cs}$ was about 0.6 times what it would be if it had been homogeneously distributed in the glass (Borg, 1975). This value increased to 0.76 and 1.5 times at higher locations. Strontium-90 varied from 1.0 times at the middle sampling location to 1.35 at the highest level (no data were collected at the lowest level). These findings were part of the basis for understanding the impact of volatile precursors on radionuclide distribution. Based on all of their data, the French experiments in the Hoggar granite resulted in estimates of 0.2 times the ${ }^{137} \mathrm{Cs}$ in their glass samples and 0.4 to 0.8 times the ${ }^{90} \mathrm{Sr}$ (Van Kote and Balard, 1972, as reported by Borg, 1975 and Borg et al., 1976).

The French data are used here as the analog for the Shoal ${ }^{90} \mathrm{Sr}$ and ${ }^{137} \mathrm{Cs}$ distribution. Thus, it is assumed that 20 percent of the ${ }^{137} \mathrm{Cs}$ is contained within the glass puddle and 80 percent is surface deposited through the cavity and chimney, and 60 percent of the ${ }^{90} \mathrm{Sr}$ (the average between the measured French values of 40 and 80 percent) is in the glass puddle and 40 percent is surface deposited. The higher proportion of ${ }^{90} \mathrm{Sr}$ in the glass as compared to ${ }^{137} \mathrm{Cs}$ is consistent with the difference in the half-life of their gaseous precursors. The ${ }^{90} \mathrm{Kr}$ half-life is 33 seconds, whereas the ${ }^{137} \mathrm{Xe}$ half-life is 3.9 minutes, allowing more time for migration of the mass-137 chain to migrate out of the puddle glass. The intermediate volatility of ${ }^{113 \mathrm{~m}} \mathrm{Cd},{ }^{121 \mathrm{~m}} \mathrm{Sn}$, and ${ }^{126} \mathrm{Sn}$ is approximated here by assigning the same volume/surface proportions (20/80) as ${ }^{137} \mathrm{Cs}$.

The halogens, ${ }^{36} \mathrm{Cl}$ and ${ }^{129} \mathrm{I}$, can be expected to have volatile behavior in the early time, but there are also natural analogs in the geologic environment whereby halogens are included in volcanic glass. For example, chloride and fluoride are found in trace amounts (less than 1 percent by weight) in a wide variety of volcanic glasses (Hampton and Bailey, 1984). As the steam condenses in the cavity, some of the volatiles will be trapped and incorporated in the glass. It is assumed here that half of the ${ }^{36} \mathrm{Cl}$ and ${ }^{129} \mathrm{I}$ is included in the glass, and half is surface deposited. Similarly, ${ }^{40} \mathrm{~K}$ is also assumed to be distributed evenly between the melt and surfaces.

By a similar process, other volatile nuclides are probably entrained in the melt. For example, the French report that more than 50 percent of the available tritium is captured by their glasses 
Table 4.3. Release functions assigned to Shoal source term nuclides, based on literature references described in the text.

\begin{tabular}{|c|c|c|}
\hline Element & " Hydraulic Release \% & "Volume (Glass) Release \% \\
\hline $\mathrm{H}$ & 100 & 0 \\
\hline $\mathrm{C}$ & 100 & 0 \\
\hline $\mathrm{Al}$ & 5 & 95 \\
\hline $\mathrm{Cl}$ & 50 & 50 \\
\hline $\mathrm{Ar}$ & 100 & 0 \\
\hline K & 50 & 50 \\
\hline $\mathrm{Ca}$ & 5 & 95 \\
\hline $\mathrm{Ni}$ & 5 & 95 \\
\hline $\mathrm{Kr}$ & 100 & 0 \\
\hline $\mathrm{Sr}$ & 40 & 60 \\
\hline $\mathrm{Zr}$ & 5 & 95 \\
\hline $\mathrm{Nb}$ & 5 & 95 \\
\hline Tc & 5 & 95 \\
\hline Pd & 5 & 95 \\
\hline $\mathrm{Cd}$ & 80 & 20 \\
\hline Sn & 80 & 20 \\
\hline I & 50 & 50 \\
\hline Cs & 80 & 20 \\
\hline $\mathrm{Sm}$ & 5 & 95 \\
\hline $\mathrm{Eu}$ & 5 & 95 \\
\hline Ho & 5 & 95 \\
\hline Th & 5 & 95 \\
\hline $\mathrm{U}$ & 5 & 95 \\
\hline $\mathrm{Np}$ & 5 & 95 \\
\hline $\mathrm{Pu}$ & 5 & 95 \\
\hline Am & 5 & 95 \\
\hline
\end{tabular}

(Dupuis, 1970, as reported by Borg, 1975). Borg (1975) reports that only a small (but unquantified) portion of the total tritium produced can be recovered from glasses of tests conducted in saturated alluvium and tuff. At Pile Driver, Borg (1975) estimates that $1.53 \mathrm{~g}$ of a total $1.8 \mathrm{~g}$ produced by activation were contained in the melt, but notes that this was considerably less than the total tritium available. Given these uncertainties and the importance of tritium to the transport calculations, no incorporation in the melt glass is assumed here. The size of the carbon dioxide molecule can limit its inclusion in volcanic glasses (though carbon monoxide may dissolve; Hampton and Bailey, 1984), and krypton and argon are noncondensable, so these nuclides are also considered subject only to the hydraulic release function. 


\subsubsection{Cavity Infill Analysis}

It is well established that nuclear cavities and chimneys are dewatered and subsequently refilled, though the process through which the dewatering occurs is largely inferred (Borg et al., 1976). Within the cavity itself, the depressed water levels probably result from thermal and compressional forces generated by the nuclear reaction (vaporization, heat-driven flow, pressuredriven flow). Dewatering of the chimney area is additionally related to bulking caused by the collapse, which creates a region with substantially greater porosity than that of the surrounding rock. This is particularly true at Shoal, where the fractured granite has a very low estimated porosity. The effect of the rapid porosity increase is to desaturate the material. Following the desaturation immediately after the test, the cavity and chimney will infill with groundwater flowing radially from the surrounding saturated rock.

Very little data exist to estimate either the extent of dewatering or the rate of recovery following the blast. However, post-test drilling data indicate that dewatering did occur at Shoal. Geophysical logging of post-test hole PS\#1 indicated the presence of a chimney with a height of $108.5 \mathrm{~m}$ above the test point (Hazelton-Nuclear Science, 1965). PS\#1 was completed as a hydrologic observation well to monitor chimney infill, though casing constrictions and other apparent obstructions prevented access to the lower portion of the well (below a depth of $377 \mathrm{~m}$ ). No standing water could be confirmed in the chimney by observations through 1964 . On June 28,

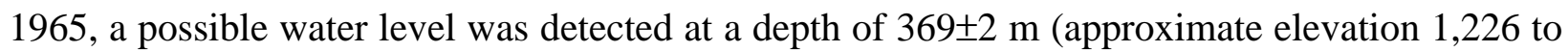
1,228 m AMSL) (Hazelton-Nuclear Science, 1965). No subsequent measurements have been found, but Hazelton-Nuclear Science (1965) concluded that infill to 1965 had been very small and calculated that the total infill and granite aquifer re-equilibrium was not expected for at least 10 years after detonation. This estimate was achieved using analytical expressions, which assumed a homogeneous and isotropic aquifer and allowed for 80 to100 days to fill up the drift complex.

An estimate of cavity infill time was also made by Pohll et al. (1998), using a single realization of their numerical flow model. They used a hypothetical post-test potentiometric surface presented by the University of Nevada (1965) as the initial water table condition following the detonation. They found the water level in the cavity reached 95 percent of the equilibrium value after 11.5 years. For the purposes of their transport modeling, it was assumed that no transport occurred until the year 1975. A similar approach was pursued with the Shoal flow model presented here; however, due to the substantial changes in the model and parameters from the Pohll et al. (1998) model, the time required for 95 percent infill increased to values greater than 100 years. Delaying transport for that length of time would result in significant reduction of the starting mass for radionuclides having half lives on the order of decades (such as tritium, ${ }^{90} \mathrm{Sr}$, and ${ }^{137} \mathrm{Cs}$ ), as a result of radioactive decay during the intervening years. This in turn heightens the importance and level of confidence needed in the specification of the infill time. As the position of the initial potentiometric surface after the nuclear test was purely hypothetical and highly uncertain, and adequate calibration of the infill rate was not possible with only one estimated water level available, it was decided that justification did not exist to support delaying transport until cavity infill was projected to occur. Rather, the transport modeling allows radionuclide transport to begin immediately after the Shoal test. Though this assumption appears 
conservative, given the known de-watering, it is also consistent with the behavior expected for nuclides injected beyond the cavity location proper (i.e., prompt injection). The process of dewatering itself may also cause dispersal of nuclides a small distance beyond the cavity, as is being simulated with prompt injection. The distribution of radionuclides in and around the cavity is discussed in detail in Section 4.2.1.

\subsubsection{Nuclear Melt Glass Dissolution}

The rock, fission products, and device components that are vaporized by the tremendous heat and pressure of a nuclear reaction quickly begin to condense and coalesce into nuclear melt glass. This glass (a solid with no crystalline structure) contains much of the radioactivity produced by a nuclear test. Radionuclides must be removed from the melt glass to be transported by groundwater. With our 20-m³ -grid blocks, the nuclear cavity is represented by eight cells in the model. At this resolution, the melt glass puddle (up to $10 \mathrm{~m}$ thick in the post-test hole; HazletonNuclear Science, 1965) cannot be represented as a separate hydraulic feature and increasing resolution to accommodate the glass would not add to model accuracy given the absence of data on hydraulic and chemical properties. Rather, the simplified approach used in previous modeling efforts (Pohll et al., 1998; Pohlmann et al., 1999) is used whereby the cavity volume as a whole is the starting location for radionuclide transport for most of the radionuclides, whether in the glass or not (a small fraction is distributed external to the cavity to account for prompt injection, as discussed in Section 4.2.1). Thus, what is needed for this simplification is a release rate (glass dissolution rate) for the radionuclides in the glass, not development of a flow model through the glass puddle with reactive transport.

Background on nuclear glass investigations and the approach used here to simulate dissolution are given in Pohll et al. (1998). Since the first phase of modeling for the Shoal site, there have been additional investigations into nuclear melt glass dissolution and the knowledge gained has been incorporated into the approach here.

There is no appreciable migration of major elements from a cavity region, so that nuclear melt glass tends to resemble the bulk rock composition (Schwartz et al., 1984). The elemental composition of the Shoal granite is dominated by $\mathrm{SiO}_{2}$ and $\mathrm{Al}_{2} \mathrm{O}_{3}$ (Table 4.4). The silica composition is particularly important for determining the dissolution rate constant. It is assumed that the radionuclide components of the glass will be released as the glass dissolves in bulk, ignoring any intra-glass diffusion that might result in variations in leaching rates from one species to another. This can be considered as etching of the glass, where the structure is broken down, rather than leaching of individual components (Adams, 1984).

Dissolution of glass under the geochemical conditions found at Shoal is expected based on thermodynamic considerations. The log of the ion activity product to the equilibrium constant ( $\log \mathrm{IAP} / \mathrm{K}_{\mathrm{T}}$ ) for amorphous silica ranges from -0.68 to -0.61 for groundwaters sampled from the Sand Springs Range at the site, indicating that under equilibrium conditions, silica glass will dissolve in contact with groundwater. Calculating the glass dissolution rate requires selecting an appropriate rate equation, and selecting appropriate values for the rate constant and specific 
Table 4.4. Comparison between chemical composition of Shoal granite and nuclear melt glass. Major and trace element composition in terms of oxides, given as weight percents. Parentheses contain standard deviations, when available.

\begin{tabular}{cccccccc}
\hline \hline & $\mathrm{SiO}_{2}$ & $\mathrm{Al}_{2} \mathrm{O}_{3}$ & $\mathrm{FeO}$ & $\mathrm{MgO}$ & $\mathrm{CaO}$ & $\mathrm{Na}_{2} \mathrm{O}$ & $\mathrm{K}_{2} \mathrm{O}$ \\
\hline $\begin{array}{l}\text { Nuclear Melt } \\
\text { Glass* }\end{array}$ & $73.1(4.9)$ & $14.2(2.5)$ & $1.18(1.59)$ & $0.22(0.27)$ & $1.06(0.86)$ & $3.49(1.68)$ & $6.6(4.2)$ \\
$\begin{array}{c}\text { Shoal } \\
\text { Granite** }\end{array}$ & $68.78(1.07)$ & $14.96(0.35)$ & $2.35 \dagger(0.25)$ & $0.43^{* * *}$ & $2.61(0.23)$ & $4.77^{* * *}$ & $3.12(0.36)$ \\
\hline \hline
\end{tabular}

${ }^{*}$ Average of six nuclear melt glass samples, as reported by Smith (1995)

${ }^{* *}$ Average of 34 Shoal granite samples obtained at 50-ft intervals in borehole ECH-D (University of Nevada, 1965)

$\dagger \mathrm{Fe}_{2} \mathrm{O}_{3}$ rather than $\mathrm{FeO}$

${ }^{* * *}$ Analysis from Pohll et al. (1998)

surface area. The rate equation used here to calculate nuclear melt glass dissolution is derived from the linear rate law used by White (1983):

$$
\zeta=\zeta_{0}+k_{l} t
$$

where $\zeta$ is the mass transfer of a chemical species into aqueous solution per unit surface area of solid (moles $\left./ \mathrm{cm}^{2}\right), \zeta_{0}$ is the mass transfer at zero time, which is a function of initial surface ion exchange (moles $\left./ \mathrm{cm}^{2}\right), k_{l}$ is the linear rate constant (moles $\left./ \mathrm{cm}^{2} \mathrm{~s}\right), t$ is the time (s). The mass transfer at zero time, or instantaneous dissolution, is ignored here. The mass involved in this term is very small relative to the total mass dissolved and, though important for short-term experimental work, it is not significant for the long-term dissolution process considered here. The derivation is then:

$$
\frac{d M}{d t}=k_{l} M A_{s p}
$$

where $M$ is the mass of glass (gm), and $A_{s p}$ is the specific surface area of glass ( $\left.\mathrm{cm}^{2} / \mathrm{g}\right)$. A comparison between this formulation and one used in other studies (Tompson et al., 1999) is presented in Appendix B. Tompson et al. (1999) includes advection, the impact of catalytic or inhibitive species, and a saturation effect as solubility limits are reached, all as part of modeling flow and reactions in the glass body on a detailed scale. Assuming the solubility limit is a constant value as a function of the activity product and equilibrium constant for amorphous silica, as done by Tompson et al. (1999), the dissolution rate at Shoal would be reduced by about 25 percent from the values presented below.

The rate constant, $k_{l}$, is a function of many parameters, most importantly the composition of the glass (particularly the silica content), the $\mathrm{pH}$ of solution, and the temperature. The first Shoal model used a $k_{l}$ of $0.87 \times 10^{-15}$ moles $/ \mathrm{cm}^{2}$ s, based on rates determined for volcanic glass at $25^{\circ} \mathrm{C}$ (White, 1983). Here, a more sophisticated approach developed by Bourcier (Lawrence Livermore 
National Laboratory, personal communication, 2001) and first presented in Tompson et al. (1999) is relied upon. Bourcier accounts for glass silica content and solution $\mathrm{pH}$, extrapolating from data presented by Mazer (1987) and then accounts for temperature using the activation energy (20 $\mathrm{kcal} / \mathrm{mole}$ is used), and a reference rate at a reference temperature. Using an average $\mathrm{pH}$ of eight (groundwater samples from nuclear cavities indicate that $\mathrm{pH}$ values are near neutral to slightly basic, consistent with regional groundwater; Smith et al., 1997), and an $\mathrm{SiO}_{2}$ content in the glass of 69 percent (consistent with that of the granite), the resultant $k_{l}$ is $1.78 \times 10^{-15} \mathrm{moles}-\mathrm{Si} / \mathrm{cm}^{2} \mathrm{~s}$ at $25^{\circ} \mathrm{C}$. This rate constant is approximately twice as large as that used in the previous Shoal modeling (Pohll et al., 1998).

The rate constant increases with increasing temperature. The temperature at the depth of the Shoal test is close to $25^{\circ} \mathrm{C}$, or slightly lower, based on temperature logs, so that the rate constant given above is appropriate for long-term dissolution under ambient conditions. Data on the thermal history of the cavity caused by the Shoal test are unavailable, but experience at other nuclear tests in Nevada and Alaska indicates that the hydraulic conductivity of an aquifer is an important variable in cooling time (Pohlmann et al., 1999; Hassan et al., 2002). Cooling is assumed rapid for Shoal.

With the dissolution rate constant given on a per unit surface area basis, the specific surface area with respect to mass is a sensitive term for projecting dissolution. It is the subject of recent research that evaluated texture and surface area of nuclear melt glass and analogous natural glass samples (Bourcier et al., 2001). That work recommends hydraulic source-term calculations employ a conservative range of 0.001 to $0.01 \mathrm{~m}^{2} / \mathrm{g}$ for the reactive surface area of nuclear melt glass. An even distribution across this range is used to develop the distribution of dissolution rates used in the model. We assume the specific surface area (surface area per mass of glass) remains constant through the dissolution process.

Post-test drilling located the Shoal explosion melt at the base of the chimney and found it to be about $10 \mathrm{~m}$ thick (Hazelton-Nuclear Science, 1965). The total mass of glass available for dissolution, estimated based on a relationship of 700 metric tons of glass produced per kiloton yield (Smith, 1995) and a 12-kt yield (U.S. DOE, 2000), is 8,400 metric tons of glass. The dissolution calculations are not sensitive to the mass of glass produced because the reaction rate is controlled by specific surface area (on a per mass basis), not the absolute mass itself. The glass is assumed to have a gram formula weight of $60 \mathrm{gm} / \mathrm{mole}$ and a density of $2.65 \mathrm{gm} / \mathrm{cm}^{3}$. There is a continual reduction in total surface area as mass is lost (though the specific surface area is assumed constant), so that less dissolution occurs with each time step, defining an exponential decline in dissolution with time. Processes that would reduce the dissolution rate such as mantling and blocking of pores by weathering products, and saturation effects as silica concentrations increase in solution, are not included here.

In the model, radionuclides assigned to the melt glass are released into the flow field according to an exponential function to approximate the glass dissolution process (this is elaborated in Section 4.2.1). The release coefficient, $k_{g}$, is the product of the specific surface area, the dissolution rate constant, and the gram formula weight. The derivation of $k_{g}$ is given in 
Appendix B. $k_{g}$ ranges from $9.23 \times 10^{-8}$ per day to $9.23 \times 10^{-7}$ per day, as a result of using the range of $A_{s p}$ recommended for modeling (described above). At the low end of the range, just over three percent of the glass dissolves in 1,000 years; at the high end, almost 30 percent dissolves (Figure 4.3). Recall that all radionuclides have some portion released immediately after the test (see Sections 4.1.2.1 and 4.1.2.2).

\subsubsection{Retardation}

Radionuclides that are dissolved in groundwater and available for transport are subject to a variety of physical and chemical processes that can retard their movement relative to the movement of water. Together, these processes are referred to as retardation, and at Shoal, the retardation mechanisms of sorption and matrix diffusion are included in the transport analysis.

The tracer test experiment conducted in 1999 and 2000 (Carroll et al., 2000) greatly improved the understanding of solute migration in the granite aquifer at Shoal. The analysis of the test results and matching of the breakthrough curves show that the critical features of the tracer responses were effectively captured (Reimus et al., 2003). These critical features differ significantly from the conceptual model used for the previous transport calculations. The model presented by Pohll et al. (1998) assumed retardation occurred only by sorption on fracture surfaces. It was realized that matrix diffusion could be an important process in a fracture flow system, but given the low matrix porosity of the granite and lack of data to bound the process, the conservative approach of neglecting diffusion was used. The tracer test demonstrated that the aquifer at Shoal behaves as a dual-porosity system, and as such, matrix diffusion should be included as a transport process. In addition, significant sorption was observed for solutes that migrated into the matrix blocks, so that matrix retardation must be accounted for as well. The previous model included only retardation in the fractures.

\subsubsection{Sorption}

A variety of laboratory experiments were conducted to support the modeling reported by Pohll et al. (1998). These used material mined during the Shoal test to determine the partitioning of ions between groundwater and granite under equilibrium conditions (the distribution coefficient, $K d$ ). It was impractical to run individual sorption experiments for all of the elements in the nuclear source term plus daughter products, especially given the hazardous and controlled nature of many of the elements. Rather, surrogates were identified to approximate the actual source-term behavior. The parametric sorption study examined the behavior of three cations (lead, strontium, and cesium) and two anions (selenium and chromium, as selenite and chromate) under varying $\mathrm{pH}$ and ionic strength conditions. The experiments and results are described in Pohll et al. (1998) and Papelis (2001), and form the basis of the retardation assignments used for the transport modeling in Pohll et al. (1998).

The $K d$ values determined for conditions of a $\mathrm{pH}$ of 8 for granite in contact with HC-4 groundwater were selected for use in estimating the retardation. These values are $4.3 \times 10^{-5} \mathrm{~m}^{3} / \mathrm{g}$ for cesium and $4.9 \times 10^{-3} \mathrm{~m}^{3} / \mathrm{g}$ for lead. Experimental results for strontium were equivocal due to dissolution of strontium from the granite material interfering with the experiments. Previous 

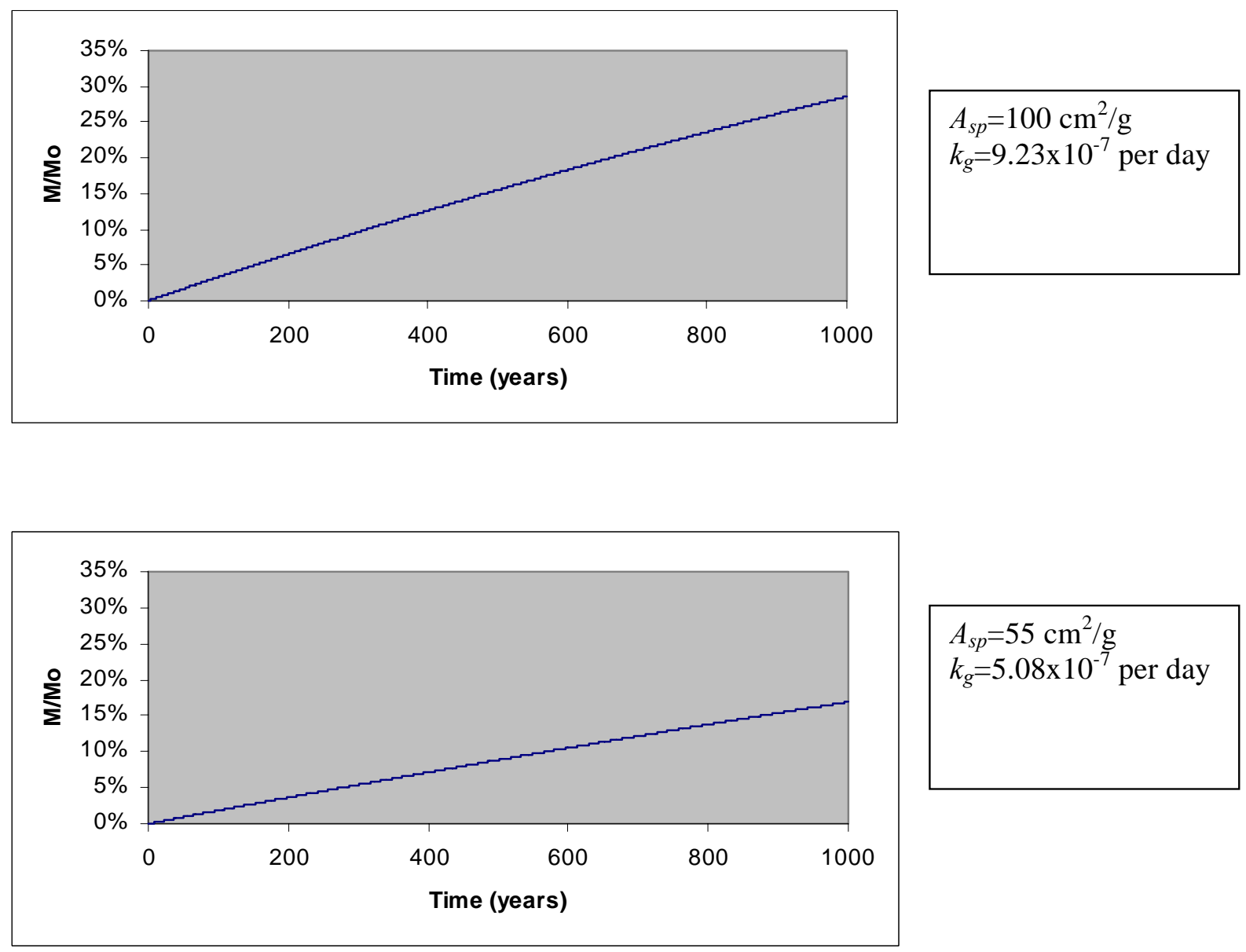

$A_{s p}=55 \mathrm{~cm}^{2} / \mathrm{g}$

$k_{g}=5.08 \times 10^{-7}$ per day
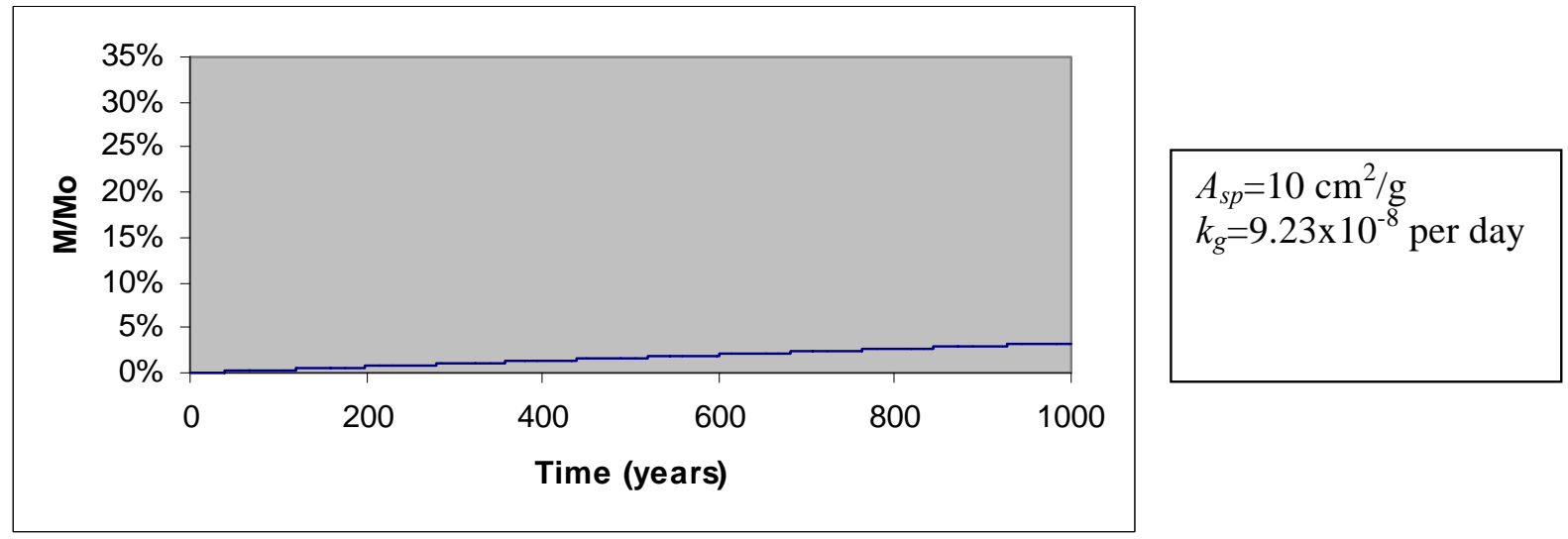

Figure 4.3. Nuclear melt glass mass dissolved per time, expressed as percent of starting mass. Three different release rates are shown corresponding to the range and midpoint of recommended specific surface areas. 
researchers (Nork and Fenske, 1970) reported a $K_{d}$ of $1.7 \times 10^{-6} \mathrm{~m}^{3} / \mathrm{g}$ for strontium in contact with Shoal granite, with a major difference from the experiments by Papelis (2001) being the use of much larger particle sizes by Nork and Fenske that are presumably more representative of the aquifer. The tracer test indicated significant sorption of lithium, another cation exhibiting weakly sorbing ion exchange behavior (lithium usually has less sorption affinity than strontium), so that strontium behavior is patterned after the lithium field data. The retardation value applied to strontium (discussed below) is consistent with a $K d$ of $3.3 \times 10^{-8} \mathrm{~m}^{3} / \mathrm{g}$, two orders of magnitude lower than that reported by Nork and Fenske (1970).

The dimensionless retardation factor, $R$, for fast reversible adsorption with a linear isotherm is represented by the following equation (Freeze and Cherry, 1979):

$$
R_{m}=1+\frac{\rho_{b}}{\theta_{m}} K_{d}
$$

where $R_{m}$ is the dimensionless retardation coefficient in the matrix blocks, $K_{d}\left[\mathrm{~L}^{3 / \mathrm{M}}\right]$ is the distribution coefficient, $\rho_{b}$ is the bulk density $\left[\mathrm{M} / \mathrm{L}^{3}\right]$, and $\theta_{m}$ is the matrix porosity. A bulk density of $2.67 \mathrm{~g} / \mathrm{cm}^{3}$ was measured for the granite. The matrix porosity is estimated as between 0.01 to 0.02 (Hershey, as cited in Reimus et al., 2003). Using these values and the $K_{d}$ values given above for cesium and lead to compute $R_{m}$ results in an estimate of $R_{m}$ for cesium of 5,700 to 11,500 and for lead of 650,000 to $1.3 \times 10^{6}$. In both cases, the range results from the range in matrix porosity, with the larger porosity leading to the lower $R_{m}$ value. The lower end of each range is used here for matrix retardation.

The $R_{m}$ assigned to strontium is that obtained directly from the tracer test for lithium. The lithium retardation value is derived from the tracer test data using a matrix diffusion transport model (discussed in the following section and presented in detail in Appendix D). The best fit to the lithium breakthrough curve using PEST (Doherty, 2000) was obtained with an $R_{m}$ of 5.4 and retardation in the fractures, $R_{f}$, of 1.2. Reimus et al. (2003) also analyzed the lithium breakthrough curve and estimated a range of lithium matrix retardation between 90 and 220, with a best-fit value of 110. The difference between their analysis and that presented in Appendix D is due to the ability of the model used here to account for multiple fractures per unit volume, which effectively increases the fracture/matrix interface area. The more conservative value for $R_{m}$ of 5.4 is used in the transport modeling for strontium.

The behavior of the sorbing solute in the tracer test implied little sorption in fractures as compared to the considerable sorption in the matrix; however, fracture-plus-matrix sorption clearly offered the best fit to the breakthrough curves (Reimus et al., 2003). Reimus estimated an $R_{f}$ for lithium of 1.3 to 1.8 , with a best fit of 1.5. The analysis in Appendix D found a best fit with an $R_{f}$ of 1.2. The value of 1.2 is applied here for fracture retardation for strontium. With the lack of a close analog in the tracer test for the fracture retardation behavior of cesium and the strongly sorbing nuclides approximated by lead, a value is calculated using the laboratory sorption data 
and fracture aperture data from the tracer test. Retardation in fractures can be represented by the following equation (Freeze and Cherry, 1979; Moreno et al., 1988; Frick et al., 1991):

$$
R=1+\frac{2 K_{a}}{b}
$$

where $K_{a}[\mathrm{~m}]$ is a surface-based sorption constant $\left(K_{a}=K_{d} / A_{s p}\right)$ and $b[\mathrm{~m}]$ is the mean fracture aperture. The specific surface area, $A_{s p}$, was measured on the materials used in the sorption experiments and found to be $0.79 \mathrm{~m}^{2} / \mathrm{g}$. Dividing the $K_{d}$ values for cesium and lead reported above by $A_{s p}$ gives $K_{a}$ values of $5.4 \times 10^{-5}$ and $6.2 \times 10^{-3} \mathrm{~m}$, respectively. Reimus et al. (2003) estimated the average fracture aperture to be between $5.8 \times 10^{-4}$ and $1.38 \times 10^{-2} \mathrm{~m}$ by extracting the value from the lumped diffusive mass transfer parameter. They state that the upper end of the range is unrealistically high for a fractured granite and attribute it to the unconstrained nature of aperture estimates obtained from independent measures of the lumped parameter, porosity, and the matrix diffusion coefficient. Using the $K_{a}$ values given above and an aperture of $5.8 \times 10^{-4} \mathrm{~m}$ gives the $R_{f}$ values for cesium and lead used here, 1.2 and 22, respectively. The $R_{f}$ value for cesium particularly is likely to be too low, based on the relative relationship of the matrix retardation values with strontium, but in the absence of better supporting data, is used here. Note that though lithium breakthrough was observed during the tracer test, cesium was also injected and never observed. The retardation values applied in the model are summarized in Table 4.5.

\subsubsection{Matrix Diffusion}

As noted previously, the tracer test demonstrated that diffusion of solutes from the fracture flow system into the granite matrix blocks is a significant process at Shoal. This was observed in the test by comparing the breakthrough of bromide with that of pentafluorobenzoate, a large molecule with a smaller free diffusion rate than bromide. Significant concentration attenuation of the reactive lithium tracer also required diffusion into stagnant matrix water to explain. Though diffusion was clearly observed, the results also indicate that the volume of matrix pore water in diffusive communication with the flowing fractures is relatively small, and thus diffusion distances into the matrix are relatively short. This is consistent with the low porosity of the granite matrix.

The results and interpretation of the multiple-tracer, cross-hole test conducted at the Shoal site indicate that a dual-porosity conceptual transport model is appropriate for describing dissolved radionuclide transport at the site. Furthermore, the results and interpretation are consistent with stagnant water in the dual-porosity system being primarily in the matrix where there is plenty of surface area for radionuclide sorption, as opposed to being free water in fractures. However, analysis of the tracer test results using analytic solutions indicate that the ratio of stagnant to flowing water volume in the system may be as small as 0.5 , which translates to an effective retardation factor of only 1.5 for nonsorbing solutes (Reimus et al., 2003). This value should be considered a lower bound because reasonable fits to the tracer responses could also be obtained assuming a large ratio of stagnant to flowing water volume that would result in a much larger retardation factor. 
Table 4.5. Retardation values used in the transport model

\begin{tabular}{ccc}
\hline \hline & $R_{m}$ & $R_{f}$ \\
\hline $\mathrm{Sr}$ & 5.4 & 1.2 \\
$\mathrm{Cs}$ & 5700 & 1.2 \\
$\mathrm{~Pb}$ & 650,000 & 22 \\
\hline \hline
\end{tabular}

Lithium sorption in the field tracer test was considerably stronger than in laboratory batch sorption experiments, possibly because sorbing mineral phases present in the field were not present in the rock cuttings used in the laboratory tests. This result suggests that the practice of using laboratory sorption data in field-scale transport predictions of cation-exchanging radionuclides, such as ${ }^{137} \mathrm{Cs}^{+}$and ${ }^{90} \mathrm{Sr}^{++}$(which sorb by the same mechanism as $\mathrm{Li}^{+}$), should be conservative.

The transport simulations for Shoal must then include the process of matrix diffusion. The matrix diffusion process is incorporated into the random-walk particle-tracking (RWPT) method using a particle transfer approach. Although similar transport models for the CNTA site utilized the particle transfer approach developed by Liu et al. (2000), more accurate methods have been developed recently and are used in the current transport model (Hassan et al., 2002; Pan and Bodvarsson, 2002; Huang et al., 2003; Pan et al., 2001).

Huang et al. (2003) has adopted a Markov chain model to simulate the particle transfer between the mobile and immobile waters. This Markov Chain model is extended to simulate the particle transfer across the fracture/matrix interface by coupling the "active diffusion range" as developed by Pan and Bodvarsson (2002) into the model. The advantage of this approach is that it allows a relatively large time interval (dt), which dramatically reduces the computation time. The model also allows for multiple fractures within a single grid cell, which effectively increases the effective fracture-matrix interface area.

Appendix D provides details on the methodology and calibration of the model to the Shoal tracer test results.

\subsubsection{Porosity}

Reimus et al. (2003) calculated a range in effective porosity of 0.027 to 0.054 from the tracer test results, but caution that the estimates may be high due to heterogeneity in the system. It is thought that the simplifying assumptions used to estimate the effective porosity from the tracer test bromide breakthrough response will lead to an overprediction in the effective porosity. In highly heterogeneous media, the travel distance from the injection well to the pumping well is not the straight-line distance as assumed. In reality, the solutes pass through a complex fracture network that will increase the travel distance. This problem is enhanced when the fractures are aligned perpendicular to the well pair alignment as is the case for the Shoal tracer test. 
An independent numerical analysis was performed to determine the error associated with the effective porosity as estimated by Reimus et al. (2003). A heterogeneous, two-dimensional flow and transport model was constructed to simulate the PSA tracer test. The numerical model FASTFLOTRAC (Reimus, 2000) was used to generate fractures, assign random hydraulic conductivities, solve the groundwater flow equation in steady-state and to calculate solute transport migration between the two wells. The fractures are generated as a series of onedimensional line traces that are mapped to the finite difference grid according to dominant fracture orientations found in the fracture analysis. The orientation of the fractures relative to the well pair was kept consistent with the Shoal tracer test geometry. Cells that did not receive a fracture via the random fracture generation process were assumed to have a hydraulic conductivity a few orders of magnitude less than the fractures that control flow. This conceptualization is similar to the regional flow model, as one set of fractures has a higher hydraulic conductivity and a defined orientation, while the other has a lower conductivity and random orientation. Neither class is meant to represent pure granite matrix, as the hydraulic conductivity for both classes is much greater than zero.

The synthetic model was performed within a Monte Carlo framework to quantify the uncertainty in the effective porosity. During each realization, fractures are mapped to the finite difference grid, creating one set of north-trending fractures (67 percent) and one set oriented to the west (33 percent). A one-dimensional, spatially distributed, Gaussian model is used to construct the hydraulic conductivity distribution along each fracture. The mean hydraulic conductivity of each orientated fracture is selected at random based on a lognormal distribution with a geometric mean of $10^{-1} \mathrm{~m} / \mathrm{d}$ and $\log _{10}$ variance of 1.0 . Cells that do not receive a fracture were simulated as a statistically isotropic, spatially distributed, random variable. A Gaussian model was used to construct the hydraulic conductivity field for the less conductive fractures (geometric mean $=10^{-4} \mathrm{~m} / \mathrm{d} ; \log _{10}$ variance $=0.5$ ). Therefore, the less conductive cells represent granite material that contains micro-fractures, with little spatial persistence and geometric organization as compared to larger, more persistent fractures that are oriented as shown in Figures 3.6 and 3.7. The final hydraulic conductivity field represents two independent random fields of hydraulic conductivity that are integrated into a single field via the fracture generation and Gaussian models.

An arbitrary transport porosity $\left(\theta_{t}\right)$ of 0.1 was applied to the model. An arbitrary transport porosity can be used because the objective is to determine the relative shift in the porosity distribution due to errors in the underlying assumptions used to estimate the porosity. Our results will, therefore, be relative to the input $\theta_{t}$. The boundary and initial conditions are identical to those of the tracer test (Carroll et al., 2001). The model grid was constructed to improve solution accuracy while still remaining efficient computationally. The grid contained 208 x 208 cells, with $\mathrm{dx}=\mathrm{dy}=0.3 \mathrm{~m}$.

A Monte Carlo analysis was performed with a total of 391 realizations to develop a distribution of effective porosities that could be used as estimates in the regional model. For each 
realization, the breakthrough curve data were used to estimate the effective porosity via (Guimera and Carrera, 2000):

$$
\theta_{c}=\frac{2\left(Q_{i}+Q_{e}\right) t_{p}}{\pi L^{2} b}\left[\frac{1}{\frac{2}{r^{2}}+\left(\frac{1}{r^{3}}-\frac{1}{r}\right) \ln \left(\frac{1-r}{1+r}\right)}\right]
$$

where $Q_{e}$ is the extraction rate $\left[\mathrm{L}^{3 / \mathrm{T}}\right], Q_{i}$ is the injection rate $\left[\mathrm{L}^{3 / \mathrm{T}}\right], t_{p}$ is the peak flux arrival time [T], $b$ is the aquifer thickness [L], $L$ is the distance between the well pair [L], and

$$
r=\frac{Q_{i}-Q_{e}}{Q_{i}+Q_{e}}[\text { dimensionless }]
$$

Because an arbitrary transport porosity was used in the numerical model, the effective porosity estimates were scaled to match the field data. If the assumption is made that the effective porosity estimate made using the field data and Equation (4.5) is a good measure of the central tendency of potential values, then a simple correction factor can be applied to estimate the uncertainty as:

$$
\omega=\left(\theta_{t} / \theta_{c}\right)
$$

where $\omega$ is the correction factor, $\theta_{t}$ is the effective porosity used in the numerical model (0.1), and $\theta_{\mathrm{c}}$ is the computed effective porosity as determined from Equation (4.5) and the numerical breakthrough curves. Equation (4.7) was applied to all 391 realizations to obtain a distribution of correction factors.

The distribution of correction factors is multiplied by the field-obtained effective porosity estimate (0.027) to obtain a distribution of effective porosity for use in the regional transport model. This process is equivalent to solving for $\theta_{\mathrm{t}}$ in Equation (4.7) to determine the appropriate transport porosity for the regional model as $0.27 \omega$. The resulting distribution is shown in Figure 4.4. The resulting distribution's geometric mean is 0.019 or 30 percent less than the value (0.027) derived from tracer test analysis. A lognormal distribution is used to describe the empirical distribution determined from the numerical analysis and represents a measure of the parametric uncertainty in effective porosity within the transport simulations. The lognormal distribution has a mean of 0.025 and a standard deviation of 0.023 . The 90 percent confidence interval ranges between 0.005 and 0.07 .

\subsubsection{Cavity Porosity}

The assignment of effective porosity is different for the region immediately around the nuclear working point, as compared to the approach used for the remainder of the domain, described above. The Shoal nuclear test created a cavity that collapsed and formed a rubble chimney. The chimney did not propagate to the land surface (i.e., there is no collapse crater). The 


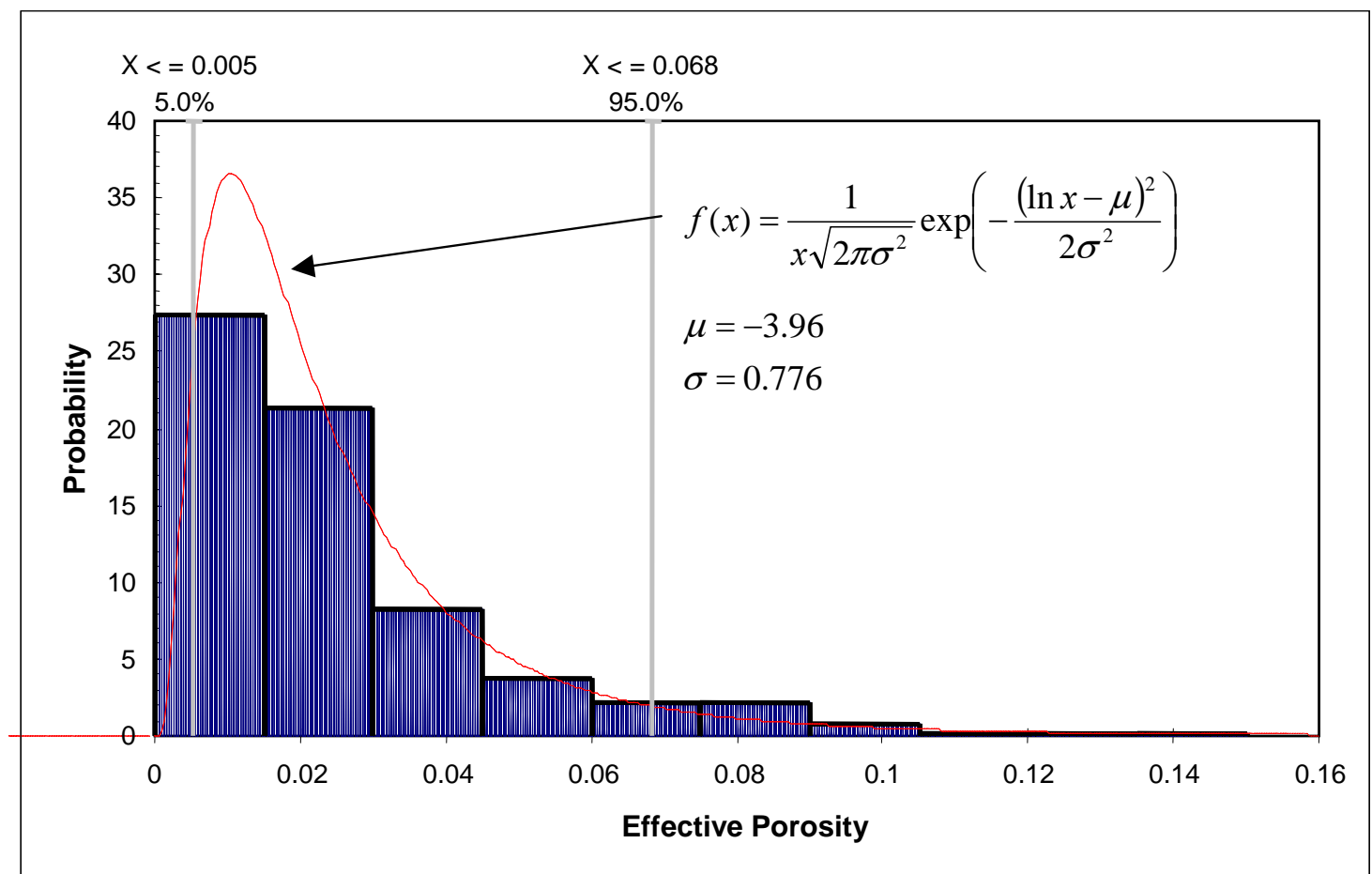

Figure 4.4. Numerically derived distribution of effective porosity and the associated lognormal distribution.

cavity radius is reported to be $26 \mathrm{~m}$ (Hazelton-Nuclear Science, 1965). The top of the chimney is located $108.5 \mathrm{~m}$ above the test location. The bulking porosity of the chimney can be inferred using geometric considerations, if it is assumed that the maximum void space within the chimney is equal to the cavity volume (Borg et al., 1976). Assuming a cylindrical chimney with hemispherical ends, the distributed porosity is

$$
B=\frac{\frac{4}{3} \pi r_{c}^{3}}{\frac{4}{3} \pi r_{c}^{3}+h \pi r_{c}^{2}}
$$

where $h_{c}$ is the chimney height without an apical top, $r_{c}$ is the cavity radius, and $B$ is the bulking porosity. At Shoal, the chimney height with an apical top is reported as $108.5 \mathrm{~m}$ and the cavity radius is $26 \mathrm{~m}$ (Figure 4.5) (Hazelton-Nuclear Science, 1965), leading to a bulking porosity of 30 percent. Borg et al. (1976) reported a range for $B$ of 18 to 35 percent for competent rocks such as granite, basalt, and indurated tuffs. Rather than assign a single value of $B$ in the transport model, uncertainty is incorporated using Borg's values as endpoints (which includes the single value estimated above for Shoal) for a uniform distribution of porosity in the cavity and chimney. These porosity values are randomly assigned to the eight model cells representing the cavity, and the overlying 16 cells that represent the chimney through the water table (Figure 4.6) (recall that the unsaturated zone is not included in the model and that the water table varies somewhat from simulation to simulation). 


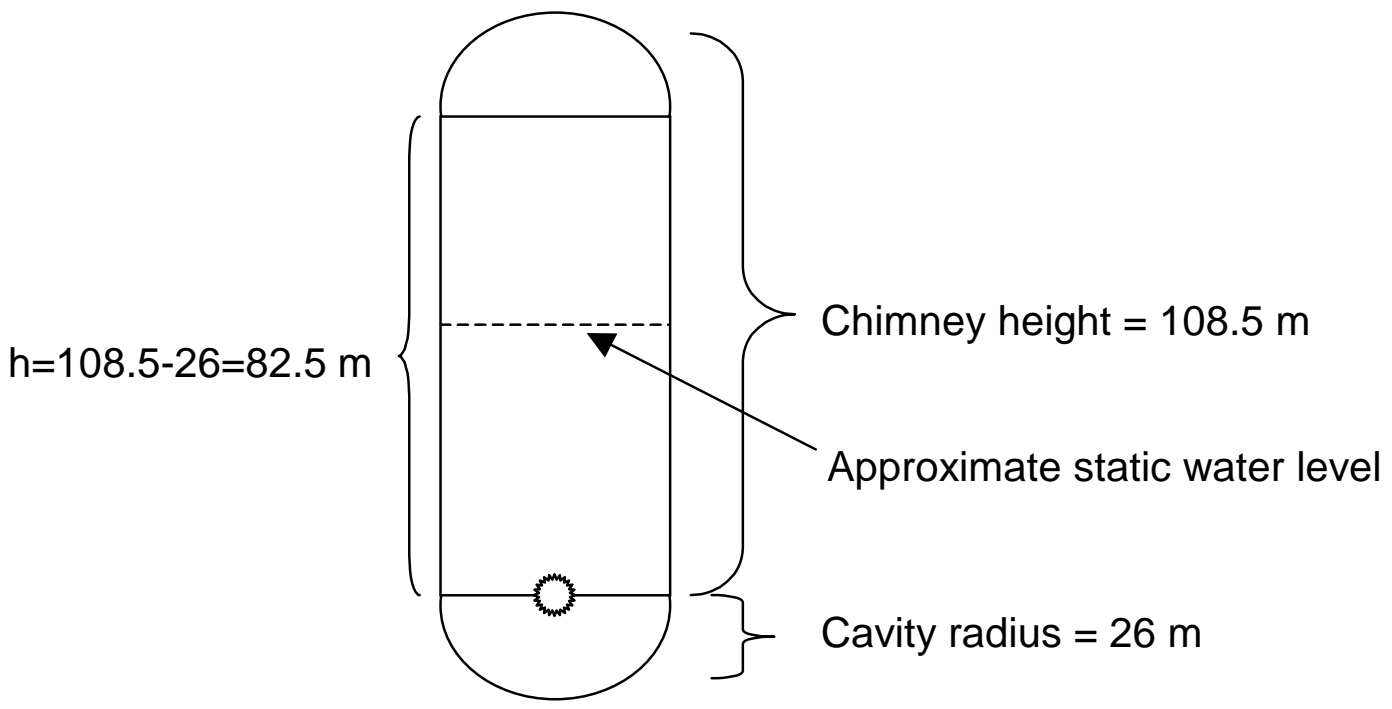

Figure 4.5. Geometry of the Shoal cavity and chimney, from data in Hazelton-Nuclear Science (1965).

The next spherical zone around the cavity (approximated by the next two cells around the cavity/chimney in the model domain) represents the damaged zone of highly disturbed rock that is assigned a range of hydraulic conductivity roughly an order of magnitude higher than the highest end of the range assigned to the fractured granite. Consistent with this conceptualization of a damaged zone, the porosity of these cells are assigned random values from a uniform distribution having endpoints of 0.07 to 0.18 , substantially higher than the undisturbed rock, but lower than that of the cavity. The conceptual model of the cavity includes a final spherical zone transitioning from the highly disturbed, near-cavity environment to the undisturbed rock (an additional two-cell rim around the damaged zone). This zone is assumed to be fractured by the test, but to fundamentally retain the hydraulic properties of the surrounding granite. This conceptualization is implemented by assigning a hydraulic conductivity in this region at the high end of the range available for the naturally fractured granite, and applying a random porosity value selected from the same distribution as used in the bulk of the domain. This presumes that though fracturing from the test may have increased $K$, the aquifer outside the cavity/chimney is nevertheless dominated by fracture flow. The porosity and hydraulic conductivity assignments are summarized in Figure 4.6.

\subsection{Numerical Modeling Strategy}

\subsubsection{Solving the Contaminant Transport Problem}

The random-walk method is used to simulate the transport and evolution of radionuclides in the generated random velocity fields. The injected mass is replaced with a large number of particles $N P$ of equal mass $m$ that are tracked in the space-time domain. The initial mass is assumed to be unity and is represented by 40,000 particles for all cases where the percent of mass in the nuclear melt glass is less than or equal to 60 percent (Transport Classes 1, 2, 3, and 5), and 


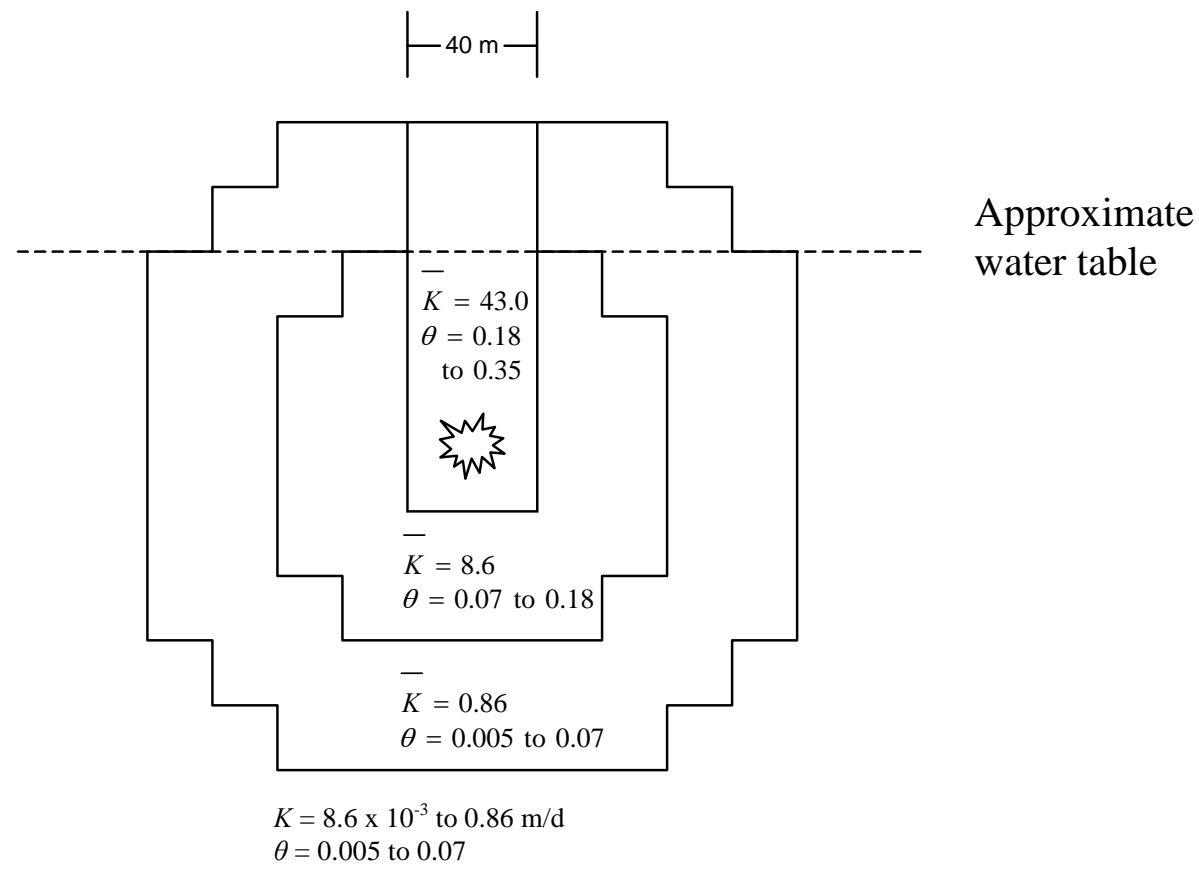

Figure 4.6. Porosity and hydraulic conductivity assignments to model cells to represent the cavity/ chimney, the damaged zone, and a transition zone from the damaged area to native fractured granite. All $K$ values are in $\mathrm{m} / \mathrm{d}$. The star represents the working point.

80,000 particles for cases where the percent of mass in glass is higher (Transport Classes 4 and 6). The six transport classes are fully described in Section 5.2.

The positions of the particles are updated at each time step according to the random-walk equation (Kinzelbach, 1988; Tompson and Gelhar, 1990):

$$
\boldsymbol{X}_{t+\Delta t}=\boldsymbol{X}_{t}+\left[\boldsymbol{V}\left(\boldsymbol{X}_{t}, t\right)+\nabla \bullet \mathbf{D}\left(\boldsymbol{V}\left(\boldsymbol{X}_{t}, t\right)\right)\right] \Delta t+\left[2 \mathbf{D}\left(\boldsymbol{V}\left(\boldsymbol{X}_{t}, t\right)\right) \Delta t\right]^{1 / 2} \bullet \boldsymbol{Z}+\frac{\mathbf{D}\left(\boldsymbol{V}\left(\boldsymbol{X}_{t} t\right)\right)}{\theta} \nabla \theta
$$

where $\boldsymbol{X}_{t+\Delta t}$ is the updated position of the particle that was at $\boldsymbol{X}_{t}$ in the previous time step, $\boldsymbol{V}\left(\boldsymbol{X}_{t}, t\right)$ is the velocity vector at the old position at time $t, \mathbf{D}$ is the local-scale dispersion tensor, $\Delta t$ is the time step, and $\boldsymbol{Z}$ is a vector of normally distributed random numbers of zero mean and unit variance, and $\theta$ is the spatially varying porosity (between cavity/chimney, the surrounding damaged zone, and the native rock). The first term on the right-hand side of Equation (4.9) represents the advective step and the second term adds the effect of the gradients of the dispersion tensor on the particle movement. This latter term is important if sharp fronts exist and whenever the gradient of $\mathbf{D}$ is significant. The term involving the porosity gradient accounts for the porosity variability in the modeled domain. The last term represents the contribution of local-scale dispersion and Brownian diffusion to the movement of the particles. 
The need for incorporating the gradient terms for the dispersion coefficient and porosity in Equation (4.9) arises due to the spatial variability of the two parameters within the modeled domain. These gradient terms assume that this variability is sufficiently smooth that one can define these gradients at any point in space. However, when abrupt changes occur in space, as is the case here due to the cavity and chimney formation, these gradients cannot be defined at the interfaces between varying blocks. An alternative to computing these gradient terms was recently proposed by LaBolle et al. (2000), where they developed a stochastic partial differential equation that is valid for discontinuous properties such as dispersion and porosity. They also integrated these equations with the RWPT, which resulted in an algorithm that avoids the computation of gradient terms. That method is applicable for cases of abrupt changes in transport parameters and velocity values. The new random-walk equations proposed by LaBolle et al. (2000) can be written as

$$
\boldsymbol{X}_{t+\Delta t}=\boldsymbol{X}_{t}+\left[\boldsymbol{V}\left(\boldsymbol{X}_{t}, t\right)\right] \Delta t+\left[2 \mathbf{D}\left(\boldsymbol{V}\left(\boldsymbol{X}_{t}+\delta \boldsymbol{X}, t\right)\right) \Delta t\right]^{1 / 2} \bullet \boldsymbol{Z}
$$

where $\delta \boldsymbol{X}$ is defined as

$$
\delta \boldsymbol{X}=\left[2 \mathbf{D}\left(\boldsymbol{V}\left(\boldsymbol{X}_{t}, t\right)\right) \Delta t\right]^{1 / 2} \bullet \boldsymbol{Z}
$$

The idea in this approach is to evaluate the advective step of the particle using the velocity at the current position of the particle, $\left(x_{t}, y_{t}, z_{t}\right)$, and at time $t$. The dispersive step is performed using dispersion coefficients evaluated at an intermediate location, $\left(x_{t}+\delta x, y_{t}+\delta y, z_{t+} \delta z\right)$, where the increments $\delta x$, $\delta y$, and $\delta z$ represent dispersive steps from the current location, $\left(x_{t}, y_{t}, z_{t}\right)$, to the intermediate location, $\left(x_{t}+\delta x, y_{t}+\delta y, z_{t}+\delta z\right)$. Comparing Equations (4.10) and (4.11) to Equation (4.9), one can see that the dispersion gradients (which are not defined at interfaces between domain blocks) are not needed in LaBolle et al.'s (2000) approach.

The approach described thus far is appropriate for a porous medium. However, the Shoal flow system is conceptualized as a fracture flow system with relatively high velocity in the fractures that separate adjacent porous blocks. A continuum approach is applied in the sense that discrete fractures are not considered in space, but instead, effective fracture properties (high conductivity and low porosity) are assigned to the discretized domain blocks. Therefore, particles are tracked in space in the same manner as for a porous medium, but they experience the high fracture velocity within each block. They also experience the process of diffusion into and out of matrix blocks. Liu et al. (2000) introduced an RWPT approach applicable to fractured porous media, using particle transfer probability expressions to diffuse the particles into the matrix and back to the fractures. The particles are tracked in space over discrete time steps and the transfer probabilities are used to move the particles back and forth between the two continua. The approach assumes that each grid block contains two overlapping continua: one represents the fractures containing the rapid migration of water and solutes, the second represents the surrounding matrix blocks that have a larger quantity of water. The water in the matrix is assumed to be immobile, undergoing no advection. 
Assuming no water flux between fractures and matrix blocks (diffusion only), the particle transfer probabilities of Liu et al. (2000) can be written as forward transfer probability $P_{f m}=F_{f m} \Delta t /$ $\left(V_{f} C_{f}\right)$, and a backward transfer probability $P_{m f}=F_{m f} \Delta t /\left(V_{m} C_{m}\right) . F_{f m}$ and $F_{m f}$ are the transport rates from fractures to matrix and vice versa, with the net solute transport rate within a grid cell being the difference between these two. The particle transfer probabilities are expressed in terms of these transport rates, the concentration, $C_{f}$, and water volume, $V_{f}$, in the fractures, and the blockaveraged concentration, $C_{m}$, and water volume, $V_{m}$, in the matrix. Liu et al. (2000) then derived the expressions for flux rates in terms of measurable quantities to arrive at the expressions given as Equations (4.5) and (4.6). According to $P_{f m}$, particles can diffuse into the matrix and are there subject to matrix advection (if any; none is assumed here for Shoal), and dispersion/diffusion. Particles can also diffuse back from the matrix to the fractures according to $P_{m}$; where they move with the underlying velocity of the fractures. This approach allows for a finite extent of the matrix blocks, and thus limited, rather than infinite, diffusion capacity of the blocks. For Shoal, the interconnected fractures and surrounding matrix blocks are assumed to have the same characteristics everywhere in the domain so that the strength of matrix diffusion is spatially invariant.

The approach of Liu et al. (2000) assumes that complete redistribution of contaminant mass associated with each particle occurs immediately once the particle is in the matrix or in the fracture. This complete and instantaneous redistribution of mass in the matrix may not be realistic in some cases. The implications of this assumption are that fracture-matrix concentration gradients that derive the values of the particle transfer probabilities may be underestimated or overestimated leading to unrealistic breakthrough results when using this approach. Hassan et al. (2002) showed that as a result of these effects, the forward particle transfer probability, Equation (4.5), underestimates the rate of particle diffusion into the matrix. Under this condition, less mass is numerically diffused from the fractures into the matrix ( $P_{f m}$ is lower than what it should be) at early times where the pulse of contaminant is assumed to be injected or released completely in the fractures. This leads to a faster migration in the fractures and an earlier breakthrough than what should be.

In our simulations, this early effect is balanced at longer times, when the concentration gradients become smaller than at early times, by using the same forward and backward transfer probabilities. Also, if one tries to calculate the values of the transfer probabilities based on the tracer test-estimated values of $D^{*}$ and estimates of $B$ and $b$, one ends up with the similar assumptions (i.e., fixed values for $P_{f m}$ and $P_{m f}$ at all times) as when obtaining the transfer probability from matching the tracer test breakthrough curve. That is, only one value for $P_{f m}$ and one value of $P_{m f}$ would be estimated from estimates of $D^{*}, B$ and $b$ and would be used in the simulations at all times. Therefore, if the estimates of $P_{f m}$ and $P_{m f}$ represent conditions that are closer to the long-time conditions, then they would significantly underestimate early-time matrix diffusion (in addition to the underestimation due to the instantaneous and complete redistribution assumption mention above, thus two additive effects occur). But if the values of $P_{f m}$ and $P_{m f}$ are based on early-time conditions, as is the case when using the tracer-test breakthrough curves, they 
will overestimate matrix diffusion at later times causing an effect that is opposite to the effect of the instantaneous and complete redistribution assumption. Therefore, it can be seen that both cases induce some errors and simplifications due to the inherent assumptions with the use of early-time $P_{f m}$ and $P_{m f}$ values leading to effects that may cancel each other, and thus this assumption is believed to be more accurate.

When first released, the radionuclide source is assumed to exist only in the fractures. The starting locations of the particles are based on observations of underground nuclear tests, which indicate that the majority of radionuclides are contained within the cavity. There are also potential processes of fracturing and prompt injection that may disperse a limited amount of mass away from the cavity region. These features are simulated by initially locating the majority of the particles within the cavity; 90 percent are uniformly distributed in a sphere of radius $20 \mathrm{~m}$, centered on the working point (this is slightly smaller than the estimated cavity radius of $26 \mathrm{~m}$ due to the model grid size). The remaining 10 percent is distributed outside the cavity sphere to a radius of $100 \mathrm{~m}$. This outer region (from 20 to $100 \mathrm{~m}$ away from the working point) is divided into 2-m-thick spherical shells (about 40 of them), with the number of particles assigned to each shell exponentially decreasing outward. The resulting particle distribution is shown in Figure 4.7.

Since the radionuclides are divided among surface deposits that can be released via hydraulic release and volume deposits, which are trapped in the melt glass, the treatment of particles representing both categories is different (though they are all spatially distributed the same, as described above). Assume that $p$ is the percentage of mass released hydraulically, and thus $1^{-} p$ represents the mass in the glass. If the total number of particles is $N P$, then a number of particles equal to $p \times N P$ (including those particles located outside the cavity via prompt injection) is released instantaneously at the time of the detonation into the flow field and is immediately subject to all the processes involved (advection, local dispersion, retardation, etc.). Particles in the glass, $\left(1^{-} p\right) N P$, are released in batches according to the glass release coefficient, $k_{g}\left(\mathrm{~T}^{-1}\right)$ (see

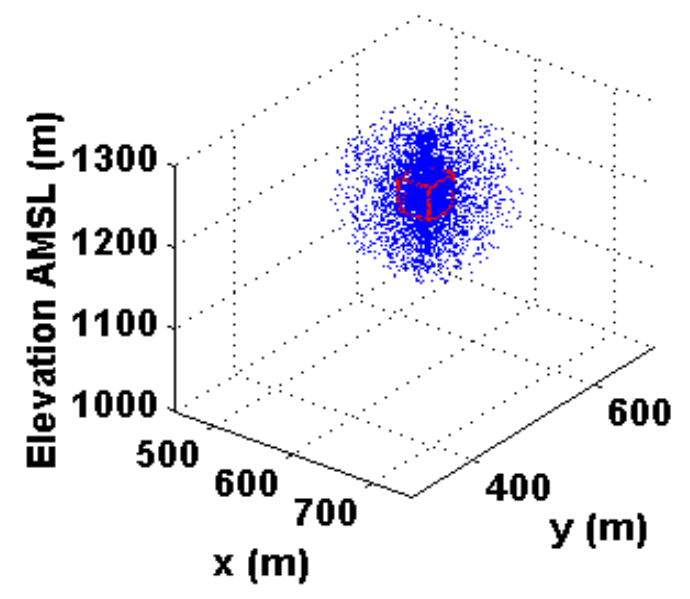

Figure 4.7. Distribution of particles representing the radionuclide source. A sphere with radius of $20 \mathrm{~m}$, centered on the working point, contains 90 percent of the mass. 
Section 4.1.2.3). Therefore, the number of particles released at any given time step, is obtained from the expression

$$
N P_{G}^{t}=[(1-p) N P]^{*}\left[\left(1-e^{-k_{g} t}\right)-\left(1-e^{-k_{g}(t-\Delta t)}\right)\right]
$$

where $N P_{G}^{t}$ is the number of particles released from the glass between times $t-\Delta t$ and $t$. At time $t=0$, no particles are released from the glass and only those released via hydraulic equilibrium are allowed to move within the flow field. The process is illustrated here using a scenario of $95 / 5$ percent glass/hydraulic release and a total of 80,000 particles. The number of particles released per time step ( $\Delta t=50$ days) is calculated using the minimum and maximum of the $k_{g}$ range presented in Section 4.1.2.3 (9.23 x 10-8 per day and $9.23 \times 10^{-7}$ per day, respectively). Based on the parameter values used in this example, no more than four particles are released per time step. Figure 4.8 shows the cumulative sum of all particles released into the flow field at any given time during the transport simulation. Note that the number of particles released at $t=0$ (denoted by the square symbol) is 4,000 , which represents the hydraulic release $(0.05 \times 80,000)$. No particles are released from the glass at this time. After one time step (e.g., 50 days), an initial batch of particles is released from the glass and is equivalent to about four particles. This number decreases slowly until the total time of 1,000 years is reached. At the end of the simulation time ( $t=1,000$ years), approximately 22,000 particles have been released at the high end of the $k_{g}$ range, which amounts to about 27 percent of the initial mass.

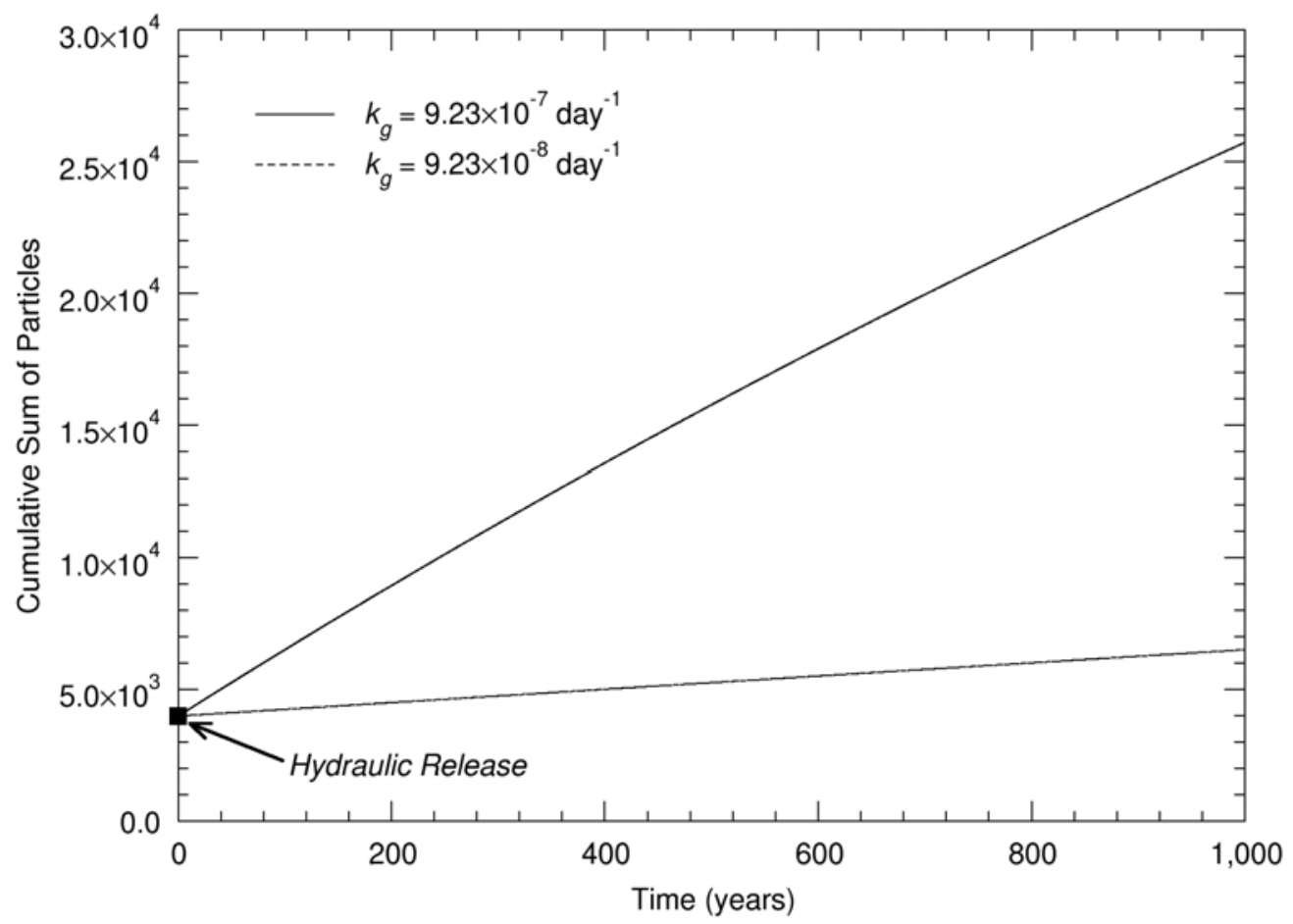

Figure 4.8. Release of particles as a function of glass dissolution rate for a total of 80,000 particles. The square symbol indicates the number of particles released hydraulically. 
Once the particles are released from the cavity by either hydraulic release or glass dissolution, they are subjected to advection, dispersion, retardation, matrix diffusion and radioactive decay. The grids of the MODFLOW model and the particle-tracking model are identical so that no interpolation of the output velocity fields of the MODFLOW solution is needed, except at particle locations. Particle velocities are obtained using a trilinear interpolation scheme, which is similar to the two-dimensional bilinear interpolation (e.g., LaBolle et al., 1996). Using the particle distribution at every time step, concentration distribution at all model cells is obtained using simple projection. The objective for the Shoal site is to determine the threedimensional volume of water that may contain contaminant concentrations above a given threshold (e.g., above limits in the Safe Drinking Water Act). The methodology employed to determine this water volume is described in the subsequent section.

The concentrations normalized relative to the initial source concentration are then processed to account for coupled in-growth and radioactive decay.

$$
C=C_{u} e^{-(\ln 2) t / \omega}
$$

where $C$ is the decayed normalized concentration at time $t$ (moles/liter), $C_{u}$ is the undecayed normalized concentration (moles/liter), $\omega$ is the half-life of nuclide (days), and $t$ is time (days).

For the general case of the decay of a parent isotope $\left(N_{1}\right)$ to a radioactive daughter $\left(N_{2}\right)$, which decays to a second daughter $\left(N_{3}\right)$ through the final daughter $\left(N_{n}\right)$, the solution giving the number of atoms of any member of the decay series as a function of time and assuming zero initial mass for the daughters has the form (Faure, 1977):

$$
N_{n}=\varepsilon_{1} e^{\lambda_{1} t}+\varepsilon_{2} e^{\lambda_{2} t} \ldots+\varepsilon_{n} e^{\lambda_{n} t}
$$

where the coefficients $\varepsilon_{n}$ are defined as:

$$
\begin{aligned}
& \varepsilon_{1}=\frac{\lambda_{1} \lambda_{2} \ldots \lambda_{n-1} N_{1}^{0}}{\left(\lambda_{2}-\lambda_{1}\right)\left(\lambda_{3}-\lambda_{1}\right) \ldots\left(\lambda_{n}-\lambda_{1}\right)} \\
& \varepsilon_{2}=\frac{\lambda_{1} \lambda_{2} \ldots \lambda_{n-1} N_{1}^{0}}{\left(\lambda_{1}-\lambda_{2}\right)\left(\lambda_{3}-\lambda_{2}\right) \ldots\left(\lambda_{n}-\lambda_{2}\right)}
\end{aligned}
$$

and $\lambda_{n}$ is the decay rate for radionuclide $N_{n}$. In a case where the initial mass of the daughter radionuclide is not zero (i.e., the radionuclide is also present in the original source), the source mass and the daughter's mass are calculated separately and summed afterward.

\subsubsection{Contaminant Boundary Maps}

Beyond simply developing confidence in the understanding of radionuclide transport from the Shoal test, a specific objective of the flow and transport model is establishing regions that may 
contain contaminated groundwater so that public health can be protected through monitoring and management of the potentially impacted resource. Appendix VI of the FFACO specifically calls for establishing contaminant boundaries that define the aggregate maximum extent of contaminant transport at or above a concentration of concern, and that express modeling uncertainty through inclusion of a confidence interval in the boundary determination.

Three two-dimensional contaminant boundary maps are produced for each radionuclide of interest: an $x-y$ plan view, an $x$-z elevation view, and a $y$ - $z$ side view. To obtain the $x-y$ maps, at location $i, j$ (corresponding to $x-y$ ), the maximum concentration (normalized with respect to $C_{0}$ ) in any vertical cell is recorded; i.e., $C_{\max }(i, j)=\operatorname{Max}\left\{\left.C(i, j, k)\right|_{k=16 N L}\right\}$, where $N L$ is the number of cells in the vertical direction. The other $x-z$ and $y-z$ maps are obtained in a similar manner. Each flow realization thus produces three two-dimensional maps of $C_{\max }$, which are statistically analyzed in a post-processing mode. Two-dimensional maps provide the cleanest picture of the distribution of maximum concentration in each coordinate direction and are therefore presented here, rather than three-dimensional maps. The analysis of these maps and the final boundary delineating areas of $C_{\max }$ exceeding the drinking water standards depends on the level of confidence selected for the analysis. A $95^{\text {th }}$ percentile map is one that indicates there is a 95 percent certainty that the volume (or area) of contaminated water is less than what the map indicates. To analyze the map for any confidence level, the set of Monte Carlo realizations is used and each cell location is analyzed separately from other cells. For a particular cell, $C_{\max }$ of the different realizations is sorted in an ascending order. Each realization also has a likelihood weight associated with it, which was determined from the flow model calibration. Again, these weights are normalized such that their sum is unity. The sorted $C_{\max }$ array and the associated weights are used to calculate a cumulative sum for the cell under consideration. The values in that new array determine the maximum concentration value at the $90^{\text {th }}$ (cumulative weight $=0.9$ ), $95^{\text {th }}, 99^{\text {th }}$, or any other confidence level. At a given confidence level, one simply compares the maximum concentration to the U. S. Environmental Protection Agency drinking water standard for a particular radionuclide to determine whether or not that cell falls within the contamination boundary. With all time steps included in the analysis, the resulting boundaries represent all locations where the radionuclide plume exceeded the drinking water standard during the entire 1,000-year period. In other words, the boundary represents the locations that may exceed the threshold throughout the 1,000-year time period. At any one point in time, the volume (or area) that encompasses the cells that exceed the standard would be smaller than this cumulative boundary. 


\subsection{RESULTS OF TRANSPORT MODELING}

\subsection{Groundwater Velocity}

Cell-to-cell groundwater velocities are calculated for each flow realization using

$$
V(\boldsymbol{X})=-\frac{1}{\theta_{\text {eff }}} K(\boldsymbol{X}) \nabla h(\boldsymbol{X})
$$

where $V(\boldsymbol{X})$ is the velocity field, and $K(\boldsymbol{X})$ and $h(\boldsymbol{X})$ are the hydraulic conductivity field and hydraulic head field simulated for each realization in the calibrated flow model. The statistical distribution of effective porosity, $\theta_{\text {eff, }}$ is obtained from a numerical analysis of the tracer test, as was described in Section 4.1.4. A single value of effective porosity is randomly chosen from this distribution for each transport realization. To present the distributions of velocities over the entire Monte Carlo simulation, all 1,000 velocity fields are scanned to find the maximum and mean values within each one.

Maximum groundwater velocities, $V_{\max }$, are roughly log-normally distributed (Figure 5.1), reflecting the log-normal distributions of hydraulic conductivity, fracture length and porosity. The average maximum velocity over all realizations, $\left\langle V_{\max }\right\rangle$, is $2.6 \times 10^{-3} \mathrm{~m} / \mathrm{d}$, while all maximum velocities fall below $1.5 \times 10^{-2} \mathrm{~m} / \mathrm{d}$. The appropriate timestep, $\Delta t$, is calculated from $V_{\max }$ for each velocity realization to prevent cell overshoot during the transport calculations.

As expected from the configuration of the flux boundaries and the principal direction of fracture strikes in the flow model, the highest mean velocities are in the $y$ and $z$ directions (Figure 5.2), parallel to the long axis of the model and the trend of the shear zone. Recall that the fracture

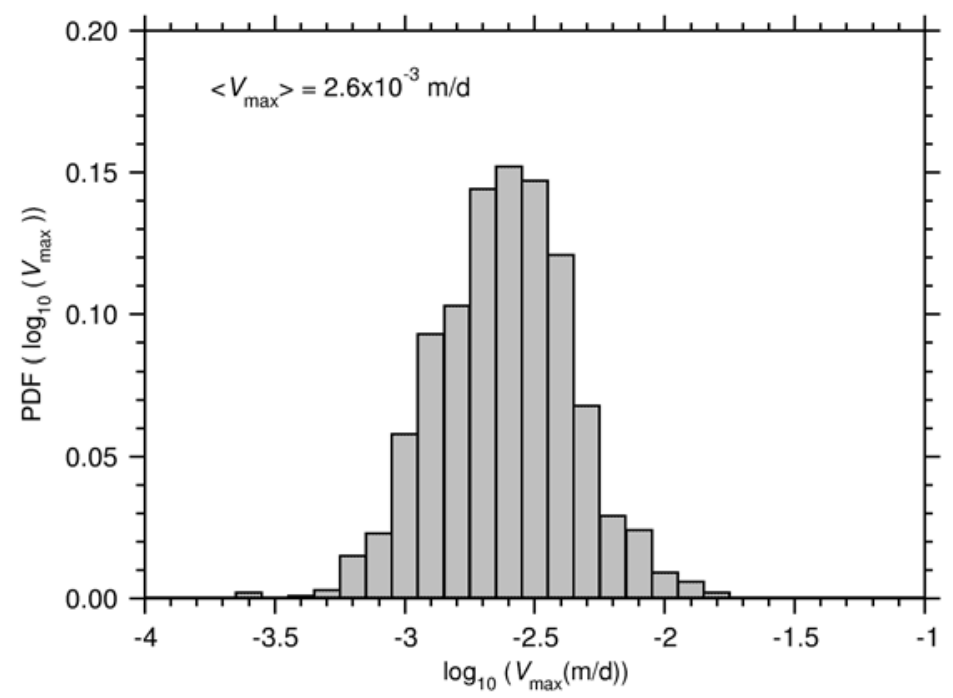

Figure 5.1. Plot of the distribution of $\log _{10}$-transformed maximum velocity vectors for all realizations. 
zones dip at about 60 to 65 degrees, so velocities downward along the fracture zones are actually higher than those shown here by about 10 to 20 percent. The small range of mean velocities in the $x$ direction (perpendicular to the long axis of the model) reflects movement along dipping fracture planes and fractures oriented off-axis to the principal fracture strike.

The distribution of mean velocity vectors falls between a log-normal and normal distribution. The expected value of approximately $8.2 \times 10^{-3} \mathrm{~m} / \mathrm{yr}\left(2.3 \times 10^{-5} \mathrm{~m} / \mathrm{d}\right)$ is much lower
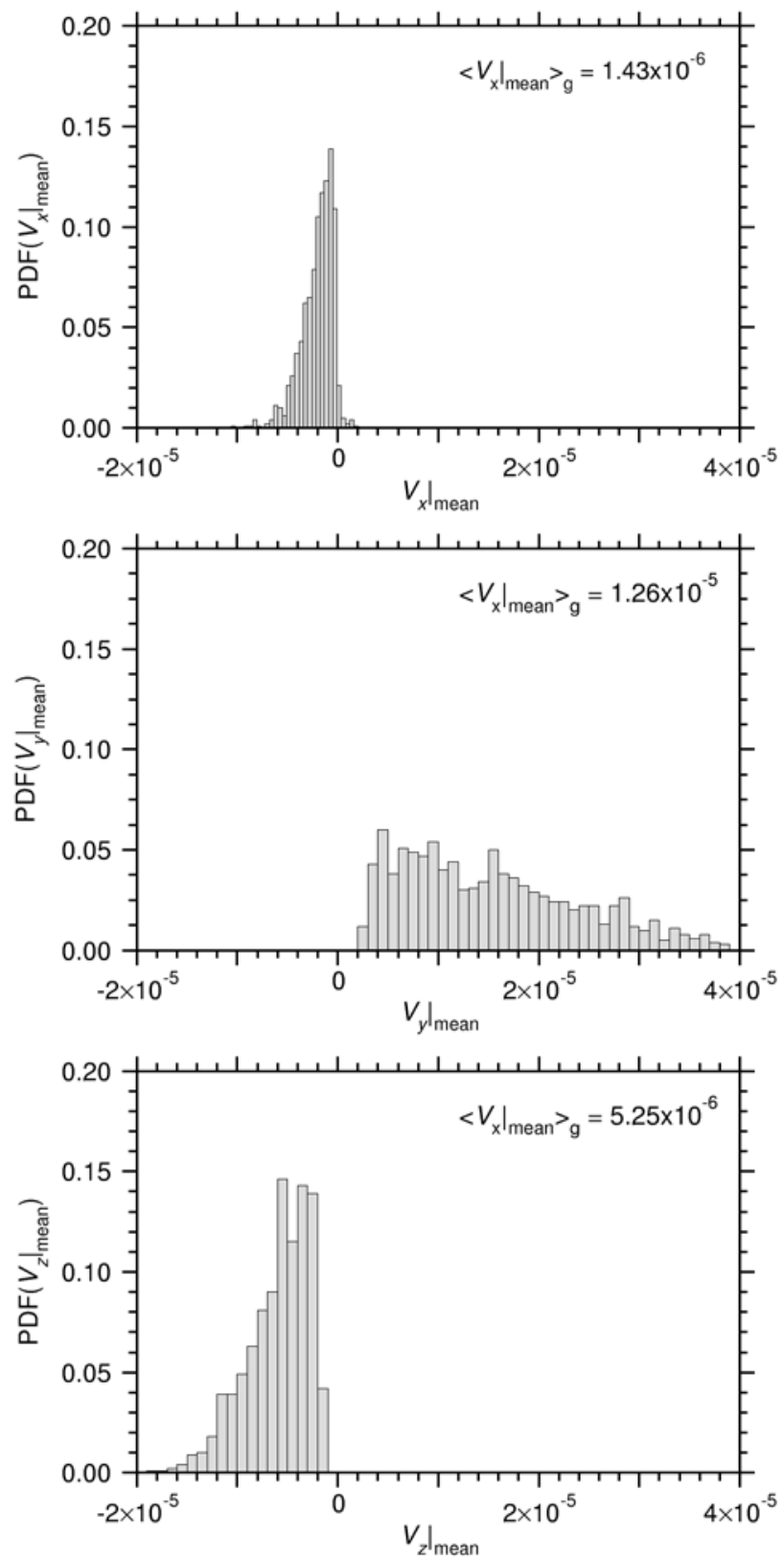

Figure 5.2. Plots of the distributions of average velocities in the three coordinate directions for all realizations. The geometric means of each distribution are also shown on each plot. 
than the $5 \mathrm{~m} / \mathrm{yr}$ calculated in the previous PSA transport model (Pohll et al., 1998), reflecting the higher mean porosity, lower recharge rate, and lower $\bar{K}$ used in the present model. Note that there is a much higher degree of confidence in the distribution of porosity used in the present model because it is based on the results of the site-specific PSA tracer test, rather than on porosity distributions reported from other sites. Likewise, estimates of the recharge rate have been refined by more detailed modeling of the recharge process at PSA, while the range of hydraulic conductivity reflects the collection and analysis of data from wells installed since 1998. The simulated mean velocity is more consistent with apparent groundwater ages suggested by the ${ }^{14} \mathrm{C}$ data.

\subsection{Transport Results}

The focus of the transport simulations is on delineating the areas where contaminant concentrations in groundwater exceed Maximum Contaminant Levels (MCLs). This can be done only by knowing the actual source mass for different radionuclides and the MCL associated with each element. This information, however, is classified and only unclassified estimates are used here for demonstration purposes. Unclassified estimates are available for the initial mass of four radionuclides (Hazleton-Nuclear Science, 1965): ${ }^{3} \mathrm{H}$, which is an element in class $1,{ }^{90} \mathrm{Sr}$, which is an element in class $3,{ }^{137} \mathrm{Cs}$, which is an element in class 5 , and ${ }^{151} \mathrm{Sm}$, which is an element in class 6. Table 5.1 lists the transport parameters for each one of these classes used in the transport simulations. The unclassified initial masses in Curies are $3.0 \times 10^{4}$ for ${ }^{3} \mathrm{H}, 1.9 \times 10^{3}$ for ${ }^{90} \mathrm{Sr}, 2.2 \times$ $10^{3}$ for ${ }^{137} \mathrm{Cs}$, and $4.2 \times 10^{2}$ for ${ }^{151} \mathrm{Sm}$. Table 5.2 lists the values of the transport parameters that do not change between the six transport classes. Transport simulations are performed using a particletracking approach with particle-transfer probabilities to account for matrix diffusion. To explain how the contaminant boundary maps are produced, a number of figures are presented to show the results of different stages of the simulation process. This set of figures is based on class 1 transport parameters, unless otherwise stated in the following discussions.

Figure 5.3 displays three snapshots of the particle distribution in the simulation domain at 100,500 and 1,000 years for a single realization. The three plots on the left represent vertical $(y-z)$

Table 5.1. Values of parameters specific to individual transport classes.

\begin{tabular}{|c|c|c|c|c|c|c|}
\hline Parameter & Class 1 & Class 2 & Class 3 & Class 4 & Class 5 & Class 6 \\
\hline $\begin{array}{c}\text { Release ratio (\%) } \\
\text { Hydraulic release/ } \\
\text { geochemical release }\end{array}$ & $100 / 0$ & $50 / 50$ & $40 / 60$ & $5 / 95$ & $80 / 20$ & $5 / 95$ \\
\hline$R_{m}$ & 1 & 1 & 5.4 & 1 & 5700 & $6.5 \times 10^{5}$ \\
\hline$R_{f}$ & 1 & 1 & 1.2 & 1 & 1.2 & 22 \\
\hline \# particles & 40,000 & 40,000 & 40,000 & 160,000 & 40,000 & 160,000 \\
\hline Radionuclides & $\begin{array}{c}{ }^{3} \mathrm{H},{ }^{14} \mathrm{C}, \\
{ }^{85} \mathrm{Kr},{ }^{85} \mathrm{Rb}\end{array}$ & ${ }^{36} \mathrm{Cl},{ }^{129} \mathrm{I}$ & $\begin{array}{c}{ }^{90} \mathrm{Sr},{ }^{90} \mathrm{Y} \\
{ }^{90} \mathrm{Zr}\end{array}$ & ${ }^{99} \mathrm{Tc}$ & ${ }^{137} \mathrm{Cs}$ & $\begin{array}{c}{ }^{151} \mathrm{Sm},{ }^{152} \mathrm{Eu},{ }^{154} \mathrm{Eu}, \\
{ }^{234} \mathrm{U},{ }^{238} \mathrm{U},{ }^{237} \mathrm{~Np}, \\
{ }^{239} \mathrm{Pu},{ }^{240} \mathrm{Pu},{ }^{241} \mathrm{Am}\end{array}$ \\
\hline
\end{tabular}


Table 5.2. Values of parameters common to all transport classes.

\begin{tabular}{|c|c|}
\hline Parameter & Value \\
\hline \multicolumn{2}{|l|}{ Location of Source, World Coordinates } \\
\hline Easting (m) & 380808 \\
\hline Northing (m) & 4339630 \\
\hline Elevation (m AMSL) & 1,220 \\
\hline \multicolumn{2}{|l|}{ Location of Source, Model Coordinates } \\
\hline $\mathrm{X}(\mathrm{m})$ & 1,211 \\
\hline $\mathrm{Y}(\mathrm{m})$ & 540 \\
\hline $\mathrm{Z}(\mathrm{m})$ & 1,220 \\
\hline Radius of Cavity (m) & 20 \\
\hline Radius of Prompt Injection (m) & 100 \\
\hline Infill Time (years) & 0 \\
\hline Total Simulation Time (years) & 1,000 \\
\hline Longitudinal Dispersivity (m) & 2.0 \\
\hline Transverse Dispersivity (m) & 0.2 \\
\hline \multicolumn{2}{|l|}{ Retardation (dimensionless) } \\
\hline Damaged Zone & 1.0 \\
\hline Cavity & 1.0 \\
\hline \multicolumn{2}{|l|}{ Porosity (dimensionless) } \\
\hline Matrix & 0.015 \\
\hline Fractures & 0.005 to 0.07 \\
\hline Damaged Zone & 0.07 to 0.18 \\
\hline Cavity & 0.18 to 0.35 \\
\hline Matrix Diffusion Coefficient (m²/d) & $1.0 \times 10^{-6}$ \\
\hline Fracture Spacing (m) & 0.5 \\
\hline Glass Release Coefficient (1/d) & $9.23 \times 10^{-8}$ to $9.23 \times 10^{-7}$ \\
\hline Number of Realizations & 1,000 \\
\hline
\end{tabular}

views at the three times where $z$ represents the elevation AMSL in $\mathrm{m}$, and the right plots represent plan $(x-y)$ views of the three-dimensional plume (particle) distribution. The figure highlights the features of the flow field, where particles move downward due to the imposed surface recharge, and laterally in the positive $y$ direction. After 500 years, particles move at most $500 \mathrm{~m}$ laterally and about $300 \mathrm{~m}$ vertically downward. In 1,000 years, about 0.005 percent of the particles (two 

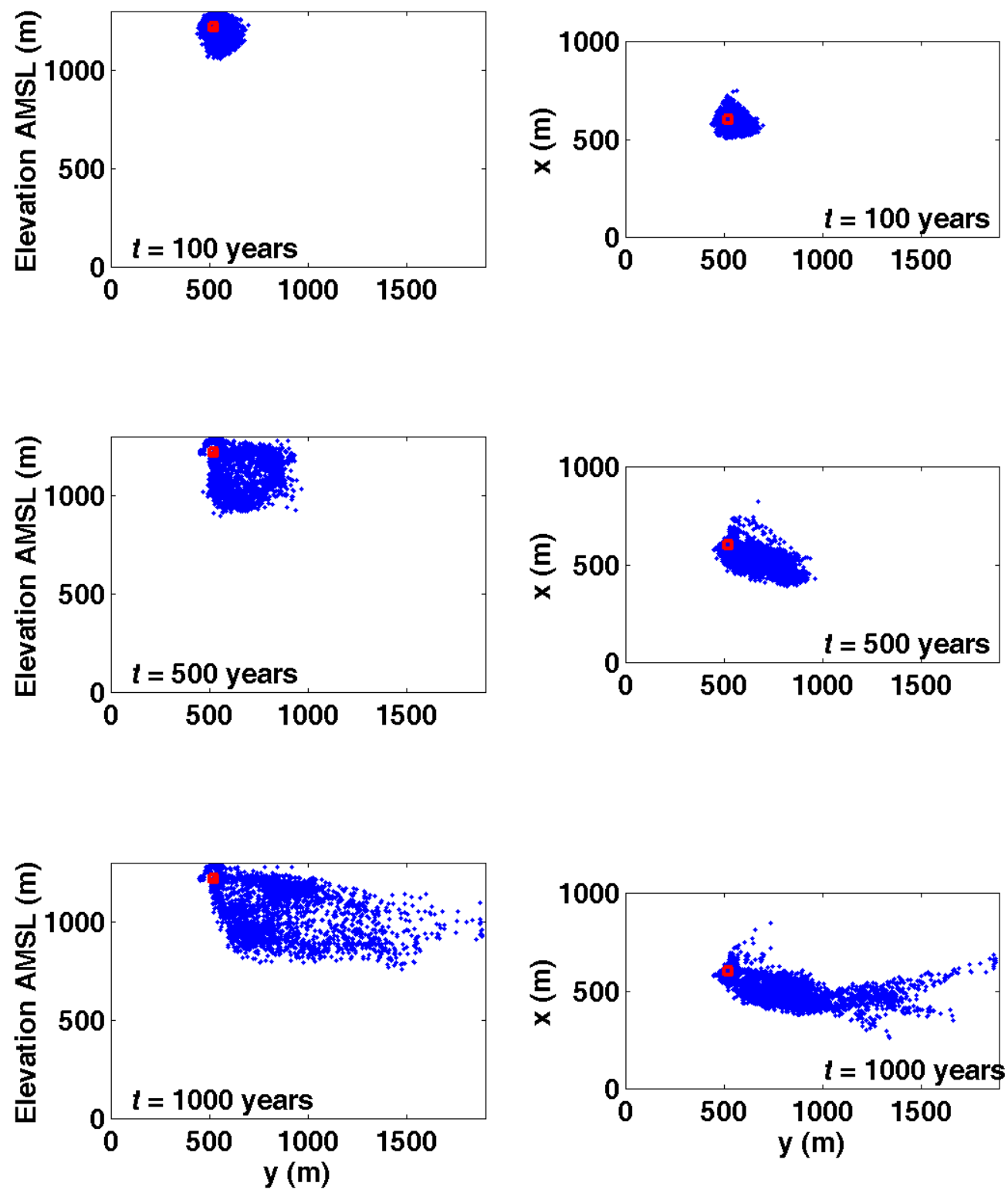

Figure 5.3. Snapshots of the three-dimensional particles distribution (projected in plan and vertical views) for class 1 simulations showing the extent and pattern of movement in a single flow realization.

particles out of 40,000) reach the boundary of the simulation domain for that particular realization. It should be mentioned, however, that the particles in these figures have undergone advection, dispersion, and matrix diffusion, but not radioactive decay. The figure is aimed at displaying the flow pattern that is repeated in many realizations: vertical downward movement accompanied 
by lateral movement in a northeasterly direction. How far the particles travel in different realizations is dependent upon the location and hydraulic conductivity of the fractures, the fracture porosity value, the surface recharge, and the value of the flux at the southern inflow boundary, all of which are spatially variable and/or uncertain parameters.

For each one of the 1,000 realizations, two-dimensional projected maps ( $x-y, x-z$, and $y-z)$ of maximum concentration are produced for those elements for which unclassified estimates of the initial source mass are available. Section 4.2.2 describes the procedure followed to obtain these maps. Figure 5.4 shows the three ${ }^{3} \mathrm{H}$ maximum concentration maps for the same flow realization used in Figure 5.3. It can be seen that very high concentration exists around the cavity and extends for about $300 \mathrm{~m}$ in the $y$ direction and for a similar distance in the vertical $z$ direction ( $\mathrm{z}$ axis as elevation, m AMSL). Beyond the $300 \mathrm{~m}$, the maximum concentration values for ${ }^{3} \mathrm{H}$ are below the MCL and they quickly fall below the detection limit. Figure 5.5 is similar to Figure 5.4, but is produced using a different flow realization. The figure exhibits less longitudinal (y-direction) movement as compared to Figure 5.4. However, the highly contaminated area is similarly localized around the cavity as in Figure 5.4. Most of the remaining realizations exhibit similar
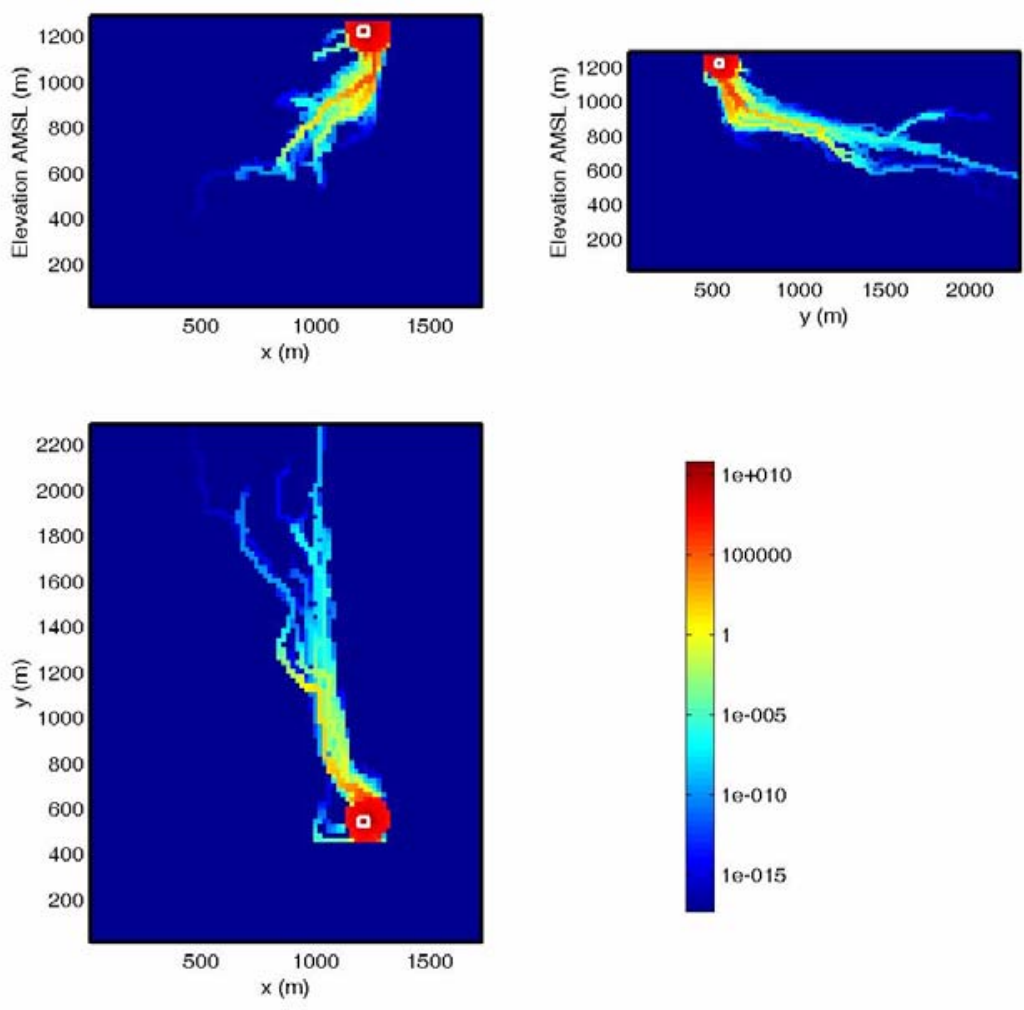

Figure 5.4. Projected maps of the maximum concentration distribution for ${ }^{3} \mathrm{H}$ for the flow realization used in Figure 5.3. 
patterns to these two realizations, with sometimes faster longitudinal or vertical transport. It should be emphasized here that the concentration values in Figures 5.4 and 5.5 are obtained with radioactive decay for ${ }^{3} \mathrm{H}$ accounted for, whereas the results of Figure 5.3 are only particle positions at different times before converting to concentration and applying the decay computation.

With the uncertainty of the flow and transport parameters, many flow scenarios are possible, and in combination with the different possibilities for the values of the transport parameters, a spectrum of possible transport regimes results, which is statistically analyzed to obtain final representative maps of the contaminant boundaries. This statistical analysis is applied in a similar manner to each one of the three projection maps of maximum concentration shown in Figures 5.4 and 5.5. For demonstration purposes, the analysis of two cells in the $x-y$ map is shown in Figures 5.6 to 5.8 and explained in detail here. Two cells are selected such that one cell is within the contaminant boundary and the other cell is outside the boundary. The description below and Figures 5.6 to 5.8 explain how the determination is made as to whether a particular cell is inside or outside the contaminant boundary. The plots of Figure 5.6 show the maximum concentrations at cell $1,\left.C_{\max }\right|_{1}$, and cell $2,\left.C_{\max }\right|_{2}$, for 12 realizations, which are the realizations producing the
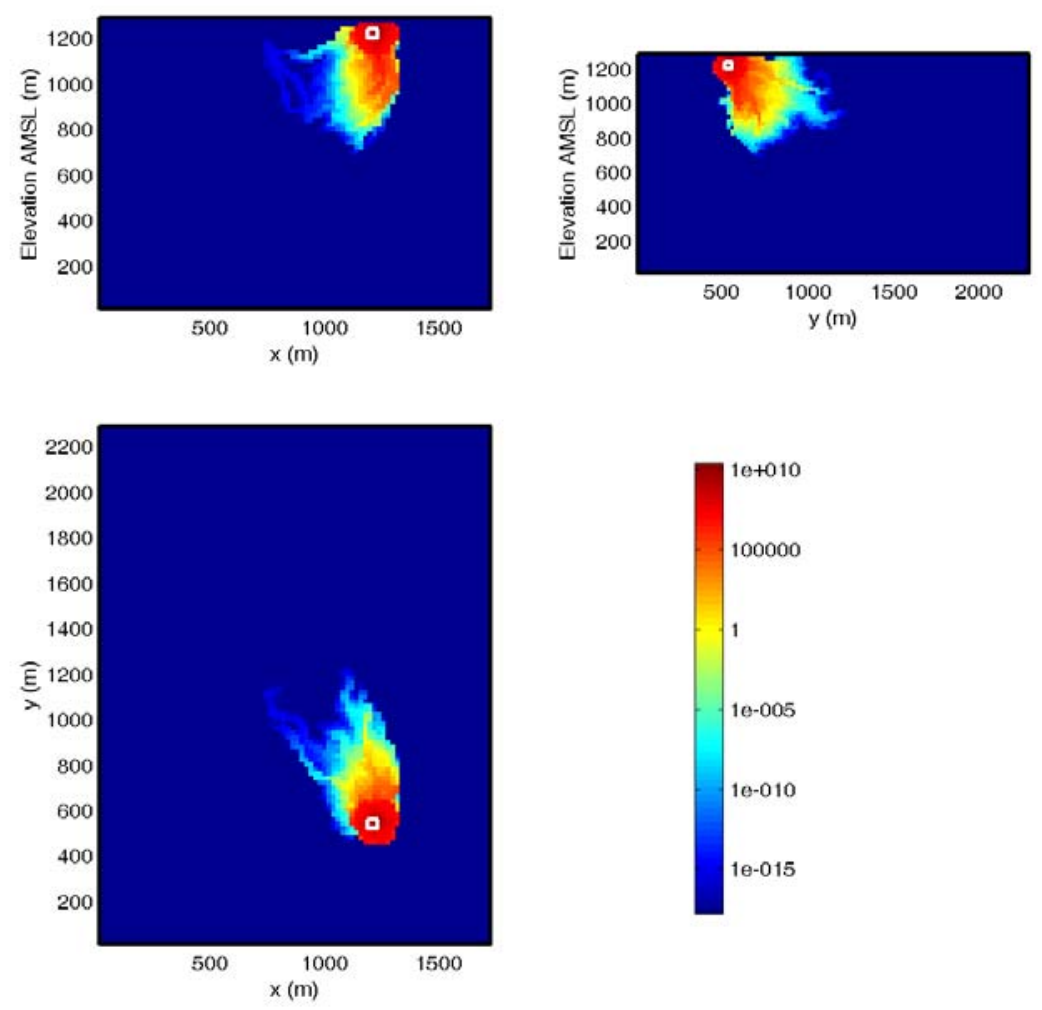

Figure 5.5. Same as Figure 5.4, but for a different realization. 
lowest $C_{\max }$ values for both cells. The concentration values in the plot are sorted in an ascending order. It is clear that the realizations producing the lowest $C_{\max }$ values are different for the two cells. Realization number 514 produced the absolute minimum value for $\left.C_{\max }\right|_{1}$, whereas realization 775 produced the absolute minimum for $\left.C_{\max }\right|_{2}$. Though the highest $C_{\max }$ values are not shown in Figure 5.6, the results of all 1,000 flow realizations show that cell 1 has attained a maximum concentration ranging from $2.1 \times 10^{9}$ to $2.7 \times 10^{11} \mathrm{pCi} / \mathrm{L}$, whereas cell 2 concentrations range from $3.7 \times 10^{6}$ to $1.2 \times 10^{9} \mathrm{pCi} / \mathrm{L}$. Once these $C_{\max }$ values are sorted in an ascending order, the GLUE weights obtained from the flow modeling and assigned to each realization are paired to the corresponding $C_{\max }$ for each realization. That weight reflects the residual difference between measured and simulated heads in the flow model, and is obtained as shown earlier in Section 3.3. Thus, the weight that is paired with the absolute minimum of $\left.C_{\max }\right|_{1}$ is the weight obtained from the flow realization number 514 as shown in Figure 5.7. For cell 2, the weight paired to the absolute minimum value of $\left.C_{\max }\right|_{2}$ corresponds to realization 775 .
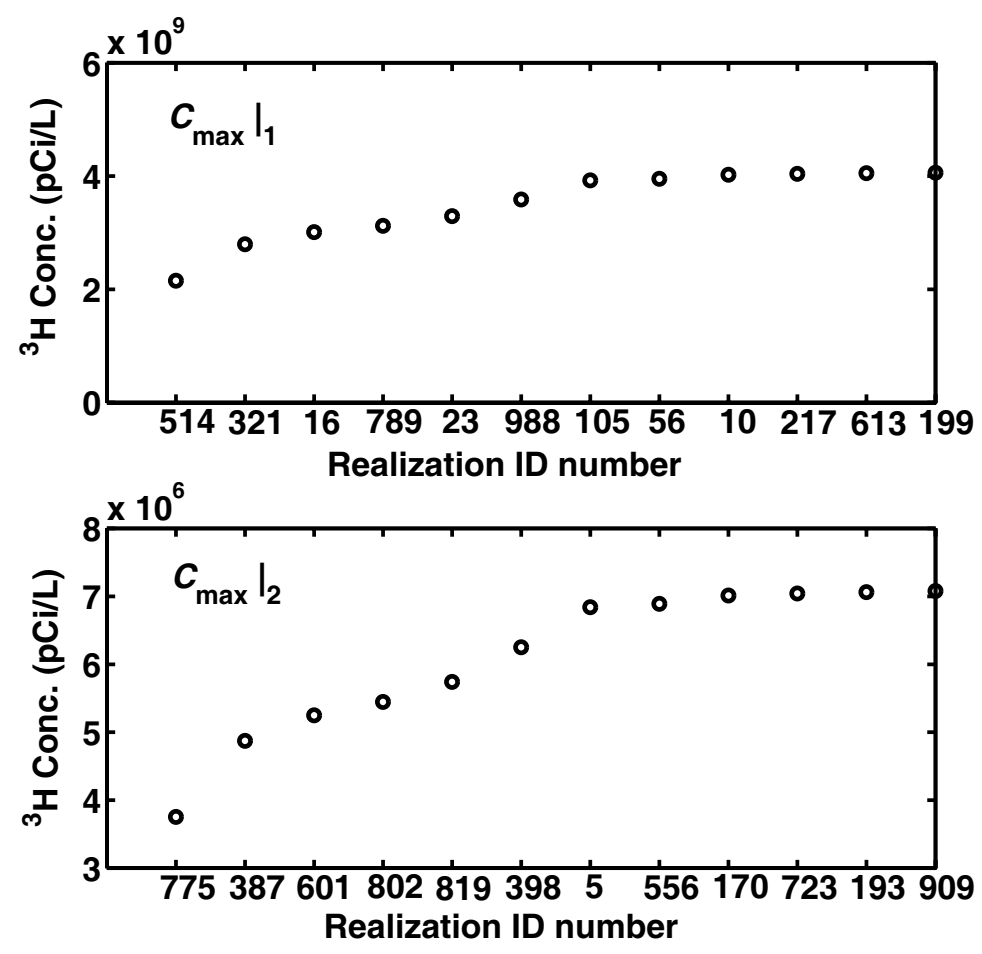

Figure 5.6. Maximum concentrations at two cells sorted in an ascending order for 12 realizations that produce the lowest $C_{\max }$ values. 


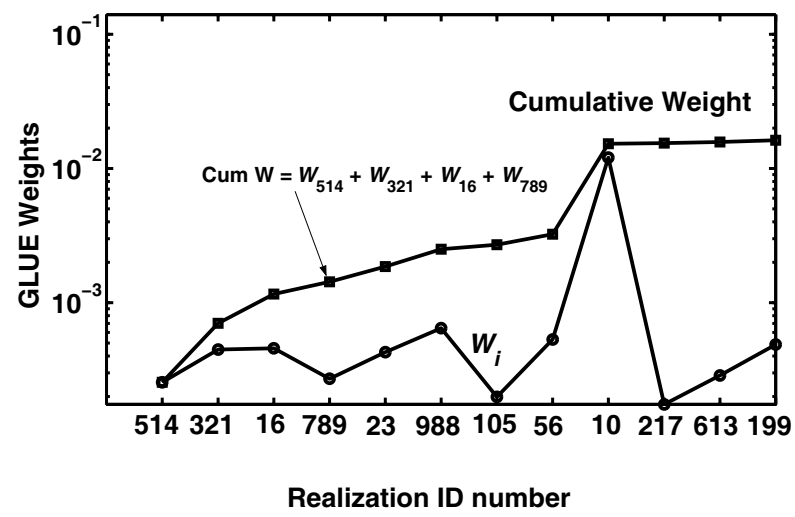

Figure 5.7. Individual GLUE weights and the cumulative weights for the 12 realizations that produce the lowest $C_{\max }$ values at cell 1 .
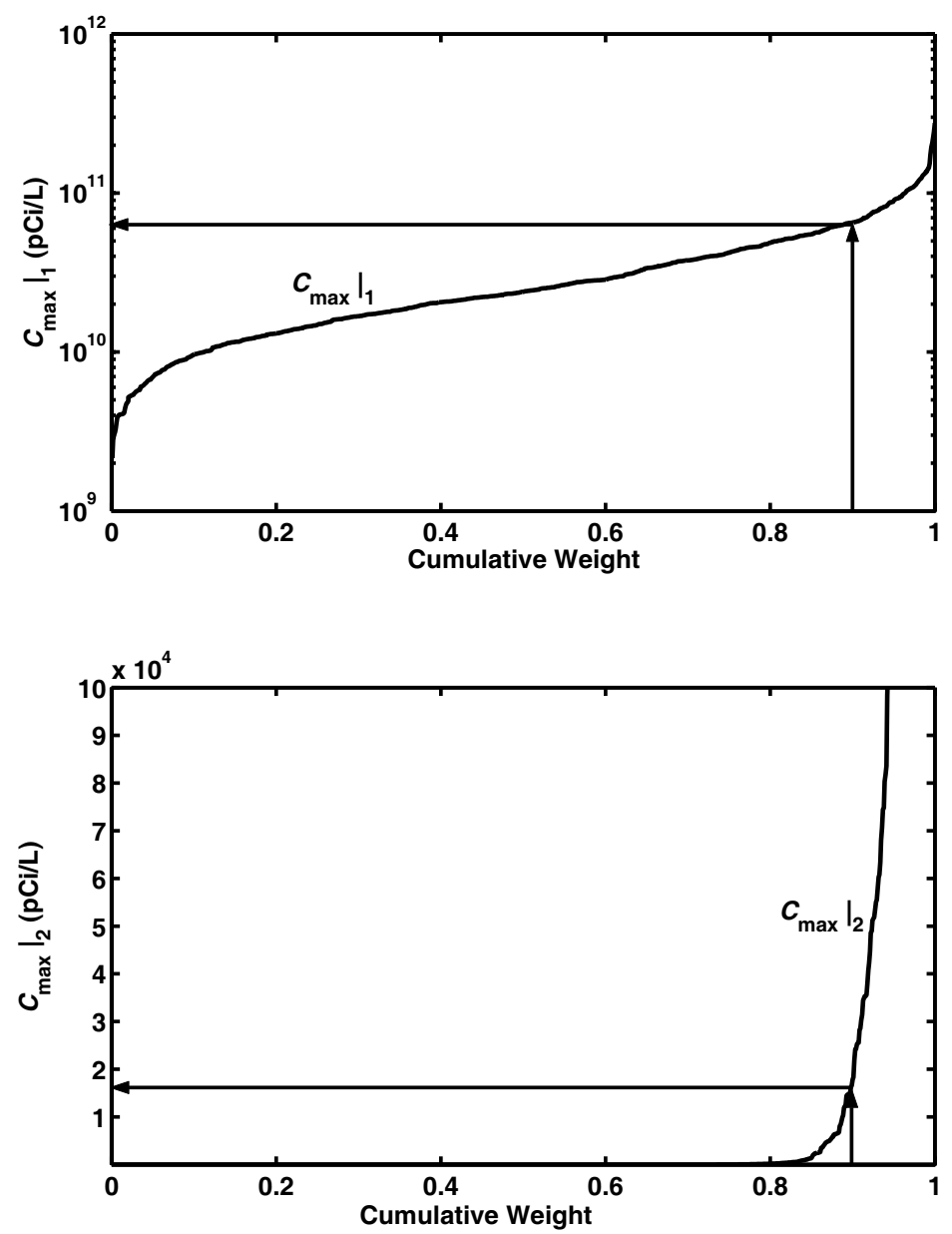

Figure 5.8. $\quad C_{\max }$ versus the cumulative GLUE weights with the arrows showing how the cell is determined to be within or outside of the contaminant boundary at the 90 percent confidence level. 
The final step is to compute the cumulative weights, which enable the determination of whether a cell is within the contaminant boundary or outside of it at any given confidence level. The plot of Figure 5.7 shows the cumulative GLUE weights obtained for the first 12 values assigned to the lowest 12 values of $\left.C_{\max }\right|_{1}$. One thus obtains a new set of paired values: $\left.C_{\max }\right|_{1}$ and the cumulative weight computed by adding the weight assigned to the current $\left.C_{\max }\right|_{1}$ value and the weights assigned to all the values of $\left.C_{\max }\right|_{1}$ smaller than the current value. This process is repeated for all the cells in the plan view of the model domain. The paired values are then plotted with the cumulative weight on the horizontal axis and the $C_{\max }$ value on the vertical axis. Figure 5.8 shows the plots of $\left.C_{\max }\right|_{1}$ versus the cumulative weight (top plot) and $\left.C_{\max }\right|_{2}$ versus the cumulative weight (lower plot). To explain how the cells are determined to be within or outside of the contaminant boundary, the desired confidence level is chosen and a vertical line is drawn at this level starting from the cumulative weight axis as shown in Figure 5.8. Then a horizontal line is drawn from the intersection of the $C_{\max }$-cumulative weight curve with that vertical line. The value that is identified by the horizontal line is then compared to the MCL for the particular radionuclide. If the value is above the MCL, then the cell belongs to the contaminant boundary area, otherwise the cell is located outside of the boundary. It can be seen that the concentration of cell 1 exceeds the MCL for ${ }^{3} \mathrm{H}(20,000 \mathrm{pCi} / \mathrm{L})$, whereas cell 2 is below this threshold $(\sim 16,000$ $\mathrm{pCi} / \mathrm{L}$ ) at the 90 percent confidence level. This is shown by the vertical arrows at the cumulative weight of 0.9 and the horizontal arrows pointing to the concentration values at this cumulative weight. This result indicates that in roughly 90 percent of the output realizations, cell 2 has ${ }^{3} \mathrm{H}$ concentrations below 16,000 pCi/L. However, increasing the confidence level up to the 95 percent level renders both cells as contaminated, and thus they would be within the contaminant boundary for the $x-y$ plan view.

The process described above is repeated for each cell in the $x-y$ map view and also for each cell in the other two vertical views, the $x-z$ and the $y-z$ projections. The contaminant boundary maps can then be presented at any desired confidence level. Figures 5.9 and 5.10 show the contaminant boundary maps for ${ }^{3} \mathrm{H}$ at the 50 percent and the 95 percent confidence levels, respectively. As can be seen in the figures, the 50 percent result shows very little high concentration extent beyond the initial source location. The 95 percent result, however, exhibits a lateral extent in the $y$ direction of about $180 \mathrm{~m}$ downgradient of the cavity and a vertical extent of about $160 \mathrm{~m}$ below the cavity. Based on these results, the ${ }^{3} \mathrm{H}$-contaminated area will be localized in the vicinity of the source.

For ${ }^{90} \mathrm{Sr}$, which is an element in class 3 , similar analysis is performed by using the transport results for class 3 (Figures 5.11 and 5.12). These results are different than the results for class 1 because 60 percent of the mass in class 3 is assumed to be trapped in a glass puddle, whereas class 1 has all mass released instantaneously via hydraulic release. Also, matrix retardation exists for class 3 with an $R_{m}$ value of 5.4. These two factors lead to a much slower transport in class 3 as compared to class 1 , and as a result, the contaminant boundary maps for ${ }^{90} \mathrm{Sr}$ are very localized around the cavity. 

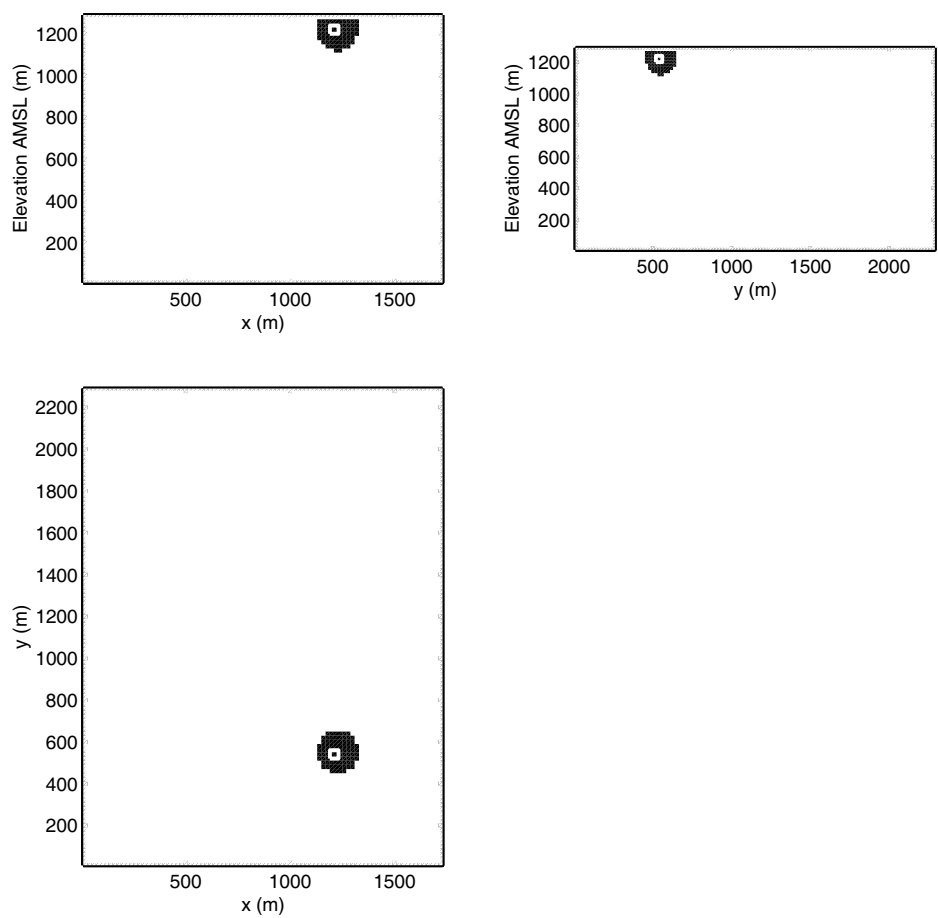

Figure 5.9. Contaminant boundary maps for ${ }^{3} \mathrm{H}$ delineating the areas exceeding $20,000 \mathrm{pCi} / \mathrm{L}$ at the 50 percent confidence level for the 1,000-year simulation period.
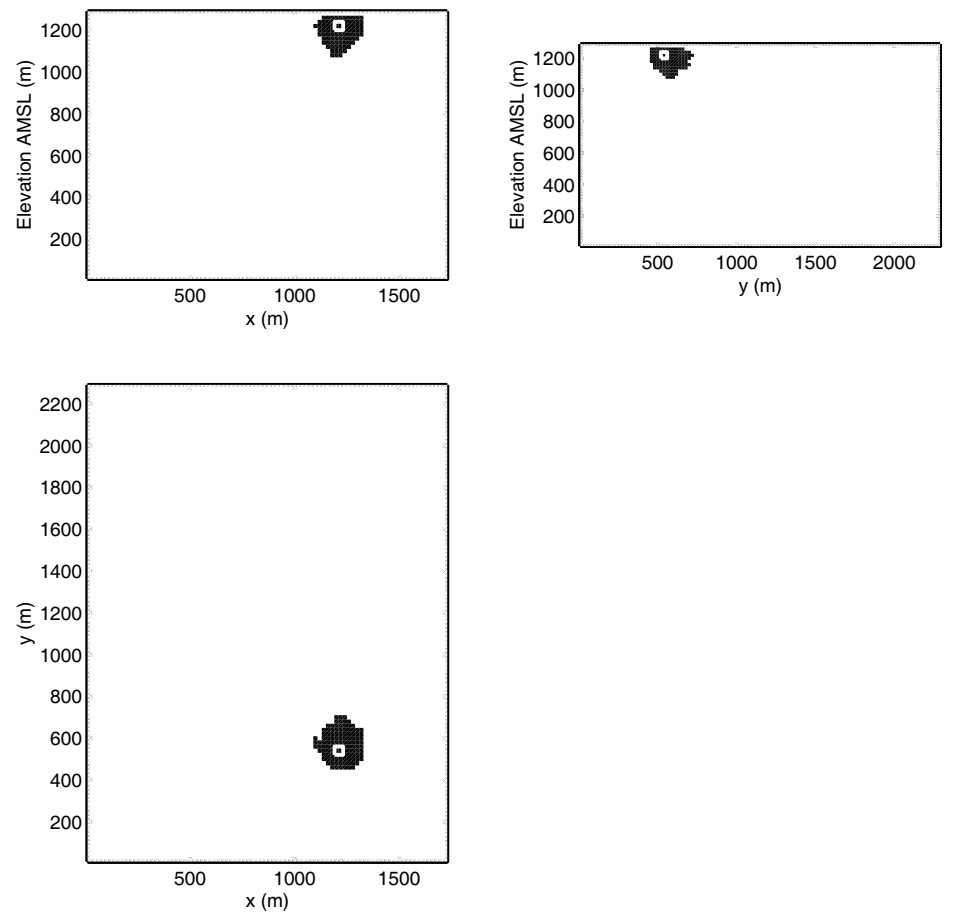

Figure 5.10. Contaminant boundary maps for ${ }^{3} \mathrm{H}$ delineating the areas exceeding 20,000 pCi/L at the 95 percent confidence level for the 1,000-year simulation period. 
The maps are even more localized for ${ }^{137} \mathrm{Cs}$ and ${ }^{151} \mathrm{Sm}$ since the matrix retardation values for these elements are two and four orders of magnitude higher than ${ }^{90} \mathrm{Sr}$, respectively. The results for these two elements are shown in Figures 5.13 to 5.16. Again, the extremely large matrix retardation inhibits transport and leads to concentration of particles in the immediate vicinity of the cavity by virtue of matrix diffusion. Very long residence times are encountered with this high matrix retardation, which allows for significant radioactive decay for these relatively short-lived nuclides.
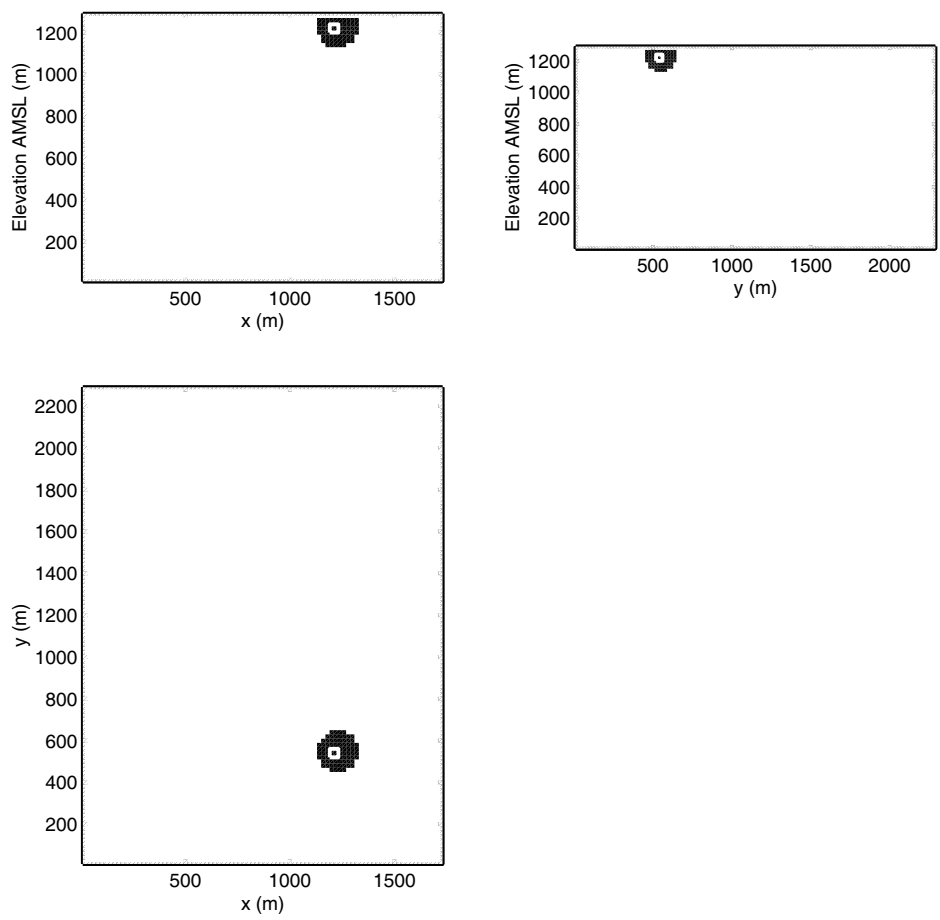

Figure 5.11. Contaminant boundary maps for ${ }^{90} \mathrm{Sr}$ delineating the areas exceeding $8 \mathrm{pCi} / \mathrm{L}$ at the 50 percent confidence level. 

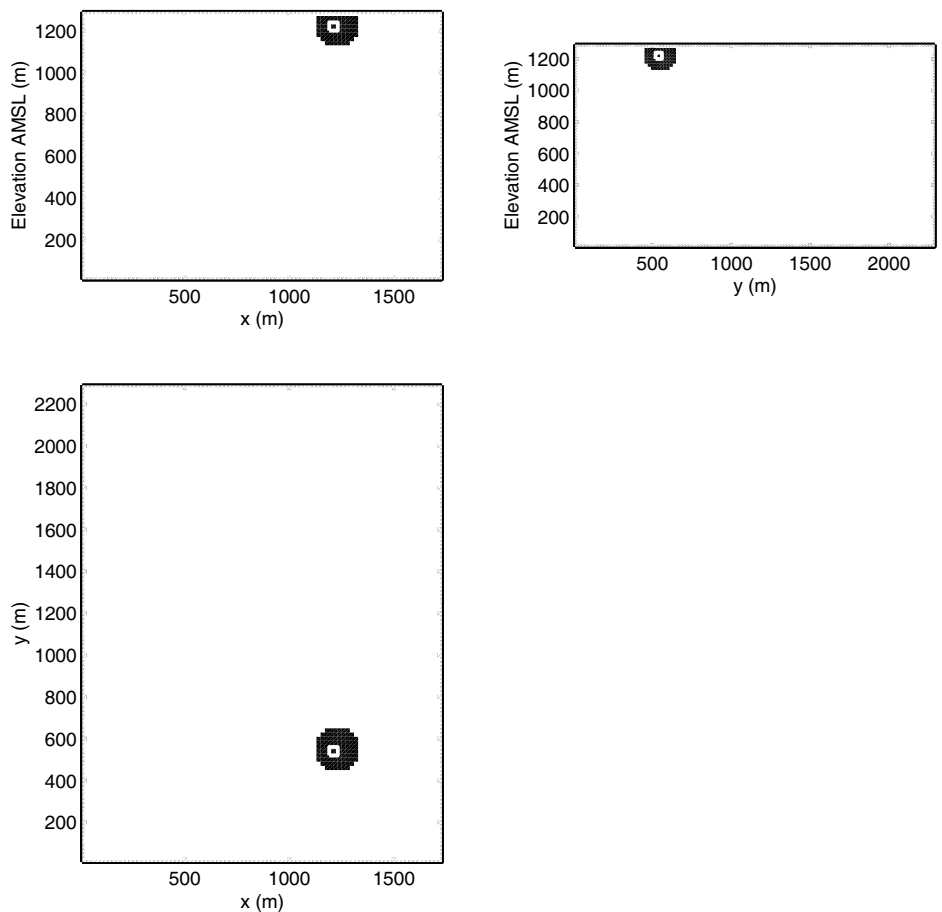

Figure 5.12. Contaminant boundary maps for ${ }^{90} \mathrm{Sr}$ delineating the areas exceeding $8 \mathrm{pCi} / \mathrm{L}$ at the 95 percent confidence level.
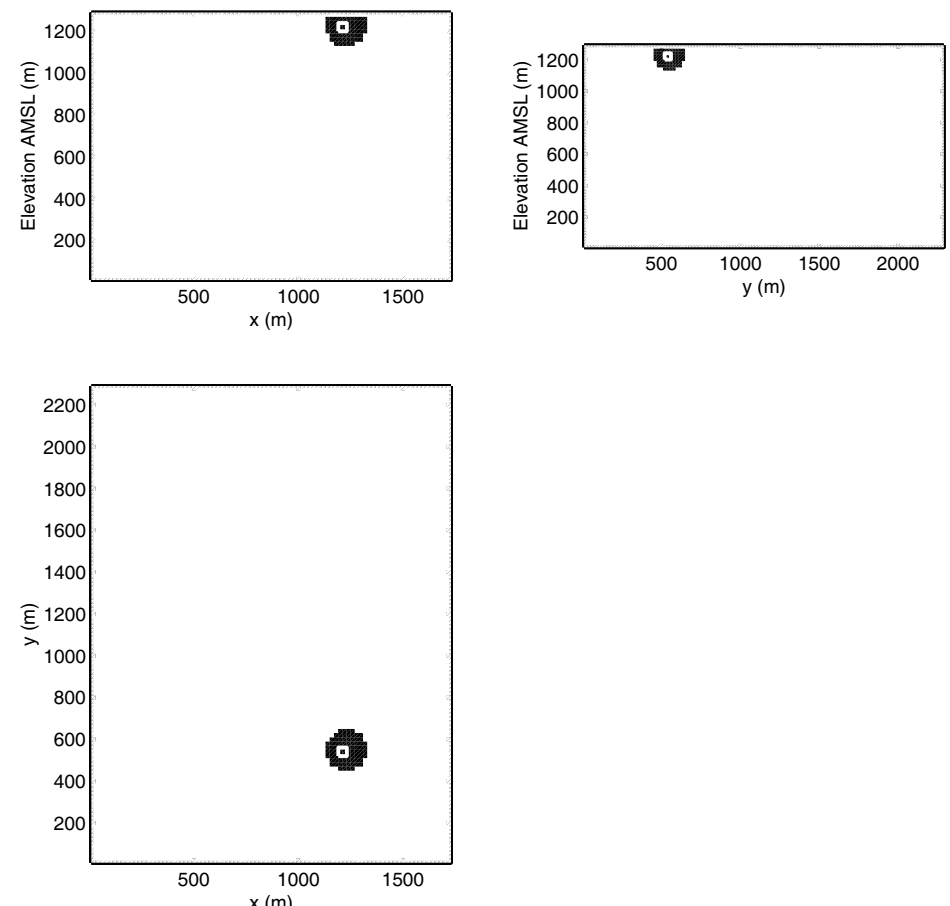

Figure 5.13. Contaminant boundary maps for ${ }^{137} \mathrm{Cs}$ delineating the areas exceeding $200 \mathrm{pCi} / \mathrm{L}$ at the 50 percent confidence level. 

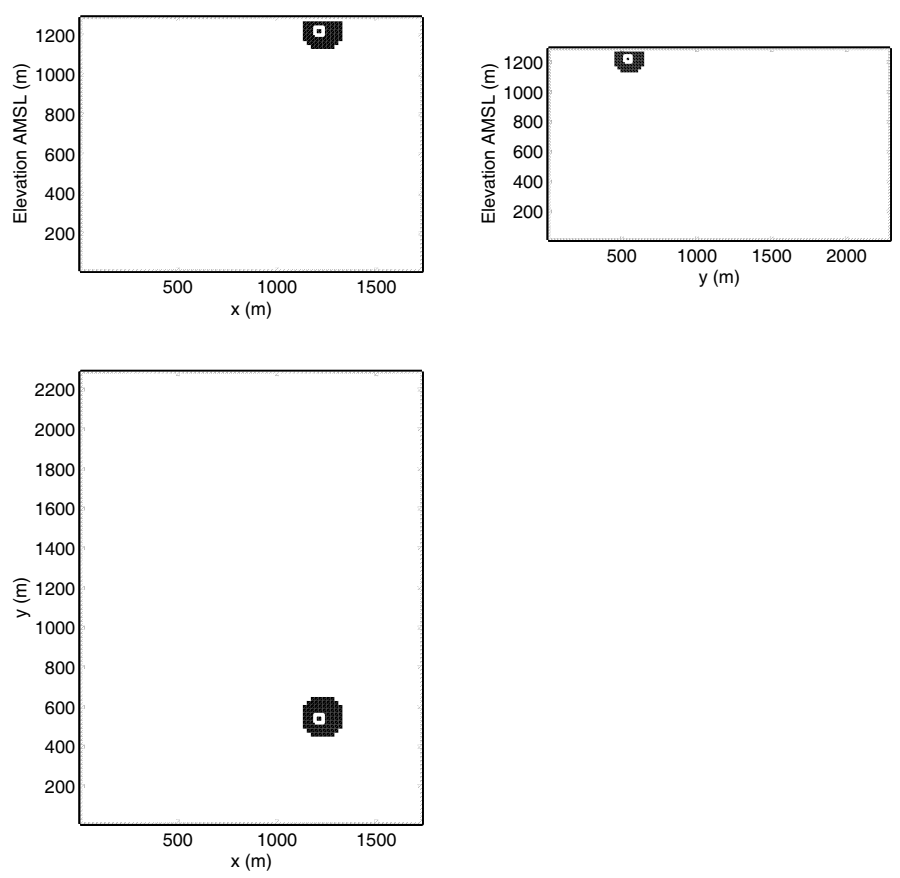

Figure 5.14. Contaminant boundary maps for ${ }^{137} \mathrm{Cs}$ delineating the areas exceeding $200 \mathrm{pCi} / \mathrm{L}$ at the 95 percent confidence level.
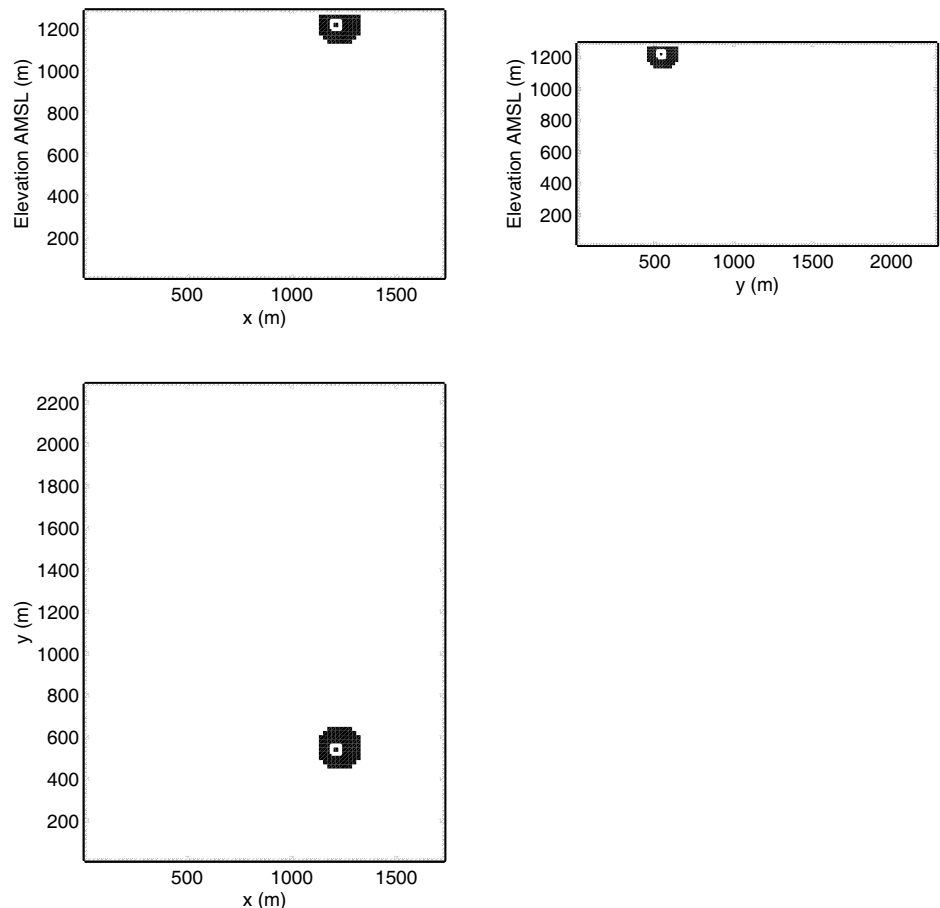

Figure 5.15. Contaminant boundary maps for ${ }^{151} \mathrm{Sm}$ delineating the areas exceeding $1,000 \mathrm{pCi} / \mathrm{L}$ at the 50 percent confidence level. 

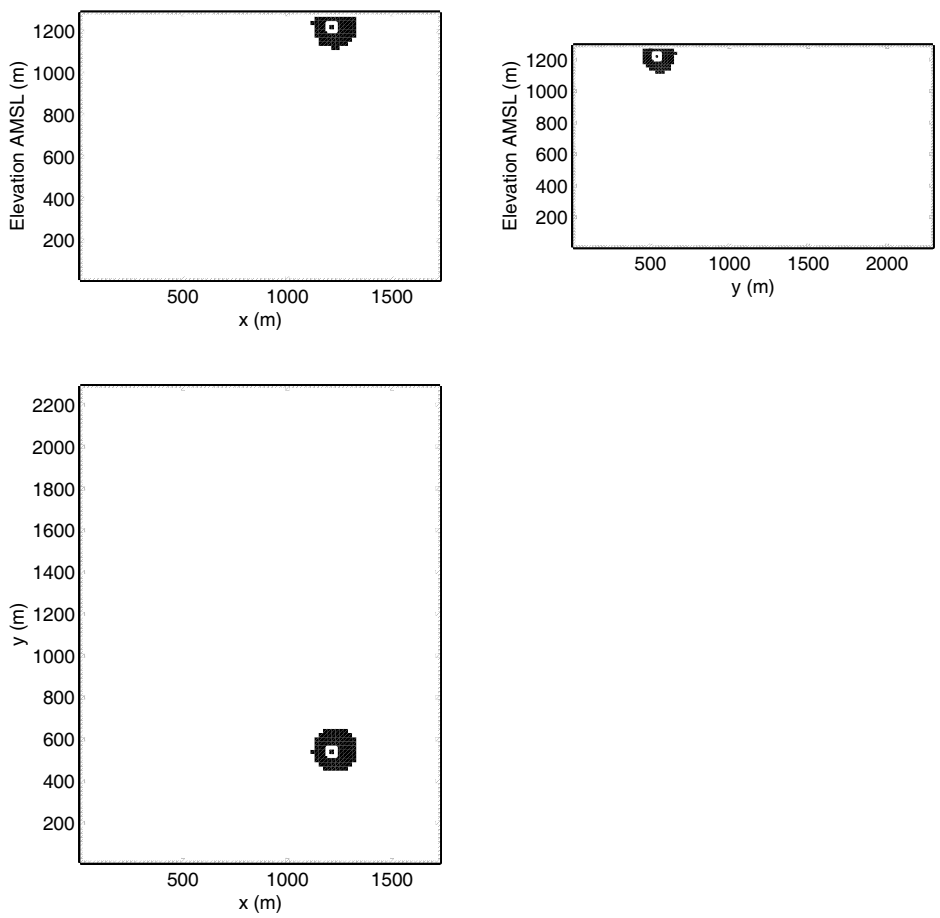

Figure 5.16. Contaminant boundary maps for ${ }^{151} \mathrm{Sm}$ delineating the areas exceeding $1,000 \mathrm{pCi} / \mathrm{L}$ at the 95 percent confidence level. 
THIS PAGE LEFT INTENTIONALLY BLANK 


\subsection{MODEL VERIFICATION}

Model verification is required in the process being followed for characterizing underground nuclear tests on the Nevada Test Site. The corrective action strategy for the offsite nuclear test areas (FFACO, 2000) specifies that the concepts developed for the UGTA CAUs on the Nevada Test Site will be applied on a more limited scale to groundwater at the Offsites. Verification of the Shoal model pursues two approaches. First, the numerical model is quantitatively verified by using the calibrated model to reproduce an independent data set. Second, aspects of the conceptual model are verified using interpretations of hydrochemical analyses.

\subsection{Numerical Model Verification}

In accordance with the FFACO and standard groundwater modeling practices, a calibrated groundwater model needs to be verified to establish a greater confidence in the model calibration (ASTM, 1995; Anderson and Woessner, 2002). ASTM (1995) provides guidance on groundwater model verification and suggests that an independent data set be used in the verification process. Furthermore, Anderson and Woessner (2002) suggest that:

In a typical verification exercise, values of parameters and hydrologic stresses determined during calibration are used to simulate a transient response for which a set of field data exists. Examples of transient data sets include pumping test data and changes in water levels in response to a drought or to long-term pumping.

The tracer test experiment conducted at Project Shoal provides an excellent data set to be used in flow model verification. The tracer test is essentially a long-term pumping test that can be used to evaluate how well the model simulates the groundwater flow conditions observed in the field.

The verification exercise is performed by utilizing the hydrogeologic parameters and stresses used in the steady-state model, but with the inclusion of the pumping and injection stresses applied during the tracer experiment. This transient modeling is performed in a Monte Carlo framework in a manner that is essentially identical to the methods utilized for the steadystate flow model. Therefore, all 1,000 realizations obtained from the steady-state analysis are used in this verification exercise. The hydraulic conductivity field and boundary conditions are used directly from the steady-state model. The pumping and injection rates are specified from measured rates taken during the tracer test experiment and are shown in Figures 6.1 and 6.2 for HC-6 and HC-7, respectively. Figures 6.1 and 6.2 show the pumping and injection rates relative to the start of the tracer test on November 3, 1999.

Converting a steady-state groundwater model to a transient model requires that the aquifer storage parameter be specified. The pumping associated with the tracer test occurred near the water table surface, so any changes in the water table elevation will be controlled by the draining and filling of fractures. The aquifer storage parameter associated with draining and filling processes in an unconfined aquifer is known as the specific yield. Anderson and Woessner (2002) suggest the use of "best guesses" for the storage parameters, because they are not used in the 
steady-state calibration process. At Project Shoal, the specific yield is not known, so an automated calibration process is used to develop our best guess for this parameter. PEST (Doherty, 2000) is used to estimate the specific yield value for each of the 1,000 realizations by adjusting the specific yield value until a reasonable agreement is met between the simulated and observed drawdowns at HC-6 (injection well) and HC-7 (pumping well).

The GLUE algorithm is used to weight individual realizations such that those realizations that are in good agreement receive higher weight. Because two sets of results (i.e. steady-state heads and transient drawdowns) are available to calculate the likelihood weights, the likelihood weights are calculated in a two-step process as:

$$
P(\vec{\theta} \mid \vec{Y})=\frac{L(\vec{Y} \mid \vec{\theta}) P(\vec{\theta})}{C}
$$

where the normalized weights calculated from the steady-state model are used as the prior distribution for each realization, the likelihood term is calculated as the inverse of the sum-of-squared errors between the simulated and observed drawdown, and $\mathrm{C}$ is a normalization constant such that the sum of the weights is unity.

The simulated and observed drawdowns are shown in Figures 6.3 and 6.4 for HC-6 and HC7, respectively. The median prediction from both HC-6 and HC-7 are in excellent agreement with the observed data. The RMSE between the median prediction and observed data is 1.2 and $3.5 \mathrm{~m}$, for HC-6 and HC-7, respectively. These errors are of the same magnitude as the errors in the steady-state model. The larger errors associated with HC-7 are attributed to the smoothing created by the median calculation. The median represents the $50^{\text {th }}$ percentile as derived from 1,000 realizations, and as such, the median for each time step is not necessarily from the same realization, thereby causing a smoothing effect.

Section 6.5.2 of the ASTM (1995) standard provides the following information on how to use the information gained from the verification simulation:

In the verification process, the modeled data are compared, not to the calibration data set, but to the verification data set. The resulting degree of correspondence can be taken as an indicator or heuristic measure of the uncertainty inherent in the model's predictions.

The verification analysis presented here shows that the modeling errors associated with the verification simulations are less than or equal to the errors produced by the calibrated steady-state model. Therefore, one can deem the flow model as successfully verified. 


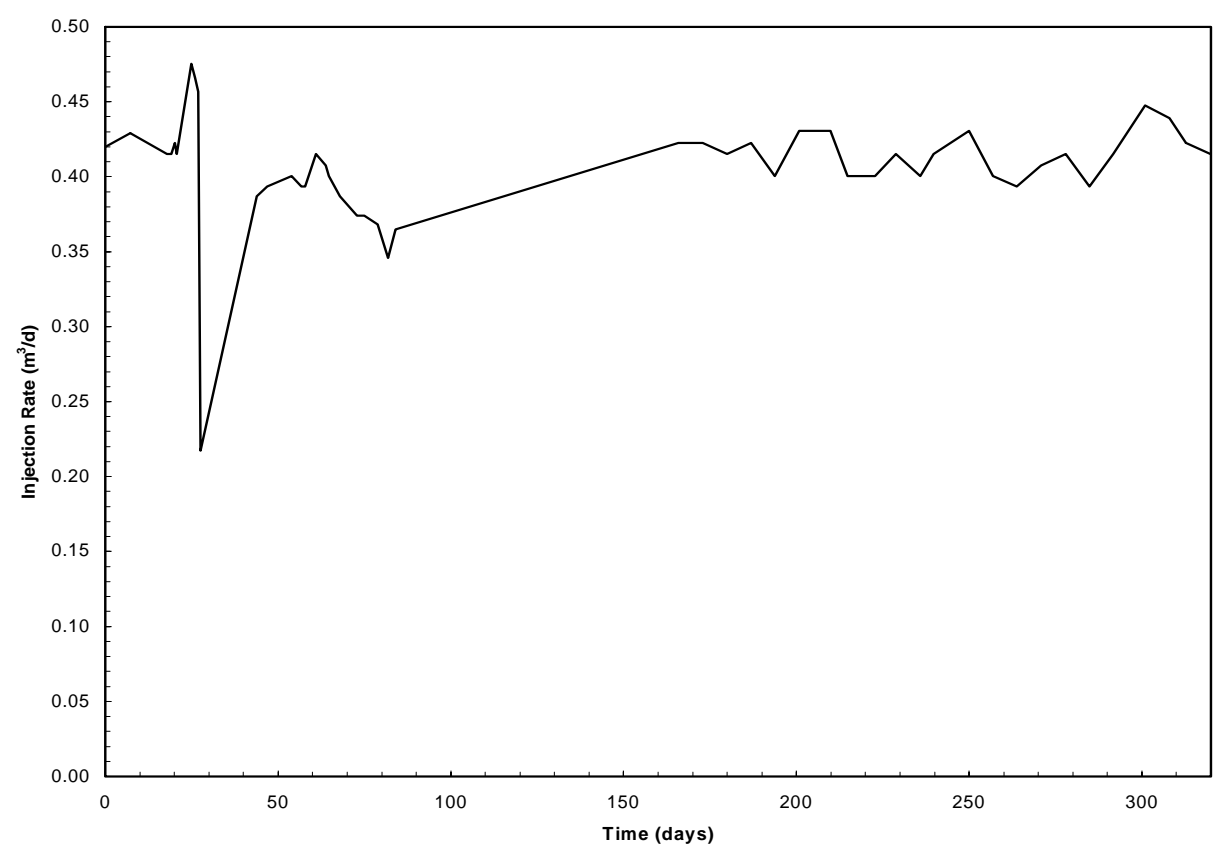

Figure 6.1. Injection rate for HC-6 during the tracer test experiment.

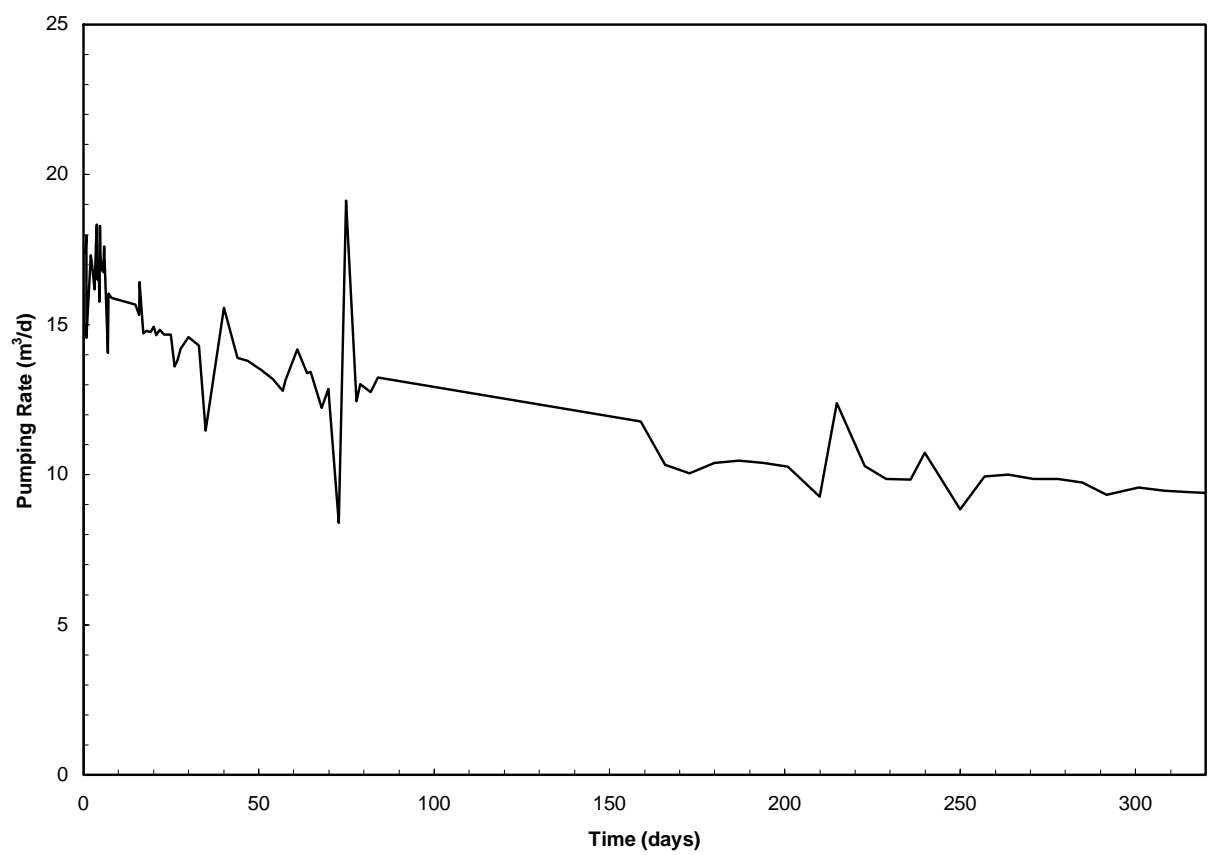

Figure 6.2. Pumping rate for HC-7 during the tracer test experiment. 


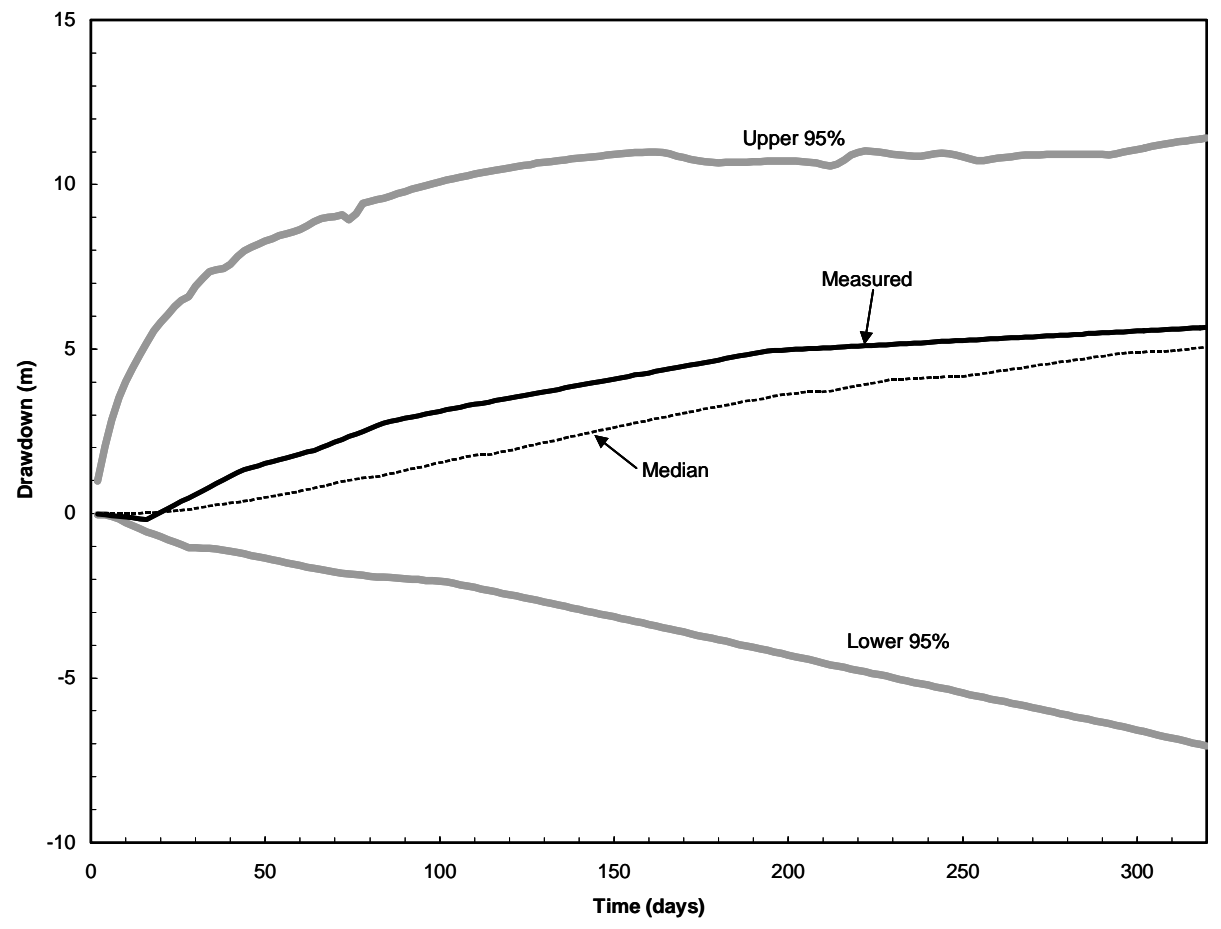

Figure 6.3. Simulated and observed drawdown for HC-6.

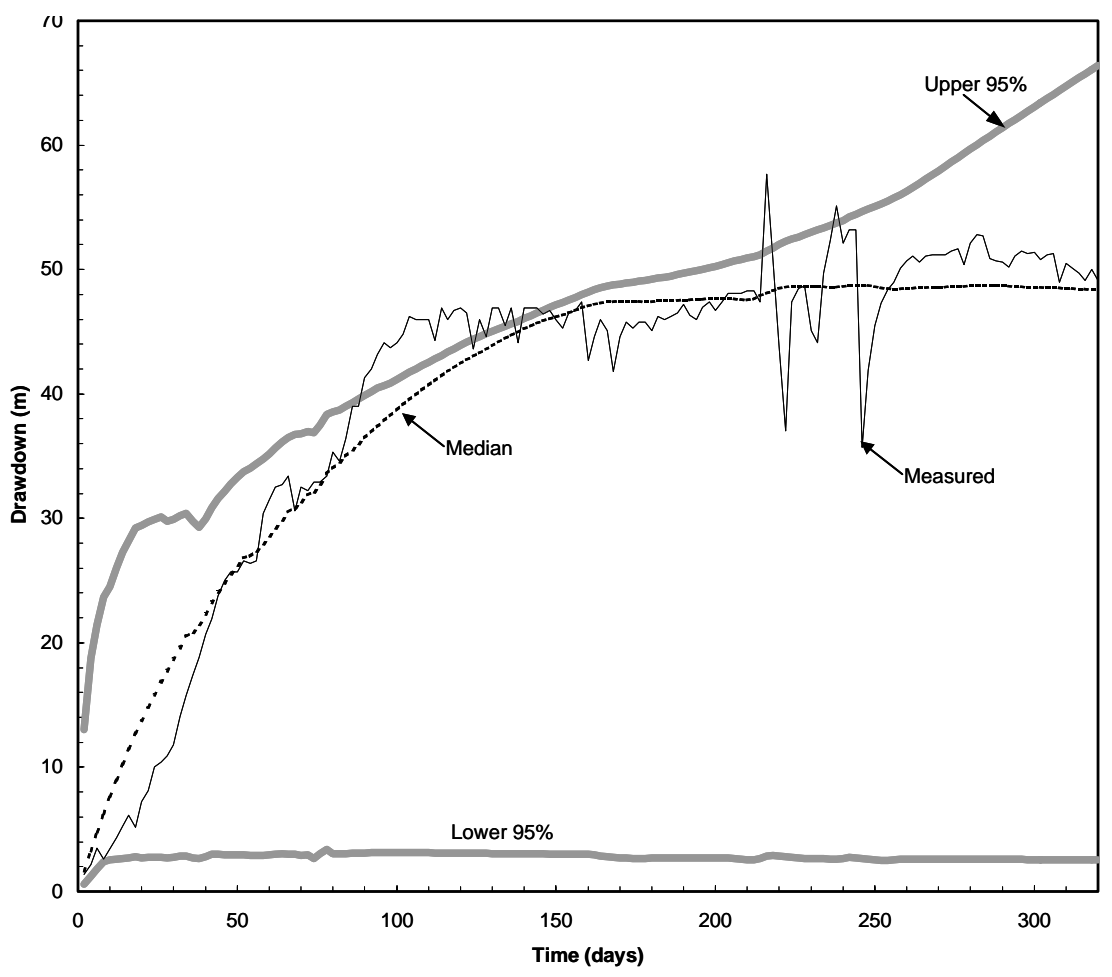

Figure 6.4. Simulated and observed drawdown from HC-7. 


\subsection{Conceptual Model Verification}

Chemical and isotopic data from groundwater collected in the Sand Springs Range and Fairview Valley were not used for development of the numerical flow models. Evaluating these data in the context of the model results thereby provides a means of evaluating the ability of the models to represent the flow system.

Inconsistencies between the previous flow model and interpretations based on the chemical and isotopic data were noted by Pohll et al. (1998). In particular, the composition of groundwater at the PSA and in Fairview Valley suggested that groundwater flow from the PSA was either not a major contributor to the alluvial aquifers in the valley and/or that travel times from range to valley were very long. This indicated that flow volumes and rates from range to valley were very low, whereas the 1998 flow model showed flow directly from the PSA toward Fairview Valley at an uncertain, but potentially high, velocity. In addition, estimates of groundwater velocity using ${ }^{14} \mathrm{C}$ yielded values one-and-a-half orders of magnitude smaller than those in the flow model. These inconsistencies were key in the decision to gather additional data at the PSA.

The additional four wells installed at the PSA in 1999 provide new chemical and isotopic data. These data are first described below, followed by the interpretation of the data in the context of the flow system.

\subsubsection{Chemical and Isotopic Characteristics of Site Groundwater}

Chemical and isotopic data from the PSA, as well as Fairview Valley, are presented in Table 6.1. Data from other samples in the region, and a more thorough discussion of the regional context, can be found in Pohll et al. (1998) and Chapman et al. (1994). Sample collection at the PSA occurred after the purging of drilling fluids and at the completion of hydraulic testing. Groundwater sampled from the Shoal HC wells exhibits a remarkable amount of chemical variability for a granite aquifer. HC-1, -2, and -4 are mixed cation-mixed anion waters; HC-6 and -7 are calcium-mixed anion waters; HC-8 is a sodium-mixed anion water; and HC-5 is a sodium-sulfate-dominated water (Figure 6.5). Total dissolved solid contents are also variable, ranging from $273 \mathrm{mg} / \mathrm{L}$ at HC8 to $995 \mathrm{mg} / \mathrm{L}$ at HC-7. The $\mathrm{pH}$ is near neutral to slightly basic, ranging from 7.72 to 8.26.

Equilibrium solubility calculations (using WATEQF; Plummer et al., 1976) indicate saturation with respect to calcite, aragonite, chalcedony, and quartz for most of the waters. This reflects a history of silicate hydrolysis and dissolution of carbonate minerals. The carbonate probably originates from carbonate dust deposited on the range by winds from the playas to the west. A fine silt layer, usually less than three meters thick, covers much of the top of the range, with a narrow band of caliche and leached granite sometimes occurring between the fresh granite and silt cover (University of Nevada, 1965). The granite bedrock is primarily comprised of quartz and feldspar, and rock away from fracture zones is usually fresh, solid, and dense. Rock in major fault zones, such as the shear zone, is highly altered, with propylitization (hydrothermal alteration), bleaching, and iron staining. Within the core of the shear zone, the rock is soft and crumbly, having decomposed to clays. 
Table 6.1a. Chemical analyses of water samples collected from the HC wells at the Shoal site, along with analyses of groundwater from other wells in the area of the Sand Springs Range (from Chapman et al., 1994). All units are mg/L unless noted otherwise.

\begin{tabular}{|c|c|c|c|c|c|c|c|c|c|c|c|c|c|c|c|c|}
\hline Well & $\begin{array}{l}\text { Depth } \\
\text { (m) }\end{array}$ & Date & $\begin{array}{c}\mathrm{T} \\
\left({ }^{\circ} \mathrm{C}\right)\end{array}$ & $\begin{array}{c}\mathrm{pH}^{1} \\
\text { (S.U.) }\end{array}$ & $\begin{array}{c}\mathrm{EC}^{1} \\
(\mu \mathrm{S} / \mathrm{cm})\end{array}$ & $\begin{array}{c}\mathrm{SiO}_{2} \\
(\mathrm{mg} / \mathrm{L})\end{array}$ & $\begin{array}{c}\mathrm{Ca} \\
(\mathrm{mg} / \mathrm{L})\end{array}$ & $\begin{array}{c}\mathrm{Mg} \\
(\mathrm{mg} / \mathrm{L})\end{array}$ & $\begin{array}{c}\mathrm{Na} \\
(\mathrm{mg} / \mathrm{L})\end{array}$ & $\begin{array}{c}\mathrm{K} \\
(\mathrm{mg} / \mathrm{L})\end{array}$ & $\begin{array}{c}\mathrm{Cl} \\
(\mathrm{mg} / \mathrm{L})\end{array}$ & $\begin{array}{c}\mathrm{SO}_{4} \\
(\mathrm{mg} / \mathrm{L})\end{array}$ & $\begin{array}{c}\mathrm{HCO}_{3} \\
(\mathrm{mg} / \mathrm{L})\end{array}$ & $\begin{array}{c}\mathrm{CO}_{3} \\
(\mathrm{mg} / \mathrm{L})\end{array}$ & $\begin{array}{c}\mathrm{NO}_{3} \\
(\mathrm{mg} / \mathrm{L})\end{array}$ & $\begin{array}{c}\mathrm{Br} \\
(\mathrm{mg} / \mathrm{L})\end{array}$ \\
\hline $\mathrm{HC}-1$ & 336 & 2-21-1997 & 13.6 & $\begin{array}{l}8.00 / \\
8.01\end{array}$ & $\begin{array}{l}423 / \\
467\end{array}$ & 19.8 & 45.7 & 6.01 & 38.7 & 2.79 & 47.7 & 52.2 & 116 & na & 11.1 & 0.7 \\
\hline $\mathrm{HC}-2$ & 347 & 3-19-1997 & na & $\begin{array}{c}\text { na/ } \\
8.03\end{array}$ & $\begin{array}{l}\text { na/ } \\
670\end{array}$ & 20.8 & 58.1 & 7.87 & 64.8 & 3.48 & 80.8 & 108.0 & 118 & na & 0.44 & 0.59 \\
\hline $\mathrm{HC}-4$ & 327 & 2-24-1997 & 13.7 & $\begin{array}{l}7.20 / \\
8.04\end{array}$ & $\begin{array}{l}658 / \\
727\end{array}$ & 22.7 & 66.4 & 9.87 & 63.7 & 3.67 & 101.0 & 90.3 & 113 & na & 26.8 & 1.67 \\
\hline $\mathrm{HC}-5$ & 476 & $1-12-2000$ & 31.5 & 8.26 & 948 & 32.2 & 31.6 & 0.20 & 170 & 2.24 & 92.1 & 228 & 83.5 & na & 0.31 & 0.23 \\
\hline HC-6 & 371 & 10-6-1999 & 24.0 & 7.72 & 1,060 & 26.1 & 139 & 19.6 & 58.5 & 4.43 & 126 & 235 & 133 & na & 16.7 & 0.4 \\
\hline $\mathrm{HC}-7$ & 371 & 11-3-1999 & 20.5 & 7.75 & 1,380 & 24.4 & 178 & 26.4 & 77 & 5.18 & 189 & 329 & 165 & na & 0.58 & 0.6 \\
\hline HC-8 & 610 & 10-29-1999 & 26.6 & 8.16 & 799 & 30.0 & 37.6 & 0.44 & 130 & 3.12 & 120 & 133 & 91.5 & na & 0.04 & 0.3 \\
\hline HS-1 & 92 & 3-30-1992 & na & $\begin{array}{l}7.72 / \\
8.14\end{array}$ & $\begin{array}{l}428 / \\
438\end{array}$ & 68.7 & 31.5 & 5.37 & 47.2 & 7.11 & 29.3 & 51.5 & $110 / 140$ & na & 3.99 & $<0.1$ \\
\hline $\mathrm{PM}-1^{+}$ & $340^{++}$ & 5-29-1963 & na & 8.4 & $2,200^{*}$ & 19 & 112 & 49 & 271 & 9 & 702 & 130 & 149 & 0.6 & na & na \\
\hline $\mathrm{PM}-2^{+}$ & $270^{++}$ & 5-29-1963 & na & 7.3 & $1,055^{*}$ & 3 & 87 & 11 & 70 & 9 & 78 & 78 & 437 & 3.6 & na & na \\
\hline $\mathrm{PM}-3^{+}$ & $330^{++}$ & 5-29-1963 & na & 8.2 & $1,050^{*}$ & 54 & 71 & 5 & 411 & 18 & 23 & 61 & 92 & 1.2 & na & na \\
\hline ECH-D & $300^{++}$ & 7-16-1962 & na & 8.5 & $657^{*}$ & 49 & 62 & 10 & 86 & 9 & 100 & 92 & 243 & 9.0 & na & na \\
\hline USBM\#1 & $280^{++}$ & 7-2-1963 & na & 8.0 & 785* & 31 & 55 & 5 & 104 & 4 & 100 & 161 & 156 & 0.6 & na & na \\
\hline
\end{tabular}

Table 6.1b. Isotopic analyses for groundwater samples from the Shoal site.

\begin{tabular}{|c|c|c|c|c|c|}
\hline Well & $\begin{array}{c}{ }^{14} \mathrm{C} \\
\text { Percent Modern Carbon }\end{array}$ & $\begin{array}{l}\delta \mathrm{D} \\
(\%)\end{array}$ & $\begin{array}{r}\delta^{13} \mathrm{C} \\
(\%)\end{array}$ & $\begin{array}{c}\delta^{18} \mathrm{O} \\
(\%)\end{array}$ & $\begin{array}{l}\text { Tritium } \\
\text { (pCi/L) }\end{array}$ \\
\hline $\mathrm{HC}-1$ & $48.68 \pm 0.83$ & -114 & -10.8 & -14.5 & $<5$ \\
\hline $\mathrm{HC}-2$ & $22.13 \pm 0.51$ & -115 & -10.4 & -14.5 & $<5$ \\
\hline $\mathrm{HC}-4$ & $5,408 \pm 51.9^{++}$ & -113 & -11.2 & -14.2 & $1,130 \pm 15$ \\
\hline $\mathrm{HC}-5$ & $6.47 \pm 0.24$ & -122 & -8.5 & -14.9 & $<2.6$ \\
\hline $\mathrm{HC}-6$ & $12.26 \pm .18$ & -113 & -9.9 & -13.8 & $<2.6$ \\
\hline $\mathrm{HC}-7$ & $7.45 \pm .15$ & -115 & -9.2 & -13.9 & $<2.6$ \\
\hline HC-8 & $9.61 \pm .15$ & -117 & -9.7 & -14.4 & $<2.6$ \\
\hline HS-1 & $8.3 \pm 0.9$ & -123 & -9.9 & -16.3 & $<10$ \\
\hline
\end{tabular}

${ }^{++}$Percent modern carbon affected by nuclear device 


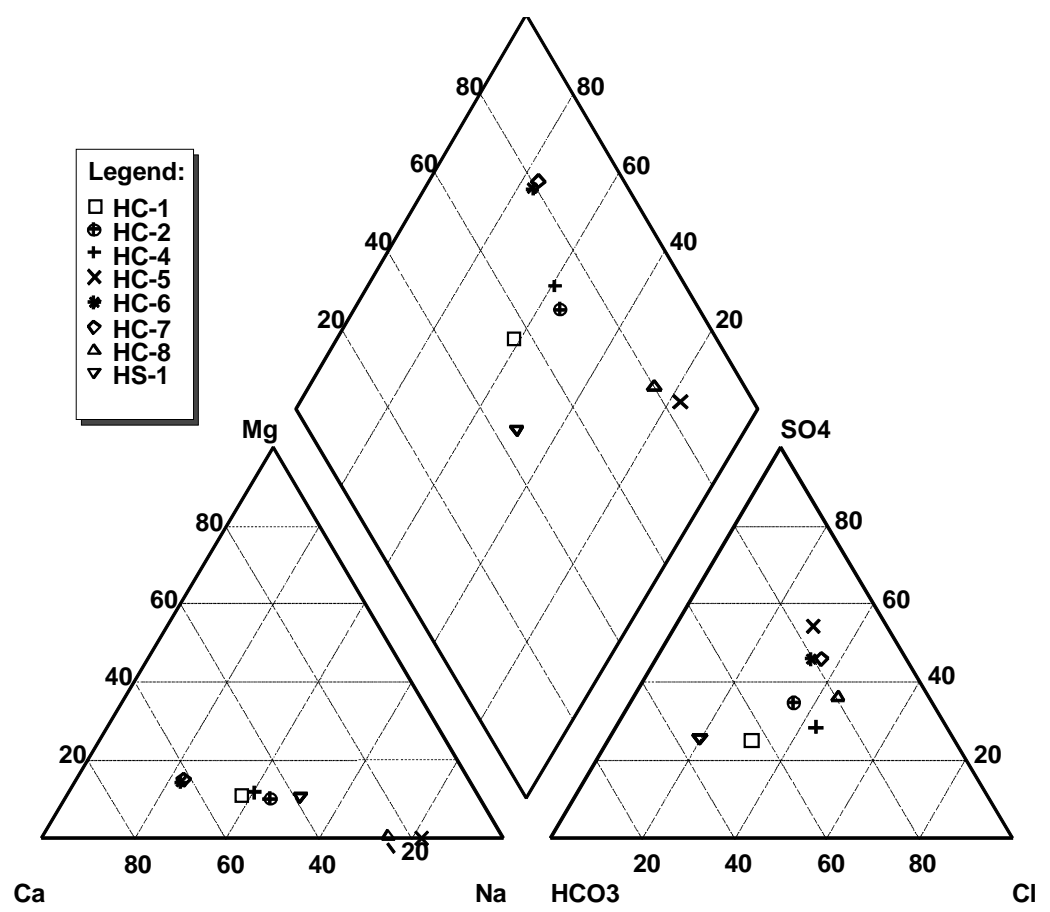

Figure 6.5. Piper diagram expressing relative percentages of major ions dissolved in Shoal groundwater.

In a general sense, the chemical variations observed in the groundwater are related to location. The groundwater sampled far west of the shear zone (HC-1, -2, and -4) is the mixed cation-mixed anion type that has the lowest salinity (Figure 6.6). The groundwater from the east side of the shear zone, and also from much greater depth in the aquifer (HC-5 and -8), is markedly different, with a dominance of sodium and proportionally much less bicarbonate, indicating less influence from carbonate dissolution. The overall salinity is slightly higher on the east side of the shear zone. The two wells immediately west of, and close to, the shear zone (HC-6 and -7) have a unique character of their own: higher in calcium and sulfate, with the highest salinity values measured on the range.

The stable isotopes of hydrogen and oxygen show less variability, given the analytical precision of \pm 1 per mil (\%) for $\delta \mathrm{D}$ and $\pm 0.2 \%$ for $\delta^{18} \mathrm{O}$. The groundwater from HC-6 and HC-7 is slightly enriched in $\delta^{18} \mathrm{O}$, relative to the group farther west of the shear zone (Figure 6.7). The most distinctive isotopic composition is that of the deep groundwater from HC-5, which is depleted as compared to the other range groundwater. With the exception of HC-5, the stable isotopic similarity of the remainder of the HC wells indicates that they were all recharged under similar climatic conditions.

In the context of the isotopic composition of waters in the region, from the valleys both east and west of the Sand Springs Range, the Shoal wells form a relatively tight group, isotopically lighter than the waters along Fourmile Flat and isotopically heavier than groundwater in Fairview 

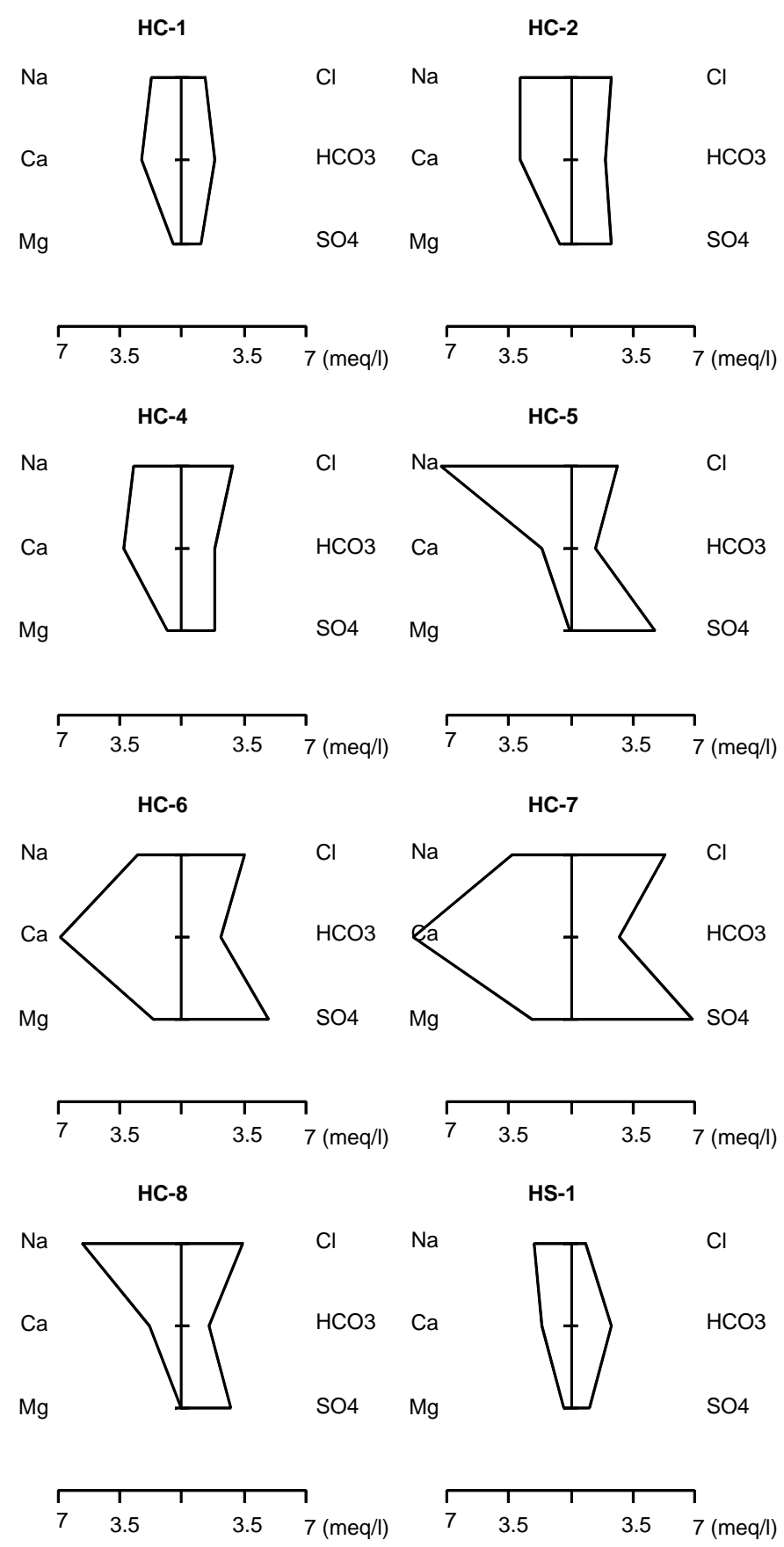

Figure 6.6. Stiff diagram expressing ion concentrations in Shoal groundwater. 

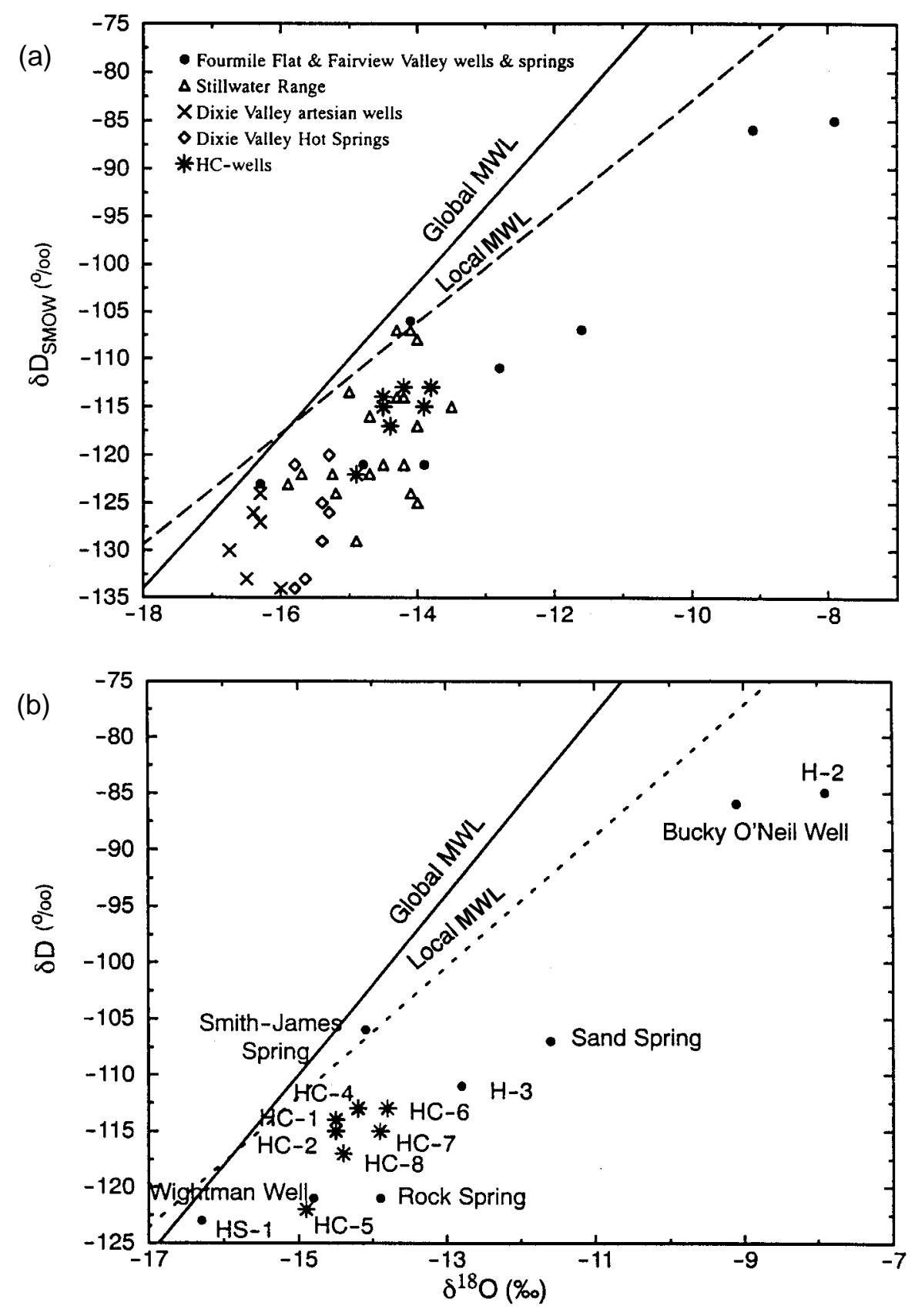

Figure 6.7. Stable isotopic composition of Shoal groundwater. The solid line is the global meteoric water line, the dashed line is a local meteoric water line (Jacobson et al. 1983). Graph (a) includes regional samples not seen on the scale used in (b). 
Valley. The relationship between $\delta \mathrm{D}$ and $\delta^{18} \mathrm{O}$ is consistent with that of meteorically derived water. The HC wells' isotopic compositions plot slightly to the right ( $\delta^{18} \mathrm{O}$ enriched) of the local meteoric water line (Jacobson et al., 1983), but that phenomenon is frequently encountered in arid regions and has been suggested to occur due to slight evaporation during infiltration (Allison et al., 1984). The Sand Springs groundwater is at the heavy-isotope-enriched end of samples collected from the Stillwater Range and deep wells and hot springs in Dixie Valley, which originate at high elevations in the Stillwater Range. This is consistent with the lower elevation, and warmer temperatures of condensation expected for the Sand Springs Range as compared to the Stillwater Range.

The stable carbon isotopic compositions vary from -11.2 to $-8.5 \%$ o $\delta^{13} \mathrm{C}$ (analytical precision is $\pm(0.2 \%)$. The more depleted compositions belong to the wells some distance west of the shear zone (HC-1, -2 , and -4$)$. The radiogenic carbon $\left({ }^{14} \mathrm{C}\right)$ contents follow the same grouping, with higher percents of modern carbon (PMC) in the western wells $\mathrm{HC}-1$ and $\mathrm{HC}-2$ (the ${ }^{14} \mathrm{C}$ in $\mathrm{HC}-4$ has been impacted by the Shoal test so that it cannot be used for dating purposes). The PMC west of the shear zone ranges from 22 to 48, while that for the wells adjacent to and east of the shear zone varies from 6 to 12 .

Little influence of dead carbon from carbonate mineral dissolution is expected in a granitic aquifer, though dissolution of some carbonate is ubiquitous in groundwater sampled throughout the Great Basin. The major ion composition of the Shoal samples indicates that carbonate dissolution has occurred, likely of carbonate dust during infiltration of precipitation. The spread of isotopically enriched ${ }^{13} \mathrm{C}$ values in groundwater recharged under similar climate conditions as indicated by the hydrogen and oxygen isotopes) suggests that HC-6, -7, and -8 have experienced additional carbonate dissolution/exchange reactions. The same applies to HC-5, but with a depleted hydrogen and oxygen component, recharge under a different climate is possible.

The apparent groundwater ages (Table 6.2) based on unadjusted ${ }^{14} \mathrm{C}$ data range from approximately 6,000 years at $\mathrm{HC}-1$ to over 22,000 years at $\mathrm{HC}-5$. This age represents the time the water has been isolated from the atmosphere, with some portion of the age representing infiltration time through the 300-m extent of the fractured-rock unsaturated zone $\left(\mathrm{CO}_{2}\right.$ diffusion in the gas phase is rapid and thus modern carbon is expected to occur to some depth below land surface, thus "isolation" from the atmosphere is not expected immediately upon infiltration). The comparison between the stable isotopes and ${ }^{14} \mathrm{C}$ indicates that the apparent ages should be corrected to account for dissolved non-radiogenic carbon. The degree of this correction is unknown: a single soil-gas $\mathrm{CO}_{2}$ sample was collected from the root zone on Gote Flat in September 1998 with a $\delta^{13} \mathrm{C}$ of $-15.5 \%$. With an equilibrium fractionation factor of $9 \%$ o between soil-gas carbon and carbon dissolved in recharging water, the starting $\delta^{13} \mathrm{C}$ would be $-6.5 \%$. This value is more enriched than that of the $\mathrm{HC}-1,-2$, and -4 groundwater and thus not representative of recharge composition, perhaps due to seasonal variability. Simply correcting using the $\delta^{13} \mathrm{C}$ of HC-1 would not reduce the ages of HC-5, $-6,-7$, and -8 into post-pluvial time $(13,000$ years or less). 
Table 6.2. Apparent groundwater ages based on carbon isotopic data.

\begin{tabular}{ccccc}
\hline \hline Well & $\delta^{13} \mathrm{C}$ & Percent Modern Carbon & \pm error & Apparent Age (years before present) \\
\hline HC-1 & -10.8 & 48.68 & 0.83 & 5,810 to 6,090 \\
HC-2 & -10.6 & 22.13 & 0.51 & 12,300 to 12,700 \\
HC-4 & -11.2 & $5,408.05^{*}$ & 51.9 & NA \\
HC-5 & -8.5 & 6.47 & 0.24 & 22,300 to 23,000 \\
HC-6 & -9.9 & 12.26 & 0.18 & 17,200 to 17,500 \\
HC-7 & -9.2 & 7.45 & 0.15 & 21,300 to 21,600 \\
HC-8 & -9.7 & 9.61 & 0.15 & 19,200 to 19,500 \\
HS-1 & -9.9 & 8.3 & 0.9 & 19,700 to 21,500 \\
\hline
\end{tabular}

*Value indicates impact from the Shoal test.

\subsubsection{Implications of Chemical and Isotopic Characteristics for Flow Beneath the Range}

The chemical and isotopic results support the hydraulic data in identifying the shear zone as a significant feature in the flow system. Rather than a homogeneous granite aquifer, marked chemical variability is evident in the Shoal samples and these variations can be related to location relative to the shear zone. The analytical results for the groundwater clearly indicate a higher proportion of calcium and sulfate immediately west of the shear zone in HC-6 and HC-7, and a large increase in sodium east of the zone, in HC-5 and HC-8. Inconsistencies between the chemical and isotopic character of the Shoal site groundwater with that observed in the valley immediately east at HS-1 (Pohll et al., 1998) support the shear zone as a barrier to eastward flow.

The expected chemical evolutionary path begins with infiltration of precipitation on the surface of the range itself. This precipitation can be expected to have a small dissolved solids load from atmospheric dust, with additional dissolution of salts originating from the salt flats to the west and deposited in the thin wind-blown silt found on Gote Flat. Movement through the plantroot zone will acidify the water with dissolved $\mathrm{CO}_{2}$, and then silicate dissolution reactions can be expected in the granite aquifer. More explanation is required, however, to account for the observed chemical variability.

In the case of the eastern samples, the elevated sodium concentration, and accompanying higher silicate concentrations, suggests that silicate hydrolysis is occurring, with destruction of plagioclase feldspar and creation of clay releasing $\mathrm{Na}$ and $\mathrm{SiO}_{2}$ into solution. The buffering of this reaction is evident in the higher $\mathrm{pH}$ values for these wells. The evolution of the silicate hydrolysis reaction east of the shear zone as compared to west may bear more relationship to the greater depth of the eastern samples, rather than their geographic location. The groundwater sampled at HC-5 and HC-8 has encountered hundreds of meters more granite between land surface and the sampling point, and at higher temperatures, than the water table wells. Smaller differences in other cation concentrations between HC-1, -2, and -4 and HC-5 and -8 may be accounted for by cation exchange reactions, while the lower bicarbonate suggests carbonate precipitation. The higher sulfate concentrations at the eastern versus western group may be related to a similar, 
though smaller magnitude, process as described below for the near-shear zone wells. HC-5 and HC-8 are not as close to the shear zone at the screened intervals as HC-6 and HC-7, but are much closer than the western wells.

The shear zone itself is noted as being propylitized, having been hydrothermally altered with resultant clays, pyrite and iron oxides formed. The high calcium and sulfate in HC-6 and HC-7 may therefore reflect dissolution of sulfides (probably pyrite) and reaction with calcite under the more acidic conditions in the altered zone. More calcite dissolution at HC-6 and -7 is consistent with the greater ${ }^{13} \mathrm{C}$ enrichment at those wells, as compared to $\mathrm{HC}-1,-2$, and -4 . Observations of water produced from HC-7 during the tracer test found it to be reducing, with fine colloidal $\mathrm{Fe}^{+3}$ in the water, oxidized from $\mathrm{Fe}^{+2}$ (P. Reimus, Los Alamos National Laboratory, personal communication, 2001). Reducing conditions are consistent with pyrite dissolution and will inhibit actinide transport.

A notable implication of the chemistry of HC-6 and HC-7 is that the groundwater at these wells appears to be impacted by the mineralogy associated with the shear zone, though the wells are located literally outside the zone itself (i.e., the rock encountered during drilling was competent granite). This may indicate that mineralization extends out beyond the strongly weathered shear zone, or that groundwater chemistry is generally homogenized in a broader region around the shear zone than delimited by the zone itself. The latter explanation is supported by the observation that HC-7, slightly closer to the shear zone than HC-6, has notably higher ion concentrations than HC-6 while retaining the same relative ion percentages. The chemical gradient between water in the shear zone and that outside may create a halo around the shear zone comprised of a mixture of shear zone water (not directly sampled during this investigation, but inferred from HC-6 and HC-7) and the distant water represented by HC-1, -2 and -4. This mixing may be primarily driven by diffusion.

With the exception of HC-5, groundwater samples from the site have similar stable isotope ratios of hydrogen and oxygen, indicating similar recharge conditions. These conditions refer principally to the temperature of condensation of the precipitation, and also to the source and history of the air mass bringing the moisture. The isotopic similarity supports the conceptual model of a single recharge source for the chemically variable groundwater by infiltration through the surface of the range. The depleted isotopic composition of HC-5 (depleted by $8 \%$ in $\delta \mathrm{D}$ ) can be interpreted as the result of recharge under pluvial conditions. Pluvial periods of cooler temperatures and greater rainfall under a more southerly jet stream have been associated with heavy isotope depletion in old groundwater in the Great Basin. The last major Lake Lahontan highstand occurred around 13,000 years before present (ybp) (Benson and Thompson, 1987), and an isotopic distinction between groundwater recharged prior to and after that time is expected. The stable isotope results suggest that the very deep groundwater sampled at HC-5 was recharged during pluvial conditions. The best example of current recharge on the Sand Springs Range is Smith-James Spring, a small spring issuing from the range several kilometers south of the Shoal site. This spring has $51 \mathrm{pCi} / \mathrm{L}$ of tritium, attesting to its modern origin, and its stable isotope content is significantly more enriched in deuterium than all of the HC samples (Figure 6.7b). 
Thus, the groundwater from the bulk of the HC wells appears to be a mixture of water recharged during pluvial times and under recent conditions.

Though inferences on groundwater age can be made from the influence of climate on the stable isotopes, radioactive isotopes are needed to truly date the time a groundwater has been isolated from the atmosphere. The apparent ages indicated by the ${ }^{14} \mathrm{C}$ data for the group of similar stable isotope samples range from 6,000 to over 21,000 ybp. The apparent ages for HC-6, -8, and particularly $\mathrm{HC}-7$ are in conflict with the $\delta \mathrm{D}$ data, indicating mixing with a recharge component from the climate of the last 13,000 years. Diffusion of groundwater from fractures into matrix blocks can increase the residence time of dissolved constituents, relative to the residence time of groundwater in the fractures. The radioactive decay of ${ }^{14} \mathrm{C}$ continues during the residence time in the matrix blocks before equilibrating and mixing with water in adjacent fractures, with the net result of apparent groundwater residence times longer than representative for most water in the fracture. Diffusion is expected to impact all of the groundwater samples reported here. The wells reporting the oldest ages all occur in relative proximity to the shear zone, suggesting they may be subject to additional processes associated with the zone. These may involve mixing between more recently recharged water with much older water adjacent to the low-hydraulic-conductivity shear zone, and/or exchange and dissolution reactions with carbon-bearing minerals in the shear zone.

The chemical differences between groundwater from HS-1 in Fairview Valley and groundwater at the PSA noted by Pohll et al. (1998) have only been amplified by data from the additional wells. The lighter stable isotopic composition and low dissolved solids content of HS-1 are now best interpreted as being due to recharge in the higher elevation Fairview Peak range, east of the valley. Fairview Peak's higher elevation would account for a more depleted heavy isotope content and the greater distance from the salt playas at Fourmile and Eightmile flats to Fairview Peak can be expected to result in less deposition of soluble salts by winds. The data indicate little contribution to Fairview Valley groundwater (as sampled at HS-1) from groundwater beneath the PSA, the lack of which can now be attributed to the barrier formed by the shear zone.

Significant chemical and isotopic differences also exist between the groundwater beneath the PSA and water sampled in the Fourmile Flat basin. Though fundamentally the differences are due to evaporative effects in the terminal basin, the extent well upgradient of the flats themselves indicates that mixing with residual brines is a major process. The incursion of these refluxing brines upgradient toward the range (Chapman et al., 1994) indicates the low contribution of flow from the Sand Springs Range westward.

The high degree of chemical variability for groundwater at the PSA additionally supports the conceptual view of a fracture flow system. The degree of chemical homogeneity in a fracture system is dependent upon the degree of interconnection between the fracture sets and exchange rates with intervening matrix blocks. The observed variability, even between wells distant from the shear zone (e.g., HC-1 and HC-2), is consistent with a relatively disconnected fracture system with large matrix blocks. 
THIS PAGE LEFT INTENTIONALLY BLANK 


\subsection{CONCLUSIONS}

Data collection, testing, and analysis during the late 1990s significantly improved the understanding of groundwater flow and transport at the Shoal site. The knowledge gained through these activities has been incorporated into the flow and transport models presented here.

Groundwater occurs within fractures in the Sand Springs granite. Flow is basically toward the northeast at the site, constrained by a groundwater divide to the west of the nuclear test and paralleling a low permeability shear zone that behaves as a hydraulic barrier to the east. There is a strong component of vertical flow, driven by surface recharge. Recharge volumes are small, consistent with the low elevation of the range, but sufficient to maintain downward-directed hydraulic gradients. Discharge occurs distant from the site, northeast beyond Fairview Valley. Groundwater velocities are generally low, averaging $2.3 \times 10^{-5} \mathrm{~m} / \mathrm{d}$.

Alternate conceptual models examined the behavior of the shear zone, flow conditions on the west side of the range, and other aspects of the boundary conditions and parameters (such as recharge and hydraulic conductivity). Basic assumptions underlying the modeling include steadystate conditions (consistent with the lack of groundwater development in the region), isothermal conditions (the geothermal gradient is ignored for this non-hydrothermal area and depths of just over a thousand meters), stochastic continuum approximation comprised of large, oriented fracture zones and intervening zones of granite with random, small fractures (consistent with field data, and recognizing the inability to meet the high data demands of discrete fracture models), and a region of higher porosity and hydraulic conductivity around the nuclear cavity (consistent with nuclear test phenomenology developed from other locations).

Radionuclides are released from the nuclear cavity both immediately after the nuclear test and via longer-term dissolution of the nuclear melt glass. Once released, the radionuclides are subject to retardation processes of sorption on fracture surfaces, matrix diffusion, and sorption within the matrix, all as demonstrated by a tracer test conducted at the site. Particle movement in the transport model reflects the flow field behavior. Particles move vertically downward, accompanied by lateral movement in a northeasterly direction. How far the particles travel in different realizations is dependent on the location and hydraulic conductivity of the fractures, the fracture porosity, surface recharge, and value of flux at the southern inflow boundary, all of which are spatially variable and/or uncertain parameters.

Uncertainty remains in many aspects of the flow and transport problem, in large part due to the spatial variability of the system and the inability to sample and test but a small portion of it. The models presented here accept this uncertainty and incorporate it into the numerical process so that the impact of uncertainty is included in the results. The specific uncertainties included are as follows: the orientation and spatial continuity of large fracture zones; the hydraulic conductivity of large fracture zones; the hydraulic conductivity of zones containing no fractures and/or small, random fractures; recharge from precipitation entering the top surface of the model; flux from the upland recharge area entering the upgradient vertical face of the model; porosity and hydraulic conductivity in the cavity/chimney region; porosity in the undisturbed granite aquifer; and the rate at which radionuclides are released from the nuclear melt glass. Some of these uncertain 
parameter values are balanced and weighted during calibration with observed data. The flow model calibration process ensures the integrity of each realization relative to known characteristics of the flow system (measured heads), and the weighting procedure carries this information into the transport calculations. The resulting confidence intervals presented for the contaminant boundaries will allow decision makers to determine future actions for the Shoal site, incorporating the model results and inherent combined uncertainty into their decisions.

The modeling was readily able to meet its purpose of providing the framework for calculating a contaminant boundary at specified confidence levels. With uncertainty in many of the flow and transport parameters directly incorporated in the calculations, a variety of possible transport regimes result and can be statistically analyzed to obtain contaminant boundary maps. These maps can be generated to represent any desired confidence interval by analyzing each cell individually and considering the maximum contaminant concentrations and calibration weights of each of the 1,000 realizations. Using unclassified estimates of four radionuclides, ${ }^{3} \mathrm{H},{ }^{90} \mathrm{Sr},{ }^{137} \mathrm{Cs}$, and ${ }^{151} \mathrm{Sm}$, and drinking water standards as a metric, examples of contaminant boundary maps are generated. The contaminant boundaries calculated are larger for the higher confidence intervals (e.g., the 95 percent confidence interval boundary is larger than that for the 50 percent interval), as expected due to the inclusion of the tails of the distribution. For the examples presented, all of the 1,000-year-maximum boundaries occur within the PSA land withdrawal area.

The boundaries presented are for demonstration purposes only, as they were generated using unclassified, and thus approximate, values for initial radionuclide mass. For the tritium example, at the 95 percent confidence level, the contaminant boundary relative to the drinking water standard of $20,000 \mathrm{pCi} / \mathrm{L}$ has an extent of about $180 \mathrm{~m}$ in the lateral direction downgradient of the cavity, as well as about $160 \mathrm{~m}$ vertically below the cavity, over a 1,000-year time period. The other nuclides have smaller boundaries than tritium, due to their retardation properties. The final contaminant boundary for Shoal will be based on the cumulative boundaries for all radionuclides, using the classified source masses. That boundary will be produced using the model presented here, after it is approved by the DOE and NDEP. 


\subsection{REFERENCES}

Adams, P.B., 1984. Glass corrosion: A record of the past? A predictor of the future? J. NonCrystalline Solids, 67:193-205.

Allison, G.B., C.J. Barnes, M.W. Hughes and F.W. Leaney, 1984. Effect of climate and vegetation on oxygen-18 and deuterium profiles in soils. International Atomic Energy Agency, IAEASM-270/20, pp. 105-123.

Anderson, M.P. and W.W. Woessner., 2002. Applied groundwater modeling; simulation of flow and advective transport. Academic Press, San Diego, CA, 381 p.

ASTM, 1995. Standard Guide for Calibrating a Ground-Water Flow Model Application, Section D18.21.10, Designation C-7, Draft No. 4. ASTM, Philadelphia, PA.

Atkinson, C.H., 1964. Subsurface Fracturing from Shoal Nuclear Detonation. U. S. Department of Interior, Bureau of Mines, PNE-3001, 30p.

Bear, J., 1972. Dynamics of Fluids in Porous Media. American Elsevier, New York.

Bedford, R.G. and D.D. Jackson, 1965. Volatilities of the Fission Product and Uranium Oxides. Lawrence Livermore National Laboratory, UCRL-12314, 37 p.

Beers, R.F., Inc., 1964. Analysis of Shoal Data on Ground Motion and Containment. U. S. Atomic Energy Commission, Vela Uniform Project Shoal, VUF-1013, 112 p.

Benson, L.V. and R.S. Thompson, 1987. Lake-level variation in the Lahontan Basin for the past 50,000 years. Quaternary Research. 28:69-85.

Beven, K.J. and A.M. Binley, 1992. The future of distributed models: Model calibration and uncertainty prediction, Hydrological Processes, (6):279-298.

Billaux, D. M., J.P. Chiles, K. Hestir and J.C.S. Long, 1989. Three-dimensional statistical modeling of a fractured rock mass - an example from the Fanay-Augeres Mine. International Journal of Rock Mechanics and Mining Science and Geomechanical Abstracts, 26(3/4):281299.

Borg, I.Y., 1975. Radioactivity trapped in melt produced by a nuclear explosion. Nuclear Technology, 26:88-100. 
Borg, I.Y., R. Stone, H.B. Levy and L.D. Ramspott, 1976. Information Pertinent to the Migration of Radionuclides in Ground Water at the Nevada Test Site, Part 1: Review and Analysis of Existing Information. Lawrence Livermore National Laboratory, UCRL-52078 Pt. 1, 216 p.

Bourcier, W.L., S. Roberts, D.K. Smith, S. Hulsey, L. Newton, A. Sawvel, C. Bruton, C. Papelis, W. Um, C. Russell and J. Chapman, in press. Determination of Reactive Surface Area of Melt Glass. Lawrence Livermore National Laboratory report.

Bryant, E.A. and J. Fabryka-Martin, 1991. Survey of Hazardous Materials used in Nuclear Testing. Los Alamos National Laboratory, LA-12014-MS, 12 p.

Caine, J.S., J.P. Evans and C.B. Forster, 1996. Fault zone architecture and permeability structure. Geology, (24):1025-1028.

Carroll, R., K. Pohlmann, G. Pohll and T. Mihevc, 2001. Investigation of Hydraulic Properties of a Shear Zone at the Shoal site and Associated Groundwater Levels. Desert Research Institute, Publication No. 45183, DOE/NV/13609-12.

Carroll, R., T. Mihevc, G. Pohll, B. Lyles, S. Kosinski and R. Niswonger, 2000. Project Shoal Area Tracer Test Experiment. Desert Research Institute, Publication No. 45177, DOE/NV/ 13609--05, 35p.

Chapman, J., T. Mihevc and A. McKay, 1994. Groundwater flow near the Shoal site, Sand Springs Range, Nevada: impact of density-driven flow. Desert Research Institute, Publication No. 45130, DOE/NV/10845-51, 24 p.

Chapman, J., K. Pohlmann and R. Andricevic, 1995. Exposure assessment of groundwater transport of tritium from the Shoal site. Desert Research Institute, Publication No. 45132, DOE/NV/11508-01, 30 p.

Cohen, P. and D.E. Everett, 1963. A Brief Appraisal of the Ground-Water Hydrology of the DixieFairview Valley Area, Nevada. State of Nevada, Department of Conservation and Natural Resources, Ground-Water Resources - Reconnaissance Series, Report 23.

Cressie, N.A.C., 1993. Statistics for Spatial Data, Revised Edition, John Wiley \& Sons.

Daly, C., R.P. Neilson, and D.L. Philips, 1994. A statistical-topographic model for mapping climatological precipitation over mountainous terrain, Journal of Applied Meteorology, Vol. 33, pp. 140-158.

Davis, J.C., 1986. Statistics and Data Analysis in Geology, $2^{\text {nd }}$ Edition, John Wiley \& Sons. 
Derlich, S., 1970. Transformations du milieu dues a une explosion nucleaire souterraine: Etude du contenu de las cavite et de la cheminee et etude de la zone ecrasee et de la zone fracturee. Peaceful Nuclear Explosions, Proc. Panel, IAEA, Vienna, p. 123-138.

Dershowitz, W.S., G. Lee, J. Geier, S. Hitchcock and P. La Pointe, 1993. FRACMAN user documentation, Golder Associates Inc., Seattle, WA.

Deutsch, C.V., 1998. GSLIB, Geostatistical Software Library and User's Guide, Oxford University Press.

Diersch, H.-J. G., 1998. Reference Manual: FEFLOW. WASY Institute for Water Resources Planning and Systems Research Ltd., Berlin.

Doherty, J., 1984. PEST: Corinda, Australia, Watermark Computing.

Doherty, J., 2000. PEST - Model-Independent Parameter Estimation - User's Manual - Fourth Edition, Watermark Numerical Computing.

Dupuis, M., 1970. Distribution and Evolution of Radioelements After a Nuclear Explosion. Bull. Infor. Sci. Tech., 149: Lawrence Livermore National Laboratory, 1972, UCRL-Trans-10617-5.

Efron, B., 1979. Bootstrap methods: another look at the jackknife. Annual Statistician,Vol. 7, pp. $1-26$.

Efron, B., and R. J. Tibshirani, 1993. An Introduction to the Bootstrap, Monographs on Statistics and Applied Probability \#57, Chapman and Hall/CRC, New York.

Elert, M. and K. Konsult, 1999. Evaluation of Modelling of the TRUE-1 Radially Converging and Dipole Tests with Conservative Tracers. Technical Report TR-99-04, Swedish Nuclear Fuel and Waste Management Co., Stockholm, Sweden.

Evans, J.P., C.B. Forster and J.V. Goddard, 1997. Permeability of fault-related rocks, and implications for hydraulic structure of fault zones, J. Structural Geology,19(11):1393-1404.

Faure, G., 1977. Principles of Isotope Geology. John Wiley \& Sons, New York, 464p.

Franks, J. and K.J. Beven, 1997. Bayesian estimation of uncertainty in land-atmosphere flux predictions, Journal of Geophysical Research, 102 (D20): 23,991-23999.

Freer, J., K.J. Beven and B. Ambroise, 1996. Bayesian estimation of uncertainty in runoff prediction and the value of data: An application of the GLUE approach, Water Resources Research, 32 (7):2161- 2173. 
Freeze, R.A. and J.A. Cherry, 1979. Groundwater, Prentice-Hall, Inc., Englewood Cliffs, New Jersey, 604p.

Frick, U., W. Alexander, B. Baeyens, P. Bossart, M.H. Bradbury, Ch. Buhler, J. Eikenberg, Th. Fierz, W. Heer, E. Hoehn, I.G. McKinley and P.A. Smith, 1991. Grimsel Test Site - The radionuclide migration experiment-overview of investigations 1985-1990. National cooperative for the disposal of radioactive waste technical report 91-94.

Gardner, M. and W. Nork, 1970. Evaluation of the Project Shoal site, Fallon, Nevada, for Disposition, Including Identification of Restrictions, Part I. Teledyne Isotopes. Palo Alto, CA. 42p.

Glancy, P. and T. Katzer, 1975. Water Resources Appraisal of the Carson River Basin, Western Nevada, Water Resources - Reconnaissance Series, Vol. 59. Carson City, State of Nevada, Department of Conservation and Natural Resources. 126 p.

Goishi, W., B. Esser, J. Meadows, N. Namboodiri, D. Smith, J. Wild, S. Bowen, P. Baca, L. Olivas, C. Geoffrion, J. Thompson and C. Miller, 1994. Total Radionuclide Inventory Associated with Underground Nuclear Tests Conducted at the Nevada Test Site 1955-1992. Los Alamos National Laboratory, LA-CP-94-0222, 242 p., classified data.

Goishi, W., J.W. Meadows, N. Namboodiri, D.K. Smith and J.F. Wild, 1995. Radionuclide Inventory for U.S. Nuclear Tests Conducted Off the NTS and Hydronuclear and Safety Experiments Conducted on the NTS, Lawrence Livermore National Laboratory, UCRL-ID121901, classified data.

Guimera, J. and J. Carrera, 2000. A comparison of hydraulic and transport parameters measured in low-permeability fractured media. Journal of Contaminant Hydrology, 41:261-281.

Hampton, C.M. and D.K. Bailey, 1984. Gas extraction experiments on volcanic glasses. J. NonCrystalline Solids, 67:147-168.

Harbaugh, A.W. and M.G. McDonald, 1996a. User's Documentation for MODFLOW-96, an Update to the U.S. Geological Survey Modular Three-Dimensional Finite-Difference Ground-Water Flow Model, U.S. Geological Survey, Open-File Report 96-485.

Harbaugh, A.W. and M.G. McDonald, 1996b. Programmer's Documentation for MODFLOW-96, an Update to the U.S. Geological Survey Modular Three-Dimensional Finite-Difference Ground-Water Flow Model, U.S. Geological Survey, Open-File Report 96-486. 
Harbaugh, A.W., E.R. Banta, M.C. Hill and M.G. McDonald, 2000. MODFLOW-2000, The U.S. Geological Survey Modular Ground-Water Model - User Guide to Modularization Concepts and the Groundwater Flow Process, U.S. Geological Survey, Open-File Report 00-92.

Hardman, G., 1936. Precipitation map of Nevada, Nevada Agricultural Experiment Station.

Hardman, G. and H.G. Mason, 1949. Irrigated lands of Nevada. Nevada University Agricultural Station Bulletin 183, 56 pp.

Harrill, J.R. and L.B. Hines, 1995. Estimated Natural Ground-Water Recharge, Discharge, and Budget for the Dixie Valley Area, West-Central Nevada. U.S. Geological Survey, WaterResources Investigations Report 95-4052.

Hassan, A., K. Pohlmann and J. Chapman, 2002. Modeling Groundwater Flow and Transport of Radionuclides at Amchitka Island's Underground Nuclear Tests: Milrow, Long Shot, and Cannikin. Desert Research Institute, Division of Hydrologic Sciences, Publication No. 45172, DOE/NV/11508--51.

Hazelton-Nuclear Science Corporation., 1965. Post-Shot Hydrologic Safety, Project Shoal Final Report. U.S. Atomic Energy Commission, Vela Uniform Project Shoal, VUF-1014, 50 p.

Hill, M.C., E.R. Banta, A.W. Harbaugh and E.R. Anderman, 2000. MODFLOW-2000, the U.S. Geological Survey Modular Ground-Water Model - User Guide to the Observation, Sensitivity and Parameter-Estimation Processes and Three Post-Processing Programs, U.S. Geological Survey, Open File Report 00-184.

Huang, H., A. E. Hassan, and B. X. Hu, 2003. Monte Carlo study of conservative transport in heterogeneous dual-porosity media, Journal of Hydrology, 275, pp. 229-241.

International Atomic Energy Agency (IAEA), 1998. The Radiological Situation at the Atolls of Mururoa and Fangataufa, Volume 4, Releases to the Biosphere of Radionuclides from Underground Nuclear Weapons Tests at the Atolls, IAEA, Austria, 270p.

IT Corporation, 2000. 1999 Well Installation Report, Project Shoal Area, Churchill County, Nevada. Prepared for U.S. Department of Energy, Nevada Operations Office. Las Vegas, Nevada, ITLV/13052-097, variable paging.

Jacobson, R.L., N.L. Ingraham and M.E. Campana, 1983. Isotope Hydrology of a Basin and Range Geothermal System. Desert Research Institute, Publication No. 41087, 18p.

Kersting, A.B., 1996. The State of the Hydrologic Source Term. Lawrence Livermore National Laboratory, UCRL-ID-126557, 30 p. 
Kinzelbach, W., 1988. The random walk method in pollutant transport simulation. In:

Groundwater Flow and Quality Modeling, edited by E. Custodio et al., pp. 227-246, D.

Reidel, Norwell, MA.

Kirkorian, O.H., 1981. Predictive calculations of volatilities of metals and oxides in steamcontaining environments. Lawrence Livermore National Laboratory, UCRL-85553, 27 p.

LaBolle, E., G. Fogg and A.F.B. Tompson, 1996. Random-walk simulation of solute transport in heterogeneous porous media: Local mass-conservation problem and implementation methods, Water Resources Research, 32:583-593.

LaBolle, E., J. Quastel, G. Fogg and J. Gravner, 2000. Diffusion processes in composite porous media and their integration by random walks: Generalized stochastic differential equations with discontinuous coefficients. Water Resources Research, 36:651-662.

Lane, Jr., J.W., P.K. Joesten, G. Pohll and T. Mihevic, 2001. Analysis of Borehole-radar Reflection Logs from Selected HC Boreholes at the Project Shoal Area, Churchill County, Nevada. U.S. Geological Survey, Water-Resources Investigations Report 01-4014, 23p.

Liu, H.H., G.S. Bodvarsson and L. Pan, 2000. Determination of particle transfer in random walk particle methods for fractured porous media. Water Resources Research, 36:707-713.

Long, J., C. Remer, P. Wilson and P. Witherspoon, 1982. Porous media equivalents for networks of discontinuous fractures. Water Resources Research, 18(3):645-658.

Long, J.C.S, and D. M. Billaux. 1987. From field data to fracture network modeling: An example incorporating spatial structure. Water Resources Research. 23(7):1201-1216.

Long, J.C.S., (editor), 1996. Rock Fractures and Fluid Flow: Contemporary Understanding and Applications. National Academy Press, Washington, D.C.

Mardia, K.V. and P.E. Jupp, 2000. Directional Statistics, John Wiley \& Sons, Ltd.

Maxey, G. and T. Eakin, 1949. Ground Water in the White River Valley, White Pine, Nye, and Lincoln Counties, Nevada, Water Resources Bulletin, Vol. 8. State of Nevada, Office of the State Engineer, Carson City, Nevada. 59 p.

Maxey, G.B., 1967. Hydrogeology of Desert Basins. Paper presented at Symposium on GroundWater Development in Arid Basins, Logan, Utah. March 16-17, 1967, p. 10-22.

Mazer, J.J., 1987. Kinetics of glass dissolution as a function of temperature, glass composition, and solution pHs. Ph.D. thesis, Northwestern University. 
McDonald, M.G. and A.W. Harbaugh, 1984. A Modular Three-Dimensional Finite-Difference Ground-Water Flow Model, U.S. Geological Survey, Open-File Report 83-875.

McDonald, M.G. and A.W. Harbaugh, 1988. A Modular Three-Dimensional Finite-Difference Ground-Water Flow Model, U.S. Geological Survey, Techniques of Water Resources Investigations, book 6, chap. A1.

Mihevc, T., G. Pohll and B. Lyles, 2000. Project Shoal Area Field Data Summary Report. Desert Research Institute, Publication No. 45175, DOE/NV/11508--54, 258p.

Moreno, L., Y. Tsang, C. Tsang, F. Hale and I. Neretnieks, 1988. Flow and tracer transport in a single fracture: A stochastic model and its relation to some field observations. Water Resources Research, 24(12):2033-2048.

Morrow, C.A., L.Q. Shi and J.D. Byerlee, 1984. Permeability of fault gouge under confining pressure and shear stress. Journal of Geophysical Research, 89(5):3193-3200.

Morse, B. S., G. Pohll, J. Huntington, and R.R. Castillo, 2003. Stochastic capture zone analysis of an arsenic-contaminated well using the generalized likelihood uncertainty estimator (GLUE) methodology. Water Resources Research, 39(6), 1151-1159.

National Academy of Sciences, 1962, Dictionary of Geological Terms. Doubleday \& Co.

Nichols, W. D., 2000. Regional Ground-Water Evapotranspiration and Ground-Water Budgets, Nevada, United States Geological Survey Professional Paper 1628, Reston Virginia.

Nork, W.E. and P.R. Fenske, 1970. Radioactivity in Water - Project Rulison. U.S. Atomic Energy Commission, Nevada Operation Office Report NVO-1229-131, 14p.

Pan, L. and G. S. Bodvarsson, 2002. Modeling transport in fractured porous media with the random-walk particle method: The transient activity range and the particle transfer probability, Water Resources Research, 38(6), 16-1 - 16-7.

Pan, L., H. H. Liu, M. Cushey, and G. S. Bodvarsson, 2001. DCPT V1.0 - New particle tracker for modeling transport in dual continua media, users’ manual, Rep. LBNL-42958, Lawrence Berkeley National Laboratory, Berkeley, CA.

Papelis, C., 2001. Cation and anion sorption on granite from the Project Shoal Test Area, near Fallon, Nevada, USA. Advances in Environmental Research, 5:151-166. 
Plummer, L.N., B.F. Jones and A.H. Truesdell, 1976. WATEQF - A FORTRAN IV Version of WATEQ, A Computer Program for Calculating Chemical Equilibrium of Natural Waters. U.S. Geological Survey, Water-Resources Investigations Report 76-13, 63 p.

Poeter, E.P. and M.C. Hill, 1998. Documentation of UCODE, A Computer Code for Universal Inverse Modeling, U.S. Geological Survey, Water-Resources Investigation Report 98-4080.

Pohll, G., J.T. Chapman, A. Hassan, L. Papelis, R. Andricevic and C.T. Shirley, 1998. Evaluation of Groundwater Flow and Transport at the Shoal Underground Nuclear Test, Desert Research Institute, Publication No. 45162, DOE/NV11508--35.

Pohll, G., A.E. Hassan, J.B. Chapman, C. Papelis and R. Andricevic, 1999a. Modeling ground water flow and radioactive transport in a fractured aquifer. Ground Water, 37(5): 770-784.

Pohll, G., J. Tracy and F. Forsgren, 1999b. Data Decision Analysis: Project Shoal. Desert Research Institute, Publication No. 45166, DOE/NV/11508--42, 27p.

Pohll, G., T. Mihevc, J. Chapman, B. Lyles and P. Reimus, 1999c. Project Shoal Area: Field characterization plan, two-well tracer test deep-well characterization and monitoring. Desert Research Institute, Publication No. 45168, DOE/NV/11508--45, 55p.

Pohll, G., 1999. Evaluation of surface recharge flux for the Project Shoal Area. Desert Research Institute, Publication No. 45171, DOE/NV/11508--49, 18p.

Pohlmann, K., J. Chapman, A. Hassan and C. Papelis, 1999. Evaluation of Groundwater Flow and Transport at the Faultless Underground Nuclear Test, Central Nevada Test Area. Desert Research Institute, Publication No.45165, DOE/NV11508-41.

Pohlmann, K., A.E. Hassan and J. Chapman, 2000. Description of hydrologic heterogeneity and evaluation of radionuclide transport at an underground nuclear test. $J$. Contaminant Hydrology, 44(3-4):353-386.

Rabb, D.D., 1970. Particle-Size Distribution Study: Pile Driver Event. Proc. Symp. Engineering with Nuclear Explosives, CONF-700101, Vol. 2, pp.888-908.

Reimus, P., G. Pohll, T. Mihevc, J. Chapman, M. Haga, B. Lyles, S. Kosinski, R. Niswonger and P. Sanders, 2003. Testing and parameterizing a conceptual model for solute transport in a fractured granite using multiple tracers in a forced-gradient test. Water Resources Research, 39(12):1356-1370. 
Reimus, P., 2000. FORTRAN Source Code and Documentation: FASTFLOTRAC: Monte Carlo program-K generator, flow solver, and particle tracking documentation, Los Alamos National Laboratory, Los Alamos, NM.

Rush, F.E., 1968. Index of Hydrographic Areas in Nevada. Nevada Division of Water Resources, Information Report 6.

Schwartz, L., A. Piwinskii, F. Ryerson, H. Tewes and W. Beiriger, 1984. Glass produced by underground nuclear explosions. J. Non-Crystalline Solids 67:559-591.

Seber, G.A.F. and C.J. Wild, 1989. Non-Linear Regression, John Wiley, New York.

Smith, D.K., B.K. Esser and J.L. Thompson, 1995. Uncertainties Associated with the Definition of a Hydrologic Source Term for the Nevada Test Site. Lawrence Livermore National Laboratory, UCRL-ID-120322, 21 p.

Smith, D.K., 1995. Characterization of nuclear explosive melt debris. Radiochimica Acta, 69:157167.

Smith, D.K., 1997. Radionuclides recommended by the UGTA Source and Transport Subcommittee of significance for remedial investigations at the Nevada Test Site. Memorandum from Lawrence Livermore National Laboratory to Janet Wille, IT Corporation, copied to Robert Bangerter, DOE, dated April 2, 1997.

Tompson, A.F.B. and L.W. Gelhar, 1990. Numerical simulation of solute transport in threedimensional randomly heterogeneous porous media. Water Resources Research, 26(10):2541-2562.

Tompson, A.F.B., C.J. Bruton and G.A. Pawloski (editors), 1999. Evaluation of the Hydrologic Source Term from Underground Nuclear Tests in Frenchman Flat at the Nevada Test Site: The Cambric Test. Lawrence Livermore National Laboratory, UCRL-ID-132300, 319p.

Tsang, Y.W., C.F. Tsang and F.V. Hale, 1996. Tracer transport in a continuum model of fractured media, Water Resources Research, 32(10):3077-3092.

U.S. Atomic Energy Commission, 1964. Project Manager's Report Project Shoal. Reynolds Electrical and Engineering Co., Inc., U.S. Atomic Energy Commission, Nevada Operations Office, NVO-11, 82 p.

U.S. Atomic Energy Commission, 1970. Site Disposal Report, Fallon Nuclear Test Site (Shoal); Churchill County, Nevada, NVO-73, 40p. 
U.S. Department of Commerce, 1963. Maximum Permissible Body Burdens and Maximum Permissible Concentrations of Radionuclides in Air and in Water for Occupational Exposure. National Bureau of Standards Handbook 69, National Committee on Radiation Protection Report No. 22, issued in 1959 and amended in 1963, 95p.

U.S. Department of Energy, 1984. Long-Term Hydrologic Monitoring Program Project Shoal site, NVO - 276. 21p.

U.S. Department of Energy, 1996. Corrective Action Investigation Plan for Project Shoal Area CAU No. 416. Nevada Operations Office, Environmental Restoration Division, DOE/NV-454, 40p.

U.S. Department of Energy, 1998a. Data Report Project Shoal Area Churchill County, Nevada. Nevada Operations Office, Environmental Restoration Division, DOE/NV--505, variable paging.

U.S. Department of Energy, 1998b. Corrective Action Investigation Plan for Corrective Action Unit 447: Project Shoal Area, Nevada Subsurface Site. Nevada Operations Office, Environmental Restoration Division, DOE/NV--513, 71p.

U.S. Department of Energy, 1999. Addendum to the Corrective Action Investigation Plan for Corrective Action Unit 447: Project Shoal Area, Nevada Subsurface Site. Nevada Operations Office, Environmental Restoration Division, DOE/NV--513-ADD, 10p.

U.S. Department of Energy, 2000. United States Nuclear Tests July 1945 Through September 1992. United States Department of Energy Nevada Operations Office, DOE/NV--209-REV 15, 162p.

U.S. Environmental Protection Agency, 1976. National Interim Primary Drinking Water Regulations. EPA-570/9-76-003, 159p.

University of Nevada, 1965. Geological, Geophysical, Chemical, and Hydrological Investigations of the Sand Springs Range, Fairview Valley, and Fourmile Flat, Churchill County, Nevada. Vela-Uniform Program, VUF-1001.

Van Kote, F. and F. Balard, 1972. Distribution de la Radioactivité dans l'Environment d'une Explosion Nucléaire Souterraine. Commissariat à l’Energie Atomique, CEA-R-4287.

Vogel, T., K. Huang, R, Zhang and M. Th. van Genuchten, 1996. The HYDRUS Code for Simulating One-Dimensional Water Flow, Solute Transport, and Heat Movement in VariablySaturated Media, Version 5.0, Research Report No. 140, U.S. Salinity Laboratory, Agricultural Research Service, U.S. Department of Agriculture, Riverside, CA. 
Watson, P., P. Sinclair, and R. Waggoner, 1976. Quantitative evaluation of a method for estimating recharge to the desert basins of Nevada, Journal of Hydrology, Vol. 31., pp 335-357.

White, A.F., 1983. Surface chemistry and dissolution kinetics of glassy rocks at $25^{\circ} \mathrm{C}$. Geochim. et Cosmochim. Acta, 47:805-815.

Willden, R. and R.C. Speed, 1974. Geology and Mineral Deposits of Churchill County, Nevada. Nevada Bureau of Mines and Geology, Bulletin 83. 
APPENDIX A

SUMMARY INFORMATION FOR WELLS USED IN THIS STUDY

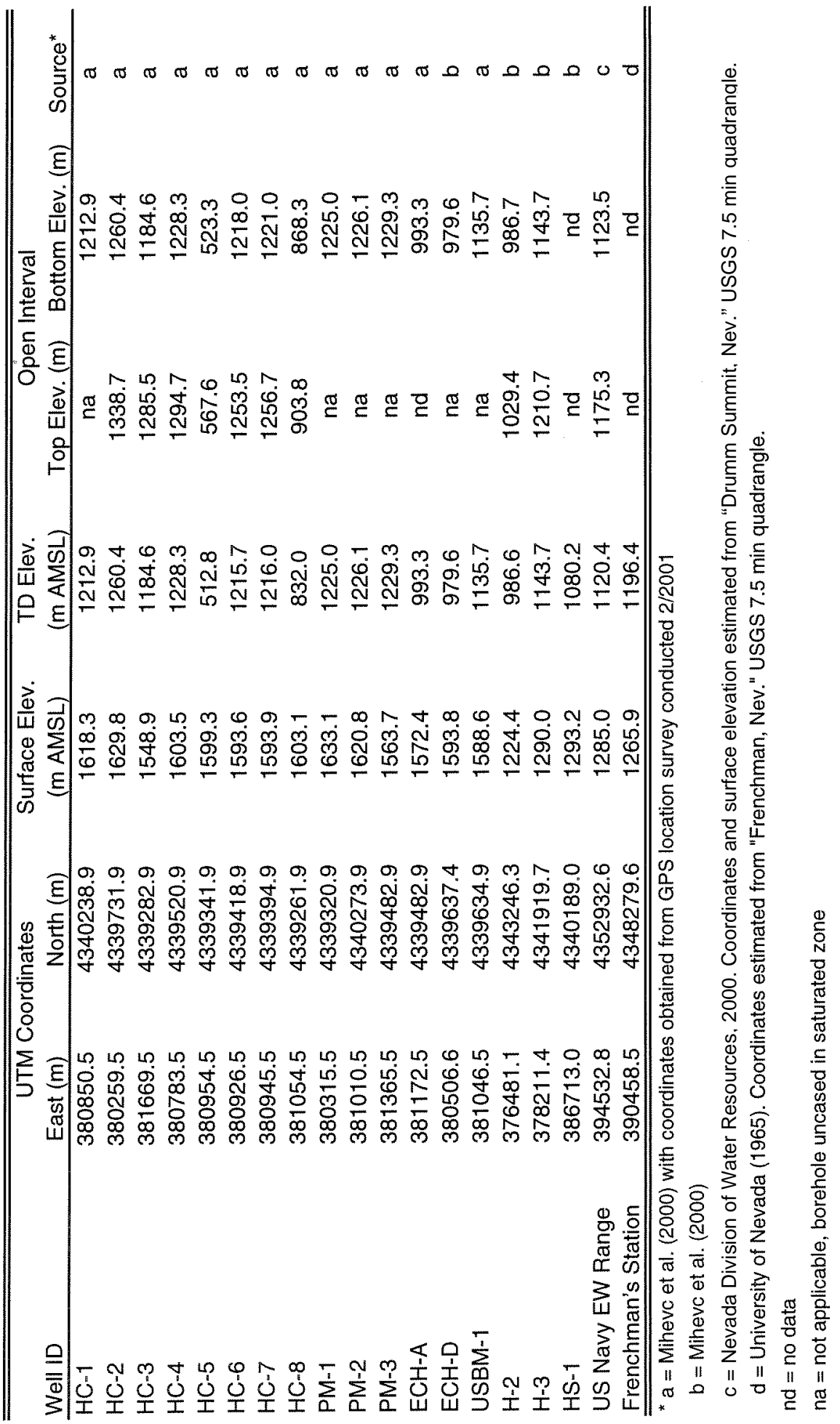




\section{REFERENCES}

Mihevc, T., G. Pohll and B. Lyles, 2000. Project Shoal Area Field Data Summary Report. Desert Research Institute, Publication No. 45175, DOE/NV/11508--54, 258p.

Nevada Division of Water Resources, 2000. Well Log Database. State of Nevada, Department of Conservation and Natural Resources, database query on 31 July 2000.

University of Nevada, 1965. Geological, Geophysical, Chemical, and Hydrological Investigations of the Sand Springs Range, Fairview Valley, and Fourmile Flat, Churchill County, Nevada. Vela-Uniform Program, VUF-1001. 


\section{APPENDIX B}

\section{QUALITY ASSURANCE STATEMENT}

The work carried out under the CAIP for Corrective Action Unit 447 was designed and implemented in accordance with the Federal Facility Agreement and Consent Order (FFACO, 2000) and the Underground Test Area Quality Assurance Project Plan (UGTA QAPP) (DOE/NV, 2000).

As stated in the UGTA QAPP, three fundamental types of activities are necessary to accomplish the project objectives. These are the assessment of data, flow and transport modeling, and data collection. The first two relate to the work presented in this report.

\section{Evaluation and Use of Existing and New Data}

Existing and new data for the Shoal project were evaluated against their intended use. This analysis consisted of screening, checking, verification, and review of the data. The historic data had already been through this process once before, during the modeling presented in Pohll et al. (1998). Some of these data were decades old and their quality was assessed by review of the testing and analysis methods presented in published reports, and assessment of the data in the context of regional and general hydrogeologic knowledge. Newly acquired data were also evaluated using a similar process, though more information regarding data quality was available.

Hydraulic head measurements provide an example of how data quality indicators are used during the modeling process. Hydraulic head measurements are available in the historic literature for several wells that are now closed. Information provided with these measurements indicates that many were affected by water injection or pumping operations and thus did not represent equilibrium conditions. Examination of time-series head data corroborated this conclusion. Hydraulic head data from the more recent HC wells also exhibits some transient effects from drilling, but of a much smaller magnitude. For the modeling, the older hydraulic head values are assigned a lower quality indicator and their use is restricted to providing general guidance during model development. Conversely, the hydraulic head values from the HC wells are assigned a higher quality and are used for model calibration.

\section{Computer Hardware and Software}

Quality assurance of the numerical modeling work performed by the Desert Research Institute for the U.S. Department of Energy Environmental Management Program relies on several overlapping efforts. These are as follows:

- Project control procedures

- Personnel qualifications

- Technical control procedures

- Peer review 


\section{Project Control}

Project control involves detailed accounting to DOE/NV Environmental Restoration Program project managers about scope, schedules, costs, technical execution, and quality achievement of task order activities. This occurred for the Shoal modeling through the development of annual task plans (which include detailed scope, assumptions, budget, and milestones), monthly reporting of cost and schedule performance relative to the plan, and semi-annual program reviews to ensure that planning document requirements were implemented.

A project kickoff meeting was conducted. In this meeting, key personnel assigned to the task were briefed on the purpose of the task, the schedule for the task, and their responsibilities for completion of the effort. Additional "kickoff" meetings occurred at the beginning of each fiscal year to reiterate expectations and communicate any adjustments as work progressed.

Prior to the start of the modeling effort, the DRI task manager ensured the following (readiness review):

- that the scope of work for the modeling was compatible with the overall objectives for the Shoal subsurface project

- that the planned modeling work was appropriate to meet the objectives

- that proper resources (e.g., personnel, computer hardware, software) to conduct the work were available

- that assigned personnel were qualified to perform the work.

\section{$\underline{\text { Personnel Qualifications }}$}

A central pillar of quality assurance for DRI's numerical modeling program is ensuring that personnel are trained and qualified to meet the job responsibilities of a modeling project. This originates through the rigorous hiring procedures followed for faculty hires into DRI. Faculty positions are filled from a competitive nationwide search. Academic records and written recommendations are required and examined as a prerequisite. Faculty have advanced degrees relevant to hydrogeology and hydrogeologic modeling and must demonstrate excellence in research through peer-reviewed publications. Project managers are scientists and members of the academic faculty, allowing close and critical oversight for the technical project aspects.

The specific faculty responsible for the Shoal modeling project are as follows:

Jenny B. Chapman - Project manager

Karl F. Pohlmann - Lead modeler

Greg Pohll - Flow modeling, recharge modeling, tracer test analysis

Ahmed E. Hassan - Transport modeling

Rosemary Carroll - Support modeler for flow

Craig Shirley - Support modeler for flow

Brief resumes for these individuals can be found at http://www.dri.edu/People/. 


\section{Technical Control Procedures}

Technical control procedures are the processes followed to ensure the computer codes are performing as required and that data input and output are managed correctly. The computer codes consist of computerized numerical models and auxiliary computer programs; and both types may be either internally developed or obtained from external sources. The routine procedures followed during the modeling process are described below.

\section{Computer Systems}

Computer hardware and software configurations must be tested by knowledgeable individuals prior to use and the results documented. For the Shoal modeling this involves installing computer codes on the various machines used in the modeling project, and verifying that they run correctly through the use of test cases. The physical media on which data, software, and results are stored are controlled and protected so that they can be physically retrievable and protected from loss, compromise, or catastrophic events.

\section{Code Evaluation}

Code developed external to DRI originates from commercial software firms (e.g. the FEFLOW code from the WASY Institute for Water Resources Planning and Systems Research Ltd.) and non-profit organizations (e.g. the MODFLOW code from the U.S. Geological Survey). External code is selected based on its technical capabilities to meet project needs and acceptance in the wider groundwater modeling community. Before selecting externally-developed code for a particular modeling purpose, a rigorous review and comparison is conducted of the available pertinent codes. Internal modeling programs are developed when external programs are not available to meet project needs and/or when additional flexibility or new algorithms are required for the task at hand (e.g. the Random-Walk Particle-Tracking code used for radionuclide transport modeling in the Shoal project).

\section{Code Verification/Validation}

Software verification and validation activities are intended to provide confidence that the software adequately and correctly performs all intended functions. Significant portions of the Shoal modeling were performed using externally developed software (e.g., FEFLOW and MODFLOW). These software packages are subjected to rigorous test-case analyses, per the software's documentation, to ensure proper operation. Externally developed modeling programs are not, to the extent practicable, modified in any way. In some cases, modifications are not possible because the source code is proprietary and not available (e.g. FEFLOW); however, even in the case of open-source software such as MODFLOW, internal modifications can prevent the application of the code to other modeling scenarios without further modifications and may increase uncertainty in the results. For these reasons, the modeling team prefers to develop input and output routines that provide the input data and accept the results in the default format of the codes. In addition, it is unlikely that internal changes would be required to, for example, improve performance or integrate additional functionality, as these factors would have been evaluated during code evaluation. Additional functionality is generally provided only by development and integration of auxiliary codes in the modeling system. 
Individuals knowledgeable in the area of code development review all newly developed DRI computer codes. These reviews consider whether the assumptions are reasonable and valid, the correctness of the mathematical models, conformance of methods to accepted and published concepts, consistency of results with known data, reasonable and prudent use of data and analysis tools, and appropriateness for the intended purpose. Where appropriate, solutions are compared to analytically derived solutions to check the theory and application represented by the codes. In the case of the random walk particle tracking code used for radionuclide transport, additional quality assurance was provided through independent peer-reviewed publication of a rigorous comparative study with other transport codes (Hassan and Mohamed, 2003).

\section{Documentation}

Continual evaluation and record-keeping are conducted during the modeling phases of the project to ensure that the work is internally consistent, well-documented, and readily repeatable for the purposes of technical review and future model refinements. All developed and procured computer codes are uniquely identified and internally documented so that it is obvious to the user of the version they are implementing. Unique run identifiers are used to link model output with the corresponding model input; and the associated documentation identifies the specific input files, versions of the codes, and other related information so that the output for any run can be readily regenerated. This procedure is followed even during initial testing of model parameterization and boundary conditions, in order to track sensitivity to these fundamental aspects of the model. Computer software code documentation is maintained in project files.

\section{Peer Review}

Peer review is an assessment of the assumptions, calculations, extrapolations, alternate interpretations, methodology, acceptance criteria, and conclusions pertaining to interpretative work products generated through the use of computer software. Peer review is performed to ensure that interpretative work products are technically adequate, properly documented, and satisfy technical and quality requirements. Peer reviewers shall possess the appropriate subject matter/technical expertise and not have participated in preparing the original work.

Internal peer review of the Shoal modeling occurred continuously as the work progressed. The modeling project was comprised of many distinct efforts conducted by different faculty. Interim work products produced by one faculty member were reviewed and evaluated by other faculty members. Periodic project status meetings allowed the opportunity of presentation of results to other members of the team for scrutiny and comment. Multiple individuals applied the codes to a variety of problems to ensure that errors and/or inconsistencies in code development were identified and rectified prior to final model runs.

Though internal peer review was extremely effective at providing quality checks, it could not replace external peer review. The external review occurred at the conclusion of the 
draft model report and used the Modeling Subcommittee of the Underground Test Area Technical Working Group. The review committee consisted of:

Andrew F.B. Tompson (Chair), Lawrence Livermore National Laboratory

David Prudic, U.S. Geological Survey

Richard Waddell, Geotrans, Inc.

Andrew Wolfsberg, Los Alamos National Laboratory

Vefa Yucel, Bechtel Nevada

The draft report was sent to the committee on October 4, 2001. The comments of the committee were incorporated into the model and model report prior to submission to NDEP. The regulatory review conducted by NDEP also serves as a peer review.

Technical comments were received from NDEP by letter dated March 20, 2003, and also verbally during a field tour and modeling briefing. These comments were incorporated into the model and model report to prepare the product presented here.

\section{REFERECES}

Federal Facility Agreement and Consent Order, Rev. 1, 2000. U.S. Department of Energy, U.S. Department of Defense, and Nevada Division of Environmental Protection.

Hassan, A.E. and M.M. Mohamed, 2003. On using particle tracking methods to simulate transport in single-continuum and dual continua porous media. Journal of Hydrology, 275(3-4): 242-260.

Pohll, G., J.T. Chapman, A. Hassan, L. Papelis, R. Andricevic and C.T. Shirley, 1998. Evaluation of Groundwater Flow and Transport at the Shoal Underground Nuclear Test, Desert Research Institute, Publication No. 45162, DOE/NV11508--35. 
THIS PAGE INTENTIONALLY LEFT BLANK 


\section{APPENDIX C \\ GLASS DISSOLUTION SOLUTION \\ by Greg Pohll}

White (1983) gives the following linear mass transfer equation for glass dissolution, normalized by area

$$
\zeta=\zeta_{0}+k_{l} t
$$

where $\zeta$ is the cumulative mass dissolved per unit area $\left(\right.$ moles $\left./ \mathrm{cm}^{2}\right), \zeta_{0}$ is the initial dissolved mass per unit area (moles $\left./ \mathrm{cm}^{2}\right), k_{l}$ is the linear rate constant (moles $\left./ \mathrm{cm}^{2} \mathrm{~s}\right)$, and $t$ is the time (s).

Taking the first derivative of Equation C1 with respect to time determines the normalized rate of change (with respect to area) of the glass. Note also that the sign must be changed to account for a loss of mass from the glass, rather than a gain as was written in Equation C1

$$
\frac{d \zeta}{d t}=-k_{l}
$$

To calculate the actual mass dissolution rate in gm/s, we must multiply Equation C2 by the specific surface area, gram formula weight and the available mass of glass

$$
\frac{d M}{d t}=-k_{l} M A_{s p} G_{f w}
$$

where $M$ is the mass of glass at any time $t(\mathrm{gm}), A_{s p}$ is the specific surface area of the glass with respect to mass $\left(\mathrm{cm}^{2} / \mathrm{gm}\right)$, and $G_{f w}$ is the gram formula weight (gm/mole). Though the surface area changes as the mass of glass decreases during dissolution, the $A_{s p}$ is assumed constant.

Note that the units of $d M / d t$ are now gm/s. One could also remove the gram formula weight, which would produce moles/s. Now, separate variables to solve for $M$

$$
\frac{d M}{M}=-k_{l} A_{s p} G_{f w} d t
$$

Integrating both sides gives

$$
\ln M=-k_{l} A_{s p} G_{f w} t+C^{\prime}
$$

where $C^{\prime}$ is the integration constant. For simplicity, let us define a new variable, $k_{g}$, which will be defined as

$$
k_{g}=k_{l} A_{s p} G_{f w}
$$

which then simplifies Equation C5 to

$$
\ln M=-k_{g} t+C^{\prime}
$$

Taking the exponents of both sides of Equation C7 yields 


$$
M=C^{\prime} e^{-k_{g} t}
$$

The integration constant is simply the initial mass of the glass (at $t=0$ ), so Equation C8 can be written as

$$
M=M_{0} e^{-k_{g} t}
$$

where $M_{0}$ is the initial glass mass (gm).

Therefore, Equation C9 defines the mass at any time $t$ for the glass structure. For modeling purposes, we are more interested in the amount of glass that is in solution, which can be described as

$$
M_{\text {solution }}=\left(M_{0}-\zeta_{0}\right)\left[A_{s p} G f w\left(1-e^{-k g t}\right)\right]+\zeta_{0} A_{s p} G \text { fw }
$$

Equation C10 also includes the small amount of mass that is lost instantaneously as defined in Equation C1 by White (1983). This term was not included in Equation C9, but can be easily added, by redefining (more correctly) the integration constant to include the mass lost at $t=0$

$$
M_{\text {solid }}=\left(M_{0}-\zeta_{0}\right)\left[A_{s p} G \text { fw }\left[e^{-k_{g} t}\right]\right]
$$

For modeling purposes, the amount of glass lost to solution between any two time steps is important so the numbers of particles that should be released can be obtained. The algorithm is as follows:

1. Assume that $p$ is the percentage of mass released hydraulically, and thus $1-p$ represents the mass in the glass.

2. Next, one must address how much mass is lost due to the instantaneous dissolution $\left(\zeta_{0} A_{s p} G_{f w}\right)$. A problem is that this term is in real mass units, which makes it difficult to use a unit mass within the transport model. Rather than relying on classified data, which will remove much of the analysis from public review, the instantaneous dissolution term is ignored here. This is justified for two reasons. First, the mass involved in this term is very small relative to the total mass dissolved. The inclusion of this term is important for short-term experimental work but not for the long-term, total dissolution process considered here. Second, the process leading to this instantaneous dissolution is considered to be due to surface ion exchange, which is handled through the partitioning of the radionuclides into both glass and surface deposits. The portion assigned to surface deposits (conservatively assumed to be five percent of the refractory nuclides, despite evidence that the actual percentage is closer to one or two percent) is assumed instantaneously dissolved in groundwater, accounting for this term.

3. By ignoring the instantaneous dissolution term, one can simply use Equation 4.13 in the body of the main report. Note that Equation 4.13 simplifies to $k_{g}$ as defined by Equation C6 above, using the gram formula weight of $\mathrm{SiO}_{2}$. 


\section{Comparison to Glass Dissolution Solution Applied to the Cambric Test (Tompson et al., 1999)}

Tompson et al. (1999) utilized a transition state-theory type of rate law for simulating the release of radionuclides from nuclear melt glass of the form:

$$
\frac{d N_{i}}{d t}=v_{i} \frac{d M}{d t}=\left(v_{i} A k\right)\left[\prod_{j} a_{j} p_{j}\right]\left[1-\frac{Q}{K}\right]
$$

where $N_{i}$ is the number of moles of component $i$ released from the glass, $A$ is the reactive surface area of the glass $\left(\mathrm{m}^{2}\right), v_{i}$ is the stoichiometric coefficient for the element $i$ in the glass (a constant, moles of element $i$ per mole of glass), $k(T)$ is the (possibly temperature-dependent) rate coefficient (moles $/ \mathrm{m}^{2}$-sec), the $\Pi$ term is the product function of catalytic or inhibitive species, and $Q$ and $K$ are the activity product and solubility product for the glass dissolution reaction. Their approach for simulating the release of radionuclides from nuclear melt glass considers 1) a temporally varying reactive surface area, 2) a product term that typically includes the $\mathrm{pH}$ dependence, and 3) an affinity term that accounts for a decrease in the dissolution rate resulting from saturation effects.

The activity-solubility product ratio is an affinity term that provides for the slowdown in the rate resulting from saturation effects. Tompson et al. (1999) cite previous studies showing that the primary cause of the slowdown is the increasing concentration of dissolved silica. Thus, they used the concentration of $\mathrm{SiO}_{2}(\mathrm{aq})$ as $Q$ (actually, they computed a value in equilibrium with \$-cristobalite and assumed it was constant for the case of Cambric) and the equilibrium constant for amorphous silica for $K$. In theory, if the aqueous silica concentrations rose above the saturation level in their simulations, glass dissolution would default to a very low, long-term rate to simulate dissolution under silica saturated conditions. In practice, they held the affinity term constant during the Cambric simulations but noted that checks suggested that silica concentrations did not substantially change during the course of the calculations. If we applied the same approach here (reducing our rate constant by a constant affinity term based on the silica concentration in Shoal groundwater), our dissolution rate would be about 75 percent of the rate we used. Therefore, in application, both Cambric and Shoal assume a constant affinity term.

Tompson et al. (1999) note that the only catalytic or inhibitive species usually considered for glass dissolution reactions is $\mathrm{pH}$, and they include the effect of $\mathrm{pH}$ in the computation of $k$. We followed their example and applied the same $\mathrm{pH}$ dependence extrapolated for different glass silica contents, as described in their section 6.2.3, assuming $\mathrm{pH}$ to be constant.

With both the product and affinity terms (last two parenthetical quantities) assumed to be constant, the equation translates into a simplified rate law of the form:

$$
\frac{d N_{i}}{d t}=v_{i} \frac{d M}{d t}=v_{i} A k_{l}
$$

where $k_{l}$ is the linear rate constant $\left(\right.$ moles $/ \mathrm{cm}^{2}$ ). If one assumes that the reactive surface area, $A$, is the product of the specific surface area and the mass $\left(A=A_{s p} M\right)$, and the glass is treated as a whole rather than its stoichiometric elements, then:

$$
\frac{d M}{d t}=A_{s p} M k_{l}
$$

This equation is identical to the molar form of Equation C3. 


\section{REFERENCES}

Tompson, A.F.B., C.J. Bruton and G.A. Pawloski (editors), 1999. Evaluation of the Hydrologic Source Term from Underground Nuclear Tests in Frenchman Flat at the Nevada Test Site: The Cambric Test. Lawrence Livermore National Laboratory, UCRL-ID-132300, 319p.

White, A.F., 1983. Surface chemistry and dissolution kinetics of glassy rocks at $25^{\circ} \mathrm{C}$. Geochim. et Cosmochim. Acta, 47:805-815. 


\section{APPENDIX D}

\section{METHODOLOGY FOR INCORPORATING MATRIX DIFFUSION IN PTRACK}

The matrix diffusion process is incorporated into the random walk particle method (RWPM) using a particle transfer approach. Although the original transport model utilized the particle transfer approach developed by Liu et al. (2000), more accurate methods have been developed recently and are used in the current transport model (Hassan and Mohamed, 2003; Pan and Bodvarsson, 2002; Huang et al., 2003; Pan et al., 2001).

A Markov chain model to simulate the particle transfer between the mobile and immobile waters has been developed by Huang et al. (2003). This Markov Chain model is extended to simulate the particle transfer across the fracture/matrix interface by coupling the "active diffusion range" developed by Pan and Bodvarsson (2002) into the model. The advantage of this approach is that it allows a relatively large time interval $(\Delta t)$, which dramatically reduces the computation time. The model also allows for multiple fractures within a single grid cell, which effectively increases the effective fracture-matrix interface area.

The forward and backward particle transfer probabilities are given as:

$$
\begin{aligned}
& \left.P_{f m}=\frac{V_{m}\left(t_{p}\right) R_{m}}{V_{f} R_{f}+V_{m}\left(t_{p}\right) R_{m}}\left[1-\exp \left(-\left(\frac{F_{f m}}{V_{f} R_{f}}+\frac{F_{m f}}{V_{m}\left(t_{p}\right) R_{m}}\right) \cdot \Delta t\right)\right)\right] \\
& \left.P_{m f}=\frac{V_{f} R_{f}}{V_{f} R_{f}+V_{m}\left(t_{p}\right) R_{m}}\left[1-\exp \left(-\left(\frac{F_{f m}}{V_{f} R_{f}}+\frac{F_{m f}}{V_{m}\left(t_{p}\right) R_{m}}\right) \cdot \Delta t\right)\right)\right]
\end{aligned}
$$

where $V_{f}$ is the fluid volume within the fracture continuum, $R_{f}$ and $R_{m}$ are the retardation factors within the fractures and matrix, respectively. For structured grids with $\Delta x=\Delta y, V_{f}$ is defined as:

$$
V_{f}=\Delta x^{2} \Delta z \phi_{f}
$$

where $\phi_{f}$ is the ratio of the fluid volume within the fractures to the total cell volume and is defined as:

$$
\phi_{f}=\frac{a}{B}
$$

where $a$ is the fracture aperture and $B$ is the fracture spacing. It is important to note that the fracture porosity $\left(\phi_{f}\right)$ as defined here assumes that each fracture is not filled with gouge material, so the fracture porosity represents the volume of fractures per unit volume of aquifer and not the porosity of the material within the fracture. Equation D3 can be represented as: 


$$
V_{f}=\frac{\Delta x^{2} \Delta z a}{B}
$$

and the volume of the matrix is defined as:

$$
\phi_{m}=\left(1-\phi_{f}\right) \Delta x^{2} \Delta z \phi_{m}
$$

where $\phi_{m}$ is the porosity of the matrix. $F$ and $Q$ in Equations (D1) and (D2) describe the strength of diffusion across fracture/matrix interface, and the strength of advection across the interfaces to adjacent cells, respectively. The detailed expressions of parameters are listed below (Pan and Bodvarsson, 2002):

$$
\begin{gathered}
F_{f m}=\max \left(Q_{f m} A, 0\right)+\frac{D_{f m} A}{S_{f m}\left(t_{p}\right)} \\
F_{m f}=\max \left(-Q_{f m} A, 0\right)+\frac{D_{f m} A}{S_{f m}\left(t_{p}\right)} \\
Q_{f}=\sum_{i=1}^{N}\left[\max \left(q_{f} A_{i}, 0\right)+\frac{D_{f_{i}} A_{i}}{S_{i}}\right] \\
Q_{m}=\sum_{i=1}^{N}\left[\max \left(q_{m} A_{i}, 0\right)+\frac{D_{m_{i}} A_{i}}{S_{i}}\right] \\
\tau_{f}=\frac{V_{f} R_{f}}{F_{f m}+Q_{f}}, \tau_{m}=\frac{V_{m}\left(t_{p}\right) R_{m}}{F_{m f}+Q_{m}}
\end{gathered}
$$

where $A$ is the contact area between fracture and matrix. For structured grids $A$ is defined as $\Delta x / B . Q_{f m}$ is the advection flux across the interface between fracture and matrix; $D_{f m}$ is the effective diffusion coefficient across the interface between fracture and matrix; $S_{f m}\left(t_{p}\right)$ is the active diffusion range into the matrix; $q_{f}$ and $q_{m}$ are the advection fluxes (outward positive) to the adjacent cell $i$ through the factures and matrix, respectively; $A_{i}$ is the contacting area between the current cell and adjacent cell $i ; D_{f_{i}}$ and $D_{m_{i}}$ are the effective dispersion coefficient within the fracture and matrix block, respectively; $S_{i}$ is the distance between the centers of current cell and adjacent cell $i ; \tau_{f}$ and $\tau_{m}$ are the critical times within the fracture and matrix (the times required to transfer all particles out of the fracture and matrix), respectively.

Pan and Bodvarsson (2002) provided the active range $S_{f m}\left(t_{p}\right)$ and effective matrix volume $V_{m}\left(t_{p}\right)$ as 


$$
S_{f m}\left(t_{p}\right)=\frac{(1-\lambda) S}{2} \cdot \frac{B^{*}\left(t_{p}\right)}{B}
$$

Note that $\lambda=1 / 3$ for parallel, equally spaced fractures.

$$
\begin{gathered}
V_{m}\left(t_{p}\right)=V_{m} \cdot \frac{B^{*}\left(t_{p}\right)}{B} \\
B^{*}\left(t_{p}\right)=\min \left[\left(4 \sqrt{4 D_{f m} t_{p} / R_{m}}\right), B\right]
\end{gathered}
$$

Note that $t_{p}$ is a spatially dependent parameter defined as:

$$
t_{p}=t_{\text {sim }}-t_{0}(i, j)
$$

where $t_{\text {sim }}$ is the total simulation time, and $t_{0}(i, j)$ is the time at which the first particle enters cell $(i, j)$, within the model domain.

Equation (D14) is based on a one-dimensional solution of diffusion equation, and it captures the transient effects of the active diffusion depth. The results given by Pan and Bodvarsson (2002) demonstrate that the breakthrough curves predicted by Pan and Bodvarsson (2002) are still quite accurate when the diffusion coefficient is low or the facture spacing is large, for which Liu et al.'s (2000) method fails. However, such method required small time step $\Delta t$, which wasn't addressed by the authors. Such limitation significantly increases the computation time. This issue will be further addressed later in this technique report.

\section{Model Verification}

The example of Liu et al. (2000) is used to check the accuracy of the revised matrix diffusion algorithm. Sudicky and Frind's (1982) analytical solution for this example serves as the perfectly accurate solution for comparison.

The time step $\Delta t$ for Liu's method and our Markov chain model is $\min \left(\tau_{f}, \tau_{m}\right) / 1.2$. However, the $\Delta t$ for Pan's method has to be as small as $\min \left(\tau_{f}, \tau_{m}\right) * 0.05$. Figure D- 1 shows the results for the various algorithms using parameters shown in Table D-1.

In this example, Liu's (2000) method fails to match the early breakthrough curves yet the current approach (as revised from Huang et al., 2003) and Pan and Bodvarsson's (2002) solution are in excellent agreement with the analytic solution. The above comparison reveals that both the Markov chain and Pan and Bodvarsson (2002) methods are more robust than the Liu et al. (2000) method. It is important to note that in order to achieve the same accuracy as the Markov chain method, the Pan and Bodvarsson (2002) method requires a very small time step $\Delta t$, which could lead to a tremendous amount of computation time.

\section{Application to Shoal Tracer Test}

The revised matrix diffusion transport model was used to simulate the Project Shoal Tracer Test. The purpose of the modeling exercise was to calibrate the matrix diffusion parameters for use in 
the Shoal transport model. Two tracers were investigated. Bromide was used to investigate a conservative solute and lithium was used to determine the retardation factors for a mildly sorbing solute

PEST (Doherty, 1999) was used to automate the calibration procedure to determine the fracture porosity, fracture spacing (B), the fractional mass participation (f), and the retardation factors for lithium. The fractional mass participation is an adjustable constant (ranging from 0 to 1 ) that both simulated tracer response curves are multiplied by to account for an arbitrary fraction of the tracer injection solution that never establishes communication with the production well and therefore doesn't "participate” in the test. A simultaneous least-squares fit was used by automatically adjusting the above parameters. Also, $R_{f}$ and $R_{m}$ were held equal to one for bromide.

This fitting procedure implicitly assumes that both tracers experience the same flow paths which is justified because the tracers were injected simultaneously and should thus have experienced the same flow system and same flow conditions. The tracers should have had the same Peclet numbers despite their different diffusion coefficients because Taylor dispersion (dispersion resulting from tracer diffusion across the local parabolic velocity profile in fractures) was estimated to be at least three orders of magnitude less than macrodispersion (Detwiler et al., 2000).

The number of particles was 20,000 for the bromide simulation and 40,000 for the lithium simulation. The time step length $(\Delta t)$ was 0.1 day for both simulations.

Table D-2 shows the parameters as estimated by PEST to obtain the best overall fit between the simulated and observed bromide and lithium breakthrough curves. The initial parameter values were chosen based on the ranges estimated by Reimus et al. In Review. Figures D-2 and D-3 show the best-fit breakthrough curves for bromide and lithium, respectively. The parameters shown in Table D-2 were used for the Project Shoal Transport model. These parameters are in agreement with the values obtained by Reimus et al. (In Review), with the exception of the lithium retardation within the matrix, Reimus et al. (In Review) estimated the matrix retardation factor to be 90 - 200, whereas this analysis used a value of 5.4. The difference in matrix retardation is due to the ability of the revised model to account for multiple fractures per unit volume, which effectively increases the fracture/matrix interface area.

Additional testing was done to determine the uniqueness of the calibration on the retardation factors. The inverse simulations showed that the solutions are non-unique, with acceptable fits being obtained for numerous combinations of fracture and matrix retardation factors (Figure D4). It is difficult to ascertain the underlying basis for this type of parameter correlation leading to acceptable fits due to the fact that the forward and backward probabilities are calculated on a cell by cell basis at each time step. Although some parameter correlation was found, the "best-fit" retardation factors of 1.2 and 5.4 for the fracture and matrix, respectively, were used for the Project Shoal transport model 


\section{REFERENCES}

Detwiler, R. L., H. Rajaram, and R. J. Glass, 2000. Solute transport in variable-aperture fractures: An investigation of the relative importance of Taylor dispersion and macrodispersion, Water Resources Research, 36(7), 1611-1625.

Doherty, J, 1999. PEST - Model-Independent Parameter Estimation - User’s Manual, Watermark Numerical Computing.

Hassan, A. E., and M. M. Mohamed, 2003. On using particle tracking methods to simulate transport in single-continuum and dual continuum porous media, Journal of Hydrology, 275, pp. 242-260.

Huang, H., A. E. Hassan, and B. X. Hu, 2003. Monte Carlo study of conservative transport in heterogeneous dual-porosity media, Journal of Hydrology, 275, pp. 229-241.

Liu, H. H, G. S. Bodvarsson, and L. Pan, 2000. Determination of particle transfer in random walk particle methods for fractured media, Water Resources Research, 36(3), 707-713.

Pan, L. and G. S. Bodvarsson, 2002. Modeling transport in fractured porous media with the random-walk particle method: The transient activity range and the particle transfer probability, Water Resources Research, 38(6), 16-1 - 16-7.

Pan, L., H. H. Liu, M. Cushey, and G. S. Bodvarsson, 2001. DCPT V1.0 - New particle tracker for modeling transport in dual continua media, users’ manual, Rep. LBNL-42958, Lawrence Berkeley National Laboratory, Berkeley, CA.

Reimus, P., Pohll, G, Mihevc, Chapman, J, Haga, Lyles, B. Kosinski, S., Niswonger, R. Sanders, P., In Review. Testing and Parameterizing a Conceptual Model for Solute Transport in a Fractured Granite using Multiple Tracers in a Forced-Gradient Test, Water Resources Research.

Sudicky, E.A., and E.O. Frind, 1982. Contaminant transport in fractured porous media: Analytical solutions for a system of parallel fractures, Water Resources Research, 18(6), 1634-1642. 
Table D-1. Parameters used for validation simulations.

\begin{tabular}{lcc}
\multicolumn{1}{c}{ Parameter } & Value & Units \\
\hline Diffusion Term & $10^{-10}$ & $\mathrm{~m}^{2} / \mathrm{sec}$ \\
Fracture Spacing & 10 & $\mathrm{~m}$ \\
Fracture Aperture & $2 \times 10^{-5}$ & $\mathrm{~m}$ \\
Matrix Tortoursity & 0.1 & dimensionless \\
Volumetric Water Content in Matrix & 0.1 & $\mathrm{~m} 3 / \mathrm{m} 3$ \\
Fracture Retardation & 1.0 & dimensionless \\
Matrix Retardation & 1.0 & dimensionless \\
Velocity in Fracture & 1.0 & $\mathrm{~m} / \mathrm{day}$ \\
Grid Spacing & 0.5 & $\mathrm{~m}$ \\
Fracture/Matrix Interface Area & 0.5 & $\mathrm{~m}^{2}$ \\
\hline
\end{tabular}

Table D-2. Calibrated matrix diffusion parameters for the Project Shoal Tracer Test.

\begin{tabular}{lcc}
\multicolumn{1}{c}{ Parameter } & Value & Units \\
\hline Dispersivity & 15 & $\mathrm{~m}$ \\
Fracture Porosity & 0.037 & $\mathrm{~m}^{3} / \mathrm{m}^{3}$ \\
Matrix Porosity & 0.015 & $\mathrm{~m}^{3} / \mathrm{m}^{3}$ \\
Fracture Spacing & 0.5 & $\mathrm{~m}$ \\
Fracture Retardation (lithium) & 1.2 & dimensionless \\
Matrix Retardation (lithium) & 5.4 & dimensionless \\
Diffusion Term & $10^{-6}$ & $\mathrm{~m}^{2} /$ day \\
Fractional Mass Participation & 0.46 & dimensionless \\
\hline
\end{tabular}




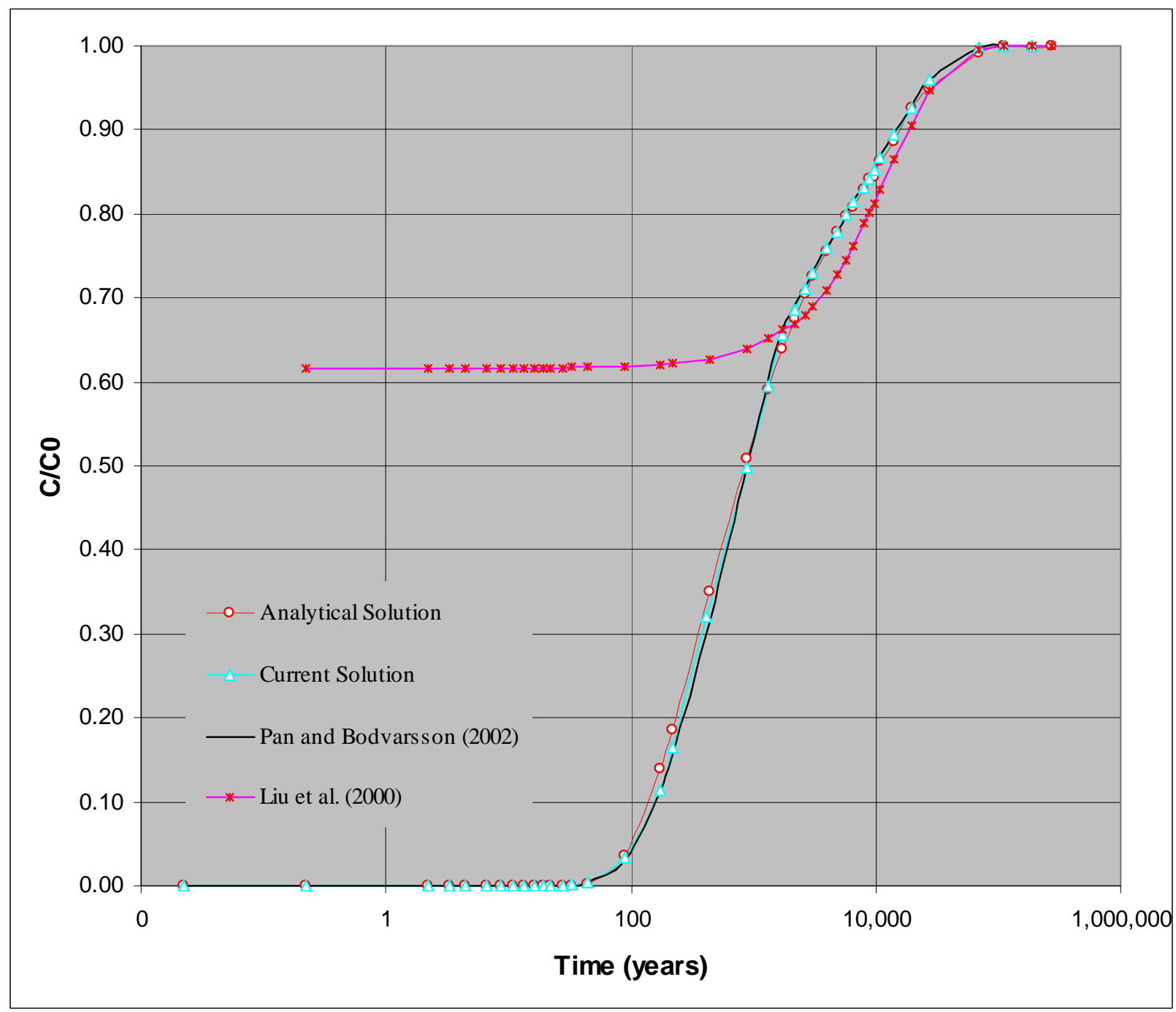

Figure D-1. Comparison of breakthrough curves for the validation simulations. 


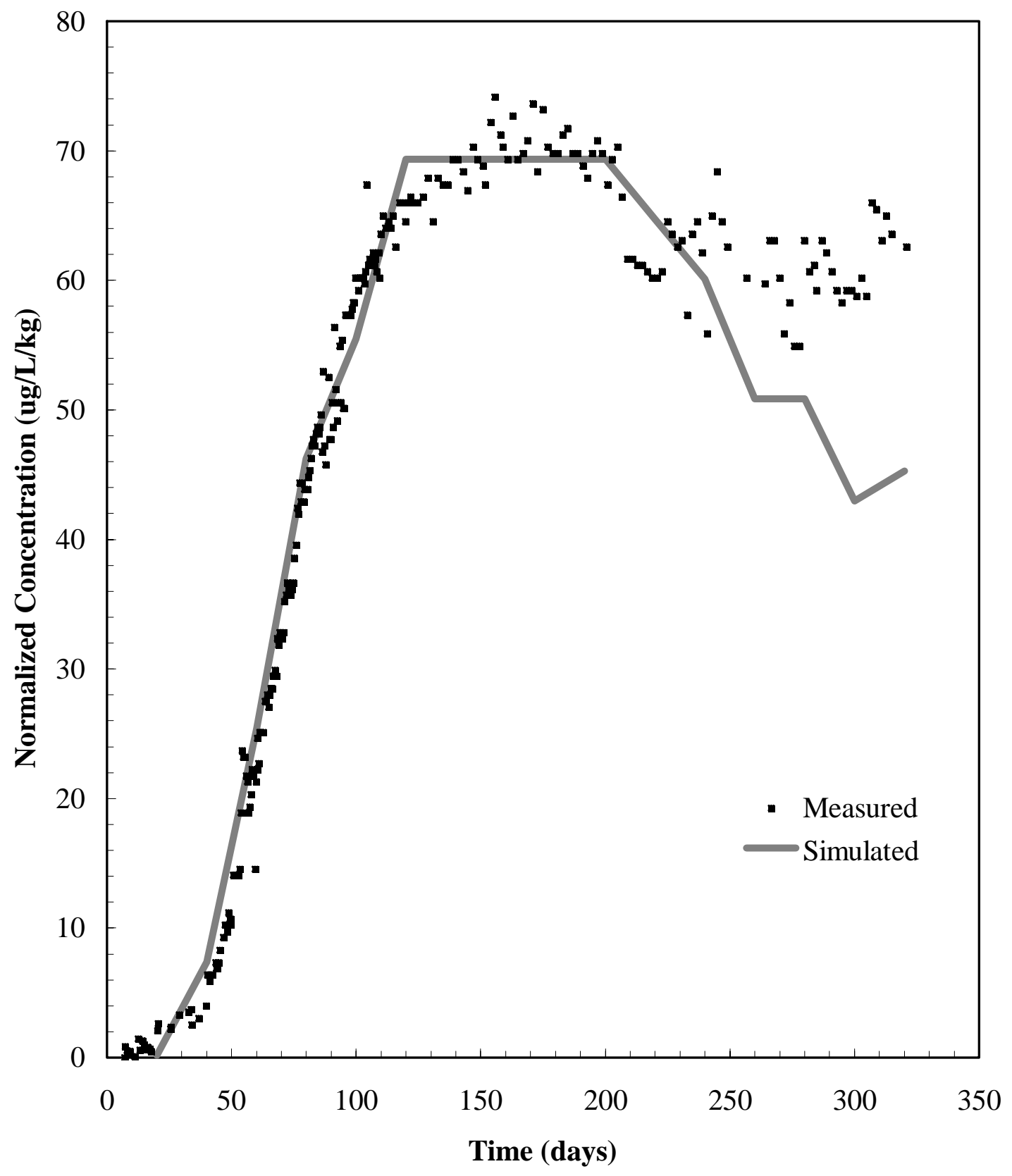

Figure D-2. Simulated and observed bromide breakthrough. 


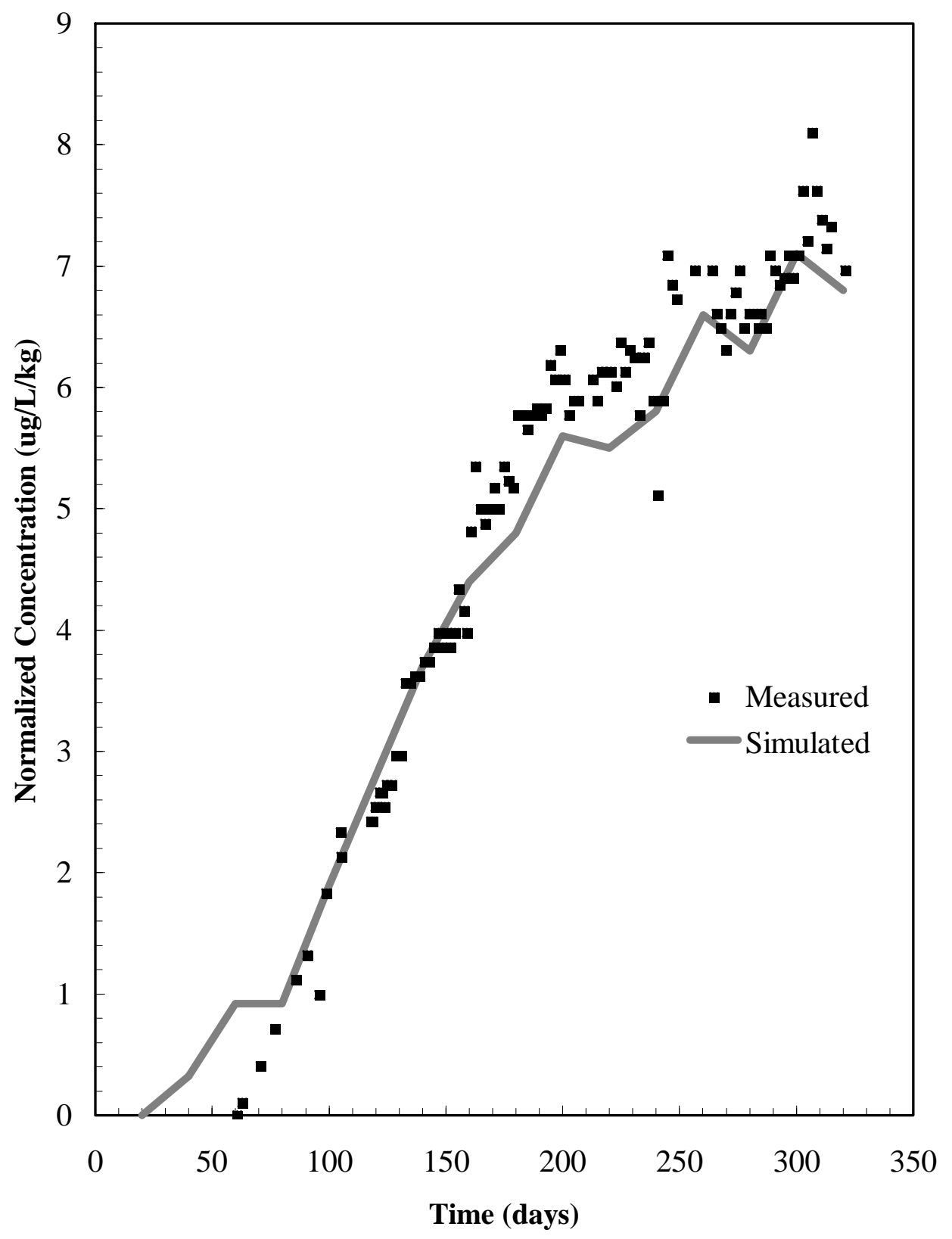

Figure D-3. Simulated and observed lithium breakthrough. 

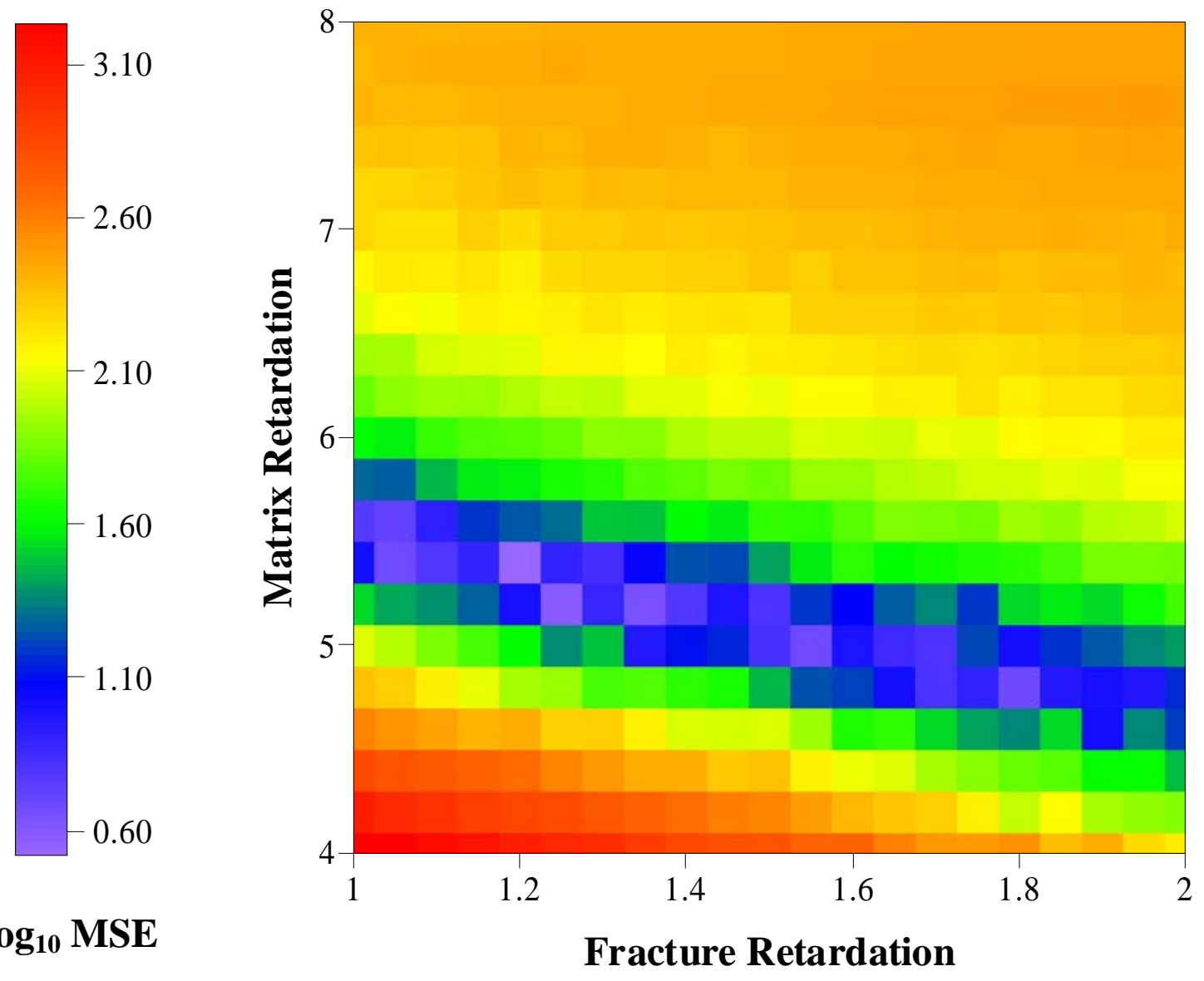

Figure D-4. Mean squared error versus fracture and matrix retardation parameters for the Project Shoal Tracer Test simulation. 